\title{
Alexander Schmidt
}

\section{Valerij Brjusovs Beitrag zur Literaturtheorie}

\author{
Aus der Geschichte \\ des russischen Symbolismus
}

Verlag Otto Sagner München · Berlin · Washington D.C.

Digitalisiert im Rahmen der Kooperation mit dem DFG-Projekt „Digi20“

der Bayerischen Staatsbibliothek, München. OCR-Bearbeitung und Erstellung des eBooks durch den Verlag Otto Sagner:

http://verlag.kubon-sagner.de

() bei Verlag Otto Sagner. Eine Verwertung oder Weitergabe der Texte und Abbildungen, insbesondere durch Vervielfältigung, ist ohne vorherige schriftliche Genehmigung des Verlages unzulässig. 


\section{Slavistische Beiträge}

Unter Mitwirkung von M. Braun, Göttingen - P. Diels, München - J. Holthusen, Würzburg - E. Koschmieder, München - W. Lettenbauer, Freiburg/Br. J. Matl, Graz - L. Müller, Tübingen - F. W. Neumann, Mainz - L. SadnikAitzetmüller, Saarbrüdken

HERAUSGEGEBEN VON A. SCHMAUS, MUNCHEN

Band 7 
ALEXANDER SCHMIDT

\section{Valerij Brjusovs Beitrag zur Literaturtheorie}

Aus der Geschichte des russischen Symbolismus

VERLAG OTTO SAGNER - MÜNCHEN

1963 


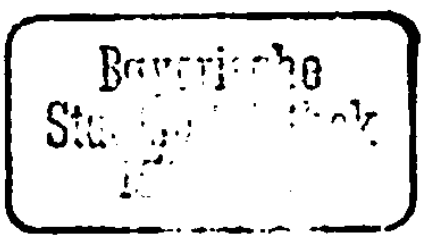

(C) 1963 by Verlag Otto Sagner/München

Abteilung der Fa. Kubon \& Sagner, München

Herstellung: Buch-und Offsetdruckerei Karl Schmidle, Ebersberg Printed in Germany 


\section{N H A LT}

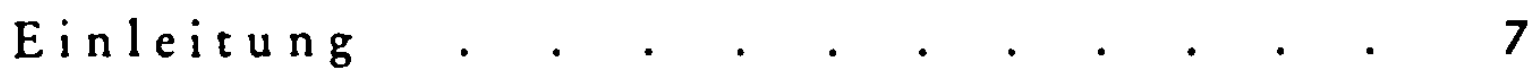

I. Die allgemeine Kunstauffassung Brjusovs

A. Die Seele des Künstlers . . . . . . . . . 16

B. Die Kunst als Welterkenntnis . . . . . . 23

C. Die Kunst als Synthese. . . . . . . . . 49

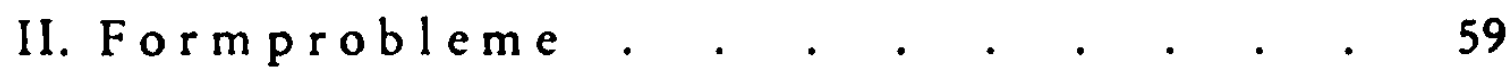

A. Der Rhythmus . • • • • . . . . . 62

B. Das Metrum . . . . . . . . . . 67

C. Die Euphonie . . . . . . . . . . 78

III. Die Kunst des Ubersetzens. . . . . 91

IV. Literaturkritik und Literaturwissen$\mathrm{schaft} \cdot$. . . . . . . . . . 118

V. Zusammenfassung . . . . . . . . . . $\quad . \quad 141$

Literaturverzeichnis . . . . . . . . . . 153

Nachwort . . . . . . . . . . . . . . 


\section{EIN LEITUNG}

Wie jede literarische "Schule" hat der russische Symbolismus bestimmte Grundsätze, die für seine Anhänger weitgehend verbindlich sind. Die Ausarbeitung dieser theoretischen Grundlagen liegt naturgemäß in den Händen der Anhänger des Symbolismus. Nun haben einige Vertreter dieser Richtung, angeregt durch eine derartige Betätigung auf dem Gebiet der Literaturtheorie, den engeren Rahmen, in dem sie zunächst arbeiteten, nämlich die Aufstellung einer Art Norm für symbolistische Dichtung, überschritten und sind mit Arbeiten allgemeineren Charakters über die Literatur an die Offentlichkeit getreten. Valerij Brjusov und Andrej Belyj waren auf diesem Gebiet besonders produktiv.

Die vorliegende Arbeit soll sich ausschließlich mit der Tätigkeit Brjusovs befassen. Brjusov gelangt auf dem Weg über die Dichtung zur allgemeinen Literaturbetrachtung und zur Literaturwissenschaft. Daher sind auch Untersuchungen seiner theoretischen Arbeiten bisher fast ausschließlich im Zusammenhang mit und im Blickwinkel von seiner Dichtung her vorgenommen worden. ${ }^{1}$ Allgemeine Literaturtheorie findet aber nicht nur in der Dichtung, sondern vor allem in der Literaturkritik, der Literaturforshung und, wie im Verlauf dieser Arbeit noch gezeigt werden soll, in der Ubersetzungstechnik ihre Anwendung. Es ist nur natürlich, daß dieser Anwendungsbereich mit seinen Gegebenheiten und Anforderungen seinerseits einen nicht unbeträchtlichen Einfluß auf die Theorie ausübt. Die Wechselbeziehungen $z$ wischen Theorie und praktischer Anwendung außerhalb der Dichtung sollen Gegenstand dieser Untersuchung sein.

Die Bewegung des russischen Symbolismus und der starke Aufschwung, den die Poesie in Rußland um die Jahrhundertwende nahm, hat ihre Wurzeln in überwiegendem Maße in der französischen Dichtung, genauer im französischen Symbolismus. Daher liegt bei den meisten Arbeiten über den russischen Symbolismus das Schwergewicht

' Vgl. u. a. Johannes Holth us en: Studien zur Asthetik und Poetik des russischen Symbolismus. Göttingen 1957. 
auf der Untersuchung des französischen Einflusses.2 Demgegenüber soll hier eine Verlagerung des Schwerpunktes vorgenommen werden, da ein verhältnismäßig starker Einfluß von russischer Seite vorliegt, und zwar nicht von der Dichtung, sondern von der Theorie her.

Dadurch ergibt sich für die Untersuchung die Notwendigkeit, die Tätigkeit Brjusovs aus dem in diesem Zusammenhang zu engen Rahmen des russischen Symbolismus herauszulösen und sie in das weitere Feld der russischen Literaturwissenschaft $z$ wischen den sechziger Jahren und dem Formalismus zu stellen.

Dieser Problemstellung entsprechend werden als Material zur Untersuchung folgende Arbeiten Brjusovs herangezogen: Schriften über die allgemeine Definition des Phänomens Literatur und Grundsätzliches zur Literaturbetrachtung, Abhandlungen über Formprobleme in der Literatur, Kritiken, Ubersetzungen, Aufsätze zur Ubersetzungstechnik.

Am intensivsten hat Brjusov sich mit dem Werk Puškins beschäftigt und zur Puškinforschung einen bleibenden Beitrag geleistet. Das Interesse an dem großen Dichter hat in ihm vor allem Lev Ivanovič Polivanov geweckt. Polivanov, der als großer Puškinkenner galt, war der Leiter des Moskauer Gymnasiums, an dem Brjusov seine Schulausbildung beendete.

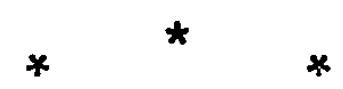

Brjusov wurde am 1. Dezember 1873 (a.St.) in Moskau geboren. Schon in der Schule begeisterte er sich lebhaft für die damalige französische Dichtung.

„Begabung, ja sogar Genie“, schreibe Brjusov unter dem 4. März 1893 in sein Tagebuch, nühren auf redlichem Wege nur sehr langsam zum Erfolg, wenn sie überhaupt dazu führen. Das ist wenig! Das ist mir zu wenig! Man muß sich etwas anderes aussuchen ... Man muß einen wegweisenden Stern im Nebel finden. Und ich sehe ihn: es ist die Dekadenz. Was auch immer darüber gesagt wird, ob sie falsch, ob sie lächerlich ist, sie schreitet vorwärts, sie entwickelt sich, die $\mathrm{Zu}$ kunft wird ihr gehören, besonders wenn sie einen würdigen Führer findet. Und dieser Führer werde ich sein! ${ }^{\alpha s}$

2 Vgl. Georgette Donchin: The Influence of French Symbolism on Russian Poetry. 's-Gravenhage 1958.

3 Zitat nach N. A šuk in: Valerij Brjusov $v$ avtobiografǐ̌eskich zapisjach, pis'mach, vospominanijach sovremennikov i otzyvach kritiki. Moskau 1929, S. 51. 
Schon mit der Veröffentlichung seines ersten Gedichtbandes verfolgt Brjusov das Ziel, der theoretische Führer einer literarischen Schule zu werden. Im Vorwort zur ersten Ausgabe des Bändchens „Russkie simvolisty" schreibt Brjusov: "Ich möchte in keiner Weise dem Symbolismus einen besonderen Vorzug geben und ich betrachte ihn auch nicht, wie es seine enthusiastischen Anhänger tun, als die ,Poesie der Zukunft', sondern ich bin einfach der Ansicht, daß auch die symbolistische Poesie ihre raison d'être hat ..." ${ }^{4}$ Diese raison d'être zu beweisen war sein Anliegen. In einem auf Grund der ersten Lieferung der "Russkie simvolisty ${ }^{\alpha}$ stattgefundenen Interview beschreibt er seine Pläne: „In jedem Falle bleibt die Vereinigung der ,Russischen Symbolisten' unsere nächstliegende Aufgabe. In diesem Rahmen ist eine Erweiterung unseres Bändchens und die Bildung einer Gesellschaft beabsichtigt. ${ }^{\alpha \theta}$

1897 etwa arbeitete Brjusov an einer "Geschichte der Lyrik ". Zwar ist diese Arbeit unvollendet geblieben, sie zeigt aber, daß er bereit und willens war, sich von Grund auf mit den Problemen der Literatur allgemein auseinanderzusetzen. Etwas später plant er die Herausgabe eines Lehrbuchs der Poesie. Auch dieses ist nie erschienen. Erst nach Abschluß seines Studiums an der Moskauer Universität, im Jahre 1899, erschien seine theoretische Abhandlung "O Iskusstve ${ }^{\alpha} .^{7}$

Uber sein Studium, das er mit dem Diplom abschloß, berichtet er selber: "Ich befaßte mich an der Universität mit den ersten Jahrhunderten der römischen Geschichte, dem salischen Recht, den ersten russischen Chroniken, der Zeit Zar Aleksej Michailovičs, der großen französischen Revolution. Daneben beschäftigte ich mich ebenfalls mit Philosophiegeschichte... e einige Zeit verwendete ich auf das Studium von Kant und der deutschen, idealistischen' Philosophie überhaupt bis zu Fichte und Schopenhauer. ${ }^{\alpha 8}$ Seine besondere Aufmerksamkeit jedoch gehörte der Literaturgeschichte. „Bei weitem mehr Zeit ${ }^{\alpha}$, schrieb er in seinen Notizen, „verwendete ich auf das Studium der Literaturgeschichte. Auf diesem Gebiet mußte ich von vorne beginnen. Soweit möglich, versuchte ich, die Evolution der Weltliteratur kennen-

- Valerij Brju s ov: Russkie simvolisty. Vyp. I. Moskau 1894.

5 Zitat nach N. A šuk in: Valerij Brjusov.... S. 56.

- Literaturnoe nasledstvo t. 27-28 (Moskau 1937), S. 268.

7 Valerij B rju sov: O iskusstve. Moskau 1899.

8 N. A ̌̌uk in: Valerij Brjusov... S. 128. 
zulernen. Indem ich von meinen Sprachkenntnissen Gebrauch machte..., las ich alle wichtigen Werke der Literaturen aller Länder und aller Zeiten im Original. ${ }^{\alpha}$

Neben diesen wissenschaftlichen Interessen befaßte sich Brjusov aber auch noch mit dem Okkultismus. Das spiegelt sich in seinem Roman "Ognennyj angel ${ }^{\alpha}$ wider. Er nahm an spiritistischen Sitzungen teil. Nach einer solchen soll er einmal gesagt haben, daß die spiritistischen Kräfte mit der Zeit erforscht und, wie Dampf und Elcktrizität, vielleicht in der Technik Anwendung finden würden.10

Während seiner Studienzeit hat Brjusov neben den drei Ausgaben der ${ }_{n}$ Russkie simvolisty ${ }^{{ }_{111}}$ noch zwei weitere Gedichtbände veröffentlicht. ${ }^{12}$

In seinen Notizen faßt Brjusov einmal zusammen, auf welchen Gebieten er sich für einen Spezialisten hält. Er zählt dort folgende zehn Gebiete auf: 1. Die zeitgenössische russische Dichtung, 2. Puškin und seine Zeit. Tjutčev, 3. fast die ganze russische Literaturgeschichte, 4. die zeitgenössische französische Dichtung, 5. teilweise die französische Romantik, 6. das XVI. Jahrhundert, 7. wissenschaftlicher Okkultismus, Spiritismus, 8. Dante und seine Zeit, 9. die letzte Epoche der römischen Literatur, 10. Asthetik und Philosophie der Kunst.13

Mit der Jahrhundertwende trat Brjusov ins Berufsleben ein. Er fand eine feste Stellung als Redaktionssekretär an der Zeitschrift ${ }_{\text {"Russkij Archiv }}{ }^{\alpha}$, herausgegeben und redigiert von P. I. Bartenev, die schon vorher einige literarhistorische und bibliographische Untersuchungen von ihm veröffentlicht hatte. Diesen Posten behielt Brjusov drei Jahre lang.

Während dieser Zeit nahm Brjusov an der Tätigkeit des Moskovskij Literaturno-Chudožestvennyj kružok teil und wurde 1902 in den Vorstand gewählt. 1908 wurde er Vorsitzender. Die Mitglieder des "Kružok ${ }^{\alpha}$ waren Kunst- und Literaturschaffende. Seine "Dienstage ${ }^{\alpha}$, wöchentliche Diskussionen und Vorträge, Vorlesungen über Fragen

- ibid. S. 272.

10 Vl. Chod a se vi $x$ : Brjusov, otryvki iz vospominanij. "Sovr. zapiski" (Pariž) 1925, Nr. 25. (Vgl. A §̌ u k i n, Valerij Brjusov... S. 121).

11 V. B r ju s ov: Russkie simvolisty. Vyp. I. Moskau 1894; vyp. II. Moskau 1894; vyp. III. Moskau 1895.

12 V. B rju sov: Chefs d'oeuvre. Moskau 1895; Me eum esse. Moskau 1897.

13 N. A ̌̌ukin: Valerij Brjusov... S. 273. 
der Kunst und der Literatur, spielten im kulturellen Leben Moskaus eine bedeutende Rolle. Der Kružok bestand von 1898 bis 1919.

Bald druckten auch andere Zeitschriften Brjusovs Arbeiten. Zunächst I. I. Jasinskijs „Ežemesjačnye Sočinenija ${ }^{\alpha}$, später besonders

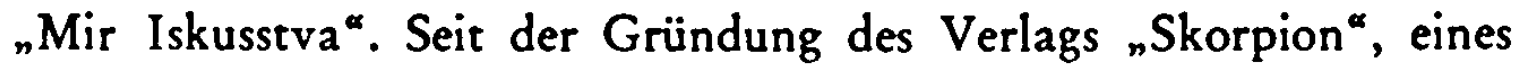
der Schwerpunkte des russischen Symbolismus, war Brjusov dort tätig, zunächst ehrenamtlich, später fest angestellt.

Als 1903 die Merežkovskijs die Zeitschrift „Novyj Put' ${ }^{\prime \alpha}$ gründeten, wurde Brjusov dort Mitarbeiter, war dabei aber nicht sehr glüdklich. Immerhin machte er dort eine gute journalistische Schule durch, so daß er, als 1904 die Zeitschrift „Vesy ${ }^{\star}$, das Organ der Moskauer Symbolisten, gegründet wurde, als Mitarbeiter ein sicheres publizistisches Können mitbrachte.

Bei den "Vesy ${ }^{\alpha}$ entfaltete Brjusov seine ganze Aktivität. Neben Bal'mont, Baltrušaitis, Belyj, Vjač. Ivanov, Vološin, Merežkovskij u. a. zeichnete er dort für den ersten Teil verantwortlich. Ober seine Tätigkeit berichtet Vl. Chodasevič: „Brjusov herrschte (in der Redaktion der "Vesy ${ }^{\alpha}$ ) unumschränkt; er führte Polemiken, schloß Bündnisse, erklärte Kriege, vereinigte und trennte, versöhnte und hetzte auf. Indem er zahlreiche Fäden spann, offen oder geheim, fühlte er sich als der Kapitän eines literarischen Schiffes und machte seine Sache mit großer Sorgfalt. ${ }^{{ } 14}$ Brjusov selber mußte sich des öfteren gegen Veröffentlichungen verwahren, in denen von den „Vesy ${ }^{*}$ als einer ${ }_{n}$ Zeitschrift Valerij Brjusovs ${ }^{\alpha}$ gesprochen wurde. Hier erhielt Brjusov erstmals Gelegenheit, seine Fähigkeiten als Literatur- ${ }_{n}$ Organisator $^{*}$ voll einzusetzen. Bis Januar 1909 blieb Brjusov den ${ }_{n}$ Vesy ${ }^{\alpha}$ treu. Nicht eine Nummer erschien, in der nicht zumindest ein Beitrag von ihm abgedrudkt war. Sein Roman "Ognennyj Angel ${ }^{\alpha}$ erschien erstmals in Fortsetzungen in den ${ }_{n}$ Vesy ${ }^{\alpha}$.

Daneben veröffentlichte der Verlag "Skorpion ${ }^{*}$ in der Blütezeit des russischen Symbolismus nicht weniger als fünfundzwanzig Bücher Brjusovs, darunter sieben Gedichtbände, zwei Auflagen des „Ognennyj Angel $^{\text {, }}$ literaturwissenschaftliche Arbeiten und Obersetzungen ausländischer, vor allem französischer Dichter.

Nachdem die "Vesy ${ }^{*}$ im Jahre 1909 ihr Erscheinen eingestellt hatten, redigierte Brjusov den literaturkritischen Teil von „Russkaja

14 Zitat nach N. A šuk in: Valerij Brjusov... S. 191. 
Mysl'œ. Ab 1912 wurden seine Arbeiten u. a. in der Petersburger Zeitschrift "Apollon ${ }^{\alpha}$ veröffentlicht.

Bereits 1912 hatte Brjusov die ersten Teile seiner Ubersetzung von Vergils Aneis beendet. Diese großangelegte Arbeit ist niemals fertiggestellt worden. Die ersten sieben Gesänge sind postum (1933) in Brjusovs Ubertragung erschienen.

Auch Theaterstücke für Moskauer Bühnen schrieb Brjusov in den Jahren kurz vor dem ersten Weltkrieg, und 1914 verfaßte er sein erstes Drehbuch.

Die ersten Kriegsmonate verbrachte Brjusov als Kriegsberichterstatter an der Front.

Anfang 1916 unternahm er eine Reise in den Kaukasus und hielt Vorträge in Tiflis, Baku und Erivan' über armenische Dichtung. Auch las er dort aus seinen Ubersetzungen aus dem Armenischen. Die kaukasische Presse lobte die Vorträge sehr, so daß Brjusov nach seiner Rückkehr in Moskau und auch in Petersburg einen Vortrag über die mittelalterliche armenische Dichtung hielt. Ende 1916 gab das Moskauer Armenische Komitee den Sammelband "Poėzija Armenii ${ }^{\alpha}$ heraus. ${ }^{15}$ Als Obersetzer zeichneten hier u. a. Baltrušaitis, Bal'mont, Bunin, Vjač. Ivanov, Aleksej Veselovskij, Fedor Sologub, Chodasevič. Die Redaktion der Ausgabe hatte Valerij Brjusov, der auch den einleitenden Aufsatz verfaßte und die Anmerkungen zusammenstellte, abgesehen davon, daß er selber den weitaus größten Teil der Ubersetzungen beisteuerte.

Aus den Vorarbeiten zum Sammelband „Poèzija Armenii“ entstand eine weitere Arbeit Brjusovs: „Letopis' istoričeskich sudeb armjanskogo naroda ot VI. v. do R. Chr. po naše vremja ". Infolge der politischen Ereignisse verzögerte sich jedoch der Drudk dieses Buches bis 1918.

Brjusov selbst nahm die Oktoberrevolution von 1917 positiv auf und trat bald auf ihre Seite. Von 1918 bis 1919 war er in der Abteilung für wissenschaftliche Bibliotheken des Narkompros (Narodnyj Komissariat po prosveščeniju) tätig. 1920 organisierte er selbständig den Lito (Literaturnyj otdel) des Narkompros. Diese Tätigkeiten gaben ihm Gelegenheit, sich noch einmal von Grund auf mit verschie-

15 Poćzija Armenii. Moskau 1916. 
denen Problemen der Literatur auseinanderzusetzen. Aus dieser Zeit stammen seine ausführlichsten Arbeiten auf diesem Gebiet, die Sammlung „Opyty po metrike i ritmike, po èvfonii i sozvučijam, po strofike i formam" sowie seine sorgfältig ausgearbeitete, wenn auch stark umstrittene Verslehre „Kratkij kurs nauki o stiche“. Daneben übernahm er die Redaktion der neuen Gesamtausgabe von Puškins Werken und veröffentlichte außerdem drei Gedichtbände (Poslednie mečty, M. 1920; V takie dni, M. 1921, Mig, Berlin-Petersburg 1922). Hinzu kommt die Úbersetzung von Oscar Wildes „Ballade vom Zuchthaus zu Reading", sowie zwei 1920 verfaßte große Drehbücher ("Rodine $v$ žertvu ljubov'“ und „Peremena sud'by “). Gleichzeitig war Brjusov der aktivste Mitarbeiter des "Dom pečati“, das in den Jahren 1920-1923 zum literarischen Zentrum Moskaus geworden war. Zahlreiche Dichtungen verschiedener Autoren wurden hier in Form einer Lesung erstmalig „veröffentlicht", da für den Druck kein Papier vorhanden war.

1921 wurde Brjusov Professor an der Moskauer Staatlichen Universität. Im Rahmen seiner Tätigkeit als Hochschullehrer hielt er u. a. folgende Vorlesungen: Geschichte der altgriechischen Literatur (1921/22), Geschichte der römischen Literatur zur Kaiserzeit (1923/ 24), Geschichte der neuesten russischen Literatur (1922/24). Daneben veröffentlichte er, vor allem in der Zeitschrift "Pečat' i revoljucija“, zahlreiche kritische und theoretische Arbeiten zum literarischen Geschehen. Seine Verslehre wurde unter dem Titel „Osnovy stichovedenija" noch einmal herausgegeben.

In dieser letzten Schaffensperiode Brjusovs entstanden auch seine überaus wichtigen Arbeiten "Zvukopis' Puškina "16 und der letzte, die Gedanken des Dichters zusammenfassende Aufsatz „Sintetika poézii“. ${ }^{17}$

Kurz vor seinem Tode gab er noch zwei Gedichtbände heraus: "Dali", Gedichte von 1922, M. 1922, und eine Auswahl seines lyrischen Lebenswerkes „Krugozor", Izbr. stichi 1893-1922, M. 1922.

Brjusov starb am 9. Oktober 1924.

Zwei der größten Werke aus Brjusovs Ubersetzertätigkeit konnten

16 V. B rjus ov: Zvukopis' Puškina. „Pečat' i Revoljucija “ 1923, II, S. $48-62$.

17 V. B rjus ov: Sintetika poezii. In: "Problemy poètiki“ pod red. V. Ja. Brjusova. Moskau-Leningrad 1925. 
erst Jahre nach seinem Tode erscheinen. Die hervorragende Ubertragung in Versen von Goethes Faust I erschien 1928 vollständig.18 Im Jahre 1933 erschien das schon erwähnte Fragment der Aneisübersetzung, zusammen mit einer Ubersetzung der restlichen Gesänge von Sergej Solov'ev. ${ }^{19}$

Von den Autoren, die sich mit dem Leben und Werk Brjusovs beschäftigten, seien hier einige erwähnt.

Eine hervorragende Sammlung und Auswahl von Dokumenten, Notizen, Kritiken usw. aus dem Leben Brjusovs bietet der Band "Valerij Brjusov, v avtobiografičeskich zapisjach, pis'mach, vospominanijach sovremennikov i otzyvach kritiki“, zusammengestellt von N. Ašukin. In diesem Band findet man neben Auszügen aus Brjusovs Tagebüchern und autobiographischen Schriften zahlreiche handschriftliche Notizen des Dichters zitiert, die Vorworte zu den einzelnen Ausgaben der ${ }_{n}$ Russkie simvolisty ${ }^{\text {, }}$ Rezensionen, Notizen und Interviews von Tageszeitungen, Berichte und Bemerkungen zeitgenössischer Autoren usw. Im ganzen stellt der Band eine vortrefflich ausgewählte und übersichtlich geordnete Sammlung von biographischem Material aller Art zur Persönlichkeit Valerij Brjusovs dar.

Einen guten Eindruck vom persönlichen Wesen und Auftreten des Dichters vermittelt "Geroj truda" (Zapisi o Valerii Brusove) von Marina Cvetaeva. ${ }^{20} \mathrm{Z}_{\text {war }}$ ist die Schilderung stark von der subjektiven Einstellung der Autorin Brjusov gegenüber gefärbt, gewinnt aber gerade dadurch an Lebendigkeit und Eindrudkskraft.

Den Beginn der literaturkritischen Tätigkeit Brjusovs kann man auf 1892 datieren. Aus dieser Zeit ist ein handschriftlicher Aufsatz über die Lyrik Nadsons erhalten, der eine sorgfältige Analyse der dort vorkommenden Motive, Versformen und Reime enthält.21

Bei einer Betrachtung von Brjusovs literaturkritischem Werk in seiner Gesamtheit wird man eine Entwidklung feststellen, die sich im wesentlichen in drei voneinander unterscheidbaren Perioden vollzieht.

18 Gete. Faust. Perevod Valerija Brjusova. Moskau-Leningrad 1928.

10 Vergilij. Eneida. Moskau-Leningrad 1933.

20 Marina C vet a e v a: Proza. New York 1953, S. 203-270.

21 Literaturnoe nasledstvo t. 27-28, S. 35 f. 
Die erste Periode reicht von etwa 1894, also dem Erscheinen der ersten beiden Lieferungen der "Russkie symvolisty", bis zur Jahrhundertwende. Das Ende dieser ersten Periode fällt in die Zeit, da Brjusov sein Studium beendet und ins Berufsleben eintritt. Wir haben es hier weniger mit den Arbeiten eines versierten Kritikers zu tun als vielmehr mit immer neuen Versuchen einer Definition der Kunst als Phänomen schlechthin. $\mathrm{Zu}$ einer konstruktiven Literaturkritik fehlt Brjusov noch ein fest fundiertes Verhältnis zur Kunst.

Die zweite Periode ist für Brjusovs Literaturkritik die entscheidende und auch einflußreichste. Ihre zeitliche Ausdehnung kann man von 1901, d. h. dem Erscheinen des Aufsatzes "Istiny" im Almanach "Severnye cvety", bis etwa zum Beginn der Oktoberrevolution festlegen. In diese Zeit fällt die Blüte des russischen Symbolismus, an dessen Entfaltung Brjusov in entscheidendem Maße vor allem als Kritiker und Publizist teilnimmt.

Die dritte Periode schließlich bringt eine mehr wissenschaftliche Auswertung der in der zweiten gewonnenen Erkenntnisse und die Hinwendung zu einer immer mehr formalen Literaturbetrachtung. In diese Zeit fallen auch die bedeutendsten Arbeiten Brjusovs über Puškin.

Diese Zeiteinteilung soll der folgenden Untersuchung weitgehend zugrundegelegt werden. 


\section{Die allgemeine Kunstauffassung Brjusovs}

\section{A. Die Seele des Künstlers}

Die erste Schrift Brjusovs, die den Versuch unternimmt, sich mit der Kunst als Phänomen auseinanderzusetzen, ist das 1899 erschienene Büchlein „O iskusstve ". .2

${ }_{n}$ Was ist Kunst? Woher kommt sie? Was ist ihr Ziel? ${ }^{223}$ ist Brjusovs ausdrüdkliche Fragestellung für diese Arbeit. Bei der Beantwortung dieser Fragen geht er von der Feststellung aus, daß der Mensch ein absolutes Individuum ist und daß es $z$ wischen $z$ wei solchen Individuen allenfalls eine äußerliche Ahnlichkeit geben kann. Das Wesen des Individuums wird durch seine Seele bestimmt. Jede Seele ist in ihrer Art einmalig. Aber nicht nur das Wesen der Seele ist einmalig, nauch die aufblitzenden Augenblicke im Leben des einzelnen Menschen wiederholen sich nicht. Jede vorübergehende Stimmung entsteht nur einmal für die Ewigkeit." ${ }^{24}$

Diese Einmaligkeit erscheint, nach der Argumentation Brjusovs, als der Anlaß zur Entstehung von Kunst. Er schreibt: ${ }_{\text {DDie Aufgabe der }}$ Kunst ist es, diesen Augenblidk, dieses Vergehende für die Zeit zu bewahren, es zu verwirklichen. ${ }^{25}$ Die Kunst soll also bestrebt sein, die Einmaligkeit einer Emotion, in weiterem Rahmen die Einmaligkeit einer individuellen Seele zu fixieren. Brjusov verlangt damit vom Künstler, daß er aufmerksam jede seiner Emotionen verfolge und sich ständig ihrer bewußt sei, denn "wenn ich mich eines gewesenen Gefühls erinnere", schreibt er, nerscheint es bereits in veränderter Form. Wenn ich mein Gefühl einem anderen vermittle durch Worte, durch Verse, oder durch Suggestion, dann wird man etwas Annäherndes erfahren, jedoch nicht das gleiche. Eine Gleichheit

22 V. B rjus o v: O iskusstve. Moskau 1899.

23 ibid. S. 7.

24 ibid. S. 11.

25 ibid. S. 12. 
gibt es nicht. Augenblicke sinken ins Grab ohne die Hoffnung einer Auferstehung. "28

Einen direkten Weg weist Brjusov dem Künstler nicht, auf dem er diese rasche Vergänglichkeit seines Gegenstandes aufhalten kann (denn die augenblicklichen Emotionen sind nach dem Gesagten der eigentliche Gegenstand der Kunst). Er deutet aber an, welches die Voraussetzung für ein solches Beginnen überhaupt ist: „Wer Künstler sein will, der muß sich selbst finden, der muß er selbst werden. ${ }^{2{ }^{27} \text { Die }}$ zweite Voraussetzung, die er verlangt, ist Aufrichtigkeit des Künstlers. „Der Künstler gibt seine Stimmung wieder, sein ständiges Ziel ist es, anderen seine Seele zu enthüllen. ${ }^{\text {} 28}$ Diese beiden Voraussetzungen werden zu Kriterien wirklicher Kunst: „Wer ein Künstler sein will, der muß aufrichtig sein, immer und ohne Vorbehalte. Alle Stimmungen sind in der Kunst gleichwertig, weil nicht eine sich wiederholt; jede ist allein schon deshalb teuer, weil sie einzigartig ist. Die Seele kennt ihrem Wesen nach das Böse nicht. Je klarer jemand seine Seele versteht, desto reiner und erhabener werden seine Gedanken und Gefühle sein. Das Streben nach einem tieferen Verstehen seiner selbst, nach einem steten Weg voran ist bereits geheiligt. Es gibt keine Verurteilung von Gefühlen eines echten Künstlers. ${ }^{~}{ }^{29}$ Ein Kunstwerk ist nur dann als solches zu bezeichnen, wenn es der Ausdruck echter Emotionen ist.

Den Akt dichterischen Schaffens beschreibt Brjusov 1895 in seinem Gedicht "Tvorčestvo“:

Ten' nesozdannych sozdanij

Kolychaetsja vo sne,

Slovno lopasti latanij

$\mathrm{Na}$ èmalevoj stene.

Fioletovye ruki

$\mathrm{Na}$ èmalevoj stene

Polusonno čertjat zvuki

$\mathrm{V}$ zvonko-zvučnoj tišine.

\footnotetext{
26 ibid. S. $11 \mathrm{f}$.

27 ibid. S. 12.

28 ibid.

20 ibid. S. 13.
} 
I prozračnye kioski,

V zvonko-zvučnoj tišine,

Vyrastajut, slovno blestki,

Pri lazorevoj lune.

Vschodit mesjac obnažennyj

Pri lazorevoj lune ...

Zvuki rejut polusonno,

Zvuki lastjatsja ko mne.

Tajny sozdannych sozdanij

S laskoj lastjatsja ko mne,

I trepeščet ten' latanij

$\mathrm{Na}$ émalevoj stene. ${ }^{30}$

Die dichterische Schöpfung wird hier als Umsetzung einer unklar traumhaft vorhandenen Emotion in greifbar umrissene Laute, Worte dargestellt. Der Schatten einer Fächerpalme auf den Kacheln des

so Eine genaue Analyse dieses Gedichts findet sich bei Johannes $\mathrm{H} \circ \mathrm{lt}$ h u sen: Studien zur Asthetik und Poetik des russischen Symbolismus. Göttingen 1957, S. 63 ff.

\section{Schöpfung}

Der Schatten ungeschaffener Schöpfungen

Wiegt sich im Traum

Wie die Blätter der Fächerpalme

Auf der Wand aus Emaille.

Violette Hände

Auf der Wand aus Emaille

Zeichnen halb im Traum Klänge

In klingend-tonreicher Stille.

Und durchsichtige Kioske

In klingend-tonreicher Stille

Wachsen, wie flimmernder Widerschein,

Beim azurfarbenen Mond.

Die blanke Luna geht auf

Beim azurfarbenen Mond...

Klänge wehen im Halbtraum,

Klänge umschmeicheln mich.

Die Geheimnisse geschaffener Schöpfungen

Umschmeicheln mich mit Zärtlichkeit,

Und es zittert der Schatten der Fächerpalme

Auf der Wand aus Emaille. 
Ofens dient als Spiegel, in dem sich dieser Vorgang abzeichnet. Er ist das Medium zur konkreten Aufzeichnung des konturlos im Unterbewußtsein vorhandenen Gefühls: „Polusonno čertjat zvuki ${ }^{\alpha}$. Uber die irrationale Ebene "lazorevaja luna ${ }^{\alpha}$ schiebt sich die Ebene des Realen, "mesjac obnažennyj" und läßt die Vorgänge rational greifbar werden: "Tajny sozdannych sozdanij s laskoj lastjatsja ko mne". Danach wird der Schatten der Fächerpalme wieder in die Realität entlassen: ${ }_{n} \mathrm{i}$ trepreščet ten' latanij na èmalevoj stene “ ${ }^{\text {. }}$.1

Aber schon damals merkte Brjusov, daß mit diesen Kriterien allein das Wesen eines Kunstwerks nicht zu definieren ist. Obwohl er vorher die Einmaligkeit jeder Emotion postuliert hatte, verlangt er zusätzlich noch Originalität in der Kunst. Hier wird auch ihm selbst eine Lücke in seinem "System" offenbar, er mag aber den Gedanken an die Einmaligkeit von Emotionen nicht aufgeben (Brjusov war 25 Jahre alt, als er diese Schrift verfaßte), sondern hilft sich damit, daß er Unaufrichtigkeit in jedem Falle gleich Unoriginalität setzt. ${ }_{n}$ Kunst stellt immer etwas Neues dar ${ }^{\alpha}$, schreibt er, "das ständige Kennzeichen unehrlicher Kunst ist, daß sie nachahmt ... Jemand, der unehrlich ist, möchte auch nicht er selbst sein; woher kennt er ein Gefühl, das er nicht selbst erfahren hat, wenn nicht von den Leuten? Die Heuchelei in der Kunst ist dazu verurteilt, andere zu imitieren; wer lügt, der ahmt nach. ${ }^{{ }_{32}}$

Für wie wichtig er das Moment der Originalität als Kriterium des Künstlerischen hält, zeigt das 1896 verfaßte Gedicht ${ }_{n}$ Junomu poètu“ :

Junoša blednyj so vzorom gorjaščim,

Nyne daju ja tebe tri zaveta.

Pervyj primi: ne živi nastojaščim,

Tol'ko grjaduščee - oblast' poèta.

Pomni vtoroj: nikomu ne sočuvstvuj,

Sam že sebja poljubi bespredel'no.

Tretij chrani: poklonjajsja iskusstvu,

Tol'ko emu, bezrazdumno, bescel'no.

${ }^{31}$ V. B r ju s o v: Polnoe sobranie sox̌inenij. St. Petersburg 1913-14, Bd. I, S. 9.

32 Poln. sobr. Bd. I, S. 152. 
Junoša blednyj so vzorom smuščennym!

Esli ty primeš' moich tri zaveta,

Molča padu ja bojcom pobeždennym,

Znaja, čto v mire ostavlju poèta. ${ }^{33}$

Unter den drei Anweisungen, die der Verfasser einem jungen Dichter gibt, steht an zweiter Stelle: "nikomu ne sočuvstvuj ${ }^{\alpha}$. Nur das wirklich Selbstempfundene ist original, ist neu. Der Dichter soll seine eigene Seele beobachten, sich ihrer bewußt werden, sich in seinen emotionalen Regungen ausschließlich auf das eigene Innenleben beschränken. Die Liebe zu sich selbst empfiehlt Brjusov dem Dichter, weil alle schöpferische Kraft, alle Anregung, jeder dichterische Impuls ausschließlich in der eigenen Seele des Dichters zu finden ist. Auf diese Weise bietet der Dichter dem Leser Zugang zu seiner Persönlichkeit, und der Umgang mit dieser stellt nach Brjusovs damaliger Ansicht den Kunstgenuß schlechthin dar. "Der Genuß eines Kunstwerks liegt in der Kommunikation mit der Seele des Künstlers", schreibt er an anderer Stelle, „der Leser, der Betrachter, der Hörer - sie werden zu Teilnehmern an einem anderen Leben. Und miteinander stehen sie durch ihre Gefühle in Verbindung ${ }^{\alpha} .^{33^{a}}$

Dabei ist es gleichgültig, ob das Kunstwerk beim Leser oder Betrachter einen heiteren oder erschütternden Eindruck hinterläßt. Wichtig ist nur, daß tatsächlich noch einmal das erlebt wird, was der Künstler bei der Schöpfung seines Werkes empfunden hat, denn "der Mensch als Persönlichkeit ist wie durch unüberwindliche Hindernisse

33

\section{Einem jungen Dichter}

Bleicher Jüngling mit brennendem Blids, Heute gebe ich dir dreimal ein Vermächtnis.

Als erstes nimm hin: Lebe nicht dem Gegenwärtigen,

Nur das Kommende ist der Bereich des Dichters.

Zum zweiten denke daran: mit niemand sollst du mitfühlen,

Nur dich selbst sollst du grenzenlos lieben lernen.

Als drittes bewahre: verehre die Kunst,

Nur sie, bedenkenlos, ziellos.

Bleicher Jüngling mit verwirrtem Blidk!

Wenn du meine drei Vermächtnisse befolgst,

Falle ich schweigend als besiegter Krieger,

Wissend, daß ich der Welt einen Dichter hinterlasse.

s3a $\mathrm{O}$ iskusstve $\mathrm{S} .16$. 
von anderen getrennt. Das ,Ich' ist etwas sich selbst Genügendes, eine schöpferische Kraft, die ihre ganze Zukunft aus sich selber schöpft. Die Welt ist meine Vorstellung. Mir sind nur meine Gedanken gegeben, meine Empfindungen, meine Wünsche - nichts mehr und niemals mehr. Aus dieser Einsamkeit sich zur Gemeinschaft durchzukämpfen, ist der leidenschaftliche Wunsch der Seele. In der Vereinigung mit einer anderen liegt für sie die Erfüllung. ${ }^{{ }_{33} \mathbf{b}}$

In dem Gedicht "Junomu poètu“ spricht Brjusov außer diesem noch einen anderen Gedanken aus, der auch später in seiner Kunstauffassung eine wesentliche Rolle spielt: die Idee von der Unabhängigkeit der Kunst. „Poklonjajsja iskusstvu, tol'ko emu ...“ ist die dritte Anweisung an den jungen Dichter. Nachdem er sich vollkommen auf sich selbst, auf seine eigene Seele konzentriert hat, in der alle künstlerische Substanz für ihn beschlossen liegt, ist es nur folgerichtig, daß er der Kunst allein dienen kann und keinerlei Bindungen an Dinge außerhalb der Kunst verträgt. n Jeden Künstler sollte man nach Gesetzen beurteilen ${ }^{\text {, }}$, schreibt Brjusov, "die er sich selbst gegeben hat. Solche Gesetze gibt es nicht weniger, als es Künstler gibt. ${ }^{\alpha 33^{c}}$

Brjusov geht sogar so weit, daß er den Künstler auch in historischer Sicht aus seiner Epoche losgelöst betrachtet und für die Kunst Unabhängigkeit von allem realen Geschehen verlangt: „Alle seine Werke findet der Künstler in sich selbst. Die Zeit gibt nur die Bilder, nur die Ausschmückung; die künstlerische Schule lehrt die äußerlichen Kunstgriffe (priemy), den Inhalt jedoch muß er aus seiner Seele schöpfen. Wer die Zeit und ihre Besonderheiten nach Kunstwerken studieren will, der findet in der Kunst nicht das Wesentliche, sondern nur das Nebensächliche; mit gleichem Erfolg kann man die Zeit nach dem Schnitt der Kleider studieren. Es ist nicht richtig, in der Kunst nur das Werk eines historischen Augenblicks zu sehen; die gegenteilige Ansicht, daß Leben und Natur aus der Kunst entstehen, ist schon etwas richtiger. In jedem Falle würde der gleiche Künstler, wenn er nach zwei Jahrhunderten wieder erschiene, vielleicht mit einem anderen Außeren, genau das gleiche noch einmal sagen. Der Mensch ist eine schöpferische Kraft. ${ }^{\text {ssd }}$

ssb ibid. S. 27.

3sc ibid. S. 17.

ssd ibid. S. 19. 
Die Form eines Kunstwerks spielt für Brjusov in dieser ersten Periode noch nicht die Rolle, die er ihr später zuteilt. Zwar ist sie für ihn ein durchaus beachtenswerter Faktor in seiner Kunstbetrachtung - was auch seine Dichtung aus dieser Zeit zeigt -, sie wird aber dem emotionalen Element durchaus untergeordnet. „Die Kunstgriffe des Schaffens wechseln (darunter wird hier das formale Element als solches verstanden), doch niemals kann die Seele sterben oder alt werden, die in ein Kunstwerk hineingelegt wurde. Wenn die Sprache einer Didhtung noch lesbar ist, wenn man an den gesammelten Bruchstücken noch die Absichten eines Bildhauers erkennen kann, dann ist die Seele des Schöpfers dieser Kunstwerke nicht gestorben, sondern für uns lebendig. In der Kunst verkörpern sich Stimmungen, in der Stimmung offenbart die Seele ihr Leben. Was aber gibt es für die Besinnung in dieser Welt, wenn nicht die Offenbarungen der Seele? Die Seele steht vor der toten Natur, welche dazu verurteilt ist, zu verschwinden wie ein Phantom. Dies ist auch der Grund, warum wir Kunstwerke als unsterblich bezeichnen. ${ }^{\alpha 3 s e}$

Das tragende Element der Kunst ist also „die Seele des Künstlers“, deren Regungen er mit künstlerischen Mitteln seinem Publikum zu vermitteln hat. Die daher postulierte Unabhängigkeit der Kunst bezieht sich auf Dinge, die außerhalb des Künstlers sind. Aber die Kunst ist seiner Seele untergeordnet, ist für diese das Mittel, sich zu offenbaren. Alle anderen Vorgänge gehören nicht in den Bereich der Kunst. „Wer die Bezeichnung Künstler zurecht trägt, begnügt sich damit, daß er seine aufblitzenden Stimmungen niederschreibt. Eingebung, das ist der Augenblick lebendigen Fühlens. Die „Kunst für die Kunst ${ }^{\alpha}$ hat keine lebendige Kraft. Eine Erzählung ist nicht als Bericht über Ereignisse mit ausgedachten Personen wertvoll, sondern als Mittel zur Erkenntnis der Seele des Schreibenden. Bei einem Bild ist die Idee wichtig, und nicht die Schönheit des dargestellten Meeres oder Körpers, diese sind in Wirklichkeit schöner. Je weiter die Kunst in ihrem Gebiet fortschreitet, desto bestimmter wird sie zu einem freien Offenbaren des Gefühls. ${ }^{\alpha 3 s i}$

Das geschilderte System ist leicht als der Gedankengang eines jungen Dichters zu erkennen, der auf irgendeine Weise in der Kunst seinen ihm zumeist noch neuen Empfindungen Ausdruck geben will.

s3e ibid. S. $14 \mathrm{f}$.

sst ibid. S. 24. 
Kunstkritik ist von einem solchen Standpunkt aus nicht möglich. Dies gibt Brjusov selbst zu, wenn er in der gleichen Arbeit schreibt: „Die Aufgabe der künstlerischen Analyse (Kritik) ist es, dem Leser, Betrachter, Hörer zu helfen. Der Deuter der Kunst ist ein Führer in neuen Welten. Er lehnt nur die Wiederholung von früher schon Gesagtem $a b$, alles andere studiert er. Ihm sind nicht die Außerlichkeiten wichtig, die eine Zeit gibt und die der Künstler mit seinen Zeitgenossen gemeinsam hat, sondern er will die Seele des einzelnen Künstlers selbst verstehen. Die Besprechung eines Kunstwerkes ist ein neues Werk: man muß, die Seele des Künstlers begreifend, neu schaffen, aber nicht mehr in flüchtigen Stimmungen, sondern auf den Grundlagen, von denen diese Stimmungen bestimmt sind. Der Deuter eines Künstlers kann nur ein Weiser sein. ${ }^{\alpha 4}$

Die Beurteilung, Einordnung und Analyse eines Kunstwerkes ist mit solchen Prämissen nicht möglich. Es geht Brjusov eigentlich nur darum, festzustellen, ob ein ihm vorliegendes Werk als echtes Kunstwerk anzusprechen ist, $d$. h. ob es seinen hierfür aufgestellten Postulaten genügt oder nicht. Er selbst faßt das noch einmal zusammen: „Für die richtig verstandene Bestimmung der Kunst hängt die Beurteilung eines Kunstwerks nicht davon $a b$, zu welcher Schule es gehört. Wenn der Künstler wahrhaft und vollständig seine Seele mitgeteilt hat, ist er mir teuer."

Den Gedanken, der den bisher geschilderten Erwägungen zugrunde liegt, hat Brjusov bereits 1895, im Vorwort zu seinem Gedichtband

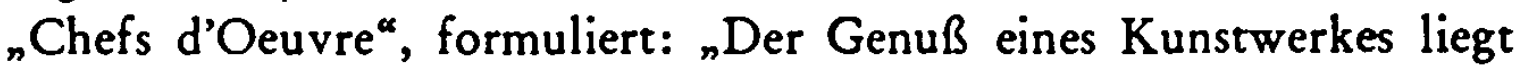
im Umgang (obščenie) mit der Seele des Künstlers ... Das Wesentliche an einem Kunstwerk ist die Persönlichkeit des Künstlers; Sujet und Idee sind die Form. ${ }^{\text {"s5 }}$

\section{B. Die Kunst als Welterkenntnis}

$\mathrm{Zu}$ Beginn der $\mathrm{z}$ weiten Periode unserer Einteilung korrigiert Brjusov diese Auffassung. Er schreibt in seinem Aufsatz "Istiny ${ }^{\alpha}$ : "Ich habe einmal ein Buch geschrieben,$O$ iskusstve'. Jetzt erkenne ich voll und ganz seinen Geist an, teile aber viele seiner Gedanken

34 ibid. S. 19.

ss Zit. nach N. A šuki n: Valerij Brjusov ... S. 98. 
nicht" ${ }^{\text {"se, }}$ und legt seine neue Auffassung dar: „Ich gelangte zu der Einsicht, daß das Ziel des Schaffens nicht die Kommunikation (obščenie), sondern Selbstbefriedigung (samoudovletvorenie) und Selbstverstehen (samopostiženie) ist. Und das Wort ist nicht zuerst zur Verständigung der Menschen untereinander entstanden, sondern zur Klärung der eigenen Gedanken."37 Hier bereits nimmt Brjusov eine Trennung zwischen dem literarischen Wort und dem im Umgang mit anderen zur Verständigung gebrauchten Wort vor. Weiter definiert er: „Demnach schafft der Dichter, um seine Gedanken und Erregungen sich selber zu erklären, sie zur Bestimmtheit zu führen. "s8 Dies sei die Voraussetzung für jedes echte Kunstwerk. Was nach dem Schreiben eines Gedichtes geschieht, sei eine andere Frage. Demzufolge gebe es keine großen und keine zweitrangigen Dichter. Ihrem Werte nach seien sie untereinander alle gleich, vorausgesetzt, daß das, was sie schaffen, ein echtes Kunstwerk ist.

Dieses Kriterium für ein echtes Kunstwerk bedarf einer genaueren Erklärung, einer Erweiterung. Zur Annäherung an dieses Problem beschreitet Brjusov zunächst zwei Wege. Der erste führt über eine Untersuchung des menschlichen Denkens. Für die Entstehung eines Gedankens postuliert er drei Axiome, deren bedingungslose Anerkennung, wenigstens in der Welt des Gedankens, unumgänglich ist. Das erste dieser Axiome ist die Freiheit des Willens, des Willens zum Denken. Jeder Kausalzusammenhang mit einer außerhalb stehenden Erscheinung ist zu leugnen. "Theoretisch kann man behaupten “, schreibt er dazu, „daß jede Erscheinung durch die vorhergehende bedingt ist und mein Gedanke eine Ursache habe. Daran kann man aber nicht glauben, dessen darf man sich nicht einmal bewußt sein, nur sprechen kann man darüber. "39 Andernfalls trete eine absolute Lähmung jeder gedanklidien Tätigkeit ein. Als zweites Axiom des Denkens verlangt Brjusov die Anerkennung der Möglichkeit, das Wesen der Dinge auch auf dem Wege des Gedankens zu erfassen (neben anderen Wegen wie Träume, Vorahnungen u. a.). "Andernfalls", so schreibt Brjusov, "wird jede Uberlegung unnötig. Warum sollte ich beginnen nachzudenken, wenn ich im voraus weiß, daß meine

\footnotetext{
30 V. B rjusov: Istiny (Načala i nameki). In: "Severnye cvety na 1901 g. ${ }^{\alpha,}$ Moskau 1901, S. 195.

37 ibid.

38 ibid. S. 196.

39 ibid. S. 189.
} 
Schlußfolgerung ein neuer Fehler in der langen Reihe ähnlicher sein wird?" ${ }^{40}$ Das dritte Axiom ist die Vielheit der Prinzipien (načala). „Der Gedanke und das Leben überhaupt entsteht aus der Gegenüberstellung von wenigstens zwei Prinzipien. Ein einzelnes Prinzip ist das Nichtsein, eine einzelne Wahrheit ist das Nichtdenken. Gäbe es keine Entfernung, dann gäbe es weder rechts noch links, gäbe es keine Moral, dann gäbe es weder Gut noch Böse. " 11 Ein Denker könne diese Axiome zwar bestreiten, er muß sie aber unterbewußt dennoch akzeptieren, da ohne den Glauben an sie kein Denken möglich sei.

$\mathrm{Da}$ demnach das Denken nicht von sich aus entstehen kann, sondern erst die Annahme von Axiomen es überhaupt ermöglicht, ist es naheliegend, dem Denken seinen $Z$ wedk in ihm selbst zuzuordnen. Jede Wissenschaft entsteht somit nur aus dem Verlangen nach Betätigung des Denkens. „W or ü b e r gedacht wird, welches die Schlußfolgerungen sind, das ist zweitrangig, wichtig ist nur, wi e gedacht wird. Sind uns denn nicht Spinoza und Leibniz, Spencer und Schopenhauer in gleicher Weise teuer, obwohl wir die endgültigen Thesen ihrer Philosophie nicht teilen? Unterwegs haben sie wahre Gedanken ausgesagt. ${ }^{{ }{ }^{2} 2}$

Von hier ist nur ein Schritt bis zum Leugnen der Existenz einer absoluten Wahrheit. Womit die ausdrückliche Forderung des oben erwähnten zweiten Axioms als Axiom ihre Berechtigung erhält. Brjusov äußert an dieser Stelle einen zentralen Gedanken, der für sein gesamtes Schaffen mitbestimmend wirkt: „Man muß sich nur dessen bewußt sein, daß sämtliche möglichen Weltanschauungen in gleicher Weise wahr sind; man muß, nachdem man seine eigene Wahrheit gefunden hat, sidh nicht damit zufriedengeben, sondern weiter suchen. Der Gedanke ist der ewige Ahasver, er darf niemals stehenbleiben, seine Wege können kein Ziel haben, weil dieses Ziel der Weg selbst ist. $^{\alpha 43}$

Als zweites stellt Brjusov in diesem Aufsatz eine Untersuchung über den Begriff des Gefühls an. Er unterscheidet zwischen zwei Kategorien von Gefühlen, dem mehr oberflächlichen oder äußeren und dem tieferen Gefühl. Da die Sprache für die tieferen Gefühle keine eigenen Bezeichnungen besitze, müsse man sie zum $Z$ wecke der Unter-

10 ibid. S. 190.

42 ibid.

42 ibid. S. 191.

43 ibid. 
scheidung mit Liebe, Haß, Verlangen, Abscheu bezeichnen, obwohl sich diese Worte eigentlich nur auf die Oberfläche der Seele beziehen. Oft werden tiefere Gefühle durch solche der Oberfläche verdeckt. Dabei kann das äußere Gefühl dem tieferen entgegengesetzt sein.

"Im gewöhnlichen Leben“, schreibt Brjusov, „sind tiefere Gefühle selten wahrnehmbar, für die meisten eröffnen sie sich nur für Augenblicke. " 44 Die äußeren seien redegewandt. Für sie finde man immer Worte, man spreche gut und überzeugend. Die tieferen Gefühle seien schweigsam. Brjusov zitiert in diesem Zusammenhang Tjutčevs Worte: nmysl' izrečennaja est' lož’ “.

Dies wendet Brjusov wie folgt auf die Dichtung an: "Die oberflächlichen Gefühle sind Gemeingut der oberflächlichen Poesie, welche Gefühle und Leidenschaften so ausdrückt, a ls ob sie da seien, als ob sie wirklich erlebt würden ... ${ }^{\alpha_{45}} \mathrm{Zu}$ dieser Dichtung zählt er die Dramen Shakespeares, da dort „alles vereinfacht und logisch"46 sei, die Lyrik A. Tolstojs, A. Majkovs, L. Polonskijs, die gesamte französische Dichtung bis auf die jüngste Zeit. „Der Dichter, der es wagt, bis in die Tiefe der Seele zu schauen, sieht Abgründe und Entsetzen. Bei uns wagten es Tjutčev, Dostoevskij, Fet ...“47

Hicraus ergeben sich zwei Grundeinstellungen dem Phänomen Kunst gegenüber. Auf der einen Seite steht die Suche nach Wahrheit mit rein rationalen Mitteln. Die gesuchte Wahrheit dient aber nicht als Ziel, sondern die Suche selbst ist Weg und Ziel zugleich. Dem steht der emotionale Faktor gegenüber, der in eine oberflächliche und eine tiefere Schicht zerlegt wird. Das Gegenüberstehen dieser beiden Prinzipien, des rationalen und des emorionalen, bildet im wesentlichen die Grundlage, auf der Brjusovs Einstellung zur Kunst in der zweiten der oben erwähnten Perioden fußt. Das literarische Kunstwerk entsteht, wie schon zitiert, um dem Dichter sowohl seine eigenen Gedanken als auch seine Erregungen zu erklären.

In der ersten Hälfte der zweiten Periode setzt sich Brjusov mit den Schriften René Ghils auseinander, in denen dieser seinen Standpunkt der Literatur gegenüber erläutert. Es handelt sich dabei vor allem um die Abgrenzung und das Verhältnis zwischen Kunst und Wissenschaft

\footnotetext{
44 ibid. S. 195.

45 ibid.

10 ibid.

47 ibid.
} 
(gemeint sind hier in erster Linie die Naturwissenschaften). Wenn man das, was Brjusov in seinem oben besprochenen Aufsatz "Istiny" über den Gedanken sagt, auf die Kunst, insbesondere die Wortkunst anzuwenden versucht, dann stößt man 2 wangsläufig auf den Gegensatz von Kunst und Wissenschaft.

Ghil fordert zunächst von der Dichtung, daß sie ${ }_{n}$ zeitgenössisch ${ }^{*}$ sei. Das umgebende Leben sei uns allen das nächstliegende, darum solle der Dichter ein "Sänger des Lebens", und zwar des augenblicklichen, des gegenwärtigen Lebens sein. Andererseits könne die Dichtung natürlich nicht die Rolle eines Spiegels übernehmen, sie soll vielmehr der Wirklichkeit einen Sinn geben, ihr Verhältnis zu den bestehenden historischen und soziologischen Gesetzmäßigkeiten feststellen. Wirklichkeit aber ist für Ghil Wissenschaft. Zwar lehnt Ghil es ab, die Kunst zu einer ${ }_{n}$ ancilla scientiae ${ }^{\alpha}$ machen zu wollen, verlangt aber von der Wissenschaft, ihren belebenden Atem in der Kunst zu suchen. Die Kunst soll also in diesem Falle zum Propheten für die Wissenschaft werden. Das Gemeinsame in Wissenschaft und Kunst sieht Ghil in der Tatsache, daß die sogenannte "Intuition" bei jeder gedanklichen Arbeit unentbehrlich ist. ${ }^{48}$

Dieser Annahme Ghils sei die Definition H. Bergsons gegenübergestellt, der die Intuition nur einem Bereich gedanklicher Arbeit, nämlich der Metaphysik als Methode zuweist. Hier wird die Metaphysik der Wissenschaft als Gegensatz gegenübergestellt und dadurch die Úberlegung allgemein gefaßt. "Wir weisen also der Metaphsik", schreibt Bergson, „einen begrenzten Gegenstand zu, vor allem den Geist, und eine besondere Methode, vor allem die Intuition. Dadurch unterscheiden wir klar die Metaphysik von der Wissenschaft. Aber dadurch schreiben wir beiden auch einen gleichen Wert zu. Wir glauben, daß sie, und zwar die eine wie die andere, die Wirklichkeit selbst erfassen können. ${ }^{{ }^{4} \mathbf{4}^{*}}$

Während aber Ghil lediglich die Intuition als Motor für beide, Kunst und Wissenschaft, annimmt, sieht Brjusov in der Dichtung, auch in der Dichtung Ghils, doch mehr emotionale Werte als nur die zu jedem Anfang notwendige Intuition.

In einem Aufsatz über René Ghil, erschienen 1904, äußert sich

48 René G hil: De la Poésie scientifique. Paris 1909.

48* René Ghil: Oeuvres complètes. Paris 1938, Bd. III, S. 207; Henri B e rgs on: Denken und schöpferisches Werden. Obers. von L. Kottje. Meisenheim a. Glan 1948, S. 49. 
Brjusov dazu folgendermaßen: ${ }_{n}$ Ghil möchte glauben, daß er in seiner Dichtung wissenschaftliche Hypothesen aufstellt, aber die symbolischen Bilder seiner Poeme übertreffen die Wirklichkeit. Die wissenschaftliche Intuition verallgemeinert nur die einzelnen Tatsachen, zwischen denen das gewöhnliche logische Denken nicht die Kraft hat, Verbindungen herzustellen. Ghil aber als echter Dichter errät schöpferisch das, was mit Tatsachen zugedeckt ist, die Dinge, denen die Erscheinungen der Welt nur als durchsichtiges Kleid dienen. In seiner

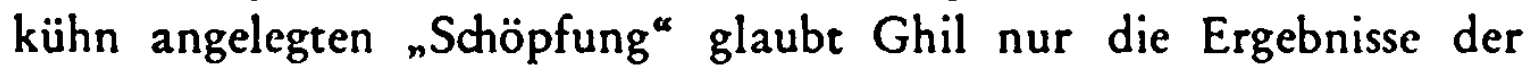
Errungenschaften des heutigen Wissens zusammenzufassen; er tut aber etwas unendlich viel Größeres: er erfaßt zwischen Augenblicken des Universums einige Grundtatsachen, die bisweilen der Aufmerksamkeit der Dichter und der Kompilatoren heiliger Bücher nicht zugänglich waren. Er verkörpert diese Augenblicke in Bildern, er hält noch an einigen Stellen den ewigen Wasserfall der Augenblicke und Jahrtausende auf, gibt uns die Möglichkeit, sicheren Fußes neue Standpunkte einzunehmen, um von ihnen aus eben diese Unendlichkeit zu betrachten, in der zu sein wir verdammt sind. ${ }^{{ }_{49}}$

An anderer Stelle geht Brjusov noch einmal auf das Verhältnis von Kunst und Wissenschaft ein. In einem Vortrag, den er 1903 im Historischen Museum in Moskau gehalten hat, umreißt er seine Ansicht darüber wie folgt: „Unser ganzes Bewußtsein betrügt uns, indem es seine Eigenschaften, die Bedingungen seines Wirkens auf außerhalb gelegene Gegenstände überträgt. Wir leben inmitten einer ewigen, althergebrachten Lüge. Der Gedanke und demnach auch die Wissenschaft haben nicht die Kraft, diese Lüge aufzudecken. Was sie tun können, ist, darauf hinzuweisen, ihre Unvermeidbarkeit zu erklären. Die Wissenschaft bringt nur eine Reihenfolge in das Chaos lügenhafter Vorstellungen und ordnet sie nach Rangstufen, indem sie ihr möglichstes tut, die Erkenntnis von ihr zu erleichtern, jedoch nicht die Erkenntnis. ${ }^{{ }_{30}}$

Einige Jahre später, 1909, nimmt Brjusov zu diesem Thema endgültig Stellung, angeregt durch die inzwischen erschienene Arbeit Ghils ${ }_{n}$ De la Poésie Scientifique ${ }^{\alpha}$.

Brjusov meint, die Kritik sei an einem Punkt angelangt, an dem es Zeit sei, alles bis dahin vom natürlichen Ziel der Kunst von Aristoteles, Hegel, Schiller, Spencer, Tolstoj u. a. Gesagte beiseite zu

"V. Brjus ov: René Ghil. "Vesy" 1904, XII, S. 30 f.

so V. B rjus ov: Ključi tajn. „Vesy ${ }^{\star 1}$ 1904, I, S. 19. 
räumen. Er beruft sich auf Potebnja, durch dessen Theorie von der Kunst als einer besonderen Methode der Erkenntnis ${ }^{51}$ er nun alles Herkömmliche ersetzen will. Er zieht daraus einen Schluß, der das Verhältnis zwiscinen Wissenschaft und Kunst ein für allemal festlegen soll: „Von diesem Standpunkt aus gesehen finden wir zwischen der Wissenschaft und der Kunst einen Unterschied nur in den Methoden, die sie anwenden. Die Methode der Wissenschaft (um bekannte Termini anzuwenden) ist die Analyse, die Methode der Kunst die Synthese. Die Wissenschaft versucht auf dem Wege des Vergleichens, der Gegenüberstellung von Wechselbeziehungen die Erscheinungen der Welt in ihre ursprünglichen Elemente zu zerlegen. Die Kunst will auf dem Wege der Analogie die Elemente der Welt zu etwas Ganzem zusammenfügen. Demnach gibt also die Wissenschaft die Elemente her, aus denen der Künstler schafft, und die Kunst beginnt dort, wo die Wissenschaft aufhört. ${ }^{{ }_{52}}$

Auf dem Gebiet der Kunsterkenntnis hat Brjusov am meisten den Arbeiten Aleksandr Potebnjas zu verdanken. Er steht hierbei mit seiner Wiederbelebung des Gedankengutes von Potebnja nicht allein da. Wenn Roman Jakobson schreibt, daß die Symbolisten "Potebnja kanonisiert " haben ${ }^{53}$, so trifft das durchaus zu. So gehen z. B. auch zahlreiche Arbeiten Belyjs auf Gedanken von Potebnja zurück. ${ }^{54}$

Potebnja ging seinerseits, vor allem durch Wilhelm von Humboldt und Steinthal angeregt, von dem Gedanken aus, daß Sprache und Dichtung in ihren Elementen einander entsprechende Phänomene seien.

Um die Berechtigung einer solchen Analogie zu belegen, wird von

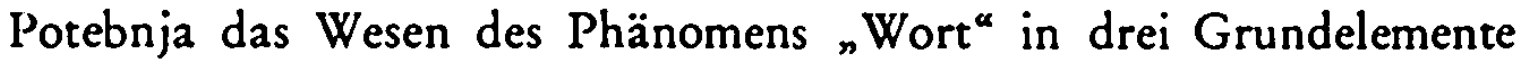
zerlegt: $n .$. die ä u ß e r e Form, d. h. den artikulierten Laut, den I nhalt (soderžanie), der mit Hilfe des Lautes objektivierbar ist, und die in nere Form oder die nähere etymologische Bedeutung eines Wortes, die Art und Weise, mit der der Inhalt ausgedrüdkt wird. ${ }^{\alpha s s}$

s1 Vgl. Anm. 48a.

s2 V. Brjusov: Naučnaja poézija. "Russkaja mysl“ 1909, VI; Izbr. soč. (M. 1955), II, S. 208.

ss Roman J a k obs o n: Brjusovskaja stichologija i nauka o stiche. "Naučnye izvestija" 1922, II, S. 223.

34 Vgl. u. a. Andrej B el y j: Smysl iskusstva. "Simvolizm“, Moskau 1910, S. 195-230; oder Lirika i èksperiment. Ibid. S. 231-285.

ss Aleksandr P ot e b n j a: Mysl'i jazyk. Char'kov 1913 (3. Aufl.), S. 145 f. 
Diese drei Begriffe unterzieht Potebnja einer genauen Analyse. Den Unterschied von Inhalt und innerer Form erläutert er an Hand eines Beispiels: bei den Wörtern annuum, gage, žalovan'e kann der allen gemeinsame Begriff der Zahlung als der gemeinsame Inhalt angenommen werden, während dieser Inhalt durch die innere Form der einzelnen Wörter auf ganz verschiedene Weise zum Ausdruck gebracht wird: annuum bezeichnet das, was jährlich bewilligt wird, gage bezeichnet eine Zuwendung auf Grund einer von zwei oder mehr Personen getroffenen Vereinbarung, während žalovan'e der Etymologie nach ein Geschenk aus persönlicher Zuneigung ist, in keiner Weise jedoch die Folge einer Vereinbarung.

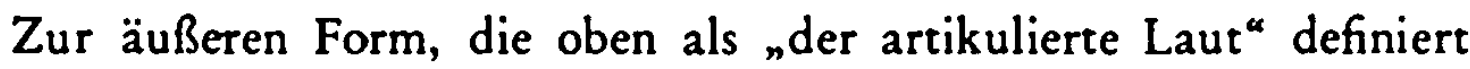
wurde, gibt Potebnja noch eine zusätzliche Erklärung: „Die äußere Form ist untrennbar von der inneren, ist mit ihr vertauschbar, hört ohne sie auf, für sich selbst zu existieren, ist deshalb aber nicht weniger vollkommen von ihr unterschieden; besonders leicht ist dieser Unterschied bei zwei Wörtern verschiedenen Ursprunges zu spüren, die mit der Zeit die gleiche Aussprache bekamen: für den Ukrainer unterscheiden sich die Wörter $\mathrm{mylo}$ und $\mathrm{milo}$ durch die innere Form, aber nicht durch die äußere. ${ }^{{ }_{5 b}}$

Bei der Übertragung dieses Systems aus innerer Form, äußerer Form und Inhalt auf die Kunst bedient sich Potebnja wiederum eines Beispiels. Er geht von folgender Uberlegung aus: „Dies ist die Marmorplastik (äußere Form) einer Frau mit einem Schwert und einer Waage (innere Form), welche die Gerechtigkeit darstellt (Inhalt). "5i In diesem Zusammenhang verwendet er für den Begriff der inneren Form auch die Bezeichnung "Bild" (obraz) und für Inhalt die Bezeichnung „Idee ${ }^{\alpha}$. Wiederum stellt Potebnja die drei Begriffe einander gegenüber. Den Unterschied von innerer Form (Bild) und Inhalt (Idee) faßt er wie folgt: „... wir beziehen die Qualität und das Verhältnis der Figuren, die auf einem Gemälde dargestellt sind, das Geschehen und die Charaktere eines Romans usw. nicht auf den Inhalt, sondern auf das Bild - die Darstellung des Inhalts, und unter dem Inhalt eines Bildes verstehen wir eine Reihe von Gedanken, die durch die Bilder im Leser oder Betrachter hervorgerufen werden oder die

\footnotetext{
so ibid. S. 146.

57 ibid.
} 
dem Künstler als Grundlage für ein Bild während der Zeit des Schöpfungsaktes dienen. ${ }^{\alpha 38}$

Etwas schwieriger stellt sich Potebnja die Differenzierung von innerer und äußerer Form dar. Der Gedankengang Potebnjas läuft etwa auf folgendes Ergebnis hinaus: Beim Wort ist die äußere Form die Lautung. Form und Inhalt des Wortes werden zusammengefaßt und einem neuen, weiteren Inhalt gegenübergestellt und bilden für diesen die Form. Durch eine solche Uberlegung gelangt Potebnja zu der Definition: „Die Form eines Kunstwerkes wird nicht der Laut sein, die ursprüngliche äußere Form, sondern das Wort, die Einheit von Laut und Bedeutung. "so

Das Ergebnis dieses Gedankenganges faßt Potebnja zusammen: „... im Kunstwerk sind die gleichen Elemente vorhanden wie auch im Wort: I n halt (oder Idee), der dem gefühlsmäßigen Bild oder dem daraus entwickelten Begriff entspricht; in ne re Form, B ild (obraz), welches auf diesen Inhalt hinweist und der Vorstellung entspricht ... und schließlich die äu B e r e Form, in der das künstlerische Bild objektiviert wird" ${ }^{\alpha 0}$, wobei sich die Begriffe ${ }_{n}$ gefühlsmäßiges Bild“ und „Vorstellung“ auf das vom Wort Gesagte beziehen.

Von hier aus gelangt Potebnja, wiederum durch Analogieschluß, vom Wort zum Kunstwerk, zu der Erklärung des Kunstwerkes als $\mathrm{S}$ y $\mathrm{n} \mathrm{th}$ e se. Soweit er das Wort betrifft, ist dieser Gedankengang ebenfalls von W. v. Humboldt angeregt, welcher schreibt: „Von dem ersten Elemente an ist die Erzeugung der Sprache ein synthetisches Verfahren, und zwar ein solches im echten Verstande des Wortes, wo die Synthesis etwas schafft, das in keinem der verbundenen Teile für sich liegt. ${ }^{\alpha 01}$

Dem liegt sowohl bei Humboldt als auch bei Potebnja die Vorstellung von der "Ganzheit" ("Totalität") des Ausdrucks bzw. des Kunstwerkes zugrunde, d.h. nicht die Summe der enthaltenen bekannten Einzelbegriffe formt einen neuen Begriff, sondern die Gesamtheit aller Elemente, also auch der unbekannten.

\footnotetext{
68 ibid. S. $146 f$.

so ibid. S. 149.

6 ibid. S. 151.

-1 Wilhelm von $\mathrm{H} \mathrm{umboldt}$ : Uber die Verschiedenheit des menschlichen Sprachbaues. Darmstadt 1949, S. $98 \mathrm{f}$.
} 
Durch diese Prämisse wird es Potebnja möglich, die Methoden der Kunst gegen die Methoden der Wissenschaft abzugrenzen: „Die Wissenschaft zerlegt die Welt, um sie von neuem in einem großen System von Begriffen zu beurteilen; aber dieses Ziel entfernt sich um so mehr, je mehr man sich ihm nähert, das System bricht durch jede Tatsache, die in ihm nicht aufgenommen ist, zusammen, die Zahl der Tatsachen aber kann unerschöpflich sein. Die Poesie umgeht diese unerreichbare Kenntnis von der Harmonie der Welt; indem sie auf diese Harmonie mit ihren konkreten Bildern hinweist, ohne eine unendliche Vielheit von Wahrnehmungen vorauszusetzen, indem sie die Einheit des Begriffes durch die Einheit der Vorstellung ersetzt, entschädigt sie mit einem Bild für die Unvollkommenheit des wissenschaftlichen Gedankens und befriedigt das dem Menschen angeborene Verlangen, überall ein Ganzes und Vollendetes zu sehen. ${ }^{\text {“62 }}$

Dies ist der gleiche Gedanke, den Brjusov (übrigens unter Hinweis auf Potebnja) in seinem oben besprochenen Aufsatz zu René Ghils "De la Poésie Scientifique" entwickelt. Die Vorstellung von der Kunst als Synthese verschiedener Elemente bleibt auch über die zweite Periode unserer Aufteilung hinaus einer der Grundgedanken in Brjusovs Kunstauffassung.

Ebenso geht Brjusovs Definition der Kunst als Form der Erkenntnis auf Potebnja zurück. Dieser gelangt zu einer solchen Auffassung wiederum durch Analogieschluß vom Wort her. „Wirkliches Wissen“, schreibt er, nist für den Menschen nur das Wissen um das Wesen der Dinge; die verschiedenartigen Kennzeichen a, b, c, d, die an einem Gegenstand wahrgenommen werden können, bilden nicht den Gegenstand A selbst, weder einzeln genommen ... noch in ihrer Gesamtheit, denn erstens ist diese Gesamtheit eine Summe, eine Vielheit, während der Gegenstand für uns stets eine Einheit ist; $z$ weitens deshalb, weil A als Gegenstand in sich nicht nur die Summe der uns bekannten Merkmale $a+b+c$, sondern auch die möglicherweise vorhandenen Unbekannten $x+y$... vereinigen und dadurch von seinen Kennzeichen unterschieden werden soll ... Im Wort als Vorstellung einer Einheit und Gemeinsamkeit des Bildes, als Ersatz zufälliger und auswechselbarer Kombinationen ... gelangt der Mensch zuerst zur Erkenntnis des Seins eines dunklen Kerns des Gegenstandes, zur Kenntnis des wirklichen Gegenstandes. "

62 Mysl' i jazyk S. 166.

13 ibid. S. 125. 
der Parallelität von Kunst und Sprache auf das Kunstwerk überträgt, gelangt Potebnja zu dem Schluß: „Dichtung (Kunst) wie auch Wissenschaft sind die Deutung (tolkovanie) der Wirklichkeit, ihre Bearbeitung für neue, kompliziertere, höhere Ziele des Lebens. "04

Neben der rationalen Seite in Brjusovs Kunstauffassung nimmt in der zweiten Periode der emotionale Faktor noch einen verhältnismäßig breiten Raum ein.

In einem Vortrag, "Ključi tajn“, den er 1903 im Historischen Museum in Moskau hielt, umreißt er seine Problemstellung: „Kunst bereitet Vergnügen - wer wird darüber streiten! Kunst belehrt, wir wissen das aus Tausenden von Beispielen. Doch gleichzeitig damit gibt es in der Kunst oft keine nähergelegenen Ziele, keinen Nutzen - das können nur Fanatiker bestreiten. Schließlich führt Kunst den Menschen zur Gemeinsamkeit, öffnet die Seele, macht alle zu Teilnehmern am Schaffen des Künstlers. Was ist nun Kunst? Was ist gleichzeitig ihr Nutzen? Dient sie der Schönheit und ist doch oft abstoßend? Ist sie ein Mittel der Verständigung (obščenie) und schließt sie den Künstler aus?" 65

Was ist Kunst, fragt Brjusov und zerlegt seine Frage in eine Anzahl Teilfragen. Jedoch nicht, ohne vorher gesagt zu haben, was Kunst ganz entschieden nicht ist: zweckgebundenes Kommunikationsmittel. Und dann zeigt Brjusov den Weg zur Lösung dieser Frage: „Die einzige Methode, die Aussicht hat, diese Frage zu lösen, ist die Intuition, das inspirative Erraten, die Methode, derer sich zu allen Zeiten die Philosophen bedienten, die Denker, die die Geheimnisse des Seins zu enträtseln suchten. "BB Hier tritt ein Widerspruch zutage, wenn man diese Außerung mit den oben dargestellten Gedankengängen Brjusovs vergleicht. Zwar ist es durchaus möglich, in der Weiterführung der Theorie Potebnjas die Kunst selbst als eine Form der Intuition zu interpretieren, wie es z. B. Benedetto Croce tut ${ }^{67}$, aber die Intuition als Lösungsmethode für die Frage nach dem Wesen der Kunst zu empfehlen, ist schlecht möglich, wenn man wie Brjusov hier zu einer Definition gelangt, die leicht als das Ergebnis eines ziemlich komplizierten und durchaus rationalen Gedankenganges von

84 Aleksandr P ot e b n j a: Iz zapisok po teorii slovesnosti. Char'kov 1905, S. 67.

os Ključi tajn S. 18.

or ibid.

67 Vgl. Benedetto Cr o c e: Grundriß der Asthetik. Leipzig 1913, S. 7 ff. 
Potebnja zu erkennen ist. Denn Brjusov fährt fort: ${ }_{n}$ Beim Philosophen selbst ist die Asthetik zu sehr mit dessen Metaphysik gekoppelt. Aber wenn man seine Inspiration aus dem engen Blickwinkel seines Gedankens herausreißt, wenn man seine Kunstlehre von dem völlig zufälligen Beiwerk seiner Lehre von den "Ideen" befreit, die als Vermittler zwischen der Welt des Numens und den Phänomenen dient, dann erhalten wir eine einfache und klare Wahrheit: die Kunst ist ein Begreifen der Welt auf anderen, nicht verstandesmäßigen Wegen. ${ }^{\text {"88 }}$ Soweit handelt es sich also doch noch um eine rationale Definition der Kunst. Aber Brjusov begnügt sich nicht damit. Als Dichter fährt er fort: „Kunst ist das, was wir in anderem Zusammenhang eine Offenbarung nennen würden. Die Schöpfungen der Kunst sind das einen Spalt breit geöffnete Tor zur Ewigkeit. ${ }^{\text {"⿻ }}$

Die letzte Behauptung erinnert sowohl in ihrem sachlichen Inhalt als auch in dem zur Umschreibung gewählten Bild zunächst an Croce, der schreibt: ${ }_{\text {. }}$. die Kunst ist Vision oder Intuition. Der Künstler schafft ein Bild oder Phantasma; der Kunstgenießende stellt sein Auge auf den Punkt ein, den ihm der Künstler gewiesen, blickt durch die Spalte, die er ihm geöffnet hat, und reproduziert in sich jenes Bild. ${ }^{\text {"70 }}$ Wie weit sich diese Einstellung Brjusovs auf die Ästhetik Vladimir Solov'evs gründet, ist schwer festzustellen, denn er gibt in diesem Zusammenhang keine genauere Erklärung des Gesagten. Dagegen spräche die Tatsache, daß er, wie noch gezeigt werden soll, die Auffassungen Vjačeslav Ivanovs und A. Bloks ablehnt, die hauptsächlich Solov'evs Aisthetik aufgreifen und entwidkeln.

Zwar dient Brjusov die Kunst dazu, dem Künstler seine Empfindungen und sein innerstes Wesen zu erklären, jedoch nicht mit den Mitteln eines intellektuellen Gedankenganges. Wesentlich ist in der Kunst stets der emotionale Faktor in seiner höchsten Potenz, in der Leidenschaft (strast'). Aber auch darauf müsse sich die Kunst erst besinnen. "Unsere russischen Dichter gingen in ihren wesentlichen Versen der Leidenschaft aus dem Wege", schreibt Brjusov, "sie verwenden lediglich ihr Spiegelbild in der Liebe. Die Romanciers machten es sich fast zur Pflicht, in allem, was die Liebe betrifft, das Geistige über das Gefühl zu stellen. ${ }^{{ }^{71}}$ Die in der Kunst dargestellte Gefühls-

\footnotetext{
68 Ključi tajn S. $18 \mathrm{f}$.

1 ibid. S. 18.

i0 Grundriß der Asthetik S. 7.

"1 V. B r ju s o v: Vechi I. Strast'. „Vesy“ 1904, VIII, S. 25.
} 
welt spielt sich an der Oberfläche ab. Leidenschaft ist nur ein Vorwand, um Verirrungen in Schutz zu nehmen. Oder es wird die Uberwindung der Leidenschaft geschildert. Dies entdeckt Brjusov vor allem bei Turgenev und Tolstoj. „Beide schätzen die Leidenschaft als kräftigen Motor zu irgendetwas anderem, nur nicht diese selbst. Nur bei Dostoevskij, in den rätselhaften Bildern und Worten Svidrigajlovs und der Karamazov strahlt eine andere Auffassung der Leidenschaft hervor, die absichtlich verschleiert, ausgelöscht wird. Die Künstler glaubten, indem sie die Liebe von der Leidenschaft lösten, sie in den Himmel zu heben; tatsächlich aber machten sie sie nur leer. ${ }^{\alpha 2}$ Brjusov hat keine ausführliche Arbeit über Dostoevskij geschrieben. Er hat sich bei seiner kritischen Tätigkeit kaum mit Prosa beschäftigt. Es geht ihm hier wohl nur darum, zur Erläuterung seiner Gedanken die psychologischen Aspekte in den Romanen Tolstojs und Turgenevs einerseits und Dostoevskijs andererseits einander gegenüberzustellen. Dem könnte man entnehmen, daß Brjusov unter Leidenschaft (strast') die Gesamtheit der unterschwelligen Antriebe menschlichen Handelns versteht, welche von Dostoevskij erstmals in seinen Romanen für die Dichtung aktiviert wurden. Vielleicht trägt die folgende Aussage Brjusovs etwas zur Erklärung des Begriffes "Leidenschaft" bei, wie er ihn verstanden wissen will.

"Augenscheinlich sind in keinem Jahrhundert, in keinem Land die ,berufsmäßigen' Kritiker dazu bestimmt, in die Tiefe des literarischen Stromes zu tauchen, - sie befinden sich stets an der Oberfläche. Aber wenn diese in ihrem Inneren hohlen und leeren Schwimmer in Bewegung sind, dann ist das ein zuverlässiges Zeichen für das Herannahen eines Sturmes. Und da sich in unseren Tagen die Kritiker der ganzen Welt, von Nordau bis Burenin ${ }^{73}$, wutschnaubend auf den Wogen der Zeit schaukeln lassen und ihr Geschrei über die Unsittlichkeit der neuen Kunst erheben, - da werden alle begreifen, daß auf den Gebieten des Schaffens ein frischer, belebender Wind weht. "74 Die Erwähnung Nordaus weist in diesem Zusammenhang darauf hin, daß Brjusov den Begriff "Leidenschaft ${ }^{\text {" }}$ mehr im Sinne der französischen „Décadence" verstehen will, gegen die sich Nordaus Werk „Entar-

72 ibid.

is Max Nordau (1894-1923), Kultur- und Zeitkritiker, wandte sich u. a. auch gegen die "Décadence ${ }^{\alpha}$; Viktor P. B u r e n in (1841-1926), Dichter, Dramatiker und Publizist, vertrat seit den $70 e r$ Jahren eine Art konservativen Patriotismus und altväterliche Moral.

74

Vechi I, S. $21 \mathrm{ff}$. 
tung ${ }^{\alpha 75}$ wendet. Nun kennt die Décadence keinen Begriff, der das bezeichnet, was Brjusov unter "strast" " versteht. Dort wird vielmehr das menschliche Triebleben in einer überfeinerten, später entarteten und pervertierten Form kultiviert (Théophile Gautier, Marquis de Sade u.v.a.). ${ }^{76} \mathrm{Daß}$ die Leidenschaft, die Brjusov meint, zwar durchaus auch mit der Physis gekoppelt ist, geht daraus hervor, daß er zur Erläuterung seines Begriffes die gerade in seine Zeit fallende Wiederentdeckung des menschlichen Körpers für die Kunst ins Feld führt. Er beruft sich auf die Bildhauerei, auf Rodin und Klinger. Er wendet sich hier sowohl gegen den Idealismus (worunter er eine absolute Vergeistigung unter Leugnung der Physis versteht) als auch gegen den Materialismus (der seiner Ansicht nach wiederum das Geistige zugunsten der Physis leugnet). „Die neue Kunst bewahrte alle Schätze, die auf den zur Vergcistigung führenden Wegen gehütet wurden ${ }^{\alpha}$, formuliert er, „aber in der Hoffnung, ihren Reichtum zu verdoppeln, wurde ein neuer Weg beschritten, auf dem das Ideal ,Verkörperung' hieß. Der Kampf um die neue Weltauffassung spielt sich an zwei Fronten ab: gegen die ,Materialisten' sowohl als auch gegen die ,Idealisten'" 77 Hier läßt sich schon eher erkennen, daß Brjusov trotz aller Vorliebe für das Urbane - dies zeigt sich am stärksten in seiner Gedichtsammlung "Stichi Nelli“"78 - im Gegensatz zur „Décadence“ das Triebleben als einen positiven Motor menschlicher Vitalität sieht.

Die Leidenschaft ist für Brjusov die Kraft, die den Intellekt beiseiteschiebt und die im Inneren des Menschen verborgenen Dinge ans Licht bringt. „Die Leidenschaft ist das zuweilen verhüllte, aber immer lebendige Ideal des menschlichen Lebens. Nur die Hoffnung auf Leidenschaft gibt Milliarden von Generationen, die aufkommen und weggewischt werden wie Schimmel auf der Erdkugel, die Kraft, sich durch die elenden Tage der Mühe, der Sklaverei, der Schmach zu schleppen. ${ }^{\alpha 9}$

Aus dieser Sicht heraus ist es verständlich, wenn Brjusov sich gegen den Vorwurf der Perversität wehrt: „Ihre (der neuen Kunst) An-

73 Max Nord a u: Entartung. 2 Bde.

76 Vgl. A. E. Carter: The Idea of Decadence in French Literature. Toronto 1958.

77 Vechi I, S. 22.

78 V. B r ju s o v: Stichi Nelli. Moskau 1913.

70 Vechi I, S. 22. 
kläger sagen, indem sie versuchen, ihren Schaden und ihren Verlust an Erfolg bei den Lesern auf sie, die neue Kunst, abzuwälzen, bescheiden die Augen niederschlagend, daß sie nämlich nicht durch den Kult der Leidenschaft in Verlegenheit gebracht worden seien, sondern durch den Kult der Perversität. Das ist ein nichtssagendes Wort! Diese Leute wissen nicht, daß die Mathematik nicht einmal in der Lage ist, genau zu definieren, wclche von zwei Linien eine Gerade ist und welche cin Bogen mit unendlichem Radius. Wir wissen nicht, ob unser Raum wirklich der ist, in welchem die Gesetze der euklidischen Geometrie gelten. Und dieser unser Zweifel ist das Symbol unseres ganzen Wissens. Jedes menschliche "gerade" und "gebogen ", "links" und "rechts" ist relativ. Bei einem einzigen Punkt im unendlichen Raum kann man nicht feststellen, ob er in Bewegung ist oder in Ruhe: der menschliche Verstand braucht einen zweiten zum Vergleich. Jede "Abweichung " kann nur von einer vereinbarten Norm stattfinden. ${ }^{\text {80 }}$ Damit rückt Brjusov das Problem auf cine andere Ebene. Es geht ihm

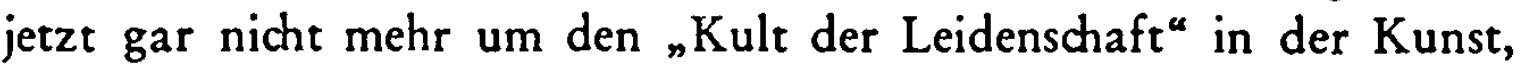
dem der Aufsatz "Strast'" eigentlidh gewidmet ist, sondern er greift ein viel grundsätzlicheres Problem der Kunstauffassung auf: das Problem des Verhältnisses vom Inhalt eines Kunstwerkes, d. h. des in diesem behandelten Stoffes, zu seiner Form.

Es erhebt sich die Frage, ob Brjusov mit dem oben zitierten Exkurs in die Mathematik der Kritik jegliche Berechtigung absprechen will. Er knüpft hier wieder an das an, was er bereits in dén "Istiny" gesagt hat: an die Leugnung einer absoluten Wahrheit. Damals schrieb er: "W o r ü be r gedacht wird, ist zweitrangig, wichtig ist nur, w i e gedacht wird." ${ }^{81}$ Und eben dieses Kleben an dem, w a s gesagt wird, die Nichtbeachtung des Wie wirft er seinen Kritikern vor:

„Die Kritiker aber fragen nur, w as schildern die Künstler, und nicht $w$ i e. Ein Runderlaß an die Schriftsteller aller Länder, der die Anwendung dieser oder jener Wörter verbietet, kann augenblicklich in der ganzen Welt eine Epoche literarischer Tugendhaftigkeit einleiten. Zu billig verkaufen die Doktoren und Apotheker der Zeitschriftenseiten, en gros und en détail, ihre Medizin gegen Unsittlichkeit, nur damit ihr Recht zum Ausschreiben von Rezepten nicht angezweifelt wird." ${ }^{\text {"2 }}$

\footnotetext{
80 ibid. S. 27.

81 Istiny S. 191.

22 Vechi I, S. 28.
} 
Im Problem Inhalt-Form ist auch die Ursache der Differenz Brjusovs mit Andrej Belyj zu suchen. Die erste geistige Auseinandersetzung beider wurde ausgelöst durch Belyjs Aufsatz "Apokalipsis v russkoj poèzii“. ${ }^{\text {g3 }} \mathrm{Um}$ ein möglichst genaues Bild von den Punkten in Belyjs Ausführungen zu geben, an die Brjusov in seiner Arbeir anknüpft, seien hier zwei Abschnitte aus dem Aufsatz Belyjs wörtlich wiedergegeben.

"Das Ziel der Kunst ist es, das Antlitz der Muse zu finden, in diesem Antlitz die Welteinheit der allgemeinen Wahrheit auszudrücken. Das Ziel der Religion ist es, diese Einheit zu verkörpern. Das Bild der Muse der Religion verwandelt sich in das vollständige Antlitz der Menschheit, das Antlitz des Weibes, eingekleider in die Sonne. Die Kunst ist für den Didhter der kürzeste Weg zur Religion. Hier vereinigt sich die Menschheit, ihr Wesen erkennend, mit der Einheit des ewigen Weibes: Das Schaffen, bis zum Ende fortgeführt, leitet unmittelbar in das religiöse Schaffen über, in die Theurgie. ${ }^{84}$ Die Kunst schafft mit Hilfe von Marmor, Farben, Worten das Leben des Ewigen Weibes; die Religion reißt diese Hülle herunter. Man kann sagen, daß auf jeder Statue, die aus Marmor gehauen wurde, Ihr Lächeln erstirbt, und umgekehrt: Sie, - die Madonna, ist in die Ewigkeit gemeißelt. Das uranfängliche Chaos, zusammengesetzt nach den Gesetzen der freien Notwendigkeit, vergöttlicht sich und wird zu Ihrem Leibe. Wenn die Menschheit eine realere Alleinheit ist, dann wird die Nationalität zur ersten Begrenzung der Menschheit. Hier vor uns ist der Eingang zur Einheit, bei einer gleichzeitigen freien und selbständigen Entwicklung der einem Volk innewohnenden Kräfte. Das Bild der Muse muß die Entwidklung der nationalen Poesie krönen. ${ }^{\alpha 8}$

83 Andrej B e l y j: Apokalipsis v russkoj poèzii. „Vesy" 1905, IV, S. 11-28.

84 Zur Erklärung des aus der Mystik übernommenen Begriffes "Theurgie" schreibt Solov'ev: "Nicht die Gottheit zu betrachten ist die Pflicht der Menschheit, sondern selbst göttlich zu werden. Demgemäß kann die neue Religion nicht nur passive Gottesverehrung (theosebeia) oder Gottesanbetung (theolatreia) sein, sondern sie muß aktives Gottwirken (theourgia) werden, das heißt gleichzeitiges Wirken von Gottheit und Menschheit zum Umschaffen der letzteren aus einer fleischlichen oder natürlichen in eine geistliche oder göttliche. Dies ist nicht Schöpfung aus dem Nichts, sondern $U \mathrm{msch}$ af $\mathrm{fe} \mathrm{n}$ oder Wandlung der Materie in Geist, des fleischlichen Lebens in Göttliches." (Deutsche Gesamtausgabe der Werke von Wladimir Solowjew, Freiburg i. Br., Bd. II, 1955, S. 102.)

Apokalipsis $\mathbf{v}$ russkoj poézii S. $16 \mathrm{f}$. 
Aus dem Zitierten ist ohne weiteres der Solov'evsche Gedanke der "All-Einheit ${ }^{\alpha}$ herauszulesen. Nach Vladimir Solov'ev kann eine Tätigkeit nur dann zur Vollkommenheit gelangen, wenn sie innerhalb eines Ganzen mit allen Arten von Tätigkeiten verschmilzt. "Inwieweit das wirkliche Sein eines jeden allem anderen widerspricht und Sinnlosigkeit ist, insoweit erscheint sein Sinn als $S t r e b e n$ oder Drang zum anderen, und dieses Streben, das - trotz der das Universum beherrschenden $Z$ wietracht - einem jeden innewohnt, bindet alle in eins und zeigt, daß der Sinn der Welt die A 1 l-Einheit ist. ${ }^{\text {"8s }}$ Die Kunst darf sich nicht in Wiedergabe und Darstellung erschöpfen, sondern sie muß aktiv in das Leben eingreifen. "Die endgültige Aufgabe der vollkommenen Kunst ist es, das absolute Ideal nicht nur in der Vorstellung, sondern auch in der Tat selbst zu verwirklichen, sie muß unser tatsächliches Leben durchgeistigen, verwandeln. ${ }^{\text {"87 }}$

Belyj fährt fort: "Die Entwicklung der russischen Dichtung von Puškin bis in unsere Tage ist von einem dreifachen Wechsel ihrer ursprünglichen Gestalt begleitet. Drei Umhüllungen fallen vom Antlitz der russischen Muse, drei Gefahren drohen ihrem Erscheinen. Die erste Umhüllung fällt mit der Puškinschen Muse; die zweite mit der Muse Lermontovs; die dritte Umhüllung fällt für das wirkliche Erscheinen des Ewigen Weibes. Zwei Strömungen zeidınen sich deutlich in der russischen Poesie ab. Eine nimmt ihren Ursprung von Pǔ̌kin, die andere von Lermontov. Mit dem Verhältnis zu der einen oder anderen Strömung erklärt sich die Eigenart der Poesie Nekrasovs, Tjutčevs, Fets, Vl. Solov'evs, Brjusovs und endlich Bloks. Nur diese Namen dringen tief in unsere Seele; die Begabung der genannten Dichter fällt mit ihrer providentiellen Stellung im allgemeinen System der Entwidklung des nationalen Schaffens zusammen. Dichter, die nicht von der Enträtselung der Geheimnisse Puškinschen oder Lermontovschen Schaffens ergriffen sind, können uns nicht tief erschüttern. ${ }^{\text {" } 88}$

Brjusov antwortet in einem offenen Brief. "Wenn es in den Tiefen der russischen Dichtung bestimmt ist, wie du versicherst, eine neue, der Welt noch unbekannte Religion hervorzubringen, wenn die russische Dichtung providentiell ist, dann werden die hervorragenden

\footnotetext{
* Deutsche Gesamtausgabe der Werke von Wladimir Solowjew. Bd. II, S. 73.

87 Vladimir Solov'ev: Smysl iskusstva. Berlin 1924, S. 162.

88 Apokalipsis v russkoj poèzii S. 17.
} 
Vertreter dieser Dichtung auch die Vertreter der "Apokalypsis in der russischen Dichtung " sein. Und wenn sich diese Vertreter als zweitrangige Dichter erweisen, dann ist hier die Dichtung nicht daran schuld! Und ist denn Blok wirklich mehr ein Vertreter der russischen Dichtung als Bal'mont, oder ist die Poesie Baratynskijs wirklich weniger bedeutend als meine? Du bewertest die Dichtung danach, wie sie sich zum "Weib, eingekleidet in die Sonne" verhält. Die Kritiker der 60er Jahre beurteilten Dichter nach ihrem Verhältnis zu den fortschrittlichen Ideen ihrer Zeit. Diese haben aus ihrem Schema Fet ausgeklammert, du aus deinem Bal'mont. Es ist richtig, der Unterschied ist nicht groß. Beide Methoden reichen sich die Hand. "89

Durch den Vergleich mit den Kritikern der 60er Jahre, welche eine utilitaristische Bindung der Kunst an - meist sozialreformerische Ideen verlangen, bekennt sich Brjusov zu seinen Ideen von der Kunst. Aber er erläutert hier noch nicht weiter, warum für ihn gerade eine solche Bindung der Kunst an Ziele, die nicht in ihr selber liegen, unannehmbar ist. Er erklärt nicht ausdrücklich, daß er eine Wertung an Hand eben dieser Ziele von seinem Standpunkt aus nicht vertreten kann. Was Brjusov in erster Linie kränkt, ist die Ausklammerung von ihm geschätzter Dichter aus der Zahl der wirklich großen. Er ist empört. n... das bedeutet", schreibt er, „daß die anderen nicht im Gedächtnis haften ble iben. Nein, ich distanziere mich entschieden von der Ehre, unter den sechsen zu sein, wenn dafür Kol'cov, Baratynskij, Bal'mont vergessen werden sollen. Ich will lieber aus den Vertretern der zeitgenössischen Dichtung ausgeschlossen sein, zusammen mit Bal'mont, als mich mit Blok allein dazuzuzählen. " ${ }^{\circ}$

Hier spricht aus Brjusov einfach seine Sachlichkeit und ein verletztes Gerechtigkeitsgefühl. Das versteht auch Belyj, denn in seiner Antwort an Brjusov erklärt er sich insofern mit Brjusov einig, als er sagt, daß er mit seiner Auswahl keine Wertung vornehmen wollte, sondern lediglich diejenigen Dichter erwähnt habe, deren Werk oder Persönlichkeit am klarsten zu definieren sind und ihm daher zur Erklärung seines Systems, das er für sehr kompliziert hält, am geeignetsten erscheinen. „Die Neuheit und Kompliziertheit meines Gesichtspunktes verlangt die äußerste Vereinfachung, und diese Vereinfachung konnte nur mit dem Hinweis auf diejenigen erreicht werden, die die Gestalt des Schemas verändert haben, und nicht auf die,

${ }^{89}$ V. B r ju s o v: V zaščitu od odnoj pochvaly. „Vesy" 1905, IV, S. 37. oo ibid. 
die in diesem Schema nur einen wenn auch ehrenvollen Platz einnehmen. ${ }^{{ }{ } 1}$

In einer 1909, also vier Jahre später verfaßten Abhandlung entwickelt Belyj sein ganzes System. Es würde in diesem Rahmen zu weit führen, seinen Gedankengang im einzelnen wiederzugeben. Es seien daher nur die wichtigsten Grundzüge dargestellt. Indem er sich an anderer Stelle bereits zu der Losung "Die Kunst ist nicht nur Kunst; in der Kunst ist unwillkiirlich ein religiöser Kern verborgen ${ }^{492}$ bekennt, ist der Symbolismus für ihn nicht eine Kunstrichtung, sondern eine "Ideologie". "Die Prinzipien des Symbolismus", schreibt er, nsollen uns ein beständiges philosophisches System vorzeichnen: den Symbolismus als Weltanschauung einzusetzen, ist möglich. ${ }^{\text {"9s }}$

Dieses philosophische System erläutert Belyj an Hand eines Diagramms, das er als Emblem der symbolistischen Weltanschauung kennzeichnet. Ein gleichseitiges Dreieck wird in 25 gleichgroße, ebenfalls gleichseitige Dreiecke aufgeteilt. Auf diese Weise entstehen fünf Schichten, von denen die an der Basis 9 Dreiecke enthält, während die oberste nur aus einem besteht. Diesen Teildreiedken werden jeweils Begriffe zugeordnet, die von Schicht zu Schicht einander übergeordnet sind. Die linke untere Ecke des großen Dreiecks trägt die Bezeichnung ${ }_{n} Z$ ahl ${ }^{\alpha}$ (̌̌islo), die rechte untere Edke die Bezeichnung "Chaos". Dementsprechend werden die Begriffe der unteren Schicht von links nach rechts gruppiert. Das Dreieck ganz links trägt die Be.zeichnung "Mechanik ${ }^{\alpha}$, das in der Mitte die Bezeichnung "Sein ${ }^{\alpha}$, das ganz rechts "Primitiver Symbolismus". Die Dreiecke der obersten Reihe sind als "Metaphysik", "Theosophie" und "Theurgie" ausgezeichnet. Das Dreieck an der Spitze trägt die Bezeichnung "Wert" (Cennost'). Der Scheitelpunkt ist als "das verkörperte Symbol “ (Simvol voploščennyj) angegeben.

Am Schluß seiner Ausführung faßt Belyj seine Ideen in kurzen Stichworten zusammen:

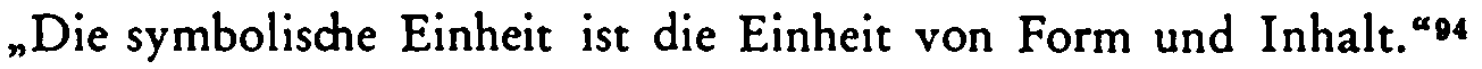
"Das Symbol ist im Symbolismus gegeben."

" A. B e l y j: V zaščitu od odnogo narekanija. (Offener Brief an Brjusov.) „Vesy" 1905, VI, S. 41.

92 A. B el y j: "Simvolizm ${ }^{\alpha}$ S. 10.

93 ibid. S. 51.

24 ibid. S. 92. 
${ }_{n}$ Eine Symbolisierung wird in einer Reihe symbolischer Bilder gegeben."

"Das Symbol ist kein Begriff, wie auch der Symbolismus keine Methode ist. ${ }^{\alpha{ }^{\alpha}}$

Es handelt sich vor allem darum, daß Belyj im Gegensatz zu Brjusov den Symbolismus als eine im Sinne Vladimir Solov'evs "ganzheitliche ${ }^{\alpha}$ Weltanschauung auffaßt und somit der Kunst andere, wichtigere Aufgaben neben rein ästhetischen zuweist. Der wirkliche Dichter führt die reine Kunst in die Religion über.

Belyj hat aber andererseits auch genau verstanden, worum es Brjusov im Grunde genommen auch in seinem Falle geht, nämlich um die Unabhängigkeit der Kunst, die Unabhängigkeit auch von der Religion. Hier versucht Belyj noch einen Kompromiß zwischen der Freiheit der Kunst und ihrer Bindung an religiöse Momente zu finden. Er will seine Einbeziehung des religiösen Momentes in die ästhetische Betrachtung als eine andere Methode ästhetischen Wertens, künstlerischen Schaffens verstanden wissen. "Wenn der Gedanke der Unabhängigkeit des ästhetischen Prinzips parallel mit dem Gedanken der Freiheit des wissenschaftlichen Schaffens geht ${ }^{\alpha}$, schreibt er, ${ }_{n}$ so muß diese Freiheit keineswegs gewaltsam der Kritik aufgedrängt werden. Das Gebiet des Schönen - nehme ich an - darf, wenn es die Form des Eindringens in das Geheimnis der Welt ist, keinerlei Material verachten, das in diese Form hineinführen kann. Die Religion ist eine Form, die das Geheimnis streift. Ihr Gebiet ist auch grenzenlos." Das religiöse Moment wird als Faktor der literarischen Asthetik eingeführt. "Warum", beklagt sich Belyj bei Brjusov, ${ }_{n}$ nimmst du mir eigentlich das Recht zu analysieren, wie sich diese oder jene religiöse Idee mit den einen oder anderen ästhetischen Formen überschneidet? Oder muß ich immer wieder aufs neue die Unabhängigkeit der Schönheit verkünden? ${ }^{\alpha_{\theta 6}}$

Brjusov dagegen hält an seiner rein ästhetischen Kunstauffassung fest. Zwar ist das künstlerische Schaffen Einflüssen unterworfen, doch dürfen diese keinesfalls aus einer außerhalb der Kunst liegenden Sphäre kommen. In seiner Kritik über den von G. I. Culkov herausgegebenen Lyrik-Sammelband "Fakely ${ }^{\alpha 7}$ schreibt er dazu: „Programme von echten, nicht erdachten literarischen Schulen schreiben auf

95 ibid. S. $139 \mathrm{f}$.

or $\mathrm{V}$ zašcitu od odnogo narekanija S. 41.

07 V. B rjus ov: Vechi, Fakely. "Vesy“ 1906, V, S. 54-58 (Avrelij). 
ihre Banner vor allem literarische Prinzipien, künstlerische Vermächtnisse. Die Romantik war der Kampf gegen die Konventionalität und die engen Regeln des Pseudoklassizismus; der Realismus verlangte die wahrheitsgetreue Darstellung der zeitgenössischen Wirklichkeit; der Symbolismus brachte die Idee des Symbols als neues Mittel des Ausdrucks. Auf eine und dieselbe realistische Schule konnten sich Schriftsteller, die einander so unähnlich waren wie Dostoevskij, L. Tolstoj und Turgenev, beziehen, weil sie ähnliche Kunstgriffe (priemy) des literarischen Schaffens verwenden, nämlich realistische. ${ }^{{ }^{98}}$ Brjusov lehnt jede utilitaristische Bindung der Kunst ab und hält jede Auswah! von Kunstwerken, bei der das einigende Motiv nicht aus künstlerischen Erwägungen besteht, für gegenstandslos: ${ }_{n}$ Kunstwerke nach Merkmalen auszuwählen, die keine Beziehung zur Kunst haben, bedeutet eine Abkehr von der Kunst, - es bedeutet eine Gleichstellung mit den „Peredvižniki ${ }^{\alpha_{\theta \theta}}$ und den Verfechtern einer nutilitaristischen ${ }^{\alpha}$ Dichtung. In Almanachen nur Gedichte und Erzählungen von Autoren zu sammeln, die "von der Welt nicht anerkannt" werden, ist das gleiche, wie wenn man nur die Mitarbeit derjenigen Autoren erbäte, die gelbe Augen haben oder deren Familiennamen mit einem Vokal oder einem Zischlaut beginnen. ${ }^{{ }_{100}}$

Dieses unbedingte Festhalten an der Unabhängigkeit der Kunst veranlaßt Brjusov auch dazu, gegen Vjačeslav Ivanov Stellung zu nehmen. Auch Ivanov greift Solov'evs Idee von der "theurgischen" Funktion der Kunst auf. Er ist der Ansicht, daß der Symbolismus nicht $\mathrm{n}$ u r Kunst sein will. Vielmehr führe der Symbolismus die Kunst zu ihrer eigentlichen Bestimmung, zu einer Art Wirksamkeit höherer Sphären auf niedrigere. Eine ähnliche Haltung nimmt auch der als Dichter hervorragende Aleksandr Blok ein (1910). Für ihn muß der Künstler "Theurg" sein, der Vermittler $z$ wischen dem Vordergrund der Welt und dem, was - für andere nicht schaubar im Hintergrund vorgeht. Er beklagt, daß er sich so lange damit begnügt habe, nur Dichter zu sein, ohne die viel wichtigere und "höhere" Aufgabe eines "Theurgen" zu erkennen.101 Auch gegen ihn muß Brjusov sich von seiner Warte aus wenden.

28 ibid. S. 56.

9o Peredvižniki: eine Künstlervereinigung um die Jahrhundertwende, die vor allem Wanderausstellungen organisierte. In diesen wurden die Werke der damals modernen Maler, vor allem Impressionisten, ausgestellt.

100 Fakely S. 56.

101 Vgl. V. V. Z e n'k ovskij: Istorija russkoj filosofii, t. II, Paris 1950. 
In scharfen Worten mißbilligt er solche Umdeutungen des Begriffs: „Wie sehr ich auch die künstlerische Begabung und Energie Vjačeslav Ivanovs achte, so kann ich doch in keiner Weise zugeben, daß als "Symbolismus" das bezeichnet wird, was ihm gerade gefällt. „Symbolismus" wie auch "Romantik" sind ganz bestimmte historische Erscheinungen, die mit bestimmten Daten und Namen verbunden sind. Entstanden als literarische Schule Ende des 19. Jahrhunderts in Frankreich (nicht ohne englischen Einfluß), hat die "symbolistische" Bewegung in allen europäischen Literaturen Anhänger gefunden, hat mit ihren Ideen andere Kunstarten befruchtet, und es war unmöglich, $\mathrm{da}$ B sie sich nicht in der Weltanschauung dieser Zeit widerspiegelte. Aber sie entwickelte sich ausschließlich auf dem Gebiet der Kunst. Vjačeslav Ivanov kann den Symbolismus in Zukunft auf die verschiedensten Ziele hinlenken, ebenso sein „Baedeker" ${ }^{102}$ auf dem Weg zu diesen Zielen, aber beide haben nicht das Recht und können auch nicht das verändern, was gewesen ist. Wie es sie auch verdrießen mag, der "Symbolismus" wollte immer nur Kunst sein und war es immer." ${ }^{103}$

In seinem 1910 erschienenen Aufsatz "O sovremennom sostojanii russkogo simvolizma "103" gibt Blok einen Abriß seiner Vorstellungen vom Symbolismus, von der Kunst und den Aufgaben des Künstlers überhaupt. Den schöpferischen Vorgang beim Künstler, d. h. beim s y mbolist is che n Künstler, gliedert er in "These" und „Anti-

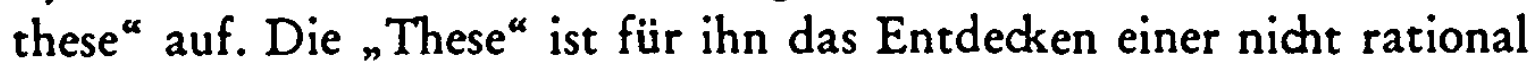
greifbaren Welt durch den Künstler. Zur Schilderung dieser Welt bedient er sich verschiedener Bilder und versucht folgerichtig eine nicht rationale Welt seinem Leser mit nicht rationalen Mitteln zu schildern. Blok übernimmt dabei z. T. Bilder aus Vlad. Solov'evs "Tri svidanija“, gliedert sie aber seinen eigenen Betrachtungen völlig ein. Die wichtigsten Bilder in Bloks Erörterung sind das "Goldene Schwert", auch das "Strahlende Schwert" (lučezarnyj meč) und die Farbe purpur-lila: $n . .$. schließlich erweist sich eine Farbe als vorherrschend, die ich am ehesten als purpur-lila bezeichnen kann .... ${ }^{\alpha 103^{b}}$

102 Blok bezeichnet sich in seinem Aufsatz als „Baedeker" Vjačeslav Ivanovs.

103 V. B r ju s o v: O reči rabskoj. "A Apollon “ 1910, IX, S. 31-34.

103a Aleksandr Blok: $O$ sovremennom sostojanii russkogo simvolizma. "Apollon" 1910, VIII.

103b ibid. S. 23. 
Ungefähr kann man das erste der drei Bilder der These zuordnen, das zweite der Antithese. Den Vorgang künstlerischen Schaffens stellt Blok etwa wie folgt dar: Der Künstler beginnt neben der ihn umgebenden realen Welt weitere irreale Welten zu erkennen. Diese Welten sind zunächst verlockend, aber auch bis an die Grenze des Erträglichen erregend. Um so weit zu gelangen, muß der Künstler „Theurg“ sein. Diesen Begriff entlehnt Blok ebenfalls von Vlad. Solov'ev.

Mit dem Wissen, daß „eine Spaltung zwischen dieser Welt und ,anderen Welten " existiert ${ }^{\alpha}$, beginnt der Künstler seinen Weg ins Irrationale: „Die Klinge des geheimnisvollen Schwertes ist schon auf die Brust gesetzt; der Symbolist ist schon von Anfang an Th e u r g, d.h. der Besitzer geheimnisvollen Wissens, hinter dem ein geheimnisvolles Geschehen steht. "109" Rings um das "goldene Schwert" entsteht eine Welt in der genannten Farbe purpur-lila (purpurnolilovyj). Der Künstler befindet sich auf dem Höhepunkt einer Ekstase: „Das goldene Schwert durchdringt die purpur-lila Welten und entbrennt mit blendend heller Flamme - und durchbohrt das Herz des Theurgen." ${ }^{103 \dot{i}}$ Danach beginnt der Umschwung, die Erregung läßt nach: "Als neide er dem einsamen Theurgen die strahlende Klarheit, zerreißt jemand jählings den goldenen Faden der erblühenden Wunder; die Klinge des strahlenden Schwertes verblaßt und ist allmählich nicht mehr im Herzen zu fühlen. Die Welten, die vom goldenen Licht durchdrungen waren, verlieren ihre purpurne Schattierung. ${ }^{\text {"103e }}$ Der Künstler ist nicht mehr passiv, er beginnt schöpferisch tätig zu werden. "Dies alles erlebend", heißt es weiter bei Blok, „ist er schon nicht mehr allein; er ist voll zahlreicher Dämonen (anders auch „Dopp elgäng e r" genannt), aus denen sein böser schöpferischer Wille eine Gruppe jederzeit nach Belieben auswechselbarer Gesprächspartner macht. Jeden Augenblick entdeckt er mit Hilfe dieser Gesprächspartner irgendeinen Teil seiner eigenen Seele. Dank dieses trügerischen Netzes - je raffinierter, desto wunderbarer wird die ihn umgebende lila Finsternis - kann er mit seinen Mitteln jeden Dämon hervorbringen, mit jedem Doppelgänger eine Verbindung aufnehmen; alle brüllen sie in den lila Welten und, je nach seinem Willen, verschaffen sie ihm die schönsten Kostbarkeiten, alles, was er sich nur

103c ibid. S. 22.

103d ibid. S. 23.

10se ibid. S. 24. 
wünscht ... ${ }^{\alpha 103 f} \mathrm{Er}$ ist jetzt im Besitz künstlerischen Materials und kann mit diesem nach eigenem Willen verfahren: „Dies alles wirft ihr Herr in den Tiegel seines künstlerischen $\mathrm{Schaf}$ f e n s. ${ }^{\alpha 103 g}$

Symbolistische Kunst ist für Blok höchste Emotion. Um Symbolist zu sein, muß man die natürliche Begabung zum Theurgen besitzen. „Daher können Schriftsteller, sogar sehr begabte, nichts mit der Kunst anfangen, wenn sie nicht mit dem ${ }_{n}$ Feuer und Geist ${ }^{\alpha}$ des Symbolismus getauft sind. " ${ }^{103 h}$ Blok ist kein klarer Theoretiker und greift zur Erläuterung seiner Gedanken stets zu mystischen Vorstellungen. Aber ihm ist es darum nicht weniger ernst um das Anliegen der Kunst zu tun. "Sich Hirngespinsten hinzugeben“, schreibt er, „bedeutet noch nicht, ein Künstler zu sein, aber ein Künstler zu sein heißt, den Wind aus den Welten der Kunst zu ertragen, die dieser Welt nicht ähnlich sind, sondern nur einen furchtbaren Einfluß auf sie haben; in jenen Welten gibt es nicht Ursache und Wirkung, nicht Zeit und Raum, nicht Materielles und Immaterielles, und diese Welten kennen keine Zahl. ${ }^{\text {} 108 i}$

Brjusov aber wehrt sich gegen die Einführung mystischer Begriffe in die Kunsttheorie. Er sieht im Symbolismus ganz nüchtern eine Methode der Kunst, die in der nsymbolistischen ${ }^{\alpha}$ Schule bewußt angewandt wird. Die Kunst habe nichts mit dem Rationalismus der Wissenschaften zu tun und ebensowenig mit Mystik. „Die Kunst ist autonom: sie hat ihre Methoden und Aufgaben. Wann wird es möglich sein", beklagt sich Brjusov, ndiese Wahrheit nicht mehr zu wiederholen, die längst zum $\mathrm{ABC}$ geworden ist!“104

Im Prinzip billigt Brjusov den Gedankengang Bloks als für diesen gültig: „Ohne im geringsten den geistigen Weg zu verurteilen, den A. Blok in leicht ausdeutbaren Sinnbildern in seinem Aufsatz dargelegt hat, kann man in keiner Weise diesen Weg als typisch für den heutigen Dichter ansehen. "104"

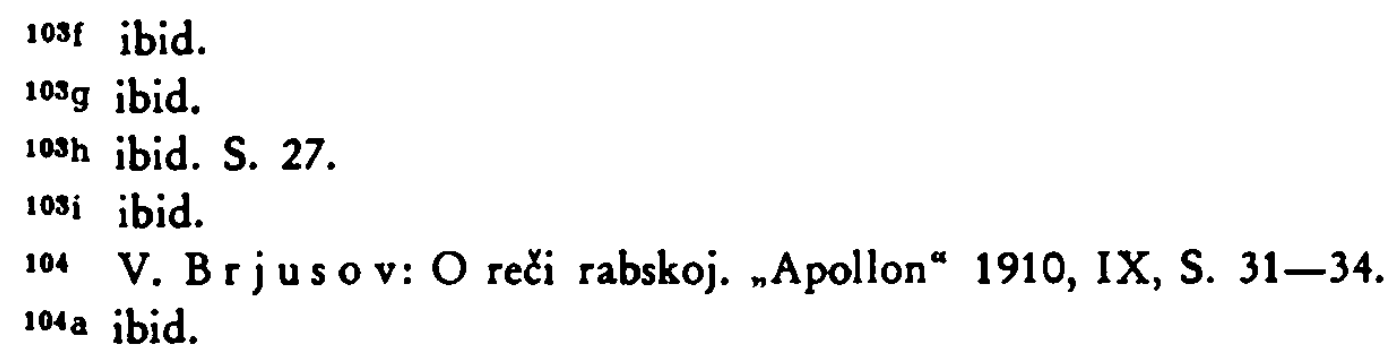


In Brjusovs Gedicht "An einen Dichter ${ }^{\star}$ heißt es:

'Ty dolžen byt' gordym, kak znamja;

Ty dolžen byt' ostrym, kak meč;

Kak Dantu, podzemnoe plamja

Dolžno tebe ščeki obžeč'. ${ }^{104^{b}}$

Hier nähert er sich mit seinem Bild den Vorstellungen Bloks, wel-

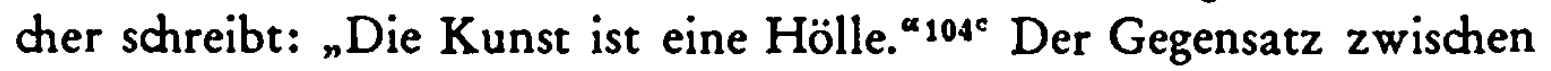
Brjusov und Blok in der Auffassung des Symbolismus ist hier wohl nur zum Teil grundsätzlicher Art; zum Teil dürfte Brjusovs Ablehnung auch durch die Art der Darstellung von Gedanken, wie sie Blok eigen ist, hervorgerufen sein. Während Brjusov scharf zwischen Dichtung und Theorie trennt, tut Blok dies durchaus nicht.

Brjusov erkennt jedoch an, daß sowohl Blok als aud Vjačeslav Ivanov sich durch ihre religiösen Theorien nicht davon abhalten ließen, weiterhin gute Dichter zu bleiben, und er empfindet es als Selbstverleumdung, wenn Blok seine jüngsten Gedichte als „sklavische Reden ${ }^{\alpha}$ bezeichnet. ${ }^{105}$

Entschieden aber wehrt sich Brjusov gegen die Bemühungen Bloks und Ivanovs, dem Symbolismus eine andere, außerhalb des künstlerischen Bereiches liegende Bedeutung zu unterlegen. Dies hieße nach Brjusovs Meinung, die Dichtung von einem Wege abzubringen, den sie schon Jahrtausende beschreitet. Abgesehen davon, daß er das nicht für möglich hält, zweifelt er auch an der "theurgischen ${ }^{*}$ Berufung der beiden Dichter. ${ }^{100}$

Bitter beklagt er sich darüber, daß seine Bemühungen um die ${ }_{n} \mathrm{Be}$ freiung " der Kunst nun durch die Unterstellung der Kunst unter ein ihr fremdes Prinzip zunichte gemacht werden sollen. „Ist es denn wirklich so, daß man, nachdem man die Kunst gezwungen hatte, der Wissenschaft und der Gesellschaft zu dienen, sie jetzt zwingen wird, der Religion zu dienen! Gebt ihr endlich die Freiheit! ${ }^{\boldsymbol{1}_{07}}$

Die Kunst müsse zwar frei sein, schreibt Brjusov an anderer Stelle,

104b Du sollst stolz wie ein Banner sein;

Du sollst scharf wie ein Schwert sein;

Wie Dante, so soll dir die unterirdische Flamme die Wangen versengen.

${ }^{104} \mathrm{c}$ A. B l ok: O sovremennom sostojanii russkogo simvolizma. "Apollon" 1910, VIII, S. 27.

105 Dies ist eine Anspielung Brjusovs auf einen Ausspruch Solov'evs.

$100 \mathrm{Vgl}$. O reči rabskoj.

107 O reči rabskoj. 
doch fällt ihr diese Freiheit nicht von selbst zu. Immer wieder sind es die verschiedensten ästhetischen Theorien, die den Künstler verwirren, er kommt nicht dazu, sich selber über das Phänomen Kunst Rechenschaft abzulegen. „Die Geschichte der neuen Kunst ist vor allem die Geschichte ihrer Befreiung. Romantik, Realismus und Symbolismus sind drei Stadien im Kampf der Künstler um die Freiheit. ${ }^{\mathbf{1} 108}$

Immer wieder sind die Künstler durch verschiedene, rein zufällige Ziele versklavt worden. Erst um die Jahrhundertwende ist es der Kunst gelungen, sich der Ketten dieser Versklavung zu entledigen.

Am Schluß seines oben erwähnten Vortrages "Klư̌ci tajn " ruft Brjusov noch einmal aus: „Jetzt wendet sie (die Kunst) sich bewußt ihrer höchsten und einzigen Bedeutung zu: Erkenntnis der Welt zu sein außerhalb rationaler Formen, außerhalb kausalen Denkens." Und er fährt fort: ${ }_{n}$ Stört die neue Kunst nicht in ihrer ... jedem Nutzen fremden und den Notwendigkeiten des Heute fernstehenden Aufgabe!

Für die zweite der oben genannten drei Perioden in Brjusovs literaturtheoretischem und kritischem Schaffen ergibt sich nach dem Gesagten etwa folgende Auffassung der Literatur:

Die wesentlichste Forderung für die Kunst und auch an die Kunst ist ihre absolute Freiheit von irgendwelchen utilitaristischen, außerhalb des künstlerischen Bereiches liegenden Bindungen, ist ihre "Autonomie".

Das Verlangen nach Freiheit der Kunst gipfelt nicht in einer abseitsstehenden l'art pour l'art-Auffassung vom Sinn der Kunst. Diese dient vielmehr dazu, dem Künstler seine eigenen Gedanken und Empfindungen auf einem anderen als rationalen Weg zu erklären und bewußt werden zu lassen; denn in der Kunst tritt zum rein rationalen Vorgehen ein emotionaler Faktor und das ist es, was sie von anderen Denkmethoden unterscheidet. Die Kunst vereinigt beide Elemente in sich auf dem Weg einer Synthese.

Wesentlich an einem Kunstwerk ist nicht, w as es darstellt, sondern $w$ i e es darstellt. Hierbei handelt es sich jedoch nicht um eine rein formale Kunstauffassung, sondern das "Wie" bezeichnet neben der Form der Aussage vor allem die Art eines dem Kunstwerk zu-

${ }^{108}$ Ključi tajn S. 20. 
grundeliegenden Gedankens. Der sachliche Inhalt eines Werkes wird diskutiert zur Untersuchung der dadurch zum Ausdrudk gebrachten Gedanken und Emotionen.

Die Geschichte der Kunst ist die Geschichte ihrer Befreiung von außerästhetischen Bindungen.

In ihren wesentlichen Zügen lehnt sich diese Auffassung an die Arbeiten Potebnjas an. Der Gedanke von der Kunst als Synthese wurde von Brjusov in dieser Periode zwar aufgeworfen, aber nicht ausgearbeitet und über das von Potebnja Gesagte hinaus genauer erklärt und im einzelnen präzisiert.

\section{Die Kunst als Synthese}

Das Problem der Freiheit der Kunst wurde für Brjusov noch einmal während des ersten Weltkrieges akut. Wie überall griff damals auch in Rußland die patriotische Begeisterung allzu sehr auch auf den Bereich der Kunst über. Bedeutende Dichter und Schriftsteller gaben sich dazu her, tendenziöse Machwerke unter ihrem Namen herauszugeben. Für Brjusov lebte damals die wahre Kunst nur noch im Verborgenen.

Die alles nivellierende Welle des Patriotismus hatte alle bestehenden Kunstrichtungen erfaßt. „Die meisten Dichter“, beklagt sich Brjusov, "stürzten sich um die Wette auf die Produktion von patriotischen und kriegerischen Versen. Die "Nachfrage ${ }^{\alpha}$ nach Produkten dieser Art (und zwar nicht nur seitens wöchentlich erscheinender Boulevardblätter, sondern auch seitens seriöser, „dicker" Zeitschriften) verursachte ein überreiches "Angebot". Diese kriegerischen, slavophilen und - leider - nicht selten ultramonarchistischen Gedichte wurden in unvorstellbaren Mengen nach einem bestimmten, ein für allemal festgelegten Rezept angefertigt. Beim Verfassen solcher Verse vergaßen die Dichter alle Tradition und alle Vermächtnisse ihrer "Schule", und oft war es sdiwierig, in der Reihe dichterischer Lieferungen nach Bedarf die betreffenden Arbeiten eines ehemaligen Futuristen von denen eines ehemaligen Realisten zu unterscheiden. ${ }^{{ } 100}$

Am schmerzlichsten empfand es Brjusov, daß diese Massen an minderwertigen literarischen Produkten in der Lage waren, auch das

${ }^{109}$ V. B r jus o v: Věera, segodnja i zavtra russkoj poézii. „Pečat' i revoljucija“" 1922, VII, S. 41. 
Urteilsvermögen der Leser zu trüben. "Rein künstlerische Aufgaben traten überhaupt nicht ins Blickfeld, sie verschwanden völlig im Hintergrund ... Und solche Produkte wurden zu Tausenden gelesen, sie traten zeitweise an die Stelle echter Poesie, die inzwischen natürlich weiterlebte, deren Existenz aber sowohl von den Lesern als auch von den Kritikern vergessen wurde. ${ }^{{ }{ }_{110}}$

1918 schloß sich Brjusov jedoch der Revolution an. Damit wurde naturgemäß auch seine Verteidigung der Freiheit der Kunst etwas zurückhaltender. Er geht einmal sogar so weit, daß er wenigstens vom Literaturhistoriker auch eine Untersuchung der Zusammenhänge zwischen sozialen Erscheirungen der betreffenden Zeit und der jeweiligen Literatur verlangt. Dieser Wandel in der Einstellung macht sich in der Folge insofern positiv bemerkbar, als Brjusov einen weiteren Blick für allgemein historische Zusammenhänge in ihren Auswirkungen auf die Außerungen der Kunst gewinnt, die zweifellos vorhanden sind.

Vage nur äußert sich Brjusov in einer Besprechung von Gumilevs "Pis'ma o russkoj poèziii". ${ }^{111}$ Gumilev, der Begründer und führende Kopf der "Akmeisten“, einer Schule, die im Gegensatz zum Symbolismus logische ${ }_{n} \mathrm{Klarheit}{ }^{\text {in }}$ in der Dichtung verlangt, gibt in diesem Band eine kritische Ubersicht über das literarische Geschehen in den Jahren 1909-1915. Diese Betrachtungen sind rein literarischer $\mathrm{Na}$ tur und haben keinerlei Bezug auf irgend eine der damaligen politischen Richtungen. ${ }^{112}$ Brjusov bemerkt dazu: "Es fehlt in den "Pis'ma“ völlig der soziale Hintergrund. Natürlich, eine Kritik ist keine Literaturgeschichte, und es braucht von einem Zeitgenossen nicht verlangt zu werden, daß er den Zusammenhang einer Neuerscheinung. eines neuen Gedichtbandes mit dem Kampf sozialer Kräfte in der betreffenden Zeit aufdeckt. Aber bei Gumilev finden wir eine absichtliche, voreingenommene Trennung von Dichtung und Gesellschaft. " ${ }_{113}$

Diese Außerung kennzeichnet aber noch kaum einen grundsätzlichen Umschwung in Brjusovs allgemeiner Einstellung zur Kunst, wenn man bedenkt, daß die erwähnte Besprechung erst 1923, also

110 ibid.

11 N. Gumile v: Pis'ma o russkoj poèzii. Petrograd 1923.

112 Nikolaj S. Gumile $\mathbf{1}(1886-1921)$ wurde von den Kommunisten wegen gegenrevolutionärer Tätigkeit erschossen.

113 V. B r ju sov: Sud akmeista. "Peč. i rev." 1923, III, S. 100. 
sechs Jahre nach dem Beginn der Revolution erschien. Weit bezeichnender erscheint mir für die Grundhaltung Brjusovs ein Passus aus einem Vortrag, der bereits 1918 gehalten wurde und den Brjusov auch in seinen im gleichen Jahr erschienenen Sammelband "Opyty po metrike i ritmike, po èvfonii i sozvučijam, po strofike i formam ${ }^{\boldsymbol{\alpha}_{114}}$ aufnahm. "Schließlich und endlich", erklärte Brjusov damals, "sind alle Mittel in der Poesie gut, wenn sie ihrem Ziel dienen, nämlich die Ausdruckskraft eines Wortes zu verstärken, und es gibt keine " edlen ${ }^{*}$ und nunedlen" Mittel. Deshalb ist die nicht selten zum Ausdruck gebrachte Mißachtung einem "Thema" gegenüber unvorsichtig. Das, was uns jetzt gering und unbedeutend erscheint, kann sich in der Hand eines genialen Poeten als eines der stärksten Mittel erweisen, um den gewünschten Eindruck zu erreidien. ${ }^{{ }^{115}}$

Hieraus geht eindeutig hervor, wie Brjusov die in einem literarischen Werk behandelten Themen einstuft, nämlich als eines von verschiedenen Mitteln, die dazu dienen, einen gewünschten Eindruck hervorzurufen, einen bestimmten emotionalen Wert zu vermitteln.

$\mathrm{Da}$ für Brjusov diese Anschauung für die Beurteilung eines literarischen Werkes auch weiterhin maßgebend geblieben ist, dafür spricht die abschließende Erklärung in seinem Aufsatz über die Entstehung und die Wirkungsweise der Literatur. Dieser Aufsatz, nSintetika poèzii “, ist erst 1924 erschienen. Trotzdem kann das, was hier gesagt wird, durchaus als eine Ergänzung und Bestätigung des oben erwähnten Vortrages von 1918 dienen: „Der Streit über das betreffende Werk, ob es Dichtung ist oder nicht, kann auf der Basis objektiver Merkmale entschieden werden, und nicht auf Grund subjektiver Feststellungen oder einer impressionistischen Kritik. Wo es kein synthetisches Denken gibt, wo es keine abschließende Synthese voin zwei oder mehreren Bildern gibt, dort gibt es auch keine Dichtung. ${ }^{* 116}$

Die Gegenüberstellung objektiver Merkmale und subjektiver Feststellungen erhält ihre Definition aus der anschließenden Forderung nach einer vollkommenen Synthese zweier Bilder, die hier zweifellos als das objektive Merkmal eines echten dichterischen Werkes gedacht ist.

114 V. Brjus o v: Opyty po metrike i ritmike, po évfonii i sozvučijam, po strofike $\mathrm{i}$ formam. Moskau 1918.

113 Opyty S. 40.

110 V. B r jus o v: Sintetika poèzii. Izbr. soł. S. 356. 
Das Fehlen der in der zweiten Periode so vehementen Aufrufe zur Befreiung der Kunst dürfte bei Brjusov nicht nur durch die Ideologie der Revolution bedingt sein, sondern vielmehr durch die allgemeinen literarischen Ereignisse der Zeit, durch die Vielfalt üppig blühender literarischer "Schulen ${ }^{\alpha}$, denen eine Bindung der Kunst zum großen Teil durchaus fremd war. Man darf bei dieser Uberlegung nicht überschen, daß die Kulturpolitik der Sowjetregierung zu Beginn der zwanziger Jahre im Vergleich zur späteren Zeit fast liberal war. Der "soziale Auftrag" wurde der sowjetischen Kunst nicht vor 1929 erteilt, und danach erst begann die völlige Gleichschaltung der Literatur. Vorher ist eine starke Aktivität im literarischen Leben Rußlands zu verzeichnen. ${ }^{117}$

Angesichts einer solchen allgemeinen Situation war es für Brjusov nur naheliegend, sich aktuelleren Fragen der Literaturkritik und der Literaturtheorie zuzuwenden. Zumal damals bereits ein Teil der wichtigsten Werke der Formalisten erschienen war und zur Aktivität auch auf literaturtheoretischem Gebiet aufforderte.

Ebenfalls eine Erweiterung erfährt die von Potebnja übernommene Ansicht, die Kunst diene dazu, dem Künstler seine eigenen Gedanken und Empfindungen zu erklären. So schreibt Brjusov in einem 1922 erschienenen kritischen Aufsatz zu den Forderungen der verschiedenen literarischen Schulen und Gruppen: „Die Dichtung entsteht vielleicht, wie jede Kunst, aus dem Verlangen des Dichters, sich selbst seine Erlebnisse zu zeigen, sie sich zu erklären (Theorie von Potebnja)". Und einschränkend fährt er fort: „Aber wie jede Kunst wird die Dichtung danach bewertet, ob sie etwas aussagt, was vom Leser aufgenommen wird." 119

Später, 1924, definiert Brjusov den Begriff Kunst noch einmal im gleichen Sinne. ${ }^{119}$ Kunst, d.h. in diesem Falle besonders die Dichtung, ist Erkenntnis. Brjusov basiert dabei wieder ausschließlich auf der Idee W. v. Humboldts, der Analogie zwischen Sprachschöpfung und dichterischem Schaffen.

In diesem Zusammenhang greift er die bereits geschilderte Feststellung vom Verhältnis zwischen Kunst und Wissenschaft wieder auf. Beide hätten als endgültiges Ziel das gleiche, nämlich Erkenntnis.

117 Vgl. Gleb Struve: Geschichte der Sovjetliteratur. Deutsche Ausgabe. München 1957.

118 V̌era, segodnja... S. 54.

110 Sintetika poézii. 
Noch einmal wiederholt Brjusov seine frühere Definition: „Wenn die Dichtung wie die Wissenschaft eine Form der Erkenntnis ist, wodurch unterscheiden sich dann Erkenntnis durch Wissenschaft und Erkenntnis durch poetisches Schaffen? Ausschließlich durch die M eth od e. Die Methode der Wissenschaft ist die Analyse; die Methode der Dichtung ist die Synthese. ${ }^{{ }^{120}}$

Während es aber Brjusov früher bei der kurzen Definition des Unterschiedes $z$ wischen Kunst und Wissenschaft bewenden ließ, so zwingt ihn jetzt seine im Laufe der Zeit und der Ereignisse nüchterner gewordene Auffassung von der Kunst zu einer genaueren Erläuterung des Begriffes Synthese in seiner Anwendung auf die Kunst. Sein 1924 verfaßter Aufsatz "Sintetika poèzii“ befaßt sich ausschließlich mit dieser Frage.

Brjusov geht davon aus, daß er die Denkweise der Wissenschaft zerlegt und zeigt, daß es sich dabei um einen analytischen Vorgang handelt. „Die Feststellung, der Mensd ist sterblich', folgert Brjusov, „ist eine analytische Auflösung dessen, was bereits im Begriff Mensch enthalten ist. Im Grunde genommen müssen alle wissenschaftlichen Wahrheiten, die möglich sind, bereits implicite in den Axiomen der Wissenschaft eingeschlossen sein. Es wäre ausreichend, den Inhalt der Axiome analytisch aufzudecken, um daraus alle "Gesetze der Natur" und alle "Gesetze des sozialen Lebens" zu erhalten. Praktisch ist dies natürlich nicht möglich. ${ }^{\alpha 121}$

Wesentlich erscheint Brjusov bei dieser Methode die Verallgemeinerung. „Der Gelehrte“, fährt er fort, „zieht eine allgemeine Schlußfolgerung, indem er eine Reihe einzelner faktischer Beobachtungen verallgemeinert. Jedoch muß diese allgemeine Schlußfolgerung unbedingt mit schon vorher bekannten wissenschaftlichen Gesetzen so verbunden sein, daß die neue Behauptung sich als ein spezieller Fall eines oder mehrerer von ihnen erweist. Mit anderen Worten, eine neue wissenschaftliche Wahrheit muß sich immer als die analytische Auflösung einer der schon vorher bekannten Wahrheiten darstellen. ${ }^{\prime 122}$

Brjusov erläutert das an einem fiktiven Beispiel. Ein Gelehrter, der psychische Erscheinungen beobachtet, postuliert zunächst einmal,

\footnotetext{
120 ibid. S. 357.

121 ibid. S. 358.

122 ibid.
} 
daß jeder einzelnen eine bestimmte physiologische Erscheinung und eine bestimmte chemische Reaktion entspreche, die sich wiederum als Ursache psychischer Vorgänge erweisen. Das bedeutet, so folgert Brjusov, daß der Gelehrte einen noch unerklärten (in diesem Falle psychischen) Vorgang mit einem bereits erklärten (in diesem Falle chemischen) Vorgang in Verbindung bringe und auf diese Weise beim chemischen Vorgang eine neue Bedeutung entdecke, die man vorher nicht gesehen habe. Das Ergebnis sei dann das gleiche, als habe der Gelehrte die Gesetze der Chemie analysiert und aus ihnen ein neues Gesetz abgeleitet.

Wenn Brjusov mit diesem stark simplifizierten Beispiel auch über das Ziel hinausschießt. so muß man ihm zugute halten, daß er lediglich einen Kontrast zu seiner Erläuterung der künstlerischen Arbeitsweise, um die es ihm in diesem Aufsatz geht, hat schaffen wollen.

"Im Gegensatz zur Wissenschaft", schreibt er weiter, „bedient sich die Kunst, insbesondere die Dichtung, als grundlegender Methode der Synthese. Ein Werk der Dichtung ist eine synthetische Feststellung oder eine Reihe synthetischer Feststellungen; und eine solche Synthese ist jedes poetische Bild. ${ }^{{ } 223}$

Was Brjusov darunter versteht, wird von ihm genauer erläutert: "Wenn die Feststellung der Mensch ist sterblich" in ihrem Wesen analytisch ist, obwohl man auf dem Wege der Induktion zu ihr gelangte, nämlich durch die Beobachtung, daß alle Menschen sterben, dann ist die Außerung eines Dichters (F. Tjutčev) nzvuk usnul " (der Ton schlief ein) eine synthetische Feststellung. So sehr man auch den Begriff "zvuk" (Ton) analysiert, man wird darin niemals "son" (Schlaf) entdecken; man muß zu ${ }_{n} z v_{k}$ " etwas von außen hinzufügen, mit ihm verbinden, eine Synthese zustandebringen, um die Verbindung $n$ zvuk usnul ${ }^{\alpha} \mathrm{zu}$ erhalten. "124

Hierbei handele es sich um einen der gebräuchlichsten Kunstgriffe der poetischen Synthese, der sogenannten ${ }_{n}$ Personifizierung ${ }^{\alpha}$. Den gedanklichen Hergang erläutert Brjusov folgendermaßen: dem Dichter sind die Vorgänge im "beseelten " Leben aus persönlicher Erfahrung eher bekannt als die der unbelebten Welt, und er erklärt diese mit Hilfe der Vorgänge in seinem eigenen Leben. Brjusov führt zu dieser Art der poetischen Synthese einige weitere Beispiele, ebenfalls aus Tjutčev, an, unter anderem "lenivo dyšit polden'“ (träge atmet der

123 ibid. S. 359.

124 ibid. 
Mittag) und "lazur' nebesnaja smeetsja" (das Blau des Himmels lacht).

Brjusov bringt diesen Gedankengang auf eine einfache Formel, indem er sagt, daß der Arbeitsweg der Wissenschaft vom Detail zum Allgemeinen führe, von einer konkreten Erscheinung, einer bestimmten Vorstellung zum generellen Begriff. Umgekehrt die Dichtung. Hier liegen ganz spezielle, einmalige Ereignisse, bestimmte Begriffe als Material vor. Aus diesen wird dann auf dem Wege der Synthese eine vollkommene Vorstellung geformt, die sich nun statt aus den verwendeten allgemeinen Begriffen aus konkreten Erscheinungen und Gegenständen zusammensetzt.

Jedoch liege jeder dieser konkreten Erscheinungen, jeder dieser Vorstellungen in der Dichtung eine bestimmte allgemeine These, eine "relative Wahrheit" (uslovnaja istina) zugrunde. Eine solche dient dem Dichter als Axiom. Indem er nun Vorstellungen synthetisch verbindet, verbindet er auf die gleiche Weise auch diese Axiome miteinander. Es entsteht dann aus einem oder mehreren Axiomen ein neues. Dieses neue Axiom, das ja eine neue "Wahrheit ${ }^{*}$ darstellt, sei das treibende Moment überhaupt, das zur Entstehung eines Kunstwerkes führt. In welcher Form sie im fertigen Kunstwerk erscheint, hängt von dem Können des betreffenden Dichters ab: „Diese neue Wahrheit erscheint im vollendeten poetischen Kunstwerk ebenfalls als Vorstellung, im weniger vollendeten vielleicht als abstrahierte Feststellung. " ${ }^{125}$

Brjusov zeigt nun an konkreten Beispielen, wie die Ergebnisse dieser Untersuchung bei der Interpretation von lyrischen Werken praktisch anzuwenden sind. Als erstes Beispiel untersucht er Puškins "Prorok ${ }^{\alpha}{ }^{126}$ Brjusov legt dem Gedicht zwei Hauptideen zugrunde, die beide in Vorstellungen wurzeln, die zu Beginn des 19. Jahrhunderts in Dichterkreisen weit verbreitet waren. Das Gedicht sollte eine Erläuterung der Tätigkeit des Poeten werden. Das eine Axiom, die eine "Wahrheit" ist die Feststellung, daß der Dichter ein gewöhnlicher Mensch wie auch andere sei. Das zweite Axiom ist die Feststellung, daß der Dichter Dinge ausspricht, die der gewöhnliche

125 ibid. S. 361.

120 Eine von Brjusov als fast vollständig angesehene Untersuchung dieses Gedichts wurde postum in dem Sammelband "Moj Puškin", Moskau 1928, veröffentlicht. 
Mensch nicht aussprechen kann. Diese beiden sich widersprechenden "Ideen" stellt Brjusov einander gegenüber als These und Antithese. Die Synthese aus beiden sei „die Aufgabe des Gedichtes, das Gesuchte, das X, welches Puškin vorschwebte, als er seine Verse schrieb. ${ }^{127}$

Diese Synthese bei Puškin wird von Brjusov nach Art eines mathematischen Beweises noch einmal durchdacht. Auf natürlichem Wege läßt sich eine solche Synthese nicht finden. Daher muß das auf übernatürliche Weise geschehen. Übernatürliches zeigt man zwedkmäßigerweise in einer Umgebung, die von unserer augenblidklichen Wirklichkeit räumlich und zeitlich weit entfernt ist. $\mathrm{Zu}$ diesem $\mathrm{Zweck}$ ersetzt Puškin das Bild "Poet" durch das Bild "Prophet" und versetzt damit die Handlung in eine vorderasiatische Wüste zu biblischer Zeit. Dabei trifft vom Standpunkt des Romantikers Puškin alles, was beim Propheten bewiesen wird, auch auf den Dichter zu. So weit die Voraussetzung der Brjusovschen Beweisführung. Jetzt beginnt die Ableitung: Dem Propheten erscheint ein „šestikrylyj serafim ${ }^{\alpha}$. Dieser verwandelt die Kennzeichen des gewöhnlichen Menschen (Lider, Ohren usw.) in Organe mit übernatürlichen Kräften, z. B. wird das Herz zu "ugl', pylajuščij ognem“. Es ist offensichtlich, daß eine solche Verwandlung des Menschen nur durch ein übernatürliches Wesen, durch einen „Seraphim“ vorgenommen werden kann. Von hier aus folgert Brjusov: „Der Dichter empfängt seine Eingebung von oben, vom Himmel, q.e.d. Die Synthese zweier sich widersprechender Ideen ist gefunden. ${ }^{\alpha 128}$

Diese Beweisführung zeigt die praktische Anwendbarkeit der zu Beginn des Aufsatzes entwickelten Gedanken. Ohne $Z$ weifel sind diese Ausführungen erst das Ergebnis langjähriger Erfahrung beim Interpretieren von Lyrik, da ja Brjusov den Aufsatz erst kurz vor seinem Tode geschrieben hat. Der ihm zugrundeliegende Gedanke jedoch ist für Brjusovs Interpretationsmethode fast seit seinen frühesten Arbeiten grundlegend gewesen. Dies soll später noch an Hand kritischer Arbeiten von Brjusov gezeigt werden.

Brjusov behandelt in gleicher Weise noch zwei weitere Beispiele (Tjuť̌ev und Fet) und gelangt zu dem folgenden, immer wieder während der zweiten und dritten Periode seines kritischen Schaffens ausgesprochenen, aber erst hier so präzis formulierten gedanklichen Fun-

127 Sintetika poèzii S. 361 .

ibid. S. 362. 
dament eines lyrischen Kunstwerks: „Somit ist das typische dichterische Werk eine Synthese aus zwei Bildern, in denen sich zwei Ideen befinden. $\mathrm{Zu}$ dieser Synthese gelangt der Dichter durch eine Reihe von Hilfssynthesen. Und jedes „poetische Bild" (im engsten Sinne des Wortes) ist ebenfalls die Synthese aus zwei Vorstellungen. Das dichterische Werk ist, wie vorher gezeigt wurde, ein System von Synthesen. ${ }^{\alpha 129}$

Dies ist gleichzeitig die exakte Definition des von Brjusov in kritischen Arbeiten oft verwendeten Begriffes „idejnaja kompozicija “.130

Zum Schluß dieses Aufsatzes setzt sich Brjusov noch einmal mit der Frage auseinander, die ihm sein ganzes Leben lang am Herzen lag: Wodurch unterscheidet sich ein echtes Kunstwerk von anderen literarischen Produkten? Ein Werk könne an und für sich noch so wertvoll sein, schreibt Brjusov, es könne gefallen und begeistern, solange es aber mit anderen Mitteln als mit denen der Kunst wirkt, ist es als etwas anderes wertvoll, aber nicht als Dichtung, so lange ist es kein wirkliches poetisches Kunstwerk. "Das poetische Werk führt immer zu einer synthetischen Feststellung, die vielleicht aus seinen Bildern aufgedeckt werden kann; in einer echten Schöpfung der Dichtung, in der Schöpfung eines "großen “ Dichters wird diese Feststellung stets ein weiter neuer Gedanke sein, gleichwertig den besten Errungenschaften der Wissenschaft, denn Ideen sind das Wesen der Dichtung, und nicht etwas anderes. "131

Brjusov versteht hier unter "Ideen“ (idei) etwas anderes als Potebnja. Während dieser den Begriff "Idee“ seinem von der Sprachbetrachtung übernommenen Begriff "Inhalt “ (soderžanie) gleichsetzt und das Wesen eines Kunstwerkes erst, wie oben beschrieben, aus dem Wechselspiel von Inhalt und Bild herleitet, versteht Brjusov unter Idee das $\mathrm{E}$ rge b $\mathrm{n}$ is der Synthese verschiedener Elemente als das eigentliche Kennzeichen eines Kunstwerks.

Als Anhänger des Symbolismus muß Brjusov auch als Kritiker in einem scharfen Gegensatz zu der realistischen Kritik stehen, deren bedeutendste Vertreter Cerny̌̌evskij, Dobroljubov und Pisarev waren. Während z. B. Cernyševskij als das Charakteristische

\footnotetext{
120 ibid. S. 366.

$130 \mathrm{Vgl}$. ${ }_{n}$ Prorok ${ }^{\alpha}$ in ${ }_{n}$ Moj Puškin ${ }^{\star}$, S. 281, wo Brjusov die gleiche Operation im Rahmen einer Gesamtuntersuchung des Gedichts vornimmt: "Jedes poetische Werk ist eine Synthese zweier (oder mehrerer) Ideen." 
der Kunst die W'iedergabe des Lebens selbst bezeichnet ${ }^{132}$, ist für den Symbolismus die Wirklichkeit nur Symbol für das Höhere, das hinter ihr liegt. Mit dem Symbolismus entsteht eine Strömung, die sich entschieden gegen den seit den fünfziger und sechziger Jahren des vorigen Jahrhunderts von den Kritikern verlangten platten Utilitarismus in der Kunst wendet.

Unter den russischen Symbolisten fällt Brjusov dadurch auf, daß er Kriterien des Künstlerischen nicht in Bereichen sucht, die außerhalb der Kunst liegen. Interessant ist ein Vergleich der Methode Brjusovs mit der etwa ein halbes Jahrhundert früher entstandenen "organischen Kritik" (organǐ̌eskaja kritika) Apollon Grigor'evs (1822-1864). ${ }^{183}$ Für ihn bildete die gesamte Weltliteratur einen weitverzweigten Organismus, dessen einzelne Teile nur in Verbindung mit dem Ganzen zu verstehen sind. Aufgabe der Kritik ist es also nach Grigor'ev -, den Platz eines Werkes innerhalb des Gesamtorganismus der Literatur festzustellen. Die Gedanken Grigor'evs wurden auch schon zu seiner Zeit wenig beachtet und haben auch in Brjusovs Kunstauffassung keinen Widerhall gefunden; gemeinsam war beiden die Ablehnung außerästhetischer Kriterien, im übrigen ging jedoch Brjusov von völlig anderen Voraussetzungen aus.

\footnotetext{
132 Vgl. Istorija russkoj kritiki. Moskau-Leningrad 1958, Bd. II, S. 41-89. $133 \mathrm{Vgl}$. Istorija russkoj kritiki, Bd. I, S. 470-487.
} 


\section{Formprobleme}

Eine wesentliche Rolle in Brjusovs Literaturbetrachtung spielen Probleme der Form. Zwar kommt er erst verhältnismäßig spät dazu, sich mit theoretischen Untersuchungen formaler Probleme zu befassen, aber seine Arbeit als Lyriker und besonders seine Arbeiten als Ubersetzer von Lyrik zwingen ihn immer wieder, sich mit den formalen Elementen der Versdichtung auseinanderzusetzen.

In der frühesten Periode seines Schaffens könnte man einigen seiner Außerungen eine Geringschätzung des formalen Problems entnehmen. So schreibt er am 14. 3. 95 an P. P. Percov: „Andern Sie Ihren Standpunkt, vereinigen Sie den Dichter mit seinem Werk! Plötzlich wird alles Verworrene einfach und klar. Sei es in der Dichtung, sei es in der Kunst, an erster Stelle steht die Persönlichkeit des Künstlers selbst! Sie ist auch das Wesentliche, alles übrige ist Form! Auch das Sujet und die "Idee" sind nichts weiter als Form. ${ }^{{ }_{134}}$ Wie im vorigen Kapitel gezeigt wurde, legte Brjusov damals seiner Auffassung noch nicht die Ansicht Potebnjas von der Kunst als Erkenntnis zugrunde. Noch ist für ihn die Persönlichkeit des Schöpfers, die hinter einem Kunstwerk steht, dessen zentrales Moment. Der Begriff der Form nimmt jedoch bereits einen so weiten Bereich ein, daß auch das, was gemeinhin als "Inhalt" bezeichnet wird, also der behandelte Gegenstand, nach Brjusovs Ansicht ein Element der Form ist. Eine klare Definition der Begriffe "Sujet ${ }^{\alpha}$ und "Idee ${ }^{\alpha}$ finden wir bei ihm in der ersten Periode nicht.

Für wie wichtig er den formalen Faktor in der Dichtkunst hält, zeigt Brjusov auch in seinem "Sonett an die Form " (Sonet $k$ forme), das etwa um die gleiche Zeit entstanden sein dürfte: ${ }^{135}$

134 Pis'ma V. Ja. Brjusova k P. P. Percovu. Moskau 1927, S. 13. Der gleiche Gedanke findet sich auch, fast ebenso formuliert, im Vorwort zu "Chefs d'oeuvre", M. 1895.

135 Die Entstehung des Gedichts wurde auf 1892 datiert, jedoch ist eine Handschrift mit diesem Datum nicht gefunden worden. Erhalten ist eine solche vom 6. Juni 1895. 
Est' tonkie vlastitel'nye svjazi

Mež konturom i zapachom cvetka.

Tak brilliant nevidim nam, poka

Pod granjami ne oživet $\mathrm{v}$ almaze.

Tak obrazy izmenčivych fantazij,

Beguščie, kak v nebe oblaka,

Okamenev, živut potom veka

$\mathrm{V}$ ottočennoj i zaveršennoj fraze.

I ja choču, čtob vse moi mečty,

Došedšie do slova i do sveta,

Našli sebe želannye čerty.

Puskaj moj drug, razrezav tom poèta,

Up'etsja $v$ nem i strojnostju soneta

I bukvami spokojnoj krasoty!136

Dies ist ein Bekenntnis zur Bedeutsamkeit der Form, in der ein Gedanke Gestalt gewinnt. Erst die künstlerische Anordnung der Worte kann den flüchtigen Gedanken, das unbeständige Bild bannen. Wie der Diamant erst unter den Facetten des Schliffes zum Leben erwacht, so gelangen die Bilder der Phantasie, vorher "beguščie kak v

130 Sobr. soč. Bd. I, S. 9.

\section{Sonett an die Form}

Es gibt zarte, mächtige Verbindungen zwischen der Kontur und dem Duft einer Blume.

So ist auch der Brillant für uns nicht sichtbar, Bis der Diamant unter den Facetten Leben gewinnt.

So leben auch die Bilder der unbeständigen Phantasie flüchtig, wie am Himmel die Wolken, versteinert darauf Jahrhunderte in der geschliffenen, vollendeten Phrase.

Auch ich will, daß alle meine Träume, zum Wort und zum Licht gelangend, für sich die gewünschten Züge finden.

Möge, das Buch des Dichters aufschneidend, mein Freund sich in ihm sowohl am Ebenmaß des Sonetts als auch an den Buchstaben stiller Schönheit berauschen. 
nebe oblaka", in der gestalteten Form ("v ottočennoj i zaveršennoj fraze $^{\alpha}$ ) erstarrt ( okamenev ${ }^{\alpha}$ ) zu dauerndem Bestand.

An formtheoretischen Arbeiten hat Brjusov in seiner ersten Periode zwar nichts veröffentlicht, jedoch befinden sich im Nachlaß Vorarbeiten zu einem ${ }_{n}$ Lehrbuch der Poesie ${ }^{\alpha}$ ("Učebnik poizii“ oder "Učebnik stichotvorstva"). Ein Entwurf aus dem Jahre 1898 sieht etwa folgende Unterteilung des Stoffes vor: 1. Vorwort, 2. Allgemeine Bemerkungen zur Kunst (entsprechend dem Buch „O iskusstve" [s. o.]), 3. Der Vers, 4. Der Reim, 5. Das Bild (obraz), 6. Tropen und Figuren, 7. Gattungen: Drama, Lyrik, Novellen und Erzählungen, Fabel usw. und 8. Übersetzungen. ${ }^{137}$ Das "Lehrbuch der Poesie“ blieb Entwurf. Bezeichnend ist an dieser Aufteilung, daß Brjusov für die Kunst des Ubersetzens einen besonderen Abschnitt vorgesehen hatte.

Eine spezifizierte Unterteilung des die äußere Form eines lyrischen Werkes betreffenden Fragenkomplexes traf er erstmals anläßlich einer Rezension von Versübersetzungen, die 1904 unter dem Titel "Fialki v tigele" erschien. Dort heißt es: „Das Außere eines lyrischen Gedichts, seine Form, entsteht aus einer ganzen Reihe von Elementen, deren Verbindung auch mehr oder weniger vollständig das Gefühl und die poetische Idee des Künstlers verkörpert, - diese sind: Sprachstil (stil' jazyka), Bilder (obrazy), Metrum und Reim (razmer i rifma), Dynamik des Verses (dviženie sticha), Spiel von Silben und Lauten (igra slogov i zvukov). Ich zähle nur die wichtigsten Elemente auf und bezeichne sie mit üblichen Ausdrücken, denn die Erklärung jedes einzelnen dieser Termini würde einen ganzen Aufsatz verlangen. ${ }^{\alpha 138}$

Zwar wird in diesem Zusammenhang die Einteilung in die genannten Elemente zur Erläuterung von Ubersetzungstechniken vorgenommen, doch behält Brjusov später eine Einteilung nach ungefähr dem gleichen Prinzip bei. Es werden einzelne Elemente hinzugefügt, wieder in sich aufgeteilt, andere mit präziseren Termini bezeichnet. Das Prinzip einer Aufteilung in Elemente aber hat Brjusov stets beibehalten. Es kann daher, wie auch aus dem Folgenden ersichtlich, als der zentrale Gedanke in jeder formalen Betrachtung Brjusovs angesehen werden.

197 Literaturnoe nasledstvo Bd. 27-28, S. $493 \mathrm{ff}$.

138 V. B r jus ov: Fialki v tigele. „Vesy ${ }^{\star}$ 1905, VII. 


\section{A. Der Rhythmus}

Ein Element der Form, dem Brjusov in der Folge große Bedeutung beimißt, ist der Rhythmus (ritm) eines Gedichtes oder Verses. Zur schärferen Fassung dieses Begriffes mag er vielleicht $u$. a. von Andrej Belyj angeregt worden sein. Jedenfalls definiert ihn Brjusov anläßlich einer Besprechung von Belyjs Buch "Simvolizm", wo Belyj ausgedehnte rhythmische Untersuchungen an Versen durchführt. ${ }^{138}$

Nach dem vorher Gesagten ist es nur einleuchtend, daß Brjusov sich daran stößt, daß Belyj den Rhythmus eines Verses als dessen "Form" schlechthin bezeichnet. Brjusov geht so weit, daß er die Wis-

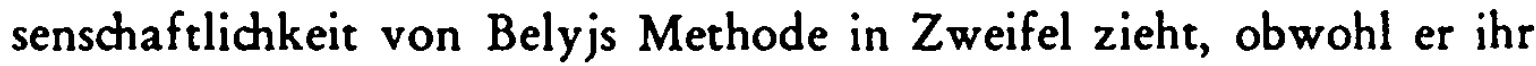
auf Grund seiner eigenen Theorien allenfalls Unvollständigkeit vorwerfen könnte. Diese glaubt er Belyj nachweisen zu können:

n... es erweist sich, daß Andrej Belyj den Rhythmus von Versen nicht nach der Gesamtheit aller Elemente, die den Rhythmus eines Verses ausmachen, beurteilt, sondern nur von einem einzelnen Element her, nämlich der Anzahl und Stellung der Pyrrhichien in den Versen des betreffenden Dichters. ${ }^{{ }_{140}}$

Aber gerade mit dieser Behauptung tut er Belyj unrecht. Dieser selbst weist ausdrücklich auf die Unvollständigkeit seiner Arbeit hin. "Allerdings", schreibt Belyj am Schluß seiner Untersuchung, "darf man nicht vergessen, daß wir, indem wir den Rhythmus in Dezimalsystem berechnen, mit einem abstrakten (otvlečennyj) Rhythmus operieren, unter Vernachlässigung der Instrumentation (instrumentovka), der Pausen (pauznye formy), zum Teil auch der logischen Betonung (logičeskie udarenija) und der Interpunktion. ${ }^{{ }^{1141}}$

In der Einleitung hatte Belyj erklärt, von welchem Gedankengang er ausgehe. „Unendlich viele Daten zur Anatomie des Stils erhalten wir, wenn wir den Rhythmus eines Dichters analysieren; indem wir eine bestimmte Einheit innerhalb der Summe aller Abweichungen von einer gegebenen metrischen Form als Rhythmus bezeichnen, erhalten wir die Möglichkeit, die Formen der Abweichungen zu klassifizieren. Gewöhnlich hört das Ohr am ehesten Beschleunigungen des Metrums; bleiben wir bei ihnen: indem wir die Summen der Abweichungen vom reinen Jambus, soweit es sich um Beschleunigungen handelt,

139 V. B r ju s o v: Ob odnom voprose ritma. "Apollon" 1910, XI, S. 52-60. 140 ibid. S. 55.

141 A. B el y j: „Simvolizm* S. 330. 
in ihrer Reihenfolge bei den einzelnen Dichtern aufnehmen, erhalten wir eine Möglichkeit, die Anatomie des Rhythmus zu untersuchen. ${ }^{{ }_{142}}$ Unter "Beschleunigung" (uskorenie) versteht Belyj die Auslassung einer Hebung.

Praktisch geht er anschließend so vor, daß er jeweils 596 vierfüßige jambische Zeilen eines Dichters nach sechs Grundformen zahlenmäßig aufschlüsselt. Bei diesen Grundformen handelt es sich um folgende Schemata:

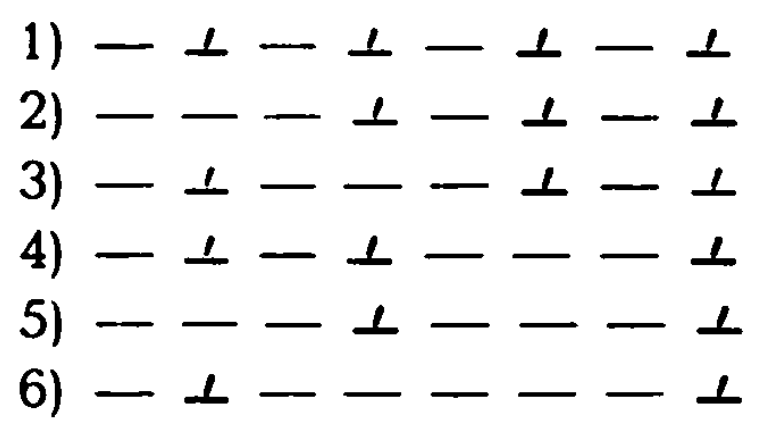

Diese Untersuchung führt er für 25 Dichter durch, darunter Lomonosov, Deržavin, Batjuškov, Žukovskij, Puškin, Lermontov, Tjutčev, Fet, Nekrasov, Brjusov, Blok. Weiter untersucht er die Häufigkeit einzelner Kombinationen dieser sechs Typen bei jeweils zwei bzw. drei Zeilen. Diese Kombinationen teilt er nach geometrischen Figuren, die diese bilden, graphisch auf. So bezeichnet er z. B. die folgende Form als ${ }_{n}$ Rhombus":

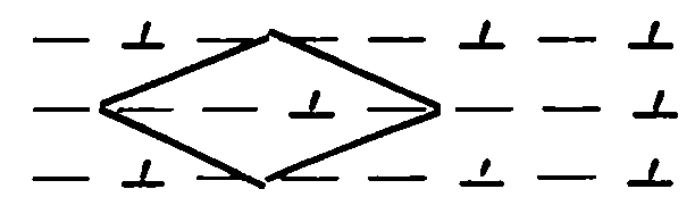

Der unbetonte Versfuß bildet den Edkpunkt der Figur. Desgleichen werden Verbindungen solcher Figuren untersucht und gezählt.

Daraus zieht Belyj verschiedene Schlüsse: „Den einzelnen rhythmischen Figuren begegnet man im allgemeinen fast bei allen Dichtern; nicht in der Anwendung der Figuren liegt die Individualität eines Dichters, sondern in ihrer Häufigkeit und in der Art ihrer Verbindung miteinander. ${ }^{\text {143 }}$

Anschließend ergeht sich Belyj noch in arithmetischen Spekulationen an Hand des gewonnenen Zahlenmaterials und zieht daraus Schlüsse

142 ibid. S. 286.

143 ibid. S. 317. 
auf "Reichtum“ (bogatstvo) und Musikalität im Rhythmus. Darauf näher einzugehen, würde zu weit führen.

Nun scheint Brjusov die oben zitierte Schlußbemerkung Belyjs übersehen zu haben. denn er betont besonders die zusätzliche Wirkung anderer Faktoren auf den Rhythmus als der von Belyj untersuchten. "Indessen bestimmen in Wirklichkeit in keinem Falle die Pyrrhichien von sich aus den Rhythmus eines Verses. Der Rhythmus besteht aus der Kombination einer ganzen Reihe von Faktoren, unter denen die Pyrrhichien nur einen bestimmten Platz einnehmen. Zu diesen Faktoren gehören außer den Pyrrhichien noch: Zäsuren, der logische Aufbau eines Verses, Wortinstrumentation (slovesnaja instrumentovka) (Alliterationen, Binnenreime, Assonanzen usw.), die Anordnung der Reime, der Aufbau der Strophen, die Struktur der Bilder u. a. ${ }^{{ }^{1144}}$

Berüdksichtigt man die Wirkung aller dieser von Brjusov genannten Elemente (die nach einer späteren Aufteilung Brjusovs zum Teil nicht mehr in das Gebiet der Rhythmik gehören), ergibt jede einzelne der oben angeführten sechs Modulationen ihrerseits wieder eine ganze Reihe verschiedener Varianten. Das ganze System wird dadurch bedeutend komplizierter. Brjusov gibt allerdings hier auch gleich eine Einschränkung, indem er darauf hinweist, daß die Bedeutung der Pyrrhichien besonders von den Zäsuren eines Verses abhängig sei.

Um seine Ausführungen zu belegen, führt Brjusov mehrere Beispiele an, die zu betrachten nicht uninteressant ist.

Zunächst untersucht Brjusov Verse mit gleicher Anordnung der Pyrrhichien, die aber auf Grund verschiedener Zäsurstellen im Rhythmus verschieden sind. Als Beispiel dienen zwei Verse:

Ticha ukrainskaja noč'.

Bogat i slaben Kočubej.

Es handelt sich bei beiden Versen, geht man von den Pyrrhichien aus, um Fälle der vierten der oben angegebenen Modulationen. Nach Belyjs Schema wären diese Verse also rhythmisch identisch. "Aber", schreibt Brjusov, nwohl auch das in rhythmischen Beobachtungen ungeübte Ohr wird den gewaltigen rhythmischen Unterschied dieser beiden Verse erkennen. Der Rhythmus des ersten ist sanft und geschmeidig, der des zweiten hart und rauh. Dieser Unterschied ist durch die verschiedenen Zäsuren bestimmt. ${ }^{\text {145 }}$

144 Ob odnom voprose ritma S. 56.

143 ibid. 
Es kommt hier auf das Verhältnis der Pyrrhichienanordnung zur Zäsurstelle an. Brjusov definiert das so: „Im ersten Vers ist der pyrrhichische Fuß nicht durch eine Zäsur abgetrennt, und der Nebenton fällt auf die vorletzte Silbe eines Wortes; im zweiten beginnt der pyrrhichische Fuß unmittelbar nach der Zäsur, und der Nebenton fällt auf die erste Silbe eines Wortes. ${ }^{\text {"146 }}$

Die nächsten beiden Beispiele übernimmt Brjusov aus Belyjs Untersuchung. Es handelt sich dabei um zwei Verse, deren metrische Struktur der sechsten, zweifellos am wenigsten häufigen Modulation entspricht. Als erstes wird ein Vers von Zinaida Gippius zitiert:

\section{Bezradostno - blagopolučno. \\ Nad pamjatnikami drožat.}

Der zweite Beispielvers ist von Belyj selbst. Der Rhythmus ist unbeholfen stolpernd, während der erste Vers einen glatten und gefälligen Rhythmus besitzt. Die Ursache dieser rhythmischen Verschiedenheit erklärt Brjusov folgendermaßen: „Bei Z. Gippius wurden besonders leichte Zäsuren gewählt (der Nebenton liegt auf der letzten und der zweiten Silbe eines Wortes), und bei Belyj die schwersten, die am wenigsten statthaften. ${ }^{\text {"147 }}$ Dadurch fallen beide Nebentöne auf Silben ein und desselben Wortes. Diese Erklärungen werden erst dann verständlich, wenn man berücksichtigt, daß Brjusov im russischen Jambus an den Stellen, wo vom Metrum eine betonte Silbe verlangt wird, diese aber ausfällt, also im pyrrhichischem Versfuß, einen N eb e nto $\mathrm{n}$ annimmt. Das Prinzip, nach dem Brjusov hier vorgeht, ist folgendes:

Es wird $z$ wischen "leichten " und "schweren "Zäsuren unterschieden. Soweit Brjusovs Ausführungen zu entnehmen ist, gehören zu den "leichten " Zäsuren" folgende Typen: Zäsur $z$ wischen $z$ wei vollbetonten Versfüßen und Zäsur $z$ wischen $z$ wei pyrrhichischen Füßen. Diese bedingen einen flüssigeren Rhythmus. Eine "schwere" Zäsur liegt dagegen vor, wenn durch sie vollbetonter und pyrrhichischer Versfuß getrennt werden. Die "Schwere" der Zäsur kann dadurch gesteigert werden, daß sie nach oder vor $z$ wei aufeinanderfolgende Pyrrhichien gesetzt wird. Brjusov scheint dieses Prinzip jedoch später fallengelassen zu haben, denn in seinen späteren Arbeiten geht er

140 ibid.

147 ibid. 
nicht mehr darauf ein und bleibt uns somit eine genaue Erläuterung sowie die Definition seiner Termini schuldig.

Neuere Arbeiten auf diesem Gebiet behandeln solche Fälle von verschiedenen Gesichtspunkten aus. B. O. Unbegaun ist der Ansicht, daß beim vierfüßigen Jambus oder Trochäus eine Zäsur überhaupt nicht auftritt. Sie kann in diesen Versen allenfalls durch Einfügung einer zusätzlichen Silbe oder eines Binnenreims entstehen. ${ }^{148}$ Desgleichen verneint Unbegaun die Existenz von Nebenbetonungen im Russischen, auch bei enklitischen oder proklitischen Konjunktionen, Präpositionen oder Partikeln. ${ }^{149}$

$\mathrm{K}$. Taranovski gründet seine Untersuchungen zum Rhythmus des russischen Verses zwar vornehmlich, wie auch Belyj, dessen Arbeit er benutzt, auf die Verteilung von betonten und unbetonten Versfüßen, setzt aber eine Zäsur auch im vierfüßigen Jambus voraus, soweit sie nicht durch eine Diärese ersetzt wird.150

Im Gegensatz zu Taranovski hält Alexander Adamczyk die Methode Belyjs für weniger glüdklich. Uberhaupt wendet sich Adamczyk gegen die Anwendung der antiken Versfüße auf die russische Lyrik. Er will vielmehr neben der rein sprachlichen Betonung die unabhängig davon im Vers auftretenden Zeit- und Lautverhältnisse (hier werden Begriffe wie Schallform, Schallfarbe u. a. eingeführt, die auf Andreas Heusler zurüidgehen) berüdksichtigt wissen.151

Zum Schluß führt Brjusov noch Beispiele von Versen mit verschiedenem Rhythmus und sowohl gleicher Pyrrhichienverteilung als auch gleicher Zäsur an. Der Unterschied liegt hier in der "logischen Betonung ${ }^{\alpha}$ (logičeskoe udarenie). Zwar definiert Brjusov nicht genau, was er unter logischer Betonung versteht, aber die angegebenen Beispiele erläutern hinreichend, worum es sich hierbei handelt. Deshalb sei eins davon hier noch einmal wiedergegeben.

„Der Einfluß der Zäsuren“, heißt es bei Brjusov, nverändert sich je nach der Anordnung der logischen Betonungen im Vers. Hier zwei Verse:

148 B. O. U n be g a u n: Russian Versification. Oxford 1956, S. 60.

149 ibid. S. 16.

${ }^{130}$ Kiril T a ra nov ski: Ruski dvodelni ritmovi. Belgrad 1953.

151 Alexander A d a m c z y k: Russische Verskunst. "Münchener Beiträge zur Slavenkunde. "Festgabe für Paul Diels. Hsg. von Erwin Koschmieder und Alois Schmaus. München 1953, S. 179-201. 


\section{I razrezajušče - ostra ...}

Ja, chitroumnyj Odissej ...

In diesen Versen sind Pyrrhichien und Zäsuren völlig gleich verteilt. Jedoch ist der Rhythmus des $z$ weiten Verses komplizierter, was damit zusammenhängt, daß hier auf den schwachen (unbetonten) Teil des ersten Versfußes die logische Betonung fällt. ${ }^{{ }_{152}}$

Im $\mathrm{zweiten}$ der beiden zitierten Verse ist es besonders offensichtlich, daß die logische Betonung den Rhythmus eines Verses wesentlich beeinflussen kann. Gedanklich liegt hier das Schwergewicht auf ${ }_{n j a}{ }^{\alpha}{ }^{\circ}{ }_{n} \mathrm{Ja}^{\alpha}$ ist das Subjekt eines Satzes, der noch über den Vers hinausgeht, während der Rest des Verses lediglich Apposition zu nja "ist. Auf diese Weise läßt sich die "logische Betonung" in vielen Fällen bereits aus dem syntaktischen Aufbau eines Verses ermitteln.

\section{B. Das Metrum}

Eine wenn auch nicht sehr ausführliche, so doch systematische Verslehre veröffentlichte Brjusov erst 1918 unter dem Titel ${ }_{n}$ Kratkij kurs nauki o stiche ". ${ }^{153}$ Den folgenden Ausführungen liegt im wesentlichen die zweite Auflage des Büchleins ( ${ }$ Osnovy stichovedenija ${ }^{a}$ ) zugrunde.

Brjusov teilt die Verslehre in verschiedene einzelne Gebiete auf, und $z w a r$ in sieben verschiedene Teilgebiete:

1. Eidologie (Ejdologija). Das ist die Lehre von den poetischen Bildern eines Verses. Es handelt sich um ${ }_{n}$ die Kunstgriffe, mit deren Hilfe in Worten das Element der Vorstellung in den Vordergrund gerüdkt wird, d.h. mit deren Hilfe die Sprache bild haf $t$ wird, Epitheta, Tropen, sprachliche Figuren ..."

2. Stilistik (Stilistika). Die Lehre vom Stil eines Gedichtes. Damit sind gemeint " die Kunstgriffe, mit deren Hilfe die Sprache zur größten Ausdruckskraft gebracht wird, das sind sprachliche Figuren, Periodizität und Zusammenhanglosigkeit u. a. ..."

3. Metrik und Rhythmik (Metrika i ritmika). Das ist die Lehre vom Aufbau eines Verses als rhythmisches Ganzes.

4. Euphonie (Evfonija). Die Lehre vom lautlichen Aufbau eines Verses.

$132 \mathrm{Ob}$ odnom voprose ritma S. 56.

$153 \mathrm{~V}$. B r ju s o v: Kratkij kurs nauki o stiche. Moskau 1918. Zwcite, etwas veränderte Auflage unter dem Titel „Osnovy stichovedenija“, M. 1924. 
5. Strophik (Strofika). Die Lehre von den Kombinationen der Verse untereinander im Rahmen größerer metrischer Einheiten.

6. Komposition (Kompozicija). Die Lehre vom Aufbau poetischer Werke im ganzen. Brjusov bemerkt hierzu, daß die Strophik sich teilweise mit der Lehre von der Komposition überschneidet. ${ }^{154}$

7. Melodik (Melodika). Dabei handelt es sich um die Lehre von der Kombination aller vorher genannten Elemente.

Von diesen sieben Teilgebieten verweist Brjusov die ersten beiden, Eidologie und Stilistik, in den Bereich der allgemeinen Poetik. Die beiden letzten, Komposition und Melodik, will Brjusov gesondert behandelt wissen.

Demnach bleiben für die eigentliche Verslehre nur noch drei Teilgebiete: 1) Metrik und Rhythmik, 2) Euphonie und 3) Strophik. Die Aufgaben der Verslehre sind somit rein formalen Charakters. Dies wird von Brjusov an anderer Stelle auch begründet. ${ }^{155}$

Es fällt bei dieser Einteilung auf, daß Brjusov offensichtlich eine Trennung von Stilistik und Eidologie selbst in der Definition nicht ganz gelingen will. Die zitierten Erklärungen zeigen, daß beide Gebiete weitgehend identisch sind und mehr oder weniger den gleichen Gegenstand behandeln. Es dürfte sich hier mehr um eine vorläufige Einteilung handeln, denn wir finden keinerlei theorerische Arbeiten von Brjusov, die sich mit diesen Gebieten eingehender befassen.

In seiner Verslehre behandelt Brjusov ausschließlich Metrik und Rhythmik. Uber Probleme der Euphonie sind von ihm ebenfalls Arbeiten erschienen, und zwar sowohl in der Periode vor 1918 als auch danach. Theoretische Abhandlungen über die Strophik finden wir bei Brjusov nicht, jedoch pflegt er in seinen literaturkritischen Arbeiten die Untersuchungen des offteren auch auf dieses Gebiet auszudehnen. Zunächst sollen hier die theorctische Metrik sowie einige Grundgedanken der Rhythmik dargestellt werden, die Brjusov seinen kritischen Arbeiten zugrundelegt.

Die Gesetze der Metrik übernimmt Brjusov fast unverändert aus der klassischen Antike und überträgt sie auf den russischen syllabotonischen Vers (sillabo-toničeskij stich). Auch alle viersilbigen Versfüße, vom Diiambus bis zu den verschiedenen Päonen, finden Verwendung. Auf fünffüßige Versfüße verzichtet Brjusov, da - wie er

154 ibid. S. $8 \mathrm{f}$.

$135 \mathrm{Vgl.} \mathrm{Opyty,}{ }^{\text {Remeslo poèta }}$. 
sagt - diese in russischen Vers nicht vorkommen. Hierzu muß bemerkt werden, daß Päone, Ioniker usw., die von ihm als Beispiel angeführt werden, durchaus in einfachere aufzulösen sind. ${ }^{156}$ Von ihm selber verfaßte Beispiele dieser Metren werden an anderer Stelle noch zu besprechen sein.

Brjusov unterscheidet drei verschiedene Arten von Metren: 1) das reine (Čistyj) Metrum, 2) das z u s a m m n geset z te (složnyj) Metrum (verschiedene Versfüße in stets gleicher Anordnung) und 3) das ge $\mathrm{m}$ is ch t e Metrum (smešannyj) (verschiedene Versfüße in verschiedener Anordnung).

Beim einfachen Metrum (Jambus, Trochäus) erklärt Brjusov die fehlenden Tonstellen durch eine Hypostasis, und zwar in diesem Falle durch eine pyrrhichische Hypostasis. (Brjusov nimmt auch eine spondeische Hypostasis, beim Jambus eine trochäische, beim Trochäus eine jambische als möglich an). Die Auflösung eines Verses entspricht etwa der Arbeitsweise Belyjs in "Simvolizm“, die schon erläutert wurde. Auf Beispiele kann hier verzichtet werden.

Brjusov unterscheidet beim einfachen Metrum drei verschiedene Arten der pyrrhichischen Hypostasis je nachdem, ob die Zäsur nach dem Pyrrhichius, vor dem Pyrrhichius oder zwischen den pyrrhichischen Silben steht.

Analog zu dem eben Gesagten verfährt Brjusov bei dreisilbigen Metren (Daktylos, Anapäst, Amphibrachys).

Bei der Behandlung mehrsilbiger Versfüße beschränkt er sich auf Diiambus, Ditrochäus und die Päone. Zu Beginn des betreffenden Kapitels stellt er fest, daß "die dipodischen Metren eine Variante des jambischen und trochäischen Metrums darstellen und im allgemeinen den gleichen Bedingungen folgen, wobei die Hypostasen durch Pyrrhichius, Spondeus, Jambus und Trochäus den Charakter einer Hypostasis durch dipodische Versfüße annehmen. ${ }^{157}$ Einen besonderen Charakter spricht Brjusov nur dem (di)jambischen Trimeter zu, und zwar deswegen, weil dieses Metrum bereits in der Antike als solches in Erscheinung tritt.

Daß Brjusov die Einführung von Dipodien in die russische Verslehre für zweifelhaft hält, geht aus der Anmerkung hervor, die Brjusov dazu gibt: "Jeder einfache Polymeter kann als diiambisches

150 Osnovy stichovedenija S. 65.

157 ibid. 
und ditrochäisches Metrum betrachtet werden. Die Bedingungen für eine Hypostasis, Katalexe, Leipo- und Hypometrie sind in dem einen oder dem anderen Falle völlig die gleichen. Allein man muß im Auge behalten, daß die bei Polymetern übliche feststehende große Zäsur ihnen die Freiheit der Hypostasis entzieht (besonders in den mittleren Versfüßen), die den diiambischen und ditrochäischen Metren in weitem Maße eigen ist. ${ }^{\text {}} 158$

Das Verhältnis zwischen Dipodie und einfachem Metrum wird dadurch noch enger, daß Brjusov von der Voraussetzung ausgeht, daß der letzte Versfuß katalektisch je nachdem aus drei, zwei oder einer Silbe bestehen kann.

Es erübrigt sich, die Beispiele, die Brjusov in diesem Zusammenhang für den Diiambus und den Ditrochäus anführt, hier zu diskutieren.

Für die Auflösung in Dipodien geben vielleicht noch die diiambischen Trimeter, die Brjusov als Beispiel anführt, eine gewisse Berechtigung. Hierbei ist zu beachten, daß die Zäsur jeweils nach dem zweiten Versfuß auftritt, so daß dieses Metrum oft auch in zwei Zeilen geschrieben wird, indem die erste Zeile aus zwei Dipodien besteht, das Zeilenende mit der Zäsur zusammenfällt und die nächste Zeile nur von der dritten Dipodie gebildet wird. Als Erläuterung mögen zwei Beispiele dienen, die Brjusov in seiner Verslehre anführt:150

My byli prazdničnye deti, I sestra i ja.

(F. Sologub)

und

Mila, kak Gracija, skromna, | kak Sandril'ona.

(E. Baratynskij)

Einen besonderen Abschnitt widmet Brjusov der Besprechung der Päone. Die hier angeführten Beispiele wirken wenig überzeugend, da sich die betreffenden Verse ohne Schwierigkeit in Jamben bzw. Trochäen auflösen lassen, wobei jeweils zwei übergangene Tonstellen anzunehmen sind.160

158 ibid.

$150 \mathrm{Vgl}$. ibid S. 72.

100 Allein etwa ein Viertel der vierfüßigen Jamben in Puškins Verserzählungen weisen nur zwei Akzentstellen auf. Vgl. B. O. Un bega un, Russian Versification S. 29. 
Es seien einige der von Brjusov angeführten Beispiele wiedergegeben:

Für den 1. Päon:

Zmei vzdragivajuščie, zmei vzvizgivajuščie.

Dieser Vers von Brjusov selber dürfte von vornherein als Päon gedacht und angelegt sein.

Für den 4. Päon:

$\mathrm{Na}$ zolotye nebesa. (Puškin)

Es liegt hier eigentlich kein Grund vor anzunehmen, daß diese bei Puškin häufige Form des vierfüßigen Jambus ausgesprochen als dipodisches Versmaß gedacht ist. Zudem besteht $m$. E. keinerlei Veranlassung, einen solchen Vers mit einem derart komplizierten Metrum wie dem Päon zu erklären.

Etwas mehr Berechtigung findet die Brjusovsche Einordnung vielleicht bei den folgenden Versen Majkovs, da hier in zwei aufeinanderfolgenden Zeilen die zu erwartenden Akzente an den gleichen Stellen fehlen:

I k obraščeniju privyk

Neobrazovannyj mužik.

Brjusov führt auch noch Beispiele für den 2. und 3. Päon an, die aber hier übergangen werden können.

Die Einführung von viersilbigen Versfüßen ließe sich am ehesten noch von rhythmischen Gesichtspunkten aus rechtfertigen, aber Brjusov geht auf diese Seite des Problems in seiner Verslehre nicht weiter ein, nicht einmal in den Abschnitten über den Diiambus und den Ditrochäus, wo dieser Gesichtspunkt schon in der Natur des Versfußes begründet wäre.

Den Begriff der Zäsur legt Brjusov in dieser Arbeit anders aus als in dem oben besprochenen Aufsatz zu Belyjs "Simvolizm“. Hier teilt er sie in "ngroße" (bol'šaja) Zäsur und "kleine" (malaja) Zäsur auf. Dabei versteht er unter "großer Zäsur" eine solche, die „1. feststehend ist, wenn sie in dem betreffendem Metrum stets an ein und der gleichen Stelle bleibt, 2. die veränderlich ist, wenn sie in den Grenzen eines Versfußes bleibt, aber nach verschiedenen Silben desselben steht, 3. die umstellbar ist, wenn sie in einem bestimmten 
Metrum in verschiedene Versfüße versetzt wird. ${ }^{{ }_{101}}$ Eine "kleine Zäsur" ist nach Brjusov eine Unterbrechung innerhalb des Metrums nach jedem Wort oder jeder Wortgruppe.

Außerdem teilt Brjusov die Zäsuren noch in folgende Arten ein: 1. männliche, 2. weibliche, 3. daktylische. Ferner werden sie entsprechend ihrem Verhältnis zum Metrum eingeteilt in 1. metrische, 2. hypermetrische und 3. leipometrische Zäsuren. Den Begriff der Dï̈rese, unter den die beiden letztgenannten Arten fallen würden, führt Brjusov nicht ein. Im Gegensatz zur Zäsur erwähnt er den Begriff der "Pause ${ }^{\alpha}$, die dem Satzbau entsprechend entsteht. ${ }^{\text {162 }}$

Dazu bemerkt $R$. Jakobson in einer Besprechung von Brjusovs Verslehre: „Die Zäsur ist nach Brjusovs Definition eine Unterbrechung des Metrums, die dieses in einzelne Teile aufteilt. Um was für eine Unterbrechung handelt es sich? Haben wir es hier mit einer Pause im physiologisch-akustischen Sinne zu tun? Wie kommt diese Unterbrechung im sprachlichen Material zustande? Darüber sagt Brjusov nichts. " ${ }^{163}$ An anderer Stelle schreibt Jakobson: "Das wissenschaftliche Problem von Halbvers, Vers, Doppelvers existiert für Brjusov nicht. " ${ }^{184}$ Jakobson berührt hier eine der schwächsten Seiten von Brjusovs Arbeiten im allgemeinen: ihre mangelnde Gründlichkeit, ihren mehr andeutenden als aussagenden Charakter. Jakobson formuliert diese Tatsache sehr scharf: „Brjusov strebt nicht danach, eine Erscheinung zu erklären, nicht einmal danach, sie zu beschreiben, sondern nur, sie zu benennen. Und in dieser Leidenschaft zur Nomenklatur bleibt Brjusov der Synonymie nicht fremd. ${ }^{185}$

Interessant sind in diesem Zusammenhang die Gedichte, die Brjusov aus seinen eigenen Werken zur Erläuterung verschiedener Formprobleme zusammenstellt und zum Teil eigens zu diesem Zweck verfaßt hat. Diese Sammlung ist 1918 unter dem Titel "Opyty po metrike $\mathrm{i}$ ritmike, po évfonii i sozvučijam, po strofike i formam" in Moskau erschienen. Zusammen mit dem einführenden Aufsatz von

\footnotetext{
101 Osnovy stichovedenija S. 27.

102 ibid. S. 28.

10s R. O. J a k ob s on: Brjusovskaja stichologija i nauka o stiche. "Naučnye izvestija ${ }^{\alpha}$ 1922, II, S. 230.

104 ibid. S. 232.

185 ibid. S. 224.
} 
45 Seiten bietet dieses Büchlein eine Übersicht über Brjusovs Standpunkt formalen Problemen überhaupt gegenüber.

Im einleitenden Aufsatz zu den "Opyty", der den aufschlußreichen Titel „Remeslo Poèta“ (Handwerk des Dichters) trägt, vertritt Brjusov entschieden die Ansicht, daß gewisse Kenntnisse formaler Gegebenheiten der Lyrik zum handwerklichen Rüstzeug eines Dichters gehören. „Es ist wohl kaum nötig zu betonen, daß jede Kunst zwei Seiten hat: eine schöpferische und eine technische. " ${ }^{166}$

Die technische Seite erstreckt sich für Brjusov ziemlich weit. So gehört zum Beispiel die gesamte Verslehre einschließlich Rhythmik und Euphonie dazu. Brjusov schreibt: „Begabung zu künstlerischem Schaffen ist eine natïrliche Gabe, wie Sdhönheit des Gesichts oder eine laute Stimme; diese Begabung kann und soll man entwickeln, erlangen aber kann man sie durch keinen Fleiß und keine Schulung. Poetae nascuntur ... Wer nicht zum Dichter geboren ist, der wird es niemals werden, wie sehr er auch danach streben mag, wieviel Mühe er auch daran verschwenden mag. Jeder oder fast jeder, mit wenigen Ausnahmen, kann, wenn er genügend Fleiß dafür aufwendet, das Versemachen lernen und so weit kommen, daß er vollkommen glatte und "schöne", ${ }^{*}$ klingende ${ }^{\alpha}$ Verse schreibt. Aber solche Verse sind niemals Poesie. ${ }^{{ }^{167}}$

Vom Dichter aber verlangt Brjusov das Erlernen der handwerklichen Grundlagen des Versemachens. Zwar könne auch durch plumpe, ungeschicktc Verse ein dichterisches Talent hindurchschimmern, aber „der Meister des Verses verfügt über Form und Ausdruck für alles, was er sagen will, er fügt jeden seiner Gedanken, alle seine Gefühle in die Wortkombinationen, dic am ehesten einen Widerhall beim Leser finden, die schärfer als alle anderen die Aufmerksamkeit treffen, die unwillkürlich für immer im Gedächtnis bleiben. Der Meister des Verses besitzt die Magie der Worte, er kann sie beschwören, und sie dienen ihm wie ergebene Geister dem Zauberer. "168

Hier drängt sich auch Brjusov die Forderung nach einer Akademie der Dichtung auf. Maler, Bildhauer, Musiker, alle erwerben ihr handwerkliches Können auf eigens hierzu eingerichteten Akademien oder Konservatorien. "Warum “, fragt Brjusov, "fällt es niemand ein, eine Symphonie zu schreiben oder eine Oper ohne entsprechende Vor-

\footnotetext{
1000 Opyty S. 7.

167 ibid. S. 7 f.

168 ibid. S. 8.
} 
kenntnisse, warum wird niemand einen Menschen beauftragen, eine Kathedrale oder einen Palast zu bauen, der nicht mit den Gesetzen der Architektur vertraut ist? Indessen für das Schreiben eines Dramas oder eines Poems halten viele die Kenntnis der grammatikalischen Regeln für ausreichend. Ist denn wirklich die Technik der Dichtung, insbesondere die Verstechnik, um soviel einfacher als die technische Seite der Musik, der Malerei, der Bildhauerei, der Architektur? ${ }^{{ }_{169} 9}$

Um die Probleme und Erscheinungen der Verstechnik zu ordnen, zu erklären, fordert Brjusov stets den Aufbau einer Wissenschaft vom Vers. $Z$ war befaßten sich damals Philologen natürlich auch mit Lyrik. Brjusov aber geht es um die exakte Wissenschaftlichkeit, mit der hier die Verstechnik behandelt werden sollte. Er denkt dabei vergleichsweise an die Naturwissenschaft oder an die Linguistik. "Als Axiom", schreibt er, "muß man annehmen, daß die Wissenschaft alles studiert; alle Erscheinungen des Universums, beginnend mit der Bewegung der Sonne bis zum Bau der Atome, von den Eigenschaften der Amöbe bis zu den historischen Gesetzen der Menschheit, dienen als Objekt wissenschaftlicher Beobachtungen. " ${ }_{\text {Der Vers ist eine }}$ der Erscheinungen, die im geistigen Leben der Menschheit einen nicht geringen Platz einnehmen." "Neben einer ,vergleichenden Sprachwissenschaft' sollte es eine, vergleichende Metrik' geben. Und man muß bedenken, daß eine vergleichende Untersuchung der Eigenschaften des Verses in verschiedenen Sprachen und in verschiedenen historischen Perioden nicht weniger wertvolle Schlußfolgerungen ergäbe als die Philologie. ${ }^{170}$

Hier greift Brjusov wiederum den Humboldt-Potebnjaschen Gedanken von der Verbindung Sprache-Dichtung auf. Folgerichtig verlangt er für die letztere Forschungsmethoden, die der Linguistik entlehnt sind.

Aber, so meint Brjusov, bis dahin sei es noch weit. Eine lange Reihe vorbereitender Arbeiten seien noch zu machen. Die gesamten Tatsachen, auf denen eine wissenschaftliche Metrik zu basieren hätte, müßten erst noch gesammelt, systematisiert werden. Generationen von Wissenschaftlern müßten sich damit beschäftigen.

Brjusov schildert, wie er sich diese Vorarbeiten vorstellt: „Es müssen Wörterbücher für die verschiedenen Dichter zusammengestellt

189 ibid. S. 9.

170 ibid. S. $10 \mathrm{ff}$. 
werden (ähnlich den Wörterbüchern zu antiken Autoren, Wörterbücher zu Dante, Shakespeare, Shelley sind mir bekannt). Es müssen Tabellen zusammengestellt werden von den Metren, die von den verschiedenen bedeutenden Dichtern verwendet werden, es müssen alle Besonderheiten ihrer Prosodie systematisiert werden, es müssen in ihren Versen alle Lautkombinationen verfolgt werden, ebenso Reime und Assonanzen usw. usw. Erst dann ergibt sich die Möglichkeit, auf wissenschaftlicher Grundlage, d.h. auf der Grundlage systematisierter Tatsachen und Beobachtungen, zunächst einc "spezielle $^{\alpha}$ Metrik und Prosodie zu schreiben, und danach auch eine allgemeine, vergleichende Metrik und eine allgemeine Theorie des Reims und des "zvukopis' ${ }^{171}$ Der Ausdruck *zvukopis' * bleibt zweckmäßigerweise unübersetzt. Eine Diskussion des Begriffes folgt an anderer Stelle.

Brjusov erläutert hier noch einmal seine Einteilung der Verslehre in Metrik und Rhythmik, Euphonie, Strophik. Die Terminologie habe er frei gewählt, da eine entsprechende bis dahin noch nicht im Gebrauch gewesen sei.

Vom Dichter verlangt Brjusov, daß er diese drei Fachgebiete beherrsche. „Diese drei Wissenschaften, Metrik und Rhythmik, Euphonie mit der Lehre vom Reim und die Strophik, sind die speziellen Wissenschaften, ohne deren Studium von einem Dichter nicht gesagt werden kann, er kenne die Technik seiner Kunst, sein Handwerk. ${ }^{\alpha}{ }^{172}$

Der kurze Abriß der Metrik, den Brjusov hier gibt, entspricht dem in ${ }_{n} \mathrm{Kratkij}$ kurs nauki o stiche ${ }^{\alpha}$ Gesagten. Es wird wiederum streng nach griechischem Vorbild vorgegangen. $\mathrm{Zu}$ den $\mathrm{zwei}$ - bis viersilbigen Versfüßen tritt hier noch der in der antiken Tragödie verwendete fünfsilbige Dochmius. In der zweiten Auflage des „Kratkij kurs ... „Osnovy stichovedenija ${ }^{\alpha}$, wird ausdrüdklich bemerkt, daß fünfsilbige Versfüße im Russischen nicht vorkommen. Auch in den "Opyty selbst findet sich kein Beispiel eines solchen Verses.

Dort unterscheidet Brjusov lediglich $z$ wischen $\mathrm{r}$ in e $\mathrm{m}$ und $\mathrm{z} u$ $s$ a m e ngesetztem Metrum. Der später eingeführte, schon erwähnte Begriff des gemischten (smešannyj) Metrums fehlt noch. Wohl vor allem, weil der u. a. von Majakovskij verwendete rein akzentuierende Vers, zu dessen Erklärung Brjusov diesen Be-

171 ibid. S. 13.

172 ibid. S. 15. 
griff braucht, erst später größere Bedeutung und Anerkennung erlangte.

$Z_{\text {war }}$ gäbe es, so argumentiert Brjusov, bei Verwendung der genannten Versfüße insgesamt nur etwa $160{ }_{\text {"reine" Metren. Doch }}$ würde auf diese W'eise das Bild der Lyrik unerträglich einförmig werden, besäße nicht j e d e r Vers s e i n e $\mathrm{n}$ besonderen, ihm eigenen Rhythmus. Deshalb solle man die Lehre vom Vers als solche auch als "Metrik und Rhythmik" bezeichnen.

Brjusov gibt nun auch die verschiedenen Elemente, die eine derartige Vielfalt von Versrhythmen bewirken, an. "Wir bezeichnen die Versfüße", schreibt er, "als das g r u ndl e ge nd e Element des Verses. Daneben gibt es zweitrangige Elemente. Diese bestimmen auch den Rhythmus eines Verses, so wie die Versfüße sein Metrum oder Versmaß bestimmen. Diese zweitrangigen Elemente sind die Hy postasis oder Ersetzung, die Zäsur oder der Einschnitt, die Katalektik oder die Lehre von den Versschlüssen. Aber weiterhin gibt es noch sozusagen zusätzliche Elemente des Verses, die ebenfalls zur Nuancierung des Versrhythmus beitragen: $\mathrm{H}$ y p e rmetrie und Leipometrie, Diärese und Synärese, Systole und Diastole, Synkope, Elision u. a. ${ }^{{ }^{173}}$

Auf diese Weise gibt Brjusov eine klarere Definition der Begriffe "Metrik" und "Rhythmik". Die Metrik befaßt sich ausschließlich mit der Untersuchung von Versfüßen und Versmaßen, während alle anderen Verselemente, die ebenfalls aus der Antike übernommen sind, in das Gebiet der Rhythmik fallen.

Als wichtigste dieser rhythmischen oder, wie Brjusov sie auch nennt, zweitrangigen Elemente bezeichnet er die Hypostasis und die Zäsur. Dies entspricht genau den Ausführungen, die er bereits in seiner Besprechung von Belyjs "Simvolizm" gemacht hatte. Nur der von Belyi übernommene Begriff des pyrrhichischen Versfußes wird hier durch den weiteren Begriff der Hypostasis ersetzt. der ja auch die Hypostasis durch einen Pyrrhichius einschließt.

Im Vorwort zu den "Opyty" schreibt Brjusov: „Einige Gedichte sind meinen früheren Büchern entnommen: ich sah keine Notwendigkeit, einen Versuch zum zweitenmal durchzuführen, wenn er mir vorher schon einmal mehr oder weniger gelungen ist. Andere Gedichte sind aus Sammelbänden, Zeitschriften oder Zeitungen nach- 
gedruckt. Aber ein wesentlicher Teil erscheint erstmalig im Druck. Es finden sich hier unter den gesammelten Gedichten Ubersetzungen, Nachahmungen, Originalstücke. Aber obwohl alle Verse, die Eingang in dieses Buch gefunden haben, hier als Beispiele für diesen oder jenen technischen Kunstgriff gedacht sind, obwohl sie alle von mir, nur recht und billig, als "Versuche ${ }^{\alpha}$ bezeichnet werden, so findet sich hier doch kein Gedicht, welches zur betreffenden Zeit nicht der echte Ausdrudk meines inneren Erlebnisses gewesen wäre. ${ }^{{ }^{174}}$

Unter den angeführten Gedichten befinden sich zwei, die in 3. Päonen geschrieben sind. Eines davon soll hier zusammen mit den Erläuterungen Brjusovs wiedergegeben werden:

Veretena. (Pèon tretij)

Zastonali, zazveneli zolotye veretena, $\mathrm{V}$ op'janjajuščem spleten'i upoitel'nogo zvona.

Rasstilaetsja svobodno vyrostajuščaja tkan'... Uspokoennoe serdce! volnovat'sja perestan'!

Eto - parki. Neuklonne neustannymi rukami

Doveršajut načatoe bezkonečnymi vekami:

Čto naznačenno, to budet! ispolnjaetsja zakon

Pod zvenjaščee žužžan'e vdochnovennych vereten!175

In der zu diesem Gedicht gehörenden Anmerkung erklärt Brjusov zunächst den Versfuß als solchen. Dabei stellt er fest, daß die Päone dem Aufbau nach dem Diiambus und Ditrochäus sehr ähnlich sind. Jedoch sei in den angeführten Beispielen der päonische Aufbau des Verses streng eingehalten. „Doch wäre es ein Fehler", schreibt er wörtlich, „stets in Päonen die Annäherung an jambische oder trochäische Metren zu meiden, indem man pedantisch jeden Nebenton auf unbetonten Silben vermeidet. Ebenso, wie es beim Jambus und Trochäus fehlerhaft ist, eine Hypostasis, d.h. eine Ersetzung des jambischen oder trochäischen Versfußes durch einen Pyrrhichius und Spondeus zu vermeiden, so ist es auch beim Päon fehlerhaft, die Hypostasis zu vermeiden; päonische Versfüße können und sollen durch Diiamben und Ditrochäen, aber auch durch andere viersilbige

174 ibid. S. $43 \mathrm{f}$.

173 ibid. S. 51. 
Versfüße ersetzt werden. Andernfalls wären die päonischen Metren der rhythmischen Vielfalt beraubt. " ${ }^{170}$

Betrachtet man das metrische Schema des oben zitierten Gedichts, so wird man entdecken, daß es sich tatsächlich um vierfüßige Päone handelt. Die erste und dritte Strophe enden akatalektisch, die zweite und vierte katalektisch. Eine Hypostasis liegt beim zweiten und vierten Fuß der sechsten Zeile vor. Hier wurde der 3. Päon jeweils durch einen 2. Päon ersetzt. Wieweit in diesem Falle eine Auflösung des Metrum's in Trochäen, wobei jeder zweite Versfußs als unbetont anzunehmen ist, dem metrischen Aufbau dieses Gedichtes gerecht wird, bleibe dahingestellt.

Für Brjusov ergibt sich insofern ein Unterschied, als er für die ausgefallene Tonstelle im pyrrhichischen Fuß eines zweisilbigen Metrums einen Nebenton annimmt, im Päon dagegen nicht. Wie schon erwähnt, wird in neueren Arbeiten ein solcher Nebenton geleugnet. Leider hat Brjusov keinerlei Begründung für seine Annahme gebracht.

Neben Beispielen für verschiedene antike Versformen, bei denen es sich meistens um Ubersetzungen von antiken Texten handelt, bringt Brjusov auch ein Beispiel für den jambischen Trimeter. In der Anmerkung zu den betreffenden Versen weist er darauf hin, daß sich dieses Metrum vom sechsfüßigen Jambus dadurch unterscheidet, daß eine Zäsur nach der sechsten Silbe vermieden wird. Er erklärt dies dadurch, daß er die Versform als dipodisches Versmaß, bestehend aus drei Diiamben, auffaßt. Das entspricht insofern nicht ganz der antiken Auffassung, als dort einfache Versfüße ohnehin zu Metren zusammengefaßt werden, die ihrerseits jeweils aus zwei Füßen bestehen. Was das von Brjusov angeführte Beispiel betrifft, so handelt es sich hierbei um eine bewußte Imitierung des in der antiken Tragödie verwendeten Versmaßes. Immerhin zeigt der Versuch, daß die dem antiken jambischen Trimeter entsprechende Form auch im Russischen verwendbar ist.

\section{Die Euphonie}

Uber die zweite "Disziplin" seiner Verslehre, die Euphonie, hat Brjusov keine besondere Arbeit geschrieben. Um uns ein Bild von

170 ibid. S. $176 \mathrm{f}$. 
den die Lautstruktur eines Verses betreffenden Vorstellungen und Grundsätzen Brjusovs zu machen, sind wir auf verschiedene Aufsätze angewiesen, die unter anderem auch dieses Thema oder wenigstens einen bestimmten $Z_{w e i g}$ dieses Themas behandeln.

In der Periode bis 1918 standen für Brjusov reine Formprobleme noch nicht so sehr im Vordergrund, daß er in seinen Arbeiten tiefer in ein so spezielles Gebiet, wie es die Euphonie ist, eingedrungen wäre. ${ }^{177}$

Hinzu kommt, daß das Gebiet der Euphonie bis dahin fast völliges Neuland war. Brjusov beklagt sich bitter über das Fehlen jeglicher Unterlagen zur russischen Euphonie. "Sicher", so schreibt er, nist die russische ,spezielle Metrik' noch nicht bearbeitet, aber sie besitzt viele Analogien mit anderen speziellen Metriken: der antiken, die großartig bearbeitet ist, der deutschen, der englischen. Und für die russische Metrik selbst gibt es auch eine Reihe Aufmerksamkeit heischender Arbeiten. Die russische Euphonie und die Lehre von den russischen Reimen ist fast überhaupt nicht bearbeitet, und man kann sich in keiner Weise auf fremdsprachige Arbeiten stützen, weil die Aussprache des Russischen sich wesentlich von der anderer Sprachen unterscheidet. ${ }^{\alpha 178}$

In den "Opyty" teilt Brjusov die Euphonie noch in die folgenden drei Teilgebiete ein:

1. Die eigent i che Euphonie (zvukopis') ${ }^{179}$ oder Wortinstrumentierung (slovesnaja instrumentovka). Brjusov definiert sie als die Lehre von den Mitteln, mit welchen erreicht werden kann, daß der Klang der Worte ihrer Bedeutung entspricht und so dazu beiträgt, einen starken Eindruck zu vermitteln. „Zvukopis'“ sei die Lehre davon, wie man mit Worten malt. Als Mittel der eigentlichen Euphonie nennt Brjusov: äußere und innere Alliteration, Buchstaben-Anapher, Antistrophe (Epiphora), Paronomasie, Antithese, Zeugma u. a., d.h. im wesentlichen rhetorische Figuren, die hier für die Anordnung der Laute verwendet werden.

17\% Was die Arbeitsmethoden Brjusovs mit euphonischen Mitteln bei seinen eigenen Dichtungen betrifft, so gewährt die Arbeit von J. Holt hus en, Studien zur Asthetik und Poetik des russischen Symbolismus, Göttingen 1957, interessante Einblidke.

138 Opyty S. 28.

179 "zvukopis', eigentlich "Lautschreibung", bleibt als Terminus zwedkmäßigerweise unübersetzt. 
2. Die Eurhythmie oder die Lehre von der Musikalität der Verssprache. Hier verweist Brjusov mit Recht darauf, daß auf diesem Gebiet keine absoluten Forderungen aufgestellt werden können und der Dichter bei jeder neuen Aufgabe, die er sich stellt, diesem Problem von einer neuen Seite her gegenübersteht. Dazu gehört audh die Kunst, Ende des einen und Anfang des nächsten Wortes so aufeinander abzustimmen, daß ein „Wohlklang" entstehe. Ebenso gehört hierher auch die Auswahl einer vom klanglichen Standpunkt günstigen grammatikalischen Form eines Wortes.

3. Die Lehre von den Reimen und Assonanzen. Dieses Gebiet ist das umfangreichste der Euphonie und wird gern gesondert behandelt. Es war damals, als Brjusov diese Aufteilung vornahm, in der russischen Versforschung fast überhaupt noch nicht untersucht worden. Erst 1923 ist von V. Žirmunskij eine Untersuchung über den russischen Reim erschienen. ${ }^{180}$ "Niemand ist es eingefallen“, beklagt sich Brjusov, „zu erklären, welche Veränderungen von Kasus- und Verbalformen zu diesen oder jenen Gleichklängen führen. Noch weniger ist für die Assonanz getan worden, deren Begriff selbst bis jetzt noch nicht genau bestimmt ist. Auf diese Weise muß der russische Dichter auf dem Gebiet des Reimes notgedrungen Autodidakt sein." 181

Brjusov verzichtet von vornherein auf jede Untersuchung von Klangmalerei und Musikalität. Seine Besprechungen und die von ihm angeführten Beispiele behandeln ausschließlich Fragen des Reims.

Den Verfassern von Reimbüchern, die in ihrem Vorwort erklären, $\mathrm{da} ß$ es unmöglich sei, sämtliche möglichen russischen Gleidıklänge zu erfassen, wirft Brjusov vor, daß sie nicht wenigstens die verschiedenen Typen der Reimbildung systematisiert haben. ${ }^{182}$

Eine derartige Aufgliederung nach Reimtypen stellt sich Brjusov etwa wie folgt vor:

Es wird z. B. eine Reimtabelle für Substantiva mit der Betonung auf der vorletzten Silbe (im Nom. Sg.) zusammengestellt. Solche Worte, wenn sie Masculina sind und auf harten Konsonanten auslauten, reimen entsprechend 1) dem Endkonsonanten, 2) dem Zusammenfall von jeweils betontem Vokal und dem $\mathrm{zwischen}$ diesem

180 Vgl. V. Zirmunskij: Rifma, ee istorija i teorija. Petrograd 1923.

181 Opyty S. 31.

182 Vgl. ibid. S. 182. 
und der Flexionsendung stehenden Konsonanten. Auf diese Weise reimen Worte auf -ed, -et, -ad, -at, (-jad, -jat), -ud, -ut, (-jud, -jut) usw. mit der dritten Person Singular und Plural Präsens oder Futur eines Verbums. Eine weitere Reihe ergeben dann diejenigen Substantiva, die mit der präteritalen Verbalendung reimen, wieder eine andere diejenigen, deren Auslaut mit den verschiedenen Partizipien einen Gleichklang bildet, usw. Daraus ergeben sich wiederum Tabellen von Substantiven, die in der Nominativform untereinander einen Reim ergeben, dann wieder andere von verschiedenen Kasus des einen Genus, die mit einem anderen Kasus des anderen Genus reimen usw.

Brjusov erläutert dann eine detaillierte Terminologie, die er vorschlägt. Er betrachtet dabei die Eigenschaften von verschiedenen Reimen nach drei Gesichtspunkten:

1. nach ihrem Verhältnis zum gesamten Vers, vom metrischen Standpunkt aus,

2. nach ihrem gegenseitigen Verhältnis, vom euphonischen Standpunkt aus, und

3. nach ihrer Anordnung innerhalb einer Strophe.

Daraus entwickelt Brjusov drei Typen von Reimen. Wir haben hier also wieder eine Aufteilung des Einzelproblems in die grundlegenden drei Elemente: Metrik und Rhythmik, Euphonie und Strophik.

Die einzelnen Gruppen der drei Reimtypen werden ihrerseits wiederum nach verschiedenen Gesichtspunkten aufgeteilt und ihnen eine entsprechende Terminologie unterlegt. Das ergibt folgendes Schema: ${ }^{183}$

I. Metrische Reime.

1) Der Silbenzahl in der Endung entsprechend gibt es:

a) männliche,

b) weibliche,

c) daktylische und

d) hyperdaktylische Reime (d.h. viersilbige, fünfsilbige usw.).

2) Der Form entsprechend gibt es:

a) offene (auf Vokal endende),

183 Das Schema wird hier so wiedergegeben, wie Brjusov es in "Opyty" (S. $184 \mathrm{f}$.) vorlegt. Lediglich die Anordnung ist der Ubersichtlichkeit halber verändert worden. 
b) erweichte (auf $j$ endende) und

c) gesdhlossene (auf Konsonant endende) Reime.

II. Euphonische Reime.

1) Eigentliche Reime:

a) genaue und annähernde (je nachdem wieweit Schreibung und Aussprache der betreffenden Wörter zusammenfällt),

b) rührende (sočnye) Reime (entsprechend dem Zusammenfall der dem betonten Vokal vorangehenden Laute),

c) gespaltene (sostavnye) Reime und einfache Reime (die ersteren bestehen jeweils aus zwei oder mehr Wörtern),

d) reiche und arme Reime; eine besondere Art der armen Reime bilden die flektiven Reime;

e) natürliche Reime (Wörter in ein und derselben grammatikalischen Form),

f) Wurzelreime (die Wortwurzel wird gereimt),

g) homonymische Reime (bei ein und derselben Schreibung in ihrer Bedeutung verschiedener Wörter),

h) tautologische Reime (Reim von zwei gleichen Wörtern in etwas verschiedener Bedeutung); ein besonderer Fall des tautologischen Reims ist der Wiederholungsreim (Wörter, die sich nur durch ein Präfix unterscheiden),

i) verkürzte Reime.

2) Assonanzen:

a) romanische Assonanzen (nur die betonten Vokale sind identisch),

b) neue Assonanzen (die betreffenden Wörter sind sich im allgemeinen in der Aussprache ähnlich).

3) Dissonanzen:

Die Endkonsonanten stimmen überein, aber die betonten Vokale sind verschieden.

4) Halbreime:

Gleichklang der Silben vor dem betonten Vokal.

III. Strophische Reime.

1) Entsprechend der Anordnung im Vers:

a) Endreime,

b) Anfangsreime,

c) Mittelreime,

d) Binnenreime zweierlei Art: ständige und gelegentliche. 
2) Entsprechend der Anordnung in der Strophe:
a) Paarreime (aa bb)
b) Kreuzreime (abab cdcd)
c) ternäre Reime (verschränkter Reim) und umarmende Reime (wenn zwei mittlere Verse miteinander reimen), quaternäre Reime usw.
d) doppelte, dreifache u. a. Reime (je nachdem, wie oft ein Gleichklang wiederholt wird).

Mit diesem Schema hat Brjusov eine Terminologie entwidkelt, an die zumindest er selbst sich in seinen späteren Arbeiten zu halten pflegte. Der Abschnitt III, welcher die strophischen Reime aufzählt, ist leider recht unvollständig und entspricht in seinen Begriffen etwa den in der deutschen Poetik bekannten Reimarten. Es wären aber verschiedene Begriffe zu ergänzen (Kettenreim, Zäsurreim usw.).

Die zu diesem Schema angeführten Beispiele entspredhen leider in nur geringem Maße der Aufstellung. Andererseits stand Brjusov wohl audı nicht mehr Raum zur Verfügung, um ein vollständigeres Beispielmaterial zusammenzustellen, was dem Schema entsprechend doch recht umfangreich hätte sein müssen.

Das Erscheinen von V. Žirmunskijs ${ }_{n}$ Rifma, ee istorija $i$ teorija ${ }^{\alpha 184}$ gab Brjusov Anlaß, im Rahmen einer Rezension dieses Buches noch einmal eine theoretische Abhandlung über Reimprobleme zu verfassen. Zwar bemängelt Brjusov weite Teile der Arbeit Zirmunskijs, kann aber nicht umhin, diese insofern anzuerkennen, als sie einem von ihm stets beklagten Mißstand abzuhelfen beginne. "Aber es darf nicht vergessen werden", schreibt er, "daß dies (die Arbeit Žirmunskijs) der erste Versuch in dieser Richtung ist. Das Buch gibt unserem Wissen über den Reim ein System, es faßt einen großen Teil dessen zusammen, was bisher getan wurde, es führt eine große Anzahl verschiedener Reime an und enthält nicht wenige interessante und feine Beobadtungen. Dies alles ist von nicht geringer Qualität, und das Buch V. Zirmunskijs legt den Grund zu weiteren Untersuchungen des russischen Reims. ${ }{ }^{185}$

Die Darstellung der Reimgeschichte bei Žirmunskij findet Brjusov, teilweise zu Recht, unvollständig. Es handelt sich dabei im wesent-

184 V. Zirmunskij: Rifma, ee istorija i teorija. Petrograd 1923.

185 V. B r jus ov: O rifme. „Pec. i rev.“ 1924, I, S. 114-123. 
lichen um drei Punkte, die Brjusov kritisiert. Einmal, daß Žirmunskij zwar die westeuropäische Dichtung bis zu altgermanischen und altromanischen Versformen zurückverfolgt, aber den zweifellos bemerkenswerten Einfluß, den vor allem im Mittelalter die arabische, persische u. a. Dichtung in Europa hatte, nicht beachtet.

Zweitens will Brjusov, im Gegensatz zu Žirmunskij, einen wesentlichen Teil des Ursprungs der Reime, deren sich die zeitgenöslische russische Kunstliteratur bedient, in der russischen Volksdichtung sehen, während Żirmunskij, wohl zu Recht, mehr auf westeuropäische (besonders polnische) Einflüsse verweist. Lediglich den Reimen in der großrussischen Byline widmet Žirmunskij einen Abschnitt. Brjusov schreibt hierzu: „Aber gerade die Byline liefert uns nur rudimentäre Formen des Reimes (zugegebencrmaßen sehr interessante). Hingegen könnten andere Arten der Dichtung eine reiche Auswahl an Tatsachen liefern. Dazu gehört die Lyrik (der Vorbehalt ciner möglichen städtischen Beeinflussung ist für eine ganze Reihe von Werken nicht bewiesen), dazu gehören Sprüche, Zaubersprüche. Sprichwörter, Redensarten, Rätsel usw. Aus diesen kann man ersehen, daß der Reim seit altersher eine Erscheinung der russischen Dichtung ist, doch gerade diese seine Besonderheit wird in dem Buch V. Žirmunskijs nicht beleuchtet. ${ }^{{ }^{188}}$

Leider hat Brjusov selber keine Untersuchung der russischen Volksdichtung auf eventuelle Reime durchgeführt. ${ }^{187}$

Tomaševskij nimmt ebenfalls Ansätze eines Reimes in der Volksdichtung an: „Embryonale Reime in der Form einer zusätzlichen Ausschmückung existierten bereits in der Volksdichtung, von wo sie in die Buchliteratur übergingen. "

Als drittes bemängelt Brjusov, daß Žirmunskij die neuen Reimformen der Futuristen (Chlebnikov, Pasternak, Aseev usw.) aus seiner Betrachtung ausschließt. Er wirft Žirmunskij vor, daß er diese Erscheinung nicht verstanden habe oder jedenfalls nicht zu schätzen wußte.

Žirmunskij sieht die Entwicklung des russischen Reimes im wesentlichen in einem allmählichen Nachlassen der Forderung nach

160 ibid. S. 115.

$187 \mathrm{Vgl}$. M. P. Stokm a r: Issledovanija v oblasti russkogo narodnogo stichosloženija. Moskau 1952. Die Frage eines eventuellen Reimes in der russischen Volkslyrik wird hier nicht berührt.

188 B. V. T o ma ̧̌ v s i j: Stilistika i stichosloženie. Leningrad 1959, S. 420 . 
Gleichheit der Laute, die auf den betonten Vokal im Reim folgen. Brjusov weist hier mit Recht darauf hin, daß dem Verfall der einen Form die Entwicklung einer neuen Form des Gleichklanges in der Dichtung parallel läuft. „In der Zeit, in der die einen Forderungen abstarben, entstanden andere. Während der neue Reim die Ännlichkeit der nachbetonten Laute verlor, gewann er etwas anderes ... Im Gegensatz zu V. Žirmunskij stelle ich mich auf den Standpunkt, daß der neue Reim nicht ein "als ob“, sondern in Wirklidakeit ein neues Reimsystem oder neues Reimprinzip ist. ${ }^{\star 180}$

An dieser Stelle gibt Brjusov eine Analyse dessen, was er den "neuen Reim“ nennt. $\mathrm{Zu}$ diesem $Z$ weck stellt er zunächst die Frage nach der Hauptaufgabe des Reims. Diese bestehe darin, „durch ähnlichen Klang der Wörter eine bestimmte Stelle (meist am Ende) in metrischen und euphonischen Lautreihen zu kennzeichnen. ${ }^{* 100}$ Diesen ähnlichen Klang suchte man früher am Ende eines Wortes, im betonten Vokal und den darauf folgenden Lauten. Der neue Reim hingegen stützt sich in erster Linie auf den Konsonanten oder die Konsonantengruppe, die dem betonten Vokal vorangeht. Weitere Reimelemente bilden dann diejenigen Silben, die vor der betonten stehen.

Brjusov erläutert diese seine Auffassung an Hand einer Reihe von Beispielen, besonders aus den Werken Pasternaks. "Im System des klassischen Reims", schreibt Brjusov, "gelten $o$ und oj als betonte Laute am Ende eines Wortes (in männlichen Endungen) selbstverständlich nicht als Gleichklänge. Für B. Pasternak reimt z. B. „krupoj - Edgarom Po ${ }^{\alpha}$ und das zeigt, daß die beiden Wörter kraft der Gleichheit des stützenden Konsonanten $p$ (und teilweise kraft des Zusammenfalls des vorangehenden $r$ oder sogar der Gruppen $\mathrm{kr}$ und gr) zusammenklingen. “191

Noch eine Reihe weiterer Reime Pasternaks führt Brjusov an: "spit-stepi“, „ne zdes' - zvezde“, "kak nibud' - na lbu" als männliche Reime, „zvonoček - nořju“, „sadnjat - palisadnik “, "repej-

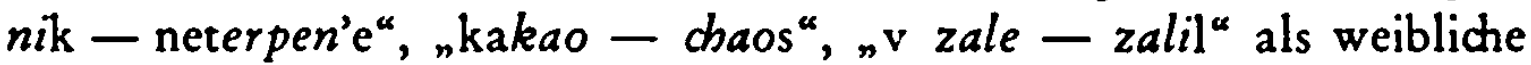
Reime.

Das Prinzip des neuen Reims faßt Brjusov so zusammen, daß er diejenigen Wörter als gleichklingend annimmt, die eine genügende

\footnotetext{
189 Opyty S. 117.

100 ibid.

191 ibid. S. $117 \mathrm{f}$.
} 
Anzahl ähnlicher Elemente enthalten. Das Zentrum dieses Gleichklanges wird vom betonten Vokal und dem Konsonanten davor gebildet. Die ähnlichen Elemente in den sich reimenden Wörtern können dabei sogar in verschiedener Reihenfolge angeordnet sein, metathetisch oder auch durch andere Laute von einander getrennt. Brjusov führt dazu wieder einige Beispiele von Pasternak an: „čerdak -

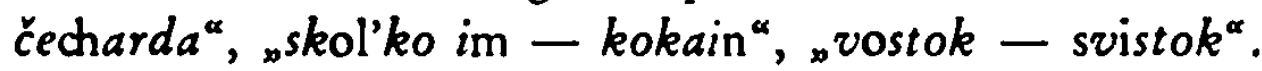

„Der neue Reim", stellt Brjusov fest, „ist ein anderer als der klassische, er ist aber in keinem Falle "weniger genau" oder "weniger streng ". ${ }^{" 192}$

Das Auftreten eines neuen Reimprinzips zu Beginn der 20er Jahre wird auch von B. O. Unbegaun beobachtet. Dieser bezeichnet die Erscheinung als "verstümmelten (truncated) Reim". Er macht die Beobachtung, daß verschiedene Laute nach dem betonten Vokal am wenigsten bei männlichen Reimen auftreten, während weibliche Endungen oft sogar im daktylischen gereimt werden. Auch die Bedeutung der Konsonanten vor dem betonten Vokal erwähnt Unbegaun und führt hierzu Beispiele aus Majakovskij an.193

B. Tomaševskij spricht in diesem Zusammenhang von ${ }_{n}$ annäherndem (priblizitel'naja) Reim “ bzw. von nungenauem (netočnaja) Reim". Seine Untersuchung beschränkt sich jedoch ausschließlich auf die Laute $\mathrm{n}$ a ch dem betonten Vokal.194

Žirmunskij will die Veränderungen im Reimgebrauch, die im Laufe der Zeit auftreten, ausschließlich durch den Wechsel im poetischen Geschmadk und Stil erklären. Brjusov weist dagegen auf die Anderung der Aussprache im Laufe der Zeit, auf die allgemeine Sprachentwicklung hin. Als Erscheinung dieser Sprachentwidklung der letzten zweihundert Jahre führt Brjusov die Verstärkung des nikan'e" an, die weitere Ausbreitung des Moskauer nakan'e" u. ̈̈.

Außerdem verweist Brjusov noch auf die Unterschiede in der individuellen Aussprache der einzelnen Dichter. Er führt sich selbst als Beispiel an: „Ich selbst (da meine Mutter aus dem Süden gebürtig ist) habe so ausgesprochen $(g=c h)$, weswegen sich in den Versen aus meiner Jugendzeit auch z. B. "mog - moch" reimt: für mich war das ein "genauer" Reim, der Aussprache und nicht der Schreibung nach." (Brjusov meint die im Südgroßrussischen übliche Aus-

192 ibid. S. $118 \mathrm{f}$.

193 B. O. Un beg a u n: Russian Versification S. $143 \mathrm{ff}$.

104 B. V. T o m a ̌̌evskij: Stilistika i stichosloženie S. $414 \mathrm{ff}$. 
sprache $g=\gamma$, das im Auslaut stimmlos ist und h entspricht.) Diese Erscheinung finden wir in fast allen Schriftsprachen. Goethe reimt z. B. der Frankfurter Ausspracie gemäß: „Ach neige / du Schmerzensreiche ....

Was die Theorie Zirmunskijs betrifft, so beschränkt sich diese auf eine Klassifikation nach den drei Gesichtspunkten Metrik, Euphonie und Semantik. Auch dies hält Brjusov für unzureichend. Er möchte u. a. auch eine morphologische Untersuchung über die Ursachen des Gleichklanges zweier Wörter im Sinne der von ihm in den "Opyty " vorgeschlagenen Reimtabellen durchgeführt wissen.

"Woher zum Beispiel", fragt Brjusov, „entstehen die klassischen männlichen Reime auf "a $v^{\alpha}$ ? Dies sind maskuline Substantiva und Eigennamen im Nominativ (sustav, Gustav), die Genitive femininer Substantiva auf a v a (glav), Adjektive in der Kurzform (kurčav), Gerundia (zastav). Völlig analog entstehen die Reime auf iv, auf e v u. a., unter Hinzunahme noch der Mundarten. Aus ähnlichen Analogien kann man z. B. alle möglichen Fälle eines Reimes auf $o \check{c} i$ - očij ableiten: der Nom. Sg. m. (rabočcij), der Nom. Pl. f. (noči), der Gen. Sg. f. (noči, moči), der Gen., Dat. Sg. f. (rabočej), der Komparativ (žestoð̌e), italienische Wörter (voce, Croce) usw. “ ${ }^{195}$

Wir haben also bei Brjusov zunächst eine Aufteilung des Reimproblems nach dem jeweiligen Standpunkt der drei Grundelemente der Verslehre (Metrik, Euphonie und Strophik) in metrische Reime, euphonische Reime und strophische Reime. Die einzelnen Gleichklänge sind ihrer grammatikalischen Ursache entsprechend in Tabellen zusammenzufassen, die sich nach dem betreffenden Schema dann beliebig erweitern lassen. Das Problem des Reimes als Ganzes ist ein Teilgebiet der Euphonie.

Praktisch durchgeführte Untersuchungen nach dieser Einteilung finden wir bei Brjusov nicht.

Uber ein weiteres Teilgebiet der Euphonie, die eige nt liche E u phonie, finden wir eine erst 1923 erschienene Arbeit Brjusovs, "Zvukopis' Puškina“. ${ }^{196}$

Brjusov umreißt das Problem wie folgt: „Man glaubt, daß der Dichter zum Ausdruck seiner Gedanken nur W or te sucht; daß es

105 Opyty S. $122 \mathrm{f}$.

100 V. B r ju s ov: Zvukopis’ Puškina. „Peč. i rev." 1923, II; Izbr. soč. S. $480-498$. 
ihm nur darauf ankommt, Ausdrücke, Bilder zusammenzustellen, die möglichst genau und möglichst anschaulich seine Idee, sein Gefühl wiedergeben. Wie diese W'orte klingen werden, hängt im wesentlichen von der Art der Sprache ab; die Sprache selbst sorgt dafür, daß in dem Wort "grom ${ }^{\alpha}$ (Donner) die rauhen Konsonanten " gr $^{*}$ enthalten sind, oder in "milyj" (lieb), "ljubov'“ (Liebe) das sanfte . ${ }^{\alpha}$... Laute auszuwählen bedeutet für viele den Sinn zu opfern. Jedoch die Praxis zahlreicher großer Dichter widerspricht einer soldhen Auffassung. Von Homer und Aischylos bis Goethe und Victor Hugo bestätigen alle Dichter übereinstimmend durch ihre Verse, daß sie anders als durch Klänge das, was sie sagen wollen, nicht ausdrücken können ... ${ }^{\alpha_{107}}$

Eine eingehendere Studie über Lautsymbolik finden wir bei $\mathrm{K}$. $\mathrm{O}$. Bal'mont. Dieser zieht zu seiner Betrachtung auch zahlreiche Beispiele aus altamerikanischen und Südseesprachen heran. ${ }^{108}$ Brjusov dagegen befaßt sich nicht weiter mit Lautsymbolik. Sein Augenmerk gilt mehr der künstlerischen Lautanordnung in der Poesie. Einer solchen Untersuchung legt Briusov die Begriffe der Strophik und poetischer Figuren zugrunde.

Es werden vier Grundformen der A 1 lit e r a t i o n oder Wiederholung (povtor) angenommen: 1) Anaphora, die Wiederholung ähnlicher Laute jeweils am Anfang eines Worets; 2) E p i p h o r a oder Ende (koncovka), die Wiederholung ähnlicher Laute jeweils am Ende eines Wortes; 3) Z e u g m a oder Fuge (styk), die Wiederholung des Endlautes eines Wortes am Anfang des folgenden Wortes; 4) R on do oder Ring (kol'co), die Wiederholung des Anfangslautes eines Wortes am Ende des folgenden.

Diese Lautwiederholungen können auf verschiedene Weise in einen Vers bzw. ein Gedicht eingebaut werden. Brjusov unterscheidet dabei be $\mathrm{n}$ a chb a rte (smežnyj) Wiederholungen, die unmittelbar aufeinander folgen; getrennte (razdel'nye) Wiederholungen, die durch ein oder mehrere Worte voneinander getrennt sind; solche, die jeweils eine bestimmte Stelle in der Lautreihe, im Vers einnehmen. Ferner unterscheidet Brjusov e in $\mathrm{f}$ a $\mathrm{ch}$ e (prostye) Wiederholungen, bei denen nur ein Laut wiederholt wird, und $z$ us a mmengesetz te (složnye), bei denen eine ganze Lautgruppe, ev. eine ganze Silbe wiederholt wird. Außerdem gibt es gen a ue (točnye), u n-

197 ibid.

${ }^{108}$ K. B a l'm o n t: Poézija kak volY̌ebstvo. Moskau 1922, S. 61 f. 
gen a u (netočnye), umgekehrte (obratnye) usw. Wiederholungen, einfache, doppelte, mehrfache usw.

Die Wiederholungen ihrerseits werden durch bestimmte Systeme miteinander verbunden. Die Anordnung der Wiederholungen im System kann aufeinanderfolgend, gekreuzt, umarmend, spiralförmig u. ä. sein. Brjusov verwendet dafür auch die Begriffe secutio, geminatio, antithesis usw.

Dies ist in kurzen Zügen das System, nach dem Brjusov bei eigentlich euphonischen Untersuchungen verfährt. In dem erwähnten Aufsatz nZvukopis' Puškina“ führt er für die verschiedenen Arten von Alliterationen jeweils mehrere Beispiele an, alle von Puškin. Einige davon seien hier wiedergegeben:

Für die Anaphora:

Blagoslovljaju bogomol'no ...

Für das Zeugma:

Bespečnyj, vljubčivyj. Vy znaete druz'ja ...

Für die Epiphora:

Kipit, bežit, sverkaja i žurča

Für das Rondo:

Nedavno černych tuč grjadoj ...

Die Lehre von den Alliterationen oder die eigentliche Euphonie wird bei Brjusov zusätzlich noch in zwei Einzelgebiete aufgeteilt: die Lehre von der Anordnung der Konsonanten, die er "zvukopis'“ nennt, und die Lehre von der Anordnung der Vokale, die er als

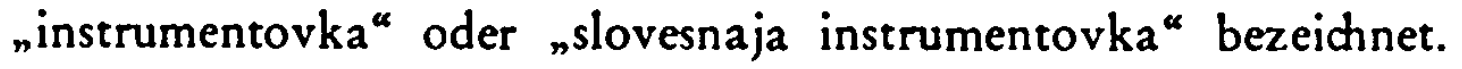

Für den dritten Zweig der Verslehre, die Strophik, stellt Brjusov kein eigenes System auf. Er begnügt sich bei seinen Untersuchungen mit den bis dahin allgemein verwendeten Begriffen. In den „Opyty werden unter dieser Rubrik Beispiele für folgende Gedichtformen angeführt: Große Sapphische Strophe, Terzine, Sonett, Rondo, Triolett, Ritornell, Villanelle, Dreieck (als Beispiel für die im 18. Jht. besonders gepflegte Figurendichtung), Ballade u. a.

Abschließend kann zu Brjusovs Verslehre bemerkt werden, daß sie sich in vieler Hinsicht von den aus der Antike und Westeuropa überkommenen Begriffen nicht zu lösen vermag, jedoch einen Versuch darstellt, konsequent die Erscheinungen der russischen Versdichtung 
in ihrer Gesamtheit in ein System zu fassen, das allen ihren Spielarten gerecht wird.

Zweifellos hätte Brjusov die zu große Starrheit seines Systems bald erkannt, wenn er den Versuch unternommen hätte, in diesem Rahmen praktische Untersuchungen durchzuführen. So ist seine Verslehre, soweit sie sich mit der Metrik befaßt, für die spätere Forschung, die sich im allgemeinen auf ein metrisches System von fünf Versfüßen stützt (Jambus, Trochäus, Daktylus, Amphibrachys, Anapäst), von geringerem Wert. ${ }^{100}$

Die Beobachtungen Brjusovs auf dem Gebiet der Euphonie, besonders hinsichtlich des "neuen Reimes". sind, wie schon erwähnt, auch in der neuesten Forschung gemacht worden. Was die eigentliche Euphonie betrifft, so hat Brjusov selbst für seine Uberlegungen reichliche Verwendungsmöglichkeiten auf dem Gebiet der Ubersetzung gefunden.

199 Vgl. B. O. U n be g a u n: Russian Versification S. 12; B. V. T o m a §̧ e v ski i : Stilistika i stichosloženie, Teil II, Kap. 1; K. T a ra n ov $s \mathbf{k}$ i: Ruski dvodelni ritmovi S. 3. 


\section{Die Kunst des Übersetzens}

Sehr früh schon beschäftigte sich Brjusov mit Versübersetzungen fremdsprachiger Lyrik. Zunächst waren es vor allem französische Dichter seiner Zeit, Maeterlinck, Verhaeren u. a., deren Gedichte er

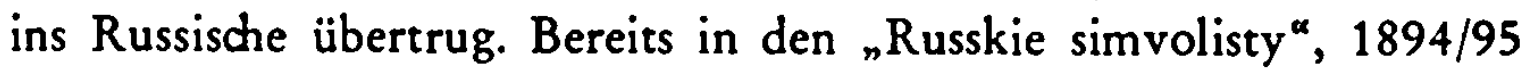
von Brjusov veröffentlicht, waren neben originellen Dichtungen auch Ubersetzungen aus dem Französischen enthalten.

Fs ist nur naheliegend, daß Brjusov durch seine Ubersetzertätigkeit dazu angeregt wurde, sich über die Technik, die Methoden und das Wesen einer Ubersetzung von Versen Gedanken zu machen. Diese Gedanken sind in mehreren kritischen Aufsätzen niedergelegt.

Eine gute Obersetzung verlangt ein tiefes Eindringen in ein Sprachkunstwerk. Sie verlangt auch eine Stellungnahme des Ubersetzers dem Kunstwerk gegenüber, der Ubersetzer muß das Kunstwerk interpretieren. Auf diese Weise ist es für uns möglich, aus den Ubersetzungen Brjusovs einige Schlüsse über seine Haltung sowohl einem bestimmten Kunstwerk gegenüber wie auch über seine Einstellung zur Kunst im allgemeinen zu ziehen.

Sein erster Aufsatz, der sich eingehender und ausschließlich mit dem Problem der Ubersetzung beschäftigt, erschien im Jahre 1905 in der symbolistischen Zeitschrift "Vesy ${ }^{*}$ unter dem Titel "Fialki $\mathbf{v}$ tigele " ${ }^{200}$ Es handelt sich dabei um eine kritische Auseinandersetzung mit den Ubertragungen G. Culkovs von Versen Maeterlindss. ${ }^{201}$

Brjusov entwidkelt hier seine Theorie des Ubersetzens. Er geht zunächst von der Frage aus, was Dichter aller Zeiten dazu treibe, neben ihrem eigenen Dichten auch Werke anderer Dichter aus anderen Sprachen in ihre eigene zu übersetzen. Puškin, Tjutčev, Fet u. a. sagt Brjusov - übersetzen nicht, um anderen Leuten, die weniger gebildet, die des Deutschen, Englischen oder Lateinischen nicht mächtig sind, fremdsprachliche Dichtung zu vermitteln, sondern aus rein

200 V. B r jus o v: Fialki v tigele. „Vesy“ 1905, VII; Izbr. soč. S. 186-192.

${ }^{201}$ M. Mèterlink: Dvenadcat' pesen', perev. G. Culkova. 1905. 
schöpferischem Antrieb. "Den Dichtern“, schreibt er, "stellt sich beim Ubersetzen von Versen eine rein künstlerische Aufgabe: das in ihrer eigenen Sprache neu zu schaffen, was sie in der fremden bezauberte, es leitet sie der Wunsch, „das Fremde im $\mathrm{Nu}$ als Eigenes zu erspüren “ ('̌užoe vmig počuvstvovat' svoim), - der Wunsch, sich dieses fremden Schatzes zu bemächtigen. Wundervolle Verse sind sozusagen eine Herausforderung an die Dichter anderer Völker, zu zeigen, daß auch ihre Sprache dazu fähig ist, die gleiche schöpferische Idee zu verarbeiten. ${ }^{\alpha 202}$

Brjusov hatte, als er diesen Aufsatz schrieb, schon lange genug selber Verse übersetzt, um zu wissen, wie begrenzt die Möglichkeiten einer wirklich adäquaten Ubersetzung sind. Er weiß auch sehr wohl, wieviel Können, wieviel Sprachkenntnis, wieviel Einfühlungsvermögen in die fremde Sprache dazu nötig sind. "Und niemals (oder nur in ganz seltenen Ausnahmefällen) werden Verse in einer fremden Sprache den gleichen Findruck vermitteln wie in der Muttersprache. Außer der K e n n t n is der Sprache braucht man noch ein besonderes $G$ ef üh $l$ für ihre Geheimnisse, um bis ins tiefste die Andeutungen des Dichters zu verstehen, - ein Gefühl, das es anscheinend nur für die Muttersprache gibt." Brjusov schildert dann, in welchem Maße unter den Gebildeten das Gefühl für eine fremde Sprache vorhanden ist: $Z$ war kennen wir von Kindheit an die deutsche Sprache, doch irre ich wohl kaum, wenn ich sage, daß die meisten von uns sich eine Vorstellung von der Dichtung Schillers nicht mit Hilfe des Originals erworben haben, sondern mit Hilfe der Zukovskijschen Ubersetzung. Ebenso haben wir alle mehr als sieben Jahre auf das Erlernen der klassischen Sprachen verwendet, wir haben in der Schule die Odyssee und die Ilias im Original gelesen, doch selten ist einer von uns mit Homer nicht durch Gnedič und Žukovskij bekanntgeworden. ${ }^{\alpha 203}$

Für Brjusov ist zunächst das Entscheidende, daß der Obersetzer sowohl in seinen Mitteln als auch in den Möglichkeiten eines Gelingens seiner Arbeit beschränkt ist. Resignierend schreibt er: „Die Schöpfung eines Dichters aus einer in eine andere Sprache zu übertragen, ist unmöglich; aber ebenso unmöglich ist es, diesem Traum zu entsagen. " ${ }^{20 s}$

202 Fialki v tigele S. 187.

203 ibid. S. $187 \mathrm{f}$.

204 ibid. S. 188. 
Erst nach diesen Vorbemerkungen hält slch Brjusov für berechtigt, die Ubersetzungen eines anderen (G. Culkov) zu kritisieren. Einige der von ihm kritisierten Ubersetzer (nicht Culkov) haben ihn in ihren Erwiderungen nit ausgesprochen boshaften Pamphleten bedacht und der Unsachlichkeit geziehen. An dieser Stelle möchte ich bemerken, daß dies zu Unrecht geschehen ist, denn Brjusov pflegte bei Rezensionen von Ubersetzungen stets vorsichtig zu Werke zu gehen, wie im folgenden gezeigt werden soll. Andererseits sind selbstverständlich auch die Arbeiten Brjusovs nicht frei von Fehlern.

Bei der Besprechung von Culkovs Maeterlindk-Ubersetzungen verlangt Brjusov zunächst die Zerlegung der Form eines lyrischen Werkes, wie schon im vorigen Kapitel erwähnt, in verschiedene Grundelemente. Diese Elemente seien hier noch einmal aufgezählt: Sprachstil, poetische Bilder, Versmaß und Reim, Dynamik des Verses, Spiel mit Silben und Klängen. „Bei der Úbersetzung eines Gedichtes alle diese Elemente vollständig und genau wiederzugeben, ist undenkbar. Der Ubersetzer bemüht sich im allgemeinen, nur eins davon oder im besten Falle zwei (meistens Bilder und Versmaß) zu übertragen, indem er die anderen verändert (Stil, Dynamik des Verses, Reim, Wortklang). ${ }^{2005}$

Die Methode des Ubersetzens besteht in der Auswahl des Elements, das man für das wichtigste hält, welches am besten den Gehalt des betreffenden Werkes kennzeichnet. Dieses Element gilt es dann in der Ubersetzung wiederzugeben. Brjusov führt dazu als Bcispiel die Methoden einiger Ubersetzer an, z. B. Bal'monts, der ausschließlich bemüht war, das Versmaß des Originals vollständig zu übertragen, mit dem Erfolg, daß alle seine Ubersetzungen, sei es Shelley, Poe oder Baudelaire, stets in der gleichen, nämlich Bal'montschen Ausdrudksweise erscheinen.

Ahnlich ist der Vorwurf, den Brjusov G. Culkov anläßlich seiner Maeterlindk-Ubersetzung macht. "Man liest Verse von Culkov und nicht von Maeterlinck auf russisch", urteilt er. Culkov hätte in diesem Falle nach einer falschen Methode gearbeitet und sich bemüht, bei der Ubersetzung der "Lieder" Maeterlincks dessen poetische Bilder und dessen Stil wiederzugeben. „Die ,Lieder' Maeterlincks, meint Brjusov, nihren Charakter, ihre Seele geben nicht die Bilder wieder,

sos ibid. 
sondern die Anlage des Verses und dessen D y n a m ik. “200 Maeterlindk habe seine "Lieder" im wesentlichen auf dem Rhythmus von Worten und Bildern aufgebaut. Ihr Versmaß basiere nicht auf der Anzahl der Silben, sondern auf dem Gleichgewicht der poetischen Bilder in den Versen und auf dem Parallelismus von Worten. "Dieser genau überlegte Kunstgriff gab das Skelett, den Rahmen für alle zwölf ,Lieder'. “207 Durch die Ubertragung der unwesentlichen Elemente (weswegen die wesentlichen verändert werden mußten) sind bei Culkov nicht "Lieder", sondern „einfach Gedichte" entstanden. Um das zu erläutern, gibt Brjusov ein Gedicht von Maeterlindk im Original und zum Vergleich die Culkovsche Übersetzung wieder. Es lohnt sich dieses Beispiel auch hier anzuführen:

Elle avait trois couronnes d'or,

A qui les donna-t-elle?

Elle en donne une à ses parents:

Ont acheté trois réseaux d'or

Et l'ont gardée jusqu'au printemps.

Elle en donne une d̀ ses amants:

Ont acheté trois rêts d'argent

Et l'ont gardée jusqu'à l'automne.

Elle en donne une à ses enfants:

Ont acheté trois noeuds de fer

Et l'ont enchaîné tout l'hiver.

Dazu die Ubersetzung Culkovs:

Ona imela tri korony zolotye,

Komu ona ich otdala?

Odnu ona roditeljam dala:

I vot kupili seti zolotye,

I do vesny ona $v$ setjach byla.

Odnu ona vljublennym podarila:

Iz serebra teneta dali $e j$,

I $\mathbf{v}$ nich ona do oseni chodila.

Odna byla podarkom dlja detej:

Togda ee $\mathrm{v}$ železo zakovali,

I zimu dolguju ee ne vypuskali.

200 ibid. S. $189 \mathrm{f}$.

207 ibid. S. 190. 
Brjusov bemängelt einige äußerliche Unzulänglichkeiten der Ubersetzung: statt "ona imela" schlägt Brjusov vor "u nee bylo", statt "vljublennym" für "ses amants" schlägt er vor "ee vozljublennych" oder "ee milych ${ }^{\alpha}$ usw. Füllworte wie ${ }_{n}$ i vot ${ }^{\alpha},{ }_{\text {"togda }}{ }^{\alpha}$ werden als unschön angesehen, ebenso zwei etwas ungeschickte Verbalreime: „podarila - chodila ", nzakovali - vypuskali“". Dies sei aber nicht das Wesentliche, was die Ubersetzung Culkovs so wenig adäquat mache, wichtiger sei vielmehr, daß in der Ubersetzung die Anlage (sklad) des Liedes verlorengegangen sei.

In diesem Falle ist leicht zu erklären, was Brjusov unter Anlage versteht. Betrachtet man den ersten Vers der ersten Terzine, dann wird man feststellen, daß sich dieser Vers fast wörtlich zu Beginn jeder folgenden Strophe wiederholt. Nur das letzte Wort wird jeweils geändert. Außerdem reimen diese letzten Worte untereinander. Gerade durch diesen Kunstgriff wird der Eindruck des "Liedes" hervorgerufen. Bei Culkov geht er verloren, weil er in den ersten beiden Strophen jeweils ein anderes Verbu $\mathrm{m}$ an den Schluß setzt, das im Original nicht weiter betont und ein Bestandteil des unveränderten Verses ist. Die zur Betonung von Maeterlinck an den Schluß der Zeile gesetzten verschiedenen Objekte (parents - amants enfants) gehen bei Culkov in der Mitte des Verses unter. Der letzte Vers einer jeden Terzine endet bei Maeterlindk mit der Bezeichnung der Jahreszeit. Um dies durchzuführen, geht er mit dem Reim frei um. Diesen hat Culkov zwar sklavisch nachgeahmt, jedoch statt der den Ablauf von Strophe zu Strophe führenden jeweiligen Jahreszeitbezeichnung am Schluß nichtssagende Verbalreime gesetzt. Auch in den mittleren Versen erscheint die liedhafte Anlage in der Ubersetzung nicht wieder.

Bei dem eben Geschilderten handelt es sich um das Grundelement, das Brjusov als "Dynamik" bezeichnet hatte. Es dürfen also alle anderen Elemente vernachlässigt werden, dies ist jedoch besonders genau zu übertragen. Die Anordnung der Reime kann in der Ubersetzung, wie oben gezeigt wurde, ohne weiteres verändert werden, auch das Versmaß ist hier in keiner Weise tragendes Element, braucht in der Ubersetzung also nicht streng durchgeführt zu werden. Ahnliches gilt für die poetischen Bilder. An ihrer Stelle können in einer Ubersetzung bis zu einem gewissen Grade andere verwendet werden, ohne daß der Charakter des Ganzen verliert. Wesentlich ist vielmehr, daß diese Bilder in ihrem Ablauf aufeinander sorgfältig abgestimmt wer- 
den und genau dem Steigen und Fallen der Zentralbegriffe in den drei Terzinen (parents - printemps, amants - automne, enfants hiver) folgen.

Zusammenfassend ergibt sich, daß Culkov von den eingangs von Brjusov aufgezählten Elementen die falschen zur Ubertragung ausgewählt hat. Culkov hat Versmaß und Reim sowie die poetischen Bilder genau ins Russische übertragen, während, wie gezeigt, die Dynamik (in der Terminologie Brjusovs) das tragende Element ist.

Eine so genaue Detaillierung seiner Methoden gibt Brjusov in späteren Aufsätzen, soweit sie Ubersetzungen betreffen, nicht mehr. Jedoch ist es für ihr Verständnis von Wichtigkeit, den Grundgedanken Brjusovs, nämlich auch in diesem Zusammenhang die Aufteilung des Problems in Einzelelemente, zu kennen.

Diese Grundeinstellung Brjusovs kommt auch bei der Ubersetzung von Dramen zum Ausdruck. Er schreibt anläßlich einer Rezension von verschiedenen Ubersetzungen eines Verhaerenschen Dramas:208 „... Vieles ist im Russischen schwächer geworden und hat seinen Glanz verloren; einige Nuancen sind verflacht, verlorengegangen, aber der allgemeine Sinn des Vorwurfs ist richtig wiedergegeben. Beim Drama liegt der Schwerpunkt auf dem Aufbau der Handlung und nicht auf der lyrischen Schönheit einzelner Stellen, und darum genügt eine richtige Ubersetzung, wenn sie auch nicht künstlerisch ist, um sich mit den Gedanken des Dichters vertraut zu machen. ${ }^{{ }_{200}}$

Dies betrifft die Stellen des Dramas, die im Original in Prosa abgefaßt sind. Das wesentliche Element, welches es in die andere Sprache zu übertragen gilt, ist in diesem Falle der Ablauf der Handlung. Dem genügen die besprochenen Ubersetzungen im wesentlichen.

Das einzige, was Brjusov noch dazu bemerkt, sind reine Stilkorrekturen, die zum Teil nicht einmal überzeugend sind. Für die Ubersetzung von "doucement ironique " gibt er "s legkoj ironiej ${ }^{\alpha}$ den Vorzug vor "s nežnoj ironiej", für nje demande " zieht er nja sprašivaju “ vor statt "ja choču znat'“. Das läßt sich allenfalls vertreten. Zweifelhaft erscheint mir jedoch, wenn Brjusov "ubit Erenian " für "on vient d'assassiner Hérénien" besser findet als "tol'ko čto ubili Eren'ena". ${ }^{210}$

208 Emil Verch a rn: Zori. Perev. A. Vorotnikova. M. 1906.

209 V. B r j u s o v: Novye perevody Vercharna. "Vesy “ 1906, IX, S. 77-80. $210 \mathrm{Vgl}$. ibid. 
Neben den Teilen in Prosa enthält das Verhaerensche Drama aber auch Stellen in Versform. Verhaeren verwendet hier ein freies Versmaß, das leicht von der Prosa in die gebundene Rede übergeht und wieder zur Prosa zurückkehrt. Dies scheint Brjusov in unserem Falle das wesentliche Moment der Versdichtung zu sein. Selbstverständlich muß er Einspruch erheben, wenn diese Stellen in strengen Jamben übertragen werden und unmittelbar an die Prosarede eine geschraubte Poesie anschließt. Er geht in diesem Falle sogar so weit, einer Prosaübertragung auch der in Versform verfaßten Stellen den Vorzug zu geben.

An anderer Stelle schreibt Brjusov allerdings: "Ich bin immer noch der Meinung, daß man bei der Ubersetzung von Versen durch Verse bestrebt sein sollte, das Original absolut genau wiederzugeben, es eben zu "übersetzen ", und nicht es "nachzuschaffen “. In der Literatur ist die Ubersetzung das, was in der Malerei die Kopie ist." 211

Die Genauigkeit liegt für Brjusov in der Auswahl des tragenden Elements einer Versdichtung für die Übersctzung, ungeachtet der eigenen dichterischen Einstellung und Ambition des Übersetzers. Darum wehrt sich auch Brjusov gegen die von Maksimilian Vološin anläßlich einer Kritik Brjusovscher Verhaeren-Ubersetzungen geäußerte Ansicht, daß der echte Verhaeren am besten in den eigenen Gedichten Brjusovs zutage trete, die nur von Verhaeren inspiriert seien.

Brjusov entgegnet hierauf: „Die Beispiele für Neuschöpfungen, die Vološin anführt, die Lermontovsche Ubersetzung von Goethes „Uber a!len Wipfeln ist Ruh'“ und Heines "Ein Fichtenbaum ...", überzeugen mich wenig. Ahnlich wie Herr Vološin könnte ich ausrufen: wie sehr ist das Lermontov, und wie wenig erinnert es an Goethe und Heine. ${ }^{212}$

Anlaß zu einer etwas umfangreicheren Arbeit auf dem Gebiet der Ubersetzungstechnik ist für Brjusov das Erscheinen der gesammelten Werke Verhaerens (Polnoe sobranie poèm) in der Ubersetzung von Georgij Sengeli.213 In seiner Rezension dieser Ausgabe gibt Brjusov

211 Die Antwort Brjusovs auf eine Kritik von M. V o l o $§$ i n, Emil Vercharn i Valerij Brjusov. "Vesy“ 1907, II, S. 74-82.

212 ibid.

213 E. Vercharn: Polnoe sobranie poem, v perevode Georgija Sengeli. T. II, M. 1922; T. III, M. 1923; T. IV, M. 1923. 
noch einmal einen Einblidk in seine Ubersetzungstheorie und -technik.214

Gleich zu Beginn des Aufsatzes legt Brjusov seinen Standpunkt klar: „Was bedeutet es, ein Gedicht, ein Poem eines echten, großen Dichters zu übersetzen? In keinem Falle heißt es den Inhalt des Poems in Versen nacherzählen, indem man einige Bilder des Originals beibehält, andere wegen des Metrums oder des Reimes wegläßt, wieder andere durch eigene ersetzt und noch andere hinzuerfindet, wieder um des Reimes willen. Statt dessen ist es bedeutend besser, ehrlicher und nützlicher, eine genaue Übersetzung in Prosa zu geben. In einer solchen wären wenigstens alle Gedanken und alle Bilder des Originals enthalten. ${ }^{\alpha 16}$

Die Auflösung der Form in Elemente verlangt Brjusov hier nicht ausdrücklich. Er faßt vielmehr die Forderungen, die er an einen Ubersetzer stellt, allgemein zusammen: „Verse schreibt man deshalb, um mehr auszudrücken, als mit Hilfe der Prosa möglich ist. Der Aufbau eines ganzen Gedichtes und der Aufbau einzelner Sätze (allgemeine und spezielle Komposition), sowie der Wortklang, der klangliche Aufbau (Alliterationen, Instrumentovka, Zvukopis', E u p h o$n$ i e überhaupt) haben in Versen eine ebenso große Bedeutung wie Gedanken und Bilder. Besonders Verskomposition und Verseuphonie unterscheiden Verse von Prosa, sie geben die Möglichkeit, mit Versen einen größeren Eindruck hervorzurufen als mit Hilfe der Prosa. Wenn man den klanglichen Aufbau nicht beachtet, wird es absolut unverständlich, wozu andere in Versen schreiben, es sei denn für Leser, die für nüchterne Prosa noch nicht reif sind!“216

Im Grunde beruhen diese Forderungen doch wieder auf einer Auflösung der Gesamtform in verschiedene Elemente und laufen darauf hinaus, eben alle diese Elemente zu beachten. Geändert hat sich gegenüber dem Aufsatz von 1905 die entsprechende Terminologie, ebenso ist auch die Gliederung und Abgrenzung der Elemente untereinander straffer geworden. Sie entspricht der im vorigen Kapitel geschilderten Verslehre. Versmaß und Reim sowie die Bezeichnung "poetische Bilder" (obrazy) hat Brjusov von früher beibehalten. Der Begriff „Dynamik des Verses“ ist zur „allgemeinen und speziellen

214 V. B r jus ov: Vercharn na Prokrustovom lože. „Pec. i rev. ${ }^{\alpha}$ 1923, III, S. $34-44$.

215 ibid.

218 ibid. 
Komposition“ geworden. Der Begriff "Spiel mit Silben und Klän-

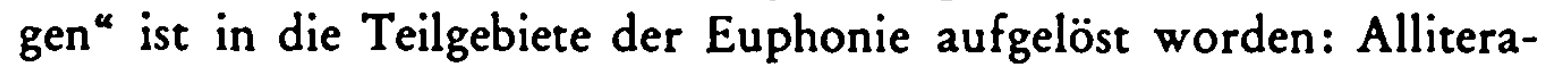
tionen, Instrumentovka, Zvukopis'.

Betrachtet man von diesem Gesichtspunkt aus die detaillierte Kritik an Sengelis Ubersetzungen, dann ergibt sich ein einheitliches Bild. Wie Brjusov in der Einleitung schon angedeutet hatte, begnügt sich Sengeli im wesentlichen damit, den rein sachlichen Inhalt, das Metrum und den Reim in der Obersetzung wiederzugeben. Also nach Brjusovs Einteilung nur e in formales Element. Dadurch, daß sich Sengeli stets der gleichen Methode (in der Terminologie Brjusovs) bedient, muß er notgedrungen früher oder später auf Werke stoßen, bei denen diese Methode nicht zutreffend ist, bei denen ein anderes formales Element als Metrum und Reim das zentrale ist.

Brjusov bespricht als erstes ein Gedicht, das erstmals von Sengeli übersetzt wurde, im Detail. Der Text des Originals lautet:

\section{Les armesdu soir}

Tandis que la nuit froide étage sa terrasse

Par au-delà des bruyères et des forêts,

Le soir qui meurt, le soir jette sur les marais,

L'éclair de son épée et l'or de son armure,

Qui vont flottant au flot le flot, flottant et vains,

A peine encor frôlés par la splendeur diurne, Mais lentement baisé, par la lèvre nocturne

De la lune pieuse et douce, au mains d'argent,

Seule, qui se souvient du jour, pâle évoquée. Et des grands ciels brandis avec de l'or au clair, Pâle évoquée, eu la pâleur pâle de l'air

Eternellement pâle et lointaine, la lune!

Als das formal tragende Element dieses Gedichtes bezeichnet Brjusov die Tatsache, daß alle drei Strophen einen Satz, eine Phrase bilden, mit einem Subjekt: le soir (der Abend), also mit Brjusovs alter Terminologie die Dynamik, mit der hier verwendeten Terminologie die allgemeine Komposition des Gedichtes. Gerade dieses Element ist in der Ubbersetzung Šengelis verlorengegangen. „Bei Sengeli ${ }^{\alpha}$, schreibt Brjusov, „sind es mehrere Phrasen, meh- 
rere Subjekte, und nach der zweiten Strophe steht sogar ein Punkt. Der ganze Aufbau des Gedichtes ist zerstört (oder nicht verstanden?). Deswegen geht Schritt für Schritt, Zeile für Zeile eine Entpersönlichung, eine Vereisung des Originals vor sich. “217 Zum Vergleich sei hier die russische Übersetzung Šengelis wiedergegeben:

Kogda voschodit noč' $\mathrm{v}$ cholodnom nebosklone

I nad kustarnikom, nad roščami plyvet

I večer merknuščij ronjaet $\mathrm{v}$ glub' bolot

Blesk mečnoj molnij i zlato tjažkoj broni

Besplodnym plamenem drožaščie $\mathbf{v}$ volne,

Ȩ̌̌̌e chranjaščie veličie dnevnoe,

No medlenno darit lobzanie nočnoe

Luna besstrastnaja v svoem legčajšem sne.

Luna, - ona odna mečtan'e sochranila

O nebe, čto gorit, vse v zolote ognej,

O blednom vozduche sred' palevych tenej,

Naveki blednoe, dalekoe svetilo.

Die allgemeine Komposition des Originals ist in dieser Ubersetzung zerstört. Der bewußt verbindende Ubergang von Vers zu Vers ist jeweils durch ein abruptes Ende des einen Verses und einen ebensolchen Anfang des nächsten Verses, der dem ganzen Satzbau nach keine Bindung zum vorhergehenden zuläßt, ersetzt. Um die Behandlung der poetischen Bilder zu verfolgen, die mehr als nötig gelitten haben, gibt Brjusov Zeile für Zeile eine kurze Analyse des Originals und der Ubersetzung. So schreibt er z. B. zum dritten und vierten Vers: „Die im höchsten Grade für den Stil Verhaerens charakteristische Wiederholung des Wortes "Abend" wird bei Sengeli fallengelassen; nder Blitz des Schwertes", d. h. die Personifizierung des Abends im Bild eines Ritters mit Schwert und Rüstung, die einen Widerschein im Wasser des Sunpfes geben, ist unsinnigerweise durch einen nicht an diese Stelle gehörenden Blitz ersetzt. ${ }^{\alpha 218}$

Dies sind bereits Probleme der ${ }_{n}$ speziellen Komposition “. Brjusov deckt noch weitere Unzulänglichkeiten in dieser Hinsicht auf: "Nicht zu bemerken, daß das Wort ,blaß, ,Blässe' im Original $f$ ü $n f \mathrm{~m}$ a $l$ wiederholt wird, und es nur $z$ weimal zu wiederholen, es das

217 ibid.

218 ibid. 
drittemal durch irgendein "Strohgelb“ (palevost') zu ersetzen; die zweimalige Wiederholung des Bildes "Gespenst " nicht zu bemerken; nicht zu bemerken, daß die kurzen Wörter im letzten Vers absichtlich mit dem mehrsilbigen "éternellement " abwechseln; daß als letztes Wort im letzten Vers nicht zufällig "Mond" steht usf., das bedeutet, den ganzen Stil, den ganzen Aufbau des Originals ertöten. ${ }^{\text {"210 }}$

Allerdings scheint Brjusov, was seine Anforderungen an einen Ubersetzer betrifft, anspruchsvoller geworden zu sein, als er es 1905 war. Damals verlangte er, daß bei der Übersetzung ein Element, "bestenfalls" $z$ wei in die andere Sprache übertragen werden sollten. In dem vorliegenden Falle wäre das die Dynamik, d.h. die allgemeine und die spezielle Komposition. "Doch das ist noch nicht alles", fährt Brjusov fort, "der Eindruck von diesen Versen Verhaerens verzehnfacht sich durch den ${ }_{\text {zzvukopis' }}$; die Laute der einzelnen Wörter bilden hier ein feines, kompliziertes Muster, von dem sich in der Ubersetzung nicht einmal eine Andeutung findet. Ohne ins Detail zu gehen, sei hier nur auf eine Stelle hingewiesen, wo der ,zvukopis" direkt ins Auge fällt:

Qui vont flottant au flot le flot, flottant et vains ...

Der ganze Vers ist auf der Wiederholung der Laute $v$ und $f$ aufgebaut, $z \mathrm{u}$ denen $t$ hinzukommt und die Nasale vont, flottant, vains ... Bei G. Šengeli steht stattdessen:

„Besplodnym plamenem drožaščie $\mathrm{v}$ volne ... ${ }^{\text {«220 }}$

Hier handelt es sich bereits nicht mehr um die reine Komposition, sondern ausgesprochen um das e $\mathrm{u} \mathrm{ph}$ o $\mathrm{n}$ i $\mathrm{s} \mathrm{ch}$ e Element eines Verses, um das, was Brjusov früher als "Spiel mit Silben und Klängen" bezeichnet hatte. Man ist versucht, Brjusov recht zu geben, denn es handelt sich dabei um einen ins Auge fallenden Zug des Gedichts. Wieweit sich aber auch dieses Element, zusätzlich zur Komposition, vollständig in eine andere Sprache übertragen läßt, bleibe dahingestellt. Eine Andeutung dieses ${ }_{n}$ zvukopis' ${ }^{\prime \prime}$ in der Ubersetzung dürfte wohl genügen, um das Werk vor Entstellung zu bewahren.

Brjusov analysiert in seinem Aufsatz noch verschiedene andere von Sengeli übersetzte Verse mit ähnlichen Ergebnissen. Zum Teil verweist er dabei auf eine eigene Ubersetzung des betreffenden Werkes,

219 ibid.

220 ibid. 
die schon vorher erschienen war, um zu zeigen, daß es möglich ist, den betreffenden Kunstgriff in der Ubersetzung wiederzugeben.

Interessant ist, daß der von Brjusov kritisierte Ubersetzer, G. Šengeli, diese Kritik in keiner Weise ruhig hinnimmt und nun seinerseits einen Aufsatz gegen Brjusov veröffentlicht.221 Dort beklagt sich Sengeli über eine ungerechte Kritik an seinen Ubersetzungen. Er hält als Argument Brjusov entgegen, daß dieser immer Ubersetzungen von sich selbst anführe, wenn an diesen nichts auszusetzen sei. Dabei seien die Ubersetzungen Brjusovs gar nicht so gut. Sengeli führt Beispiele an, in denen die Brjusovsche Obersetzung nicht einmal den von Brjusov selbst aufgestellten Forderungen entspreche.

Einen solchen Anwurf kann Brjusov natürlich nicht unbeantwortet lassen. Eine Erwiderung ist daher auch im gleichen Heft, anschlieBend an den Aufsatz Šengelis abgedrudkt.222

Brjusov verwahrt sich ganz entschieden dagegen, eine Polemik auf unsachlicher Ebene zu führen. Ob die Ubersetzungen von Valerij Brjusov gut oder schlecht seien, schreibt er, ob sein Aufsatz aus dem Jahre 1907, den Sengeli ihm ebenfalls zum Vorwurf gemacht hatte, scharf gewesen sei oder sanft wie ein Lamm, die Ubersetzungen von Georgij Sengeli würden dadurch nicht besser. Die Tatsache, daß er Ubersetzungen von sich selbst in der Kritik anführe, verteidigt er damit, daß er sie nur deshalb angeführt habe, um zu zeigen, daß man Verse dem Original getreuer übersetzen $\mathrm{k}$ a $\mathrm{n} n$. Selbstverständlich habe er zu diesem $Z$ weck solche Verse ausgewählt, deren Obersetzung einwandfrei das beweise, was er zeigen wollte.

Wieweit Brjusovs Theorie des Obersetzens tatsächlich seiner wirklichen Kunstauffassung entspricht, soll im folgenden an Ubersetzungen von Brjusov selber im Vergleich mit dem betreffenden Original gezeigt werden.

Aus der Arbeitsweise eines Ubersetzers kann man ersehen, wieweit der betreffende in das Kunstwerk in der anderen Sprache eingedrungen ist, wie er es interpretiert. Um dies zu untersuchen, ist das Brjusovsche Schema der Elemente ein brauchbares Hilfsmittel. Die Ergebnisse der folgenden Untersuchungen können naturgemäß nur die formale Seite von Brjusovs Kunstauffassung beleuchten.

221 G. Se ng e li: Valerij Brjusov meždu dvuch stul'ev. „Pex̌. i rev.“ 1923, VI, S. 78-84.

222 V. B r j u s o v: Otvet Georgiju Sengeli. „Peč. i rev. ${ }^{\star}$ 1923, VI, S. 85-86. 
Neben zahlreichen Obersetzungen französischer Lyrik hat sich Brjusov vor allem durch eine Obersetzung von Goethes ${ }_{n}$ Faust $^{\alpha}$ verdient gemacht. Der ${ }_{\text {Faust }}{ }^{\alpha}$ bietet reichhaltiges Material verschiedener Versformen und ist daher für eine Ubersetzungsanalyse besonders ergiebig.

Im folgenden sollen drei Beispiele angeführt werden: die erste Strophe der ${ }_{n} Z$ Zueignung ${ }^{\alpha}$, der Anfang des Monologes und die Anrufung des Erdgeistes.

Das Original:

Ihr naht euch wieder, schwankende Gestalten!

Die früh sich einst dem trüben Blick gezeigt.

Versuch' ich wohl, euch diesmal fest zu halten?

Fühl' ich mein Herz noch jenem Wahn geneigt?

Ihr drängt euch zu! Nun gut, so mögt ihr walten,

Wie ihr aus Dunst und Nebel um mich steigt;

Mein Busen fühlt sich jugendlich erschüttert

Vom Zauberhauch, der euren Zug umwittert.

Diese Verse lauten in der Brjusovschen Ubersetzung:

Vnov' bliziצ'sja ty, zybkij roj videnij,

Čto prežde smutno rejal nado mnoj.

Rešus' li dat' im jasnost' voploščenij,

Pozvolju l' serdcu slit'sja s toj mečtoj?

Tesnites' vy! Nu, čto ž! Vchodite, teni,

Roždennye tumanami i mgloj.

Po-junǒ̌eski grud' moja trepeščet

V dychan'i čar, v kotorom put' vaš bleščet.223

Der Untersuchung dieses und der folgenden Beispiele soll folgendes Schema von wesentlichen Elementen zugrundegelegt werden:

1) Metrum

2) Reim

3) Poetische Bilder

4) Dynamik des Verses (bei unseren Beispielen handelt es sich dabei ausschließlich um die "spezielle Komposition ${ }^{\alpha}$ )

5) Spezielle Euphonie ( ${ }^{2}$ vvukopis' $^{3}$ und ,instrumentovka ${ }^{a}$ ).

Das Metrum ist beim ersten Beispiel korrekt in die Ubersetzung übernommen worden. Lediglich die Anordnung der Pyrrhichien

:23 Gete: Faust. Perevod Valerija Brjusova. Moskau-Leningrad 1928. 
ist geringfügig verändert. Das stört jedoch den Rhythmus der Verse nicht, da die Zäsuren in der Übersetzung fast auf die Silbe genau denen des Originals entsprechen. Die Verteilung von weiblichen und männlichen Versenden ist in der Übersetzung die gleiche wie im Original.

Das $\mathrm{R}$ e i m schema des Originals, abababacc - die Oktave -, ist in der Úbersetzung genau wiedergegeben.

Brjusov hat also Metrum und Reim als wesentliches Element dieser Verse gewertet und dementsprechend sorgfältig übertragen.

Die poetischen Bilder hat Brjusov, soweit es Versmaß und Reim zuließen, übernommen (die beiden letzten Zeilen), sonst jedoch leicht verändert. Der Eindruck des Ganzen leidet darunter nicht.

Die innere Komposition wurde sehr sorgfältig in der Übersetzung wiedergegeben (Anschluß des zweiten Verses durch Relativpronomen, Gegenüberstellung Aufforderung-Zugeständnis im fünften Vers usw.).

Was die e u phon is che n Figuren (Alliterationen) betrifft, soweit sie hier im Original überhaupt aufspürbar sind, so hat sie Brjusov zum Teil übernommen, zum Teil zugunsten anderer Elemente fallengelassen. In der ersten Zeile ist bei Goethe offensichtlich a der tragende Laut, in der zweiten Zeile $\ddot{u}$ und $i$ :

Ihr naht euch wieder, schwankende Gestalten!

Die früh sich einst dem trüben Blick gezeigt.

Brjusov ersetzt das a der ersten Zeile durch y (bzw. i), das $\ddot{u}-i$ der zweiten Zeile durch e, welches er an die gleichen Stellen setzt, wie im Original die semantische Gegenüberstellung betonend:

Vnov' blizis'ja $t y, z y b k i j$ roj videnij,

Ċto prežde smutno rejal nado mnoj.

Auf die Wiedergabe der z-Alliteration in der letzten Zeile hat Brjusov verzichtet.

Aus dem Gesagten läßt sich erkennen, daß Brjusov als die tragenden formalen Elemente dieses Verses Metrum und Reim einerseits, Komposition andererseits annimmt. Es ist ihm gelungen, beide Elemente dem Original getreu in der Übersetzung wiederzugeben.

Vom nächsten Beispiel seien ebenfalls Original und Obersetzung nacheinander angeführt: 
Habe nun, ach! Philosophie,

Juristerei und Medizin,

Und, leider! auch Theologie

Durchaus studiert, mit heißem Bemüh'n.

$\mathrm{Da}$ steh ich nun, ich armer Tor!

Und bin so klug, als wie zuvor;

Heiße Magister, heiße Doktor gar,

Und ziehe schon an die zehen Jahr,

Herauf, herab und quer und krumm

Meine Schüler an der Nase herum -

Ach, v filosofiju ja vnik,

I $\mathbf{v}$ medicinu, i v prava,

Cital, uvy, kak učenik,

I bogoslovskie slova!

I vot ja vse ž stoju glupcom

I ne umnej, čem byl $\mathrm{v}$ bylom.

Ja stal magistr, vošel v rjad doktorov,

Desjaty god - učenikov

Tuda, sjuda, vpered, nazad

vožu ja za nos naugad -224

Das M e trum ist in der Ubersetzung insofern verändert, als an die Stelle des Knittelverses der vierfüßige Jambus tritt.

Das $\mathrm{R}$ e i m schema ist vollständig in die Ubersetzung übernommen worden.

Die poetischen Bilder sind dort, wo das Metrum beibehalten ist, leicht verändert worden, sonst beibehalten (die drei letzten Zeilen).

Die D y n a mik entspricht hier fast dem Original. Lediglich hat Brjusov in der dritten Zeile das Polysyndeton wegen des russischen Satzbaues durch das Prädikat unterbrechen müssen. Das Polysyndeton ist in der vorletzten Zeile durch ein Asyndeton ersetzt worden, um das Metrum beizubehalten.

Die E u ph on ie des Originals hat Brjusov sehr sorgfältig übertragen. Auf zwei Stellen sei hier hingewiesen:

224 ibid. 
Habe nun, ach! Philosophie,

Juristere $i$ und Medizin

Und, leider! auch Theologie ...

Im Original ist $\mathrm{i}$ der tragende Laut (bzw. ei). In der Ubersetzung ist das entsprechend wiedergegeben. Brjusov kam dabei zustatten, daß die Fremdwörter in beiden Sprachen gleichlautend sind, trotzdem hat er das poetische Bild zugunsten des euphonischen Effektes leicht verändert:

Ach, v filosofiju ja vnik

$I \mathrm{v}$ medicinu, $i \mathrm{v}$ prava,

Čital, uv $y$, kak učenik, ...

Desgleichen ist die kunstvolle anaphorische Alliteration bei Goethe:

Herauf, herab und quer und krumm ...

bei Brjusov als Epiphora wiedergegeben:

Tuda, sjuda, vpered, nazad ...

Zusammenfassend kann gesagt werden, daß die in der Ubersetzung wiederholten euphonischen Kunstgriffe im wesentlichen für die weitgehende lautliche Gleichheit von Original und Ubersetzung verantwortlich sind. Jeweils ein weiteres Element für die Ubertragung wählt Brjusov von Vers zu Vers verschieden aus (Metrum in den ersten drei Zeilen, ferner Dynamik, Bild in den letzten beiden Zeilen).

Zum Vergleich sei die gleiche Stelle auch in der Ubersetzung Boris Pasternaks einer Untersuchung nach denselben Gesichtspunkten unterzogen. Bei Pasternak lautet diese Stelle wie folgt:

Ja bogoslov'em ovladel,

Nad filosofiej korpel,

Jurisprudenciju dolbil

I medicinu izučil.

Odnako ja pri ètom vsem

Byl i ostalsja durakom.

$\mathrm{V}$ magistrach, $\mathrm{v}$ doktorach chožu

I za nos desjat' let vožu

Učenikov, kak bukvoed,

Tolkuja tak i sjak predmet. ${ }^{225}$

225 G e t e: Faust. Perevod so nemedkogo B. Pasternaka. Moskau 1957, S. 55. 
Wie bei Brjusov wird auch hier statt des Knittelverses der vierfüßige Jambus als $M$ e $\mathrm{trum}$ verwendex.

Das $\mathrm{R}$ e im schema entspricht im wesentlichen dem Original. Lediglich die Verbalreime in den ersten vier Zeilen stellen eine Abschwächung dar.

Die poetischen Bilder des Originals sind zwar bis zu einem gewissen Grade in die Ubersetzung aufgenommen, jedoch zum Teil ergänzt worden. So finden wir in den letzten drei Zeilen unseres Beispiels das Bild des „bukvoed ${ }^{\alpha}$, was eine Erweiterung des Ursprünglichen ergibt.

Die D y n a m ik wurde in der Pasternakschen Obersetzung weitgehend verändert. Die Interjektionen in der ersten und dritten Zeile fehlen, das Polysyndeton des ersten Satzes wurde durch Einfügung jeweils verschiedener Prädikate zu den einzelnen Teilen aufgelockert, die Hervorhebung der Theologie gegenüber den anderen Wissenschaften wurde fallengelassen, das Polysyndeton der vorletzten Zeile durch Einführung eines neuen Bildes ersetzt.

Die e u phonis chen Effekte des Originals blieben hier vom Ubersetzer weitgehend unbeachtet. Lediglich die im Original durch die Figur des Polysyndetons hervorgehobene Alliteration der vorletzten Zeile wurde in den beiden letzten Zeilen der Obersetzung durch eine weniger stark wirkende ersetzt:

UČenikov, kak bukvoed,

Tolkuja tak i sjak predmet.

Im Gegensatz zu Brjusov, der die Kunstgriffe des Originals in der russischen Fassung wiederzugeben versucht, hat Pasternak besonders auf einen zurüdkgegriffen, der für seine eigene Dichtung charakteristisch ist: den Reichtum an poetischen Bildern, die oft ineinander versponnen werden. So entstehen hier in den ersten vier Zeilen durch die neu eingeführten verschiedenen Prädikate vier verschiedene Bilder. Auch sei nochmals auf das in den beiden letzten Zeilen neu eingeführte, bereits erwähnte Bild hingewiesen.

Die dritte Stelle, die hier betrachtet werden soll, gilt als besonders gelungene UUbersetzung Brjusovs:

Es wölkt sich über mir -

Der Mond verbirgt sein Licht -

Die Lampe schwindet! 
Es dampft! - Es zucken rote Strahlen

Mir um das Haupt - es weht

Ein Schauer vom Gewölb' herab,

Und faßt mich an!

Ich fühl's, du schwebst um mich, erflehter Geist.

Enthülle dich!

$\mathrm{Ha}$ ! wie's in meinem Herzen reißt!

$\mathrm{Zu}$ neuen Gefühlen

All' meine Sinnen sich erwühlen!

Ich fühle ganz mein Herz dir hingegeben!

Du mußt! du mußt! und kostet' es mein Leben.

Temneet vokrug menja,

Skryvaet svet luna,

I merknet lampa!

Mrak! - alye luči sverkajut

Nad golovoj. - Nischodit

$S$ vysokich svodov užas, i menja

Ochvatyvaet drož'.

Ja Čuvstvuju, ty blizko, moščnyj duch!

Javis'!

O, kak trepeščet serdce vdrug!

$\mathrm{V}$ poryve novom

Vse čuvstva polny strastnym zovom!

Kto mne želannyj put' $k$ tebe otkroet?

Ty dolžen! Dolžen! Pust' to žizni stoit!226

$\mathrm{Da}$ das Versm a $B$ bei dieser Stelle offensichtlich eine untergeordnete Rolle spielt, erscheint es in der Ubersetzung meist in anderer Form. Lediglich die Zäsurstellen sind beibehalten worden. Wahrscheinlich hat der Ubersetzer ihnen einige Wichtigkeit beigemessen.

$\mathrm{R} e \mathrm{i} \mathrm{m}$ ist bis auf die letzten vier Zeilen keiner vorhanden. Dort wurde er in die Ưbersetzung mit aufgenommen.

Die poe tische n Bilder sind - bis auf das in der vorletzten Zeile - in Original und Úbersetzung die gleichen.

Die Komposition ist in der Ubersetzung die gleiche wie im Original. Lediglich die in der Übersetzung besonders enge Bindung von Zeile 6 auf 7 ist im Original in dieser Form nicht vorhanden.

220 Gete: Faust. Perevod Valerija Brjusova. 
Die e u phonischen Effekte des Originals sind in der Ubersetzung meisterhaft wiedergegeben. Die als Epiphora angeordneten Dentale ( $t, d)$ im Original:

Der Mond verbirgt sein Licht ...

erscheinen in der gleichen Form wieder in der Ubersetzung:

Skryvaet svet luna ...

Ebenso die Nasale $(m, n)$ in Zeile 11 und 12:

$\mathrm{Zu}$ neuen Gefühlen

All' meine Sinnen sich erwühlen!...

In der Ubersetzung:

\section{$\mathrm{V}$ poryve novom}

Vse čuvstva polny strastnym zovom! ...

In der letzten Zeile sind wieder Dentale das tragende lautliche Element:

Du mußt! du mußt! und kostet' es mein Leben.

Dem entspricht ähnlich angeordnet:

Ty dolžen! Dolžen! Pust' to žizni stoit.

Bei dieser Stelle ist es Brjusov gelungen, von fünf Formelementen vier in der Ubersetzung dem Original getreu wiederzugeben. Hier hat Brjusov gezeigt, in welchem Maße man manchesmal die sprachlichen und klanglichen Feinheiten eines poetischen Kunstwerkes in einer anderen Sprache wiedergeben kann, ohne deren Aufbau zu mißachten.

Ein weiteres Meisterwerk Brjusovscher Ubersetzungskunst ist seine Ubertragung von Vergils Aneis ins Russische. Leider war es ihm nicht vergönnt, das Werk zu vollenden. So mußten in der 1933 erschienenen Ausgabe 227 die letzten fünf Gesänge in der Ubersetzung eines anderen, nämlich von Sergej Solov'ev, gebracht werden.

In der Vorbemerkung zu dieser Ubersetzung erklärt Brjusov selbst seine Methode: ${ }_{n}$ Bei der Ubersetzung vieler Verse mußte ich mir zu meinem Bedauern oft bewußt werden, daß dieser oder jener Zauber des Originals in meiner Ubertragung verschwindet. Aber ich bemühte mich stets zu erraten, was gerade in dem betreffenden Vers dem Dichter selbst besonders teuer war, und dieses ${ }_{n}$ dem Dichter beson-

227 Vergilij: Eneida. Moskau-Leningrad 1933. 
ders Teure" versuchte ich im russischen Vers beizubehalten. Zuweilen bemühte ich mich, die Musik des Verses zu übertragen, indem ich sogar die wörtliche Genauigkeit der Ubersetzung opferte. Ein andermal hingegen verwischte das Bild im Vers etwas anderes, und ich suchte entsprechende Ausdrüdke im Russischen, ohne mir dabei Sorgen um den Zusammenfall von Lauten der einzelnen Wörter zu machen. Stellenweise mußte ich Alliterationen verändern und mich anderer Laute bedienen als Vergil usw. ${ }^{\text {"228 }}$

Als besonders wichtiges Element wertet Brjusov die Euphonie bei Vergil. Zur Erläuterung seien hier einige Verse erörtert, die der Obersetzer selbst in seinem Vorwort erwähnt. Er weist dort darauf hin, daß in diesen und ähnlichen Fällen von anderen Ubersetzern (Fet, Kvašnin-Samarin) die Euphonie Vergils überhaupt nicht beachtet wurde.

Vers 87 z. B. lautet:

insequitur clamorque virum stridorque rudentum.

Brjusov analysiert diesen Vers: „Es besteht kein $Z$ weifel, daß die Seele dieses Verses in seinen Alliterationen auf den Buchstaben $r$ liegt, der in jedem der fünf Wörter vorkommt. ${ }^{2220}$ Dazu führt Brjusov die Ubersetzung Fets als Beispiel an:

Sleduet vopli mužej, zatem i stony kanatov.

"Die schwache Alliteration auf $n$ in den beiden letzten Wörtern stellt das Ganze selbstverständlich nicht wieder her." Dabei ist anzunehmen, daß Fet sich der erwähnten Alliteration überhaupt nicht bewußt war. Die entsprechende Ubersetzung von Kviašnin-Samarin lautet:

Vozglasy slyšny mužej i snastej korabel'nych skripen'e.

Dazu schreibt Brjusov, daß der Laut $r$, der nur in den beiden letzten Wörtern vorkommt, ebenfalls nicht genüge. Zum Vergleich sei hier die Ubersetzung von Brjusov selber angeführt:

Vsled korabel'ščikov krik prozvučal i kripen'e verevok.

Die Alliteration Vergils ist hier fast unverändert wiedergegeben.

Als nächstes Beispiel möge der Vers 123 dienen:

accipiunt inimicum imbrem rimisque fatiscunt.

228 ibid. S. 43.

229 ibid. S. 42. 
„... die Alliteration liegt hier auf den Buchstaben $\mathrm{i}$ und $\mathrm{m}^{\alpha}$, schreibt Brjusov. „Nicht einer der Übersetzer hat auch nur versucht, diese Alliteration wiederzugeben oder sie durch eine andere zu ersetzen “. Es folgen die Übersetzungen von Fet und Kvašnin-Samarin:

und

Vosprinimajut volnu vraždebnuju, ščeli razdvinuv

Ljutuju vlagu priemljut oni i už trščiny dali.

Hier sei bemerkt, daß Briusov bei der Übersetzung von Fet offensichtlich entgangen ist, daß hier durchaus eine Alliteration vorliegt. Wieder sei dem die Übersetzung Brjusovs gegenübergestellt:

Vlagu vraždebnuju emljut oni, rassedajas' ot ščelej.

An dieser Stelle ist es Brjusov nicht gelungen, das Lautbild in der gleichen Form in der Übersetzung wiederzugeben. Er versucht einen annähernden Effekt wenigstens durch eine im Vergleich schwache e-Alliteration zu erreichen, der weniger die Aussprache zugrunde liegt als vielmehr das Schriftbild. In der darauf folgenden Zeile hat Brjusov wieder die Alliteration auf $m$ im Original in der Ubersetzung weitgehend genau wiedergeben können:

heißt bei Brjusov:

Interea magne misceri murmure pontum

A meždu tem, čto velikim roptaniem pont pomutilsja ...

Einen guten Einblick in die Arbeitsweise Brjusovs gibt auch der Vers:

quarum quae forma pulcherrima, Deiopea.

Dazu schreibt Brjusov: „Die Euphonie dieses Verses besteht darin, daß die ersten Worte auf $r$ alliterieren, was ihnen eine gewisse Strenge gibt; dem ist das letzte Wort vortrefflich gegenübergestellt, das fast nur aus Vokalen besteht ${ }^{\alpha}{ }^{230}$ Brjusov löst dieses Problem folgendermaßen:

Tu, čto krasoj vsech drugich privlekatel'nej, Dejopeju ...

Neben Übersetzungen aus den großen Literatursprachen des Abendlandes hat sich Brjusov auch an der Ubersetzung von Versen aus weniger allgemein bekannten Sprachen versucht. Wir finden von ihm Ubertragungen aus dem Finnischen, Armenischen, Lettischen. Es soll im folgenden die Ubersetzung einiger Gedichte des hervor-

230 ibid. 
ragenden lettischen Dichters Jānis Rainis besprochen werden, um zu zeigen, wie hemmend sich auch bei einem Meister der Übersetzungskunst wie Brjusov mangelnde Sprachkenntnis auswirken kann.

$\mathrm{Zu}$ beachten ist bei den folgenden Beispielen, daß in allen drei Gedichten das poetische Bild des Ganzen wie auch die einzelnen Bilder eine überragende Rolle spielen. Das erste Gedicht lautet im Original:231

Z a là pavēni.

Sāk leni slēgties sirdì vāts,

Kas ilgus gadus čūlājusi,

Tik ilgus, ilgus tukšus gadus --

Tu mazo rocinu man klusi

Uz vargo sirdi uzlikusi:

Sirds atkal silst, un staro prāts,

Un aizmirsta dzila, dzila vāts.

Sirds karstā, klusi!

Grūts celš tev priekšāa, drīz, drīz tevi cels, -

Dusi vēl, dusi2s2

Und in der Ubersetzung Brjusovs:

$$
\text { V zelenoj teni. }
$$

Uželi rana zaživet,

Cto dolgo tak sočilas' krov'ju,

Za dnjami den', za godom god?

Ty ruku nežnuju s ljubov'ju

Kladeš na serdce mne, - i, vot,

To serdce, čto sočilos' krov'ju,

231 Die Originalfassung aller drei Gedichte ist der Ausgabe Jānis $R$ a in i s: Raksti. Västeras 1952-53, Bd. I-VII entnommen, die Brjusovschen Ubersetzungen den Izbr. sox.

232 Die deutsche Ubersetzung des Gedichts:

\section{Im grünen Schatten}

Langsam beginnt sich die Wunde im Herzen zu schließen,

Die lange Jahre schwärte,

So lange, lange leere Jahre - - -

Du hast die kleine Hand mir leise

Auf das elende Herz gelegt:

Das Herz wird wieder bewegt, und der Wille strahlt,

Und vergessen ist die tiefe, tiefe Wunde.

Herz heißes, still!

Ein schwerer Weg liegt vor dir, bald, bald wirst du gewedkt, -

Schlummre noch, schlummre! 
Sogreto, - i mečta živet!

No net! Ne bejsja, serdce! Budet!

Tvoj put' ešče dalek, vzgljani,

Poka že spi! Usni! Usni!

Vergleicht man das Versmaß beider Fassungen, so stellt man fest, daß es bis zur vierten Zeile übereinstimmt, dann aber vom Ubersetzer fallengelassen wurde. In der Ubersetzung hat das Gedicht sogar eine Zeile mehr. Das läßt sich durchaus vertreten, denn es handelt sich hier nicht um eine feste Strophenform.

Desgleichen ist der Reim ähnlich angeordnet wie im Original, jedoch ohne dasselbe Schema beizubehalten, was aus dem erwähnten Grunde ebenfalls nicht unbedingt nötig gewesen wäre.

Schwieriger wird die Frage der poetischen Bilder. M.E. machen gerade diese den wesentlichen Reiz des Gedichtes aus. Bei einem Vergleich stellt man fest, daß das Bild der ersten Zeile in der Ubersetzung durch ein anderes, weniger dynamisches ersetzt wird. Während "sāk lēni" ("beginnt langsam") den Vorgang als solchen vergegenwärtigt, gibt „zaživet “ nur die Feststellung einer Tatsache. Das Bild der "leeren Jahre" in der dritten Zeile geht in der Uber-

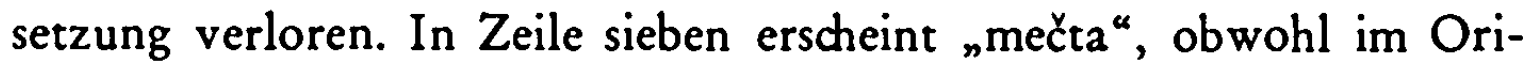
ginal davon nicht die Rede ist, und wirkt an dieser Stelle banal. Wäre in der letzten Zeile die Wiederholung des Ausrufes "Usni!“ unterblieben, entspräche es mehr dem Original.

Brjusov hat sich bemüht, die wichtigsten euphonischen Effekte des Originals wiederzugeben, was ihm allerdings nur teilweise gelungen ist. Die wiederholte Alliteration auf $s$ in der ersten Zeile

Sāk lēni slēgties sirdī vāts ...

erscheint in der Ubersetzung nur in sehr schwacher Form:

Uželi rana zaživet ...

Besser sind die Alliterationen in den beiden darauf folgenden Zeilen getroffen:

Kas ilgus gadus čulājusi

Tik ilgus, ilgus tukšus gadus...

erscheint in der Ubersetzung in der Form:

C'to dolgo tak sočilas' krov'ju,

Za dnjami den', za godom god ...

Die wesentlichen euphonischen Elemente des Originals erscheinen also in der Obersetzung. Dies würde in diesem Falle durchaus genü- 
gen, wären vor allem die poetischen Bilder genau getroffen. Daß dies unterblieben ist, liegt aller Wahrscheinlichkeit nach an ungenügender Sprachkenntnis des Ubersetzers.

Beim folgenden Gedicht liegen die Verhältnisse ähnlich wie beim vorigen:

La uz tās priedes.

Vējư augstākās priedes nolauza,

Kas kāpās pie jūrmalas stāvēja -

Pec tālēm tās skatieniem gribēja sniegt,

Ne slēpties tàs spēja ne muguru liekt:

„Tu lauzi mūs, naidīgā pretvara, -

Vēl cīna pret tevi nav nobeigta,

Vel ilgās pēc tāles dveš pēdējais vaids,

Ik zarā pret varu šnāc nerimstošs naids! ...“

Un augstākās priedes pēc lauzuma

Par kugiem iz ùdeniem iznira -

Pret vētru lepni cilājās krūts,

Pret vētru cīna no jauna dūc:

„Brāz bangas tu, naidīgā pretvara -

Mēs tāles sniegsim, kur laimība!

Tu vari mūs škelt, tu vari mūs lauzt -

Mēs sniegsim tāles, kur saule aust!" ${ }^{23 s}$

${ }^{233}$ Die deutsche Obersetzung des Gedichts:

\section{Die gebrodhenen Kiefern}

Der Wind hat die höchsten Kiefern abgebrochen,

Die in den Dünen am Strande standen -

In Fernen wollten sie mit Blicken reichen,

Sie konnten sich nicht verbergen, nicht den Rüdken beugen:

„Du brichst uns, feindliche Gegenmacht, -

Noch ist der Kampf gegen dich nicht beendet,

Noch Sehnsucht nach Fernen atmet der letzte Seufzer,

In jedem Ast keucht gegen die Macht unaufhörlicher Haß! ..."

Und die höchsten Kiefern ragen nach dem Brechen

Als Schiffe aus dem Wasser -

Gegen den Wind erhebt sich stolz die Brust,

Gegen den Wind braust von neuem der Kampf:

"Laß Wogen toben, feindselige Gegenmacht -

Wir werden die Fernen erreichen, wo Glüdkseligkeit ist!

Du kannst uns spalten, du kannst uns brechen -

Wir werden die Fernen erreichen, wo die Sonne steigt!* 
Brjusov übersetzt wie folgt:

Sosny.

Rjad sosen carstvennych groza slomila,

$\mathrm{Na}$ djunach vstavšich, nad priboem vod.

Smotreli gordo sosny $\mathrm{v}$ nebosvod.

Sklonjat' stvoly im nesterpimo bylo!

„Ty nas slomila, vražeskaja sila!

No my otmstit' sumeem v svoj čered.

Naš vzdoch poslednij o vražde poet,

I v každoj vetke nenavist' počila!"

I sosny vyplyli $\mathrm{v}$ prostor zybej

Svobodnoj staej gordych korablej,

Ich grudi smelo mčatsja protiv buri.

I zakipaet vnov's grozoj bor'ba:

„Bušuj, bezumstvuj, groznaja Sud'ba -

My vse ž prob'emsja $\mathrm{k}$ oblastjam lazuri!®

Auf den ersten Blick fällt auf, daß in der Ubersetzung die vier vierzeiligen Strophen des Originals in Form eines Sonetts erscheinen.

Die poetischen Bilder sind zum Teil in die Úbersetzung mit übernommen, zum Teil jedoch fallengelassen und durch schwächere ersetzt; so finden wir beispielsweise für das eindrucksvolle Bild der „Fernen" ein nichtssagendes "nebosvod“.

Der besondere Effekt, der im Original durch das neugeschaffene Wort "pretvara" ( Gegenmacht $^{\alpha}$ ) entsteht, geht in der Ubersetzung vollkommen verloren, denn an der einen Stelle wird es einfach durch "sila" wiedergegeben, an der zweiten durch großgeschriebenes "Sud'ba“, was dem Ganzen einen anderen Sinn unterlegt.

Als letztes soll hier noch ein Gedicht folgen, ebenfalls von Rainis, dessen Ubersetzung Brjusov besser gelungen ist:

Mans brālis.

Pākāries pāri pār kalna pleciem,

Ilgi mākonis lūkojas lejā

Ezera spogulī pats savā sejā

Drūma un skumja un ilgu pilna. - 
Staigāt un staigāt pār zemēm un jūrām,

Zilus debesu tālumus mērot

Visas pasaules skaistumu vērot,

Savas vietas sev neatrast, -

Savas vietas, kur vielu veidot, Atstāt uz mūžiem dzīvības pēdas,

- Zemei, ak, veldzēt tik kvēlošās bēdas,

Pašam savās asarās gaist. ${ }^{234}$

Moj brat.

Oblako v ozero dolgo smotrelos'

Kak črez plečo, črez vysokij utes:

Mračnoe, grustnoe, polnoe slez,

Oblako $\mathrm{v}$ zerkale vodnom vidnelos'.

Brodiš' i vidis's' i more $i$ sušu,

Meris' lazurnye dali nebes,

Znaeš' krasoty vsemirnych čudes, -

Gde ž uspokoit' ustaluju dušu?

Gde, obretja svoe mesto, ostat'sja,

Sled svoej žizni ostavit' navek,

Skorbi tvoi utoljat', čelovek,-

I samomu - v slezach rastvorjat'sja?

Der Reim, der hier nicht unwichtig ist, ist in der Ubersetzung im wesentlichen korrekt wiedergegeben.

234 Die deutsche Ubersetzung des Gedichts:

\section{Mein Bruder}

Uberhängend über die Schulter des Berges,

Blickt die Wolke lange nach unten

In den Spiegel des Sees, in ihr eigenes Gesicht:

Finster und trübe und von Sehnsucht voll. -

Wandern und wandern über Länder und Meere,

Blauer Himmel Fernen durchmessen,

Aller Welt Schönheit schauen,

Seinen Platz nicht finden, -

Seinen Platz, um da den Stoff zu gestalten,

Zurüdkzulassen auf ewig des Lebens Spuren,

- Der Erde, ach, die so brennenden Leiden lindern,

Selber in seinen Tränen vergehen. 
Die poetischen Bilder, die im einzelnen besonders charakteristisch sind, wurden in der Ubersetzung gut getroffen. Lediglich in der vorletzten Zeile wirkt "čelovek " störend, weil es nicht in das Gesamtbild hineingehört.

Die euphonischen Effekte gehen zum größten Teil in der Obersetzung nicht verloren. Besonders die s-Alliteration des letzten Verses ist gelungen wiedergegeben.

Die obigen Betrachtungen zeigen u. a., daß Brjusov sehr oft bei Ubersetzungen mit rein lautlichen Effekten arbeitet und versucht, diese möglichst dem Original getreu wiederzugeben. Das dürfte wohl das wesentliche Geheimnis seiner Ubersetzungskunst neben der Aufteilung in formale Elemente sein. Dabei sollte man nicht vergessen, daß Brjusov auch in seiner eigenen Lyrik euphonischen Mitteln einen nicht geringen Platz einräumt.

Grammatikalische Fragen und Schwierigkeiten einer inhaltlich sinngemäßen Ubertragung spielen bei seinen Betrachtungen eine mehr untergeordnete Rolle. Das wirft ein bezeichnendes Licht auf seine Kunstauffassung und bestätigt, daß für ihn das formale Element weitgehend im Vordergrund steht. Die Ehrfurcht, die Brjusov vor den formalen Kunstgriffen des fremdsprachigen Dichters beim Ubersetzen hegt, legt einen Vergleich mit der Schule der Formalisten nahe, welche ja ein Kunstwerk überhaupt nach den in ihm angewandten Kunstgriffen (priemy) beurteilt und einordnet.

Gegenstand von Brjusovs Obersetzertätigkeit sind fast ausschließlich Werke in gebundener Rede. 


\section{Literaturkritik und Literaturwissenschaft}

Während bei der Versübersetzung fremdsprachiger Dichtungen $z$ wangsläufig nur die formale Seite von Brjusovs Literaturtheorie zur Anwendung gelangt, ergibt sich im primären Anwendungsgebiet jeder Literaturtheorie, in der Kritik, ein vielseitigeres Bild. Neben dem Formalen spielen in der Literaturkritik Brjusovs noch einige andere Elemente eine wesentliche Rolle.

Es scheint mir zweckmäßig, der Untersuchung von Brjusovs kritischen Arbeiten wiederum die bereits beschriebene Einteilung in drei Perioden zugrunde zu legen. Demzufolge seien die kritischen Arbeiten und Aufsätze der zweiten und dritten Periode Gegenstand der folgenden Erörterungen. Eine Behandlung der ersten Periode ist in diesem Zusammenhang nicht notwendig, da - wie schon erwähnt aus dieser Zeit keine kritischen Arbeiten Brjusovs vorhanden sind.

Ebenso wie Brjusovs Literaturtheorie beschäftigen sich auch seine kritischen Arbeiten ausschließlich mit Versdichtung. Gegenstand seiner Betrachtungen sind sowohl die Verse seiner Zeitgenossen wie auch Werke älterer Dichter. Besonders erwähnenswert sind in diesem Zusammenhang Brjusovs Beiträge zur Puškinforschung, die anschlieBend an diesen Abschnitt einer besonderen Betrachtung unterzogen werden sollen.

In der zweiten Periode befaßt sich Brjusov hauptsächlich, soweit es sich um Zeitgenossen handelt, mit den Werken seiner eigenen Schule, mit den Werken der symbolistischen Dichter (Bal'mont, Vja. Ivanov, Blok, Baltrǔsajtis, Vološin, Z. Gippius usw.). Hierzu gab ihm auch seine Tätigkeit als Redakteur der symbolistischen Zeitschrift "Vesy" (Die Waage) Veranlassung.

Bei einem Vergleich der kritischen Arbeiten der zweiten Periode fällt eine Tatsache besonders ins Auge: Ein wesentlicher Teil der Kritik ist jeweils der Philosophie, der Weltanschauung ( canie ${ }^{\alpha}$ ) gewidmet. Die Form der jeweils besprochenen Verse wird meist nur kurz und mehr allgemein besprochen, im Gegensatz zu 
später, wo Brjusov sich im wesentlichen mit der formalen Seite der betreffenden Verse befaßt.

Diese Tatsache läßt sich wohl am besten mit Brjusovs Auffassung der Kunst als Weg der Erkenntnis erklären.

„Verse sind immer eine Beichte. Der Dichter schafft vor allem deshalb, um sich selbst seine Gedanken und Erregungen zu erklären. So hat der prähistorische Mensch, als die Sprachschöpfung noch lebendig war, ein Wort geschaffen, um einen neuen Gegenstand zu begreifen. Darum kann die wahre Poesie nicht unaufrichtig sein. In den wenigen ausgesuchten Worten eines Verses sind (dem Dichter oft nicht bewußt) die aufrichtigsten Geständnisse verborgen, sind die geheimsten Tiefen der Seele geöffnet. ${ }^{\alpha 235}$ So gesehen ist es einleuchtend, daß diese ${ }_{n}$ geheimsten Tiefen der Seele ${ }^{\alpha}$ vor allem anderen Gegenstand einer kritischen Betrachtung sein müssen.

Als Beispiel für diese Arbeitsweise Brjusovs sei an erster Stelle der ausgezeichnete einleitende Aufsatz zu der 1911 bei A. F. Marks in Petersburg erschienenen Gesamtausgabe der Werke Tjutčevs genannt. 286 Der erste Teil dieses Aufsatzes ist auschließlich der Biographie Tjutčevs gewidmet und in diesem Zusammenhang weniger von Interesse. Der zweite Teil befaßt sich mit dem Werk des Dichters.

Schon der Titel weist auf die Art der Behandlung des Gegenstandes hin: "Smysl ego tvorčestva" (Der Sinn seines Schaffens). Von den vier Kapiteln, in die der Aufsatz unterteilt ist, befassen sich drei mit der Weltanschauung des Dichters.

Brjusov bemüht sich um eine genaue Analyse der Philosophie Tjutčevs. Es gelingt ihm, eine recht umfassende Formel dafür zu finden. "Den Ausgangspunkt der Weltanschauung Tjuť̌evs", schreibt er, "kann man, wie uns scheint, in den beachtenswerten Versen finden, die den Titel tragen "Po doroge vo Vščiž “ :

Priroda znat' ne znaet o bylom,

Ej čuždy naši prizračnye gody,

I pered nej my smutno soznaem

Sebja samich - lis' grezoju prirody.

${ }_{235}$ V. B r jus ov: Vladimir Solov'ev, smysl ego poézii. "Dalekie i blizkie S. $27-40$.

2se Polnoe sobranie soč. F. I. Tjutčeva. SPB. 1911; vgl. Izbr. sož. S. 210 bis 225. 
Poočeredno vsech svoich detej,

Sveršajuščich svoj podvig bespoleznyj,

Ona ravno privetstvuet svoej

Vsepogloščajuščej i mirotvornoj bezdnoj. “2s6a

„Nur die Natur in ihrer Ganzheit ist im Besitz des echten Daseins", interpretiert Brjusov das Gedicht, "der Mensch ist nur eine "greza prirody" (Trugbild der Natur). Sein Leben, seine Tätigkeit sind nur ein "podvig bespoleznyj ${ }^{\alpha}$ (vergebliche Heldentat). Dies ist die Philosophie Tjutčevs, seine verborgene Weltanschauung."

„Es ist vollkommen verständlich ${ }^{\alpha}$, fährt Brjusov fort, „daß eine derartige Weltanschauung vor allem zu einer ehrfurchtsvollen Verehrung dem Leben der Natur gegenüber führt ... “237

Dies ist der Ansatzpunkt, von dem aus Brjusov seine Betrachtung entwickelt. Er gelangt auf diesem Wege zu zwei Schlußfolgerungen, die seiner Meinung nach eine Erklärung für die ideellen Grundlagen der Lyrik Tjutčevs liefern können. Die eine Seite von Tjutčevs Weltanschauung beschreibt Brjusov auf folgende Weise: "Aus dem Gegensatz zwischen der Machtlosigkeit des Einzelnen und der Allmacht der Natur entspringt der leidenschaftliche Wunsch, und sei es nur für einen Augenblick, in die geheimnisvollen Tiefen kosmischen Lebens zu schauen, in eben jene Seele, für die die gesamte Menschheit nur ein flüchtiges Trugbild ist. ${ }^{\text {"238 }}$ Von hier aus gelangt Brjusov zu dem anderen „Pol“ der Tjutčevschen Weltanschauung: „Ebenso kraftlos wie der menschliche Gedanke ist auch das menschliche Wort. Angesichts der Anmut der Natur empfand Tjutčev lebhaft diese Kraftlosigkeit und verglich seinen Gedanken mit einem "angeschossenen Vogel“ ("podstrelennaja ptica“). Es ist daher nicht verwunderlich, daß er uns in einem seiner offensten Gedichte so harte Ratschläge erteilt:

235 Die deutsche Ubersetzung des Gedichts:

Die Natur weiß nichts von Vergangenem.

Fremd sind ihr unsere trügerischen Jahre

Und vor ihr erkennen wir dunkel

Uns selbst - nur als Traumbild der Natur.

Alle ihre Kinder,

Die ihre vergeblichen Taten vollbringen,

Begrüßt sie der Reihe nach in gleicher Weise

Mit ihrem alles verschlingenden, Frieden stiftenden Abgrund.

237 ibid. S. 212.

238 ibid. S. 212. 
Molči, skryvajsja i tai

I dumy i mečty svoi!

Liš' žit' v samom sebe umej ... .288*

"In voller Übereinstimmung mit dieser seiner Lehre sagt Tjutčev von sich:

Duša moja, èlizium tenej!

Ctò obščego mež žizn'ju i toboju! “239

Der Dualismus in Tjutčevs Weltanschauung, der auch seine Lyrik beherrscht, ist von Brjusov treffend dargestellt. Die Irrationalität alles Existierenden, die dem Leser der Gedichte Tjutčevs immer wieder so intensiv vor Augen geführt wird, ist von Brjusov etwas zu schwach hervorgehoben worden, wohl weil er selber gerade in dieser Beziehung stark unter dem Einfluß des Dichters steht.

Im letzten Kapitel dieser Arbeit, auf etwa drei Seiten, behandelt Brjusov die formale Seite von Tjutčevs Dichtung. Er beginnt mit einer Aufzählung der Lehrmeister Tjutčevs, die vor allem in der deutschen Dichtung zu finden seien. Heine, Lenau, Eichendorff, Schiller und Goethe werden in diesem Zusammenhang erwähnt. Von seinen russischen Vorgängern habe Tjutčev kaum etwas gelernt: „Im großen und ganzen ist sein Vers äußerst unbeeinflußt, eigenständig. Tjutčev hat durchaus seine eigenen Kunstgriffe des Schaffens und des Verses, welche zu seiner Zeit, zu Beginn des XIX. Jahrhunderts, als ausgesprochen abseitig galten (osobnjakom). ${ }^{240}$ Brjusov vermutet, daß dies vielleicht die Ursache dafür war, daß man so lange die Poesie Tjutčevs nicht zu schätzen wußte. Gerade diese Vermutung wirft ein bezeichnendes Licht auf die zur Zeit der Entstehung dieses Aufsatzes (1910) bereits vorhandene Bereitschaft Brjusovs, formalen Elementen einen recht bedeutenden Platz im literarischen Geschehen einzuräumen.

Im Anschluß daran definiert Brjusov die beiden wichtigsten literarischen Kunstgriffe ("priemy“) Tjutčevs: „Der beliebteste und zugleich völlig eigenständige Schaffenskunstgriff (priem tvorčestva)

238a Schweig. verbirg dich und verheimliche

Deine Gedanken und deine Träume!

Nur in dir selbst leben mußt du können ...

230 ibid. S. 212.

Meine Seele, Elysium der Schatten,

Welche Gemeinsamkeit ist 2 wischen dem Leben und dir!

240 ibid. S. 222. 
Tjutčevs besteht in der Entwicklung vollständiger Parallelen zwischen den Erscheinungen der Natur und den Zuständen der Seele. ${ }^{\alpha 241}$

Legt man dieser Betrachtung wiederum die im vorigen Kapitel gebrauchte Einteilung Brjusovs in Formelemente (Metrik und Reim, poetische Bilder, Dynamik des Verses, spezielle Euphonie) zugrunde, dann muß man den hier definierten Kunstgriff zum Bereich der Dynamik oder Komposition zählen. Das gleiche gilt dann auch für den zweiten von Brjusov herausgestellten Kunstgriff Tjutčevs:

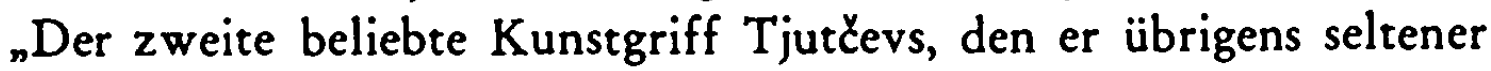
anwendet, besteht in einer Gegenüberstellung von Gegenständen, die offensichtlich völlig verschiedenartig sind, und $z w a r$ in dem Bestreben, $z$ wischen ihnen eine verborgene Verbindung zu finden. ${ }^{242}$ Hier begegnen wir wieder dem Gedanken, den Brjusov ein Jahr zuvor in Zusammenhang mit der "poésie scientifique" René Ghils angedeutet hatte und den er später in einem besonderen Aufsatz ${ }^{243}$ im einzelnen entwickelt: den Gedanken der poetischen Synthese.

Anschließend an die Erläuterung dieser beiden Kunstgriffe macht Brjusov in einem Abschnitt auf verschiedene besondere Metren, Reimschemata und Strophenformen aufmerksam. Das würde in den Bereich Metrik und Reim gehören.

Im nächsten Abschnitt schließlich zeigt Brjusov, mit welcher Sorgfalt Tjutčev Binnenreime und Assonanzen einerseits und Alliterationen andererseits in seine Dichtungen einbaut. Nach Brjusovs Definition gehören beide Untersuchungen in das Gebiet der Euphonie, die erste zur Reimlehre, die zweite zu dem Gebiet, das Brjusov als nzvukopis'“ bezeichnet.

Nicht uninteressant ist ein Vergleich der einzelnen in diesem Aufsatz behandelten Gebiete vom Gesichtspunkt ihrer Ausführlichkeit. Es ergibt sich folgendes Bild: in vier Fünftel des Aufsatzes spricht Brjusov von der Weltanschauung Tjutčevs, ein Siebentel behandelt kompositionelle Kunstgriffe des Dichters, der Rest ist metrischen und euphonischen Problemen gewidmet.

Auch bei der Besprechung der Lyrik Afanasij Fets (1903) 244 ist die Weltanschauung des Dichters Gegenstand der Abhandlung. Brjusov

241 ibid.

242 ibid. S. $222 \mathrm{f}$.

24s Sintetika poézii.

244 V. B r ju so v: A. A. Fet, Iskusstvo ili žizn'. „Dal. i bl.“ S. 18-26. 
geht hierbei von dem Widerspruch aus, der sich in den Versen Fets finden läßt. Einerseits preist Fet die Kraft und den Reichtum der künstlerischen Ausdrucksmittel, während er auf der anderen Seite die Kraftlosigkeit der Sprache beklagt. Brjusov stellt zur Erläuterung verschiedene Verse Fets einander gegenüber. Einige davon seien hier wiedergegeben:

Kak bogat ja $\mathrm{v}$ bezumnych stichach! ...

oder:

Zvuki est', dorogie est' kraski! ...

und als Gegensatz dazu:

$\mathrm{Ne}$ nami

Bezsil'e izvedano slov $k$ vyražen'ju želanij,

Bezmolvnye muki skazalisja ljudjam vekami.

Brjusov versucht dann zu klären, wie dieser Widerspruch entstanden ist. Er leitet die beiden einander gegenüberstehenden Ansichten von ein und derselben Grundeinstellung Fets ab. Diese beschreibt Brjusov wie folgt: "In ihrer wahren Bedeutung ist die Poesie Fets ein Anruf an das echte Leben, an den großen Rausch in dem Augenblick, der plötzlich, hinter Farben und Klängen, den Ausblick auf die "Sonne der Welt" eröffnet - aus der Zeit in die Ewigkeit. ${ }^{\text {245 }}$

In dieser Formulierung spiegelt sich Brjusovs damalige Vorstellung von der Ekstase, der „Leidenschaft ${ }^{\text {" }}$ (strast'), die eigentlich das Ziel der wirklichen Kunst sei. Wie bereits erwähnt, führt er in seinen allgemeinen Ausführungen $\mathrm{zu}$ diesem Thema Fet als positives Beispiel an.

Die Abhandlung enthält keine Bemerkung zur Form der Verse Fets, nicht einmal eine allgemeine Bemerkung.

Vielseitiger sind einige Aufsätze Brjusovs zu verschiedenen Gedichtbänden K.D. Bal'monts. Brjusovs Standpunkt ist in diesem Falle zwangsläufig ein anderer als in den vorher besprochenen Arbeiten, denn Bal'mont ist nicht nur ein Zeitgenosse von ihm, sondern zugleich ein Vertreter der eigenen Schule. Bemerkenswert ist, daß Brjusov auch hier der Gedankenwelt des Dichters bedeutend mehr Ausführlichkeit widmet als formalen Fragen.

Der erste dieser Aufsätze Brjusovs ist anläßlich des Erscheinens von Bal'monts Buch „Budem kak solnce! ${ }^{\propto}$ im Jahre 1903 entstanden.

245 ibid. S. 26. 
Im ersten Teil wird ausschließlich Bal'monts Einstellung zu den verschiedenen Erscheinungen des Lebens behandelt. "Leben“, schreibt Brjusov, „bedeutet für ihn, im Augenblick zu sein, sich ihm hinzugeben. ${ }^{240}$ Wieder stellt Brjusov eine zentrale Formel an die Spitze seiner Abhandlung und versucht sich mit ihrer Hilfe die Gedankenwelt des Dichters zu erklären. Zum Beispiel beschreibt er Bal'monts Einstellung zur Frau aus dieser Sicht: ${ }_{n}$ Er liebt aber vor allem die Liebe, und nicht den Menschen, das Gefühl, und nicht die Frau . . “²47

Im zweiten Teil des Aufsatzes diskutiert Brjusov zwar formale Fragen, ohne jedoch eine detaillierte Formanalyse der Verse durchzuführen. Er weist darauf hin, daß Bal'mont in der Verstechnik hauptsächlich von Lermontov und Fet gelernt hat. In diesem $\mathrm{Zu}$ sammenhang äußert er Bedenken dagegen, daß Bal'mont sich zuweilen des freien Verses bedient. „Bal'mont ist nur dann Bal'mont, wenn er in strengen Versmaßen schreibt, indem er korrekte Strophen und Reime aufeinander folgen läßt, nach allen Regeln, die in zwei Jahrhunderten unserer Versdichtung ausgearbeitet worden sind. “248

Ahnlich sind die übrigen, in "Dalekie i blizkie“ abgedruckten Aufsätze Brjusovs über Bal'montsche Lyrik angelegt. Vor allem wird das Nachlassen der Fülle an ideellem Gehalt in den Versen Bal'monts betont, während die Form eigentlich nur dann in die Betrachtung mit einbezogen wird, wenn sie offensichtliche und rein handwerkliche Mängel zeigt. Auch die letzte Bemerkung Brjusovs über die Dichtung Bal'monts, die zeitlich bereits in die dritte Periode unserer Einteilung fällt, deutet eine ähnliche Aufteilung des Problems an: „K. Bal'mont war schon vor 15 Jahren zu einem durchschnittlichen Graphomanen geworden. Die Bücher mit seinen Versen, die während der Revolutionsjahre erschienen sind, fallen durch ihre Armut an Inhalt und Form auf und durch das Fehlen auch nur des geringsten Schimmers einer einst glänzenden Begabung. ${ }^{\alpha 49}$

In einer Besprechung der Lyrik Nikolaj Maksimovič Minskijs (N. M. Vilenkin) ${ }^{250}$ geht Brịusov verhältnismäßig ausführlich auf die äußere Form von dessen Versen ein. Hier sind es jedoch krasse Un-

246 V. B r ju s o v: K. D. Bal'mont, Budem kak solnce. „Dal. i bl. “ S. 73-82.

247 ibid. S. 76.

248 ibid. S. 80.

240 V̌̌era, segodnja i zavtra russkoj poézii S. 49.

$250 \mathrm{Zu}$ N. M in sk ij, Polnoe sobranie stichotvorenij. Izd. 4-oe. SPB. 1907. 
zulänglichkeiten in Sprache und Versbau, die Brjusov zur Kritik veranlassen.

Er weist Minskij schwere metrische Fehler nach und hält sich besonders bei den ungeschickten Reimen auf. Diese führt er auf mangelndes Sprachgefühl beim Autor zurück: „Solche nicht zusammenklingenden Reime, wie "uchodja" und "doždja" (Russen sprechen "dožžja" aus), „čas" und "otražas'", und solche Banalitäten wie nserdce gorit", „želanij ogn' zažeg serdce“, „dremota skovala vzory zračkov" usw. " ${ }^{251}$ seien bezeichnend.

Die Tatsache, daß Minskij überhaupt formalen Effekten weniger Bedeutung beimißt (als z. B. Brjusov selbst in seinen Gedichten), führt er darauf zurück, daß dieser in seinen Dichtungen vor allem durch Nadson beeinflußt wurde.

„Es ist hinreichend bekannt ${ }^{\text {, }}$, meint Brjusov, „an welche Art von ,Poetik' sich Nadson hielt. Er schrieb:

Liš' by chot' kak-nibud' bylo izlito

Cem mnogozvučnoe serdce polno!

Dieses „kak-nibud'“ war auch seine Devise und die seiner Schule. Bei Nadson und seinen Schülern hatte das Metrum der Verse nicht das geringste Verhältnis zu ihrem Inhalt; als Reime wählte man die ersten besten, und diese spielten im Vers keinerlei Rolle; und darüber, daß die klangliche Seite eines Wortes seiner Bedeutung entspräche, hat sich niemand den Kopf zerbrochen. Die Farbigkeit der Sprache ist ebenfalls nicht herausgearbeitet, die Epitheta sind schablonenhaft, die Auswahl an Bildern mager, die Rede müde und schleppend - das sind die charakteristischen Züge Nadsonscher Poesie, die diese hoffnungslos überlebt erscheinen lassen. "252 Bezeichnend für die Urteilsweise Brjusovs zu dieser Zeit ist die folgende zusammenfassende Außerung über einen Gedichtzyklus Minskijs: „In diesen Gedichten steht der Gedanke an erster Stelle, und die Originalität des Gedankens leidet häufig unter der Unoriginalität der Form. “253

Nach dem bisher Gesagten kann man Brjusovs Methode in der zweiten Periode etwa wie folgt charakterisieren:

Inhalt und Form werden in der Kritik jeweils gesondert behandelt. Dabei sei hier unter "Inhalt" das verstanden, was Brjusov "miroso-

\footnotetext{
251 "Dalekie i blizkie S. 50.

252 ibid. S. 46.

253 ibid. S. 52.
} 
zercanie $^{\alpha}$ nennt. Poetische Bilder gehören dabei in den Bereich der Form.

Die Form muß in jedem Falle auf den Inhalt, die „Weltanschauung ", abgestimmt sein.

Die Weltanschauung genießt in der Behandlung einen eindeutigen Vorrang vor der Form. Dies entspricht der These Brjusovs, daß der Zwedk der Kunst Erkenntnis sei.

Formprobleme werden stets nur allgemein und im Verhältnis zur Philosophie eines Dichters sehr knapp behandelt. Auf spezielle Fragen der Form (Metrum, Euphonik usw.) wird nur dann eingegangen, wenn es gilt, offensichtliche Mängel aufzuzeigen.

In der dritten Periode erfährt die Methode Brjusovs eine Verschiebung zugunsten rein formaler Fragen. Das weltanschauliche Moment tritt oft ganz in den Hintergrund. Die formale Analyse ist bedeutend detaillierter. Hier erst gelangen die von Brjusov präzisierten Formkategorien, „Formelemente ${ }^{\alpha}$, zur vollen Anwendung in der Kritik.

Besonders bezeichnend ist in diesem Zusammenhang der 1922 in der Zeitschrift "Pečat' i revoljucija“ erschienene Aufsatz "Včera, segodnja i zavtra russkoj poèzii ${ }^{\alpha} .^{254}$ Es handelt sich dabei um eine Besprechung von literarischen Erscheinungen der Jahre 1917-1922. Brjusov versucht hier einen Gesamteindrudk zu vermitteln. Wesentliche Ereignisse werden einer etwas eingehenderen Betrachtung unterzogen, anderes wird nur vermerkt. Einige Abschnitte daraus sollen hier betrachtet werden.

Uber Velimir Chlebnikov, den eigentlichen Begründer des Futurismus, sagt Brjusov in dieser Arbeit: „... er hat ein besonderes $\mathrm{Ta}$ lent zum Neuschaffen von Wörtern und eine offensichtliche (wenn auch nicht sehr weitreichende) dichterische Begabung. Diese ist mit einer gewissen Beschlagenheit auf wissenschaftlichem Gebiet verbunden. Vieles von dem, was Chlebnikov sagt, ist unsinniges philologisches Paradoxon, das sich bei der ersten Berührung mit wissenschaftlicher Kritik in nichts auflöst. Vieles von dem, was unter seinem Namen gedruckt wurde, ist nur ein Entwurf ins Unreine, ein Versuch, bei dem durchaus Lächerliches neben Nutzlosem und Ubberflüssigem steht. Doch hinter all dem bleibt noch ein durchaus eigenständiger Beitrag zur Literatur. In seinen besten Versen - dazu ge-

254 Peč. i rev. 1922, VII. 
hört auch sein letztes Poem „Zangezi ${ }^{\alpha}, 1922$ - versteht es Chlebnikov, die Sprache oft wirklich zu reformieren, Elemente in ihr aufzuzeigen, die vorher von der Dichtung noch nicht genutzt worden waren. Doch bringt er den größten Gewinn für das dichterische Schaffen, indem er neue Kunstgriffe zeigt, mit dem Wort einen künstlerischen Einfluß auszuüben, und indem er trotz allem, bei minimaler Beanspruchung des Lesers, " verständlich ${ }^{\alpha}$ bleibt. $^{{ }^{\alpha 255}}$

Uber die Gedankenwelt des Dichters wird hier kein Wort verloren. Diskutiert wird ausschließlich die Wirksamkeit der angewandten Kunstgriffe („priemy“). Eine Spezifizierung dieser Kunstgriffe erfolgt nicht. Dabei versteht Brjusov unter "priem" ausschließlich sprachliche und kompositionelle, d.h. formale Kunstgriffe. Eine solche Behandlung weist $\mathrm{m}$. E. eine zumindest wechselseitige Beziehung zur formalistischen Schule auf. Besonders die Betonung der N e uh e i t verwendeter Kunstgriffe als Merkmal der Qualität eines Werkes finden wir in früheren Arbeiten Brjusovs nicht, hingegen sehr wohl in Schriften der Formalisten.

Noch aufschlußreicher dürften im Rahmen dieser Untersuchung die im gleichen Aufsatz enthaltenen Besprechungen von Dichtungen Majakovskijs und Pasternaks sein.

"Die Verse Majakovskijs", schreibt Brjusov, "gehören zu den schönsten Erscheinungen dieser fünf Jahre (1917-1922). Ihr lebensvoller Stil und die mutige Sprache waren ein belebendes Ferment für unsere Dichtung. In seinen letzten Gedichten hat sich Majakovskij eine Plakat-Manier angeeignet - scharfe Linien, schreiende Farben. Dabei fand er auch seine Technik, - eine besondere Abwandlung des "freien Verses", ohne dabei das Metrum allzu kraß zu verletzen, und doch der rhythmischen Vielfalt Weite gebend. Er war einer der Schöpfer des neuen Reimes, dessen Gebrauch neuerdings weit verbreitet ist und der den Besonderheiten der russischen Sprache mehr entspricht als der klassische Reim (Puskin u. a.) Schließlich fand Majakovskij im Bereich der Sprache, indem er Chlebnikovs Prinzipien maßvoll zur Anwendung brachte, eine Ausdrudksweise, die Einfachheit mit Originalität, die Schärfe des Feuilletons mit künstlerischem Takt verband. Die Schwäche der Poesie Majakovskijs liegt darin, daß die Schärfe manchmal dominierend wird, dic Einfachheit bisweilen in Prosaismen übergeht, daß einige Reime zu künstlich wir-

235 ibid. S. 55. 
ken, einige Metren sich nur durch die Art des Druckes von einfachen Jamben und Trochäen unterscheiden, daß die Plakat-Manier grob wird usw., das heißt, die Schwäche liegt darin, daß sich auch bei Majakovskij schon eine Schablone herauszubilden beginnt. Jedenfalls liegen die Gefahren für ihn noch in der Zukunft. Die Jahre 1917-22 jedoch waren eine Blüte seines Schaffens. Der Einfluß Majakovskijs auf die junge Dichtung war sehr stark, bedauerlich ist nur, daß er oft rein äußerlich nachgeahmt wurde, ohne seine Kraft, ohne seine Begeisterung, ohne die Gewandtheit seines Ausdrucks, ohne den Reichtum seines Wortschatzes. ${ }^{\alpha 256}$

Hier haben wir eine kurze, aber doch auf zahlreiche Teilgebiete der Brjusovschen Verslehre eingehende Charakterisierung. Dabei werden folgende Elemente nacheinander behandelt: Sprachstil, poetische Bilder, Metrum und Rhythmus, Reim. Charakteristisch ist, daß Brjusov auf diese Einzelfragen hier nicht nur eingeht, um bestimmte Schwächen des Dichters aufzuzeigen, sondern dies bereits tut, um ein allgemeines Bild von Majakovskijs Lyrik zu vermitteln. Die schwachen Seiten dieser Dichtung werden anschließend auf ebenso detaillierte Weise behandelt (Stil, Bilder, Reim, Metrum). Hinweise auf die Tendenz und die Weltanschauung Majakovskijs fehlen hier vollständig. Im ganzen gesehen ist diese kurze Besprechung eine der meisterhaftesten Kritiken Brjusovs. Hier fehlen die in der zweiten Periode häufigen Betrachtungen zur W'eltanschauung des rezensierten Dichters, die der eigenen gegenübergestellt wurde.

Die Besprechung von Pasternaks "Sestra moja - žizn" (das einzige Buch, das Pasternak zwischen 1917 und 1922 veröffentlichte) ist nicht umfangreicher als die eben wiedergegebene Charakterisierung der Dichtung Majakovskijs. Der Rahmen der besprochenen Einzelfragen ist hier aber noch weiter gespannt.

"Die Verse B. Pasternaks vermitteln sofort den Eindruck von etwas Neuem, etwas noch nicht Dagewesenem: bei ihm findet man stets eine eigenwillige Behandlung des Themas, die Fähigkeit, alles auf seine Weise zu sehen. Was die Form angeht, so findet man bei ihm einen Reichtum an Rhythmen, die größtenteils in traditionelle Metren gegossen sind, und eben jenen neuen Reim, als dessen Schöpfer er eigentlich weit eher bezeichnet werden kann als Majakovskij. Mit Wortschöpfungen ist Pasternak ebenfalls vorsichtig, aber wenn

230 ibid. S. $56 f$. 
er, vergleichsweise selten, seine Zuflucht zum Schaffen neuer Wörter nimmt, dann wagt er sich in neue syntaktische Konstruktionen und in originelle Wortsubordinationen. In gleichem Maße, wie Majakovskij dem Aufbau seiner Poesie nach den proletarischen Dichtern nahesteht, ist Pasternak $z$ weifellos ein Dichter der Intellektuellen. Teilweise führt das zur Breite, er läßt sich in seinen Schöpfungen von folgendem ergreifen: Geschichte und Gegenwart, Tatsachen aus Wissenschaft und Tagesgesprächen, Büchern und Leben: dies alles findet gleichberechtigt nebeneinander Eingang in die Verse Pasternaks, als läge, einer besonderen Eigenart seiner Weltanschauung entsprechend, alles auf ein und derselben Ebene. Aber teilweise entkräftet diese übermäßige Intellektualität die Poesie Pasternaks, bedrängt ihn mit antipoetischen Reflexionen, verwandelt einige seiner Verse in philosophische Abhandlungen, verzerrt bisweilen lebendige Bilder in scharfsinnige Paradoxa. ${ }^{\star 257}$

In dieser kurzen Rezension stehen Fragen der Thematik und Fragen der Form gleichberechtigt nebeneinander. Im Gegensatz zu seiner zweiten Periode verlangt Brjusov jetzt nicht mehr, daß die Form der in der betreffenden Poesie behandelten Thematik anzupassen sei, sondern er gelangt zu der Annahme, daß auch der Inhalt seinerseits eine positive oder, wie in diesem Falle, eine schädigende Wirkung auf ein dichterisches Werk haben kann.

Augenfällig wird die Veränderung, die Brjusovs kritische Methode im Ubergang von der zweiten zur dritten Periode durchmacht, wenn man Kritiken von Werken ein und desselben Dichters einander gegenüberstellt. Es handelt sich dabei um Besprechungen von Gedichten Il'a Erenburgs. Die eine entstand 1911, die andere 1923.

In der 1911 verfaßten Kritik vergleicht Brjusov die Technik Erenburgs mit der Gumilevs, und $z w a r ~ „ \ldots$. in seinem Können, eine Strophe aufzubauen, mit Reimen und mit der Zusammenstellung von Lauten Effekte zu erzielen. ${ }^{\text {258 }}$ Mehr sagt Brjusov hier nicht zur Form der Gedichte. Wesentlicher Bestandteil der Rezension sind die von Erenburg behandelten Themen. Hinzu kommt eine kurze Erwähnung des Stils: „Erenburg befaßt sich mit mittelalterlichen Vorstellungen, mit dem Kult des Katholizismus, mit der Verbindung von Religiosität und Sinnlichkeit, doch werden diese alten Themen von

257 ibid. S. 57.

258 "Dalekie i blizkie ${ }^{\alpha}$ S. 197. 
ihm elegant und schön wiedergegeben. Die Schärfe seiner Manier, die Bedachtheit seiner Epitheta, die Deutlichkeit und Klarheit seiner Ausdrudksweise zeigen, daß er alle Voraussetzungen erfüllt, um in der Poesie das Ziel zu erreichen, das er sich selber gesetzt hat. Vermutlich aber werden seine Verse immer zwei Unzulänglichkeiten aufweisen, die auch sein erstes Buch verderben: Kälte und Maniriertheit. ${ }^{250}$ Das, worauf es Brjusov letzten Endes hier ankommt, ist die Ehrlichkeit der in den Gedichten verarbeiteten Emotionen. Er sagt das noch deutlicher: „Erenburg kreist ständig in den Verhältnissen einer Welt, die von ihm selbst geschaffen wurde, in einer Welt von Rittern und Kaplanen, Troubadours, Turnieren; er spricht nicht gern von Gefühlen, die er wirklich durchlebt, sondern von denen, die er gern durchleben möchte. ${ }^{280}$

Anders geht Brjusov 1923 vor. Zunächst äußert er sein Mißfallen an den $z u$ rezensierenden Gedichten. Anschließend folgt auf fast zwei Seiten die Begründung. Es wird ein Gedicht aus dem besprochenen Band zitiert. An diesem Gedicht werden Vers für Vers dic poetischen Bilder analysiert und auf ihre logische Abfolge und ihre Kontinuität untersucht. Mit einem zweiten Gedicht verfährt Brjusov ebenso, nur nicht so ausführlich. Dann fügt er hinzu: ${ }_{n}$ Hier widersprechen sich nicht nur die Bilder, sondern auch der syntaktische Aufbau der Sätze ist mehr als zweifelhaft. ${ }^{\alpha 261}$ Brjusov bezeichnet den Satzbau Erenburgs als nachlässig und verschwommen. Dabei wird eine Bemerkung über die Reime Erenburgs eingeflochten: „Ich spreche schon nicht von solchen Nachlässigkeiten der Form, wie z. B. der Reime "polnokrov'ju - ljubovi“, " vino - noc' “, "svirel'nyj pčel'nik “, „pčely - zolot ${ }^{\alpha}$, „dvoeverki - serdca " usw., denn das sind einfach schlechte Gleichklänge und keineswegs Reime der "neuen Arr "(wie bei Majakovskij, Pasternak, Aseev). ${ }^{\alpha 282}$ Zum Ausdruck gebrachte oder fehlende emotionale Werte werden nicht erwähnt. Zusammenfassend soll noch bemerkt werden, daß Brjusov sich in seinen kritischen Arbeiten vor allem mit den lyrischen Werken seiner Zeitgenossen beschäftigte. Daneben galt sein Interesse vor allem Tjutčev und Fet.

\footnotetext{
259 ibid.

260 ibid.

261 V. B r jus o v: Sredi stichov. „Peč. i rev.“ 1923, I, S. 70-78.

262 ibid.
} 
Der größte Teil der literaturwissenschaftlichen Arbeiten Brjusovs ist jedoch dem Werk Puškins gewidmet. In der 1929 unter dem Titel "Moj Puškin " von N. K. Piksanov herausgegebenen Sammlung Brjusovscher Puškin-Aufsätze verzeichnet die vollständige Bibliographie 82 Titel von Arbeiten Brjusovs über das Werk des großen Dichters. 263

Der erste in der Piksanovschen Bibliographie verzeichnete Titel datiert aus dem Jahre 1899, fällt also zeitlich mit dem Ubergang von der ersten zur zweiten Periode unserer Einteilung zusammen. ${ }^{264}$ Es handelt sich dabei um eine Besprechung der damals erschienenen Akademieausgabe von Puškins Werken, d.h. um eine Auseinandersetzung mit textkritischen Fragen.

Uberhaupt ist der größere Teil der Puškinarbeiten Brjusovs textkritischer bzw. editionstechnischer Art. Zahlreichen Rezensionen der verschiedensten zeitgenössischen Puškinausgaben folgt schließlich 1919 die Gesamtausgabe unter der Redaktion von Brjusov. Aus den Jahren vor 1918 ist besonders seine textkritische Untersuchung der Lyzeumsgedichte ${ }^{265}$ bekanntgeworden. Die Arbeit wurde durch den 1899 erschienenen ersten Band der von L. N. Majkov vorbereiteten Akademieausgabe angeregt, der die Lyzeumsgedichte Puškins enthält. Brjusov gibt hier eine sorgfältige Textanalyse, die sich vor allem auf die ihm inzwischen zugänglich gewordenen Handschriften im Moskauer Rumjancev-Museum gründet.

Es erhebt sich die Frage, inwieweit eine Betrachtung solcher textkritischen Arbeiten für unsere Untersuchung wertvoll oder nützlich ist. Es möge folgender Gedankengang zugrundegelegt werden: Die Textkritik ist die handwerklichste aller Arbeiten, welche die Literaturwissenschaft zu leisten hat. Andererseits, und hier möchte ich Max Wehrli286 nicht widersprechen, verlangt die Textkritik ein gcfestigtes Gesamtbild des literarischen Geschehens. Um aber die Literaturauffassung eines Kritikers nachträglich aus seinen Arbeiten wieder greifbar werden zu lassen, eignen sich gerade die textkritischen Arbeiten am allerwenigsten, weil dies die letzte Stufe ist, auf der

203 V. B r jus ov: Moj Puškin. Red. N. K. Piksanova. Moskau-Leningrad 1929, S. 309-317.

264 V. B r jus ov: Cto daet akademiČeskoe izdanie soxinenij Puškina. "Russkij archiv“ 1899, XII, S. 618-631.

265 V. B r j u s o v: Licejskie stichi Puškina. Moskau 1907.

$200 \mathrm{Vgl}$. Max ehrli: Allgemeine Literaturwissenschaft. Bern 1951, S. 33 ff. 
die literartheoretische Auffassung eines Wissenschaftlers zur Anwendung gelangt. Das Ergebnis dieser Tätigkeit ist bereits wieder das Material, das den primären Theorien zugrunde gelegt wird.

Von diesem Standpunkt aus erscheint es wenig zweckmäßig, die Untersuchung auch auf das Gebiet der Textkritik und Editionstechnik auszudehnen. Vielmehr bietet sich uns gerade bei den allgemein literaturkritischen und literarhistorischen Arbeiten Brjusovs zum Thema Puškin eine ausgezeichnete Möglichkeit, die Methodik Brjusovs zu verfolgen, da er sich auf diesem Gebiet nicht nur mit mehr allgemeinen Betrachtungen begnügte, sondern auch einige ins Detail gehende Untersuchungen vorlegte. Es sei noch bemerkt, daß gerade diese im wesentlichen dazu beigetragen haben, daß die Brjusovschen Methoden auf die nachfolgende Generation von Literaturwissenschaftlern in vieler Hinsicht anregend wirkten.

In diesem Zusammenhang sei zunächst der 1909 in der PuškinAusgabe S. A. Vengerovs erschienene Aufsatz Brjusovs zum "Mednyi vsadnik" erwähnt. ${ }^{267}$

Im ersten Teil untersucht Brjusov die "Idee der Erzählung". Er geht dabei von der Prämisse aus, daß sich Fabel (fabula) und Inhalt (soderžanie) der Erzählung nicht entsprechen. Er versucht nun die Idee, die Puškin tatsächlich dem Gedicht zugrundegelegt hat, herauszuarbeiten.

In diesem Zusammenhang muß er sich mit dem Problem der Einstellung Puškins zur Gestalt Peters des Großen auseinandersetzen. Er gelangt zu dem Schluß, daß Peter der Große einer der bevorzugtesten Helden Puškins ist - er verweist u. a. auf die Vorarbeiten Puškins zu einer "Geschichte Peters des Großen". Andererseits aber stellt er fest, daß Puškin in Peter stets auch „die extremste Verkörperung der Autokratie, die an Despotie grenzt"268, sah. Brjusov schließt mit der Feststellung, daß der "Mednyj vsadnik" letzten Endes doch eine Verteidigung der inneren Freiheit des Menschen darstellt. Er schreibt dazu: „Der Eherne Reiter ist tatsächlich eine Antwort Puskkins auf die Vorwürfe Midkiewiczs wegen des Verrates an den ${ }_{n}$ freiheitsliebenden " Idealen der Jugend. “269 Waclaw Lednicki bemerkt zu diesem Problem in einem Aufsatz: „Puškins «Bewunde-

\footnotetext{
26: V. B r jus o v: Mednyj vsadnik. Soč. Puškina, red. S. A. Vengerova, t. III. SPB. 1909, S. 456-472. „Moj Puškin ${ }^{\alpha}$ S. 63-94.

208 Mednyj vsadnik. Izbr. soč. S. 426.

260 ibid. S. 440.
} 
rung» für Peter den Großen ist ein weites und kompliziertes Problem. Man möge den Ehernen Reiter nicht vergessen und die Drohung, mit der Evgenij gegen den ehernen Kaiser aufbegehrt. Hinter Evgenijs ängstlicher Revolte, der Revolte eines kleinen, gebrochenen Menschenherzens, stand der Dichter selbst, mit Mickiewiczs „Totenfeier $^{\text {“ }}$ in Händen, nachsinnend über die tragische Beziehung $\mathrm{zwischen}$ Mensch und Staat. ${ }^{\text {¿270 }}$ Noch genauer formuliert Lednicki als Ergebnis einer ausführlichen Interpretation des Gedichtes: „Und so bekennt in diesem Werk der Dichter, daß er mit Freuden seinen Verstand verlöre, um durch die wunderbaren Träume des Wahnsinns als ewigen Lebensgefährten die grenzenlose Freiheit zu gewinnen. ${ }^{\text {"271 }}$

Der zweite Teil des Aufsatzes - Brjusov betitelt ihn „Vozniknovenie $\mathrm{i}$ sostav povesti“ (Entstehung und Gefüge der Erzählung) enthält eine kurze historische und eine ausführlichere formale Untersuchung des Werkes. Die historische Untersuchung gründet sich im wesentlichen auf biographisches Material.

In der formalen Untersuchung des "Mednyj vsadnik“ finden wir zum erstenmal eine verhältnismäßig konsequente Anwendung der von Brjusov in zahlreichen Aufsätzen vorgeschlagenen Methoden. Zunächst wird die Fabel auf ihr Gedankengut und dessen eventuelle Herkunft hin (vor allem an Hand des Textes selbst) untersucht, ebenso die poetischen Bilder.

Es folgt eine statistische Auswertung des „Mednyj vsadnik“ im Vergleich zu anderen Verserzählungen Puškins. Dabei wird die Anzahl der Verse insgesamt in ihrem Verhältnis zur Menge des Ausgesagten verglichen. Anschließend wird der Sprachstil analysiert. Sodann wird als besonderes Merkmal des Verses in diesem Werk die Häufigkeit der Zäsur erwähnt. Brjusov stellt dabei fest, daß etwa jeder dritte Vers des „Mednyj vsadnik“ in der Mitte einen Punkt hat, während mehr als die Hälfte aller Verse in der Mitte einen logischen Einschnitt aufweisen. Danach wendet sich Brjusov noch euphonischen Betrachtungen zu. Er gibt eine kurze Beschreibung der verwendeten Reime sowie eine etwas ausführlichere Betrachtung der Anordnung von Alliterationen.

Die Methode, nach der Brjusov hier vorgeht, ist leicht zu erken-

270 Waclaw Lednicki: Bits of Table Talk on Pushkin, Midkiewicz, Goethe, Turgenev and Sienkiewicz. Den Haag 1956, S. 105.

271 Waclaw Lednicki: Pushkins Bronze Horseman. Berkeley and Los Angeles 1955, S. 83. 
nen. Der eine Teil ist der Untersuchung des vom Dichter vermittelten Gedankengutes gewidmet, der andere Teil der formalen Ausführung. Im zweiten Teil werden Schritt für Schritt einzelne Elemente betrachtet. Es handelt sich dabei der Reihe nach um folgende Elemente (in der Terminologie Brjusovs): Komposition, poetische Bilder, Sprachstil, Versmaß, Reim, Klang ( $n$ zvukopis'“). Es sei noch die Ausführlichkeit verglichen, mit der die einzelnen Elemente behandelt sind. Auf die Elemente Komposition und poetische Bilder entfällt etwa die Hälfte der formalen Untersuchung, auf Versmaß und „zvukopis" " je etwa ein Sechstel, während der Besprechung von Sprachstil und Reim jeweils nur ein Absatz gewidmet ist.

Aufschlußreich für das methodische Vorgehen Brjusovs bei einer rein formalen Untersuchung ist der Aufsatz „Stichotvornaja technika Puškina ", der ebenfalls in der Vengerovschen Gesamtausgabe erschien, und zwar 1915, also noch während der zweiten Periode unserer Einteilung. ${ }^{272}$

Brjusov legt der Entwidklung von Puškins Verstechnik drei Perioden zugrunde: die erste reicht bis 1820 , die zweite umfaßt etwa das Jahrzehnt der zwanziger Jahre, während der dritten die Zeit nach 1830 zugeteilt wird. Diese drei großen Perioden unterteilt Brjusov im Verlauf seiner Untersuchung wiederum, wenn er es für erforderlich hält, in mehrere kürzere Zeitabschnitte.

Sachlich ist die Arbeit wiederum nach Elementen aufgeteilt, und zwar zunächst in drei Hauptabschnitte, Metrik und Strophik, Rhythmik und Euphonie. In jedem dieser Hauptabschnitte werden die einzelnen Zeitabschnitte der Reihe nach abgehandelt.

Im Kapitel über Metrik und Strophik werden für jeden Zeitabschnitt zuerst die verschiedenen, jeweils bei Puškin vorkommenden Versfüße auf ihre Häufigkeit hin untersucht. Dabei spielt naturgemäß der Jambus, im besonderen der vierfüßige Jambus die wesentlichste Rolle. Das Vorkommen von Jamben im allgemeinen und vierfüßigen Jamben im besonderen wird im Gesamtwerk Puškins, ferner in ihrer Verteilung auf die einzelnen Zeitabschnitte, nach Prozenten ausgezählt. In gleicher Weise werden Trochäus, Daktylus, Amphibrachys und Anapäst behandelt. Bei den letzteren verzichtet Brjusov auf Prozentangaben, da diese zu selten vorkommen. Die Häufigkeit der Verwendung eines Versfußes wird noch nach der Länge des Verses

272 V. B rju sov: Stichotvornaja technika Puškina. Sox̌. Puškina, red. S. A. Vengerova, t. VI. SPB. 1915, S. 349-367. "Moj Puškin “ S. 129-166. 
aufgegliedert, bei dreisilbigen Füßen wird die Verwendung im Hexameter oder Distichon gesondert behandelt. Für jede Kategorie werden ausreichend Beispiele angeführt. Selbst wenn in eine Kategorie vielleicht nur ein einzelnes Epigramm oder ein kurzes Gedicht fällt, so wird auch dieses erwähnt. Im Gesamtzusammenhang wird dann die jeweilige Entwicklung von Zeitabschnitt zu Zeitabschnitt an Hand der vorher aufgeschlüsselten Verwendung der betreffenden Metren untersucht.

Anschließend an die Diskussion der Metren folgt in diesem Kapitel noch für jeden Zeitabschnitt eine Betrachtung strophischer Elemente. Diese beschränkt sich jedoch nur auf einige Hinweise, hauptsächlich die Länge der Strophen betreffend.

Das ganze zweite Kapitel dieses Aufsatzes ist dem Rhythmus in Puškins Versen gewidmet. Hierbei stützt sich Brjusov erstaunlicherweise zum größeren Teil auf die - bereits oben besprochenen Methoden und Vorarbeiten Belyjs. Er verweist auch im Text des öfteren auf Belyjs "Simvolizm".

Dementsprechend ist der Hauptgegenstand seiner rhythmischen Untersuchung die Anordnung von Pyrrhichien. Im Gegensatz zu Belyj verwendet Brjusov aber auf die Betrachtung der Zäsuren die gleiche Sorgfalt wie auf die Pyrrhichien. Er läßt die Zäsur als ebenbürtiges rhythmisches Element neben dem Pyrrhichius gelten. Die anderen Elemente, die Brjusov in seinem Aufsatz zu Belyjs "Simvolizm" noch für die Entstehung des Rhythmus verantwortlich machte ${ }^{273}$, sind hier bereits dem Gebiet der Euphonie zugewiesen.

Sachlich ist die Untersuchung ähnlich angeordnet wie im ersten Kapitel: Pyrrhichien und Zäsuren werden für jeden Zeitabschnitt einzeln untersucht, die Úbergänge von einer Periode zur anderen miteinander verglichen. Eine zusätzliche Unterordnung schafft Brjusov dadurch, daß er der jeweiligen Betrachtung des Rhythmus für einen Zeitabschnitt eine Aufteilung nach verschiedenen Versfüßen und Versmaßen zugrundelegt, die jedesmal mit dem vierfüßigen Jambus beginnt.

Zäsur und Pyrrhichius faßt Brjusov hier weniger als Faktoren des rhythmischen Elements auf, sondern vielmehr als eigenständige Kunstgriffe, die gleichzeitig, aber auch vice versa für die Gestaltung des Rhythmus im Vers Verwendung finden können. Daher kommt

:73 $\mathrm{Vgl}$. Ob odnom voprose ritma. 
er z. B. zu dem Schluß, daß „Puškin sich in der Lyrik zur Modifizierung des vierfüßigen Jambus vorzugsweise des Spiels mit Pyrrhichien bedient, in den Poemen des Spiels mit der Zäsur. “274

Das dritte Kapitel dieser Abhandlung ist der Untersuchung der euphonischen Mittel gewidmet, die Puškin in seinen Versen verwendet. Zur Detaillierung dieser Elemente bemerkt Brjusov: „Die klangliche Harmonie im Vers Puškins gründet sich hauptsächlich auf das Spiel mit Reimen, Alliterationen und der Wortinstrumentation (slovesnaja instrumentovka) “.275

Reime und Alliterationen werden jeweils auf mehreren Seiten besprochen, während das dritte Element, die „slovesnaja instrumentovka", d. h. also nach Brjusovscher Terminologie die Lehre vom $\mathrm{Zu}$ sammenklang von Vokalen unerwähnt bleibt.

Was die beiden ersten euphonischen Elemente, Reime und Alliterationen bzw. „zvukopis'" betrifft, so finden wir besondere Arbeiten von Brjusov, die sich jeweils mit einem dieser Elemente bei Puškin befassen. Dagegen wird die "slovesnaja instrumentovka" von Brjusov nur einmal im Rahmen einer Gesamtinterpretation, von der noch die Rede sein wird, zum Gegenstand der Untersuchung gemacht.

Unter dem Titel „Levizna Puškina v rifmach" veröffentlicht Brjusov 1924 eine Abhandlung, die ausschließlich einer speziellen Untersuchung des Puškinschen Reimes gewidmet ist. ${ }^{278}$ Dieser Aufsatz stellt im wesentlichen eine Apologie des sog. "neuen Reimes" von Majakovskij, Pasternak u. a. ${ }^{277}$ dar. Im Verlauf dieser Arbeit untersucht Brjusov Puškinsche Verse auf die Laute hin, die links vom betonten Vokal stehen, da diese ja für den "neuen Reim“ wesentlich sind. (Daher der Titel des Aufsatzes.) An der Methode ist interessant, daß Brjusov in erster Linie wieder mit statistischen Werten arbeitet. Er gelangt zu dem Ergebnis, daß weit über die Hälfte der untersuchten Verse einen Gleichklang auch im Laut vor dem letzten betonten Vokal aufweisen. Damit hat er auf eine Tatsache hingewiesen, die bis dahin von der Puškinforschung übersehen worden war.

274 Stichotvornaja technika Puškina.

275 ibid.

270 V. B r ju s o v: Levizna Puškina v rifmach. "Pcč. i rev. “ 1924, II. „Moj Puškin“ S. 246-263.

277 Vgl. V̌̌era, segodnja... 
Die zweite der oben genannten speziellen Untersuchungen ist der in dieser Arbeit schon des öfteren zitierte Aufsatz "Zvukopis' Puškina ". ${ }^{278}$ Eine Erläuterung der dort angewandten Methode erübrigt sich an dieser Stelle, da diese bereits in den vorhergehenden Kapiteln behandelt wurde. Interessant ist in diesem Aufsatz ein Vergleich des Reichtums an euphonischen Kunstgriffen bei verschiedenen Dichtern. Brjusov gelangt zu dem Ergebnis, daß in der gesamten europäischen Literatur Puškin und Vergil an erster Stelle stehen: "Sowohl bei Puškin als auch bei Vergil steht tatsächlich je der Vers, je de r Buchstabe in den Worten eines Verses, vor allem den Gesetzen der Euphonie gehorchend, an seiner Stelle. “279 Diese These wurde z.T. von späteren Puškinforschern, vor allem von Blagoj übernommen. ${ }^{280}$

Um noch ein letztes Beispiel für Brjusovs Arbeitsweise anzuführen, sei hier über die vollständige Analyse des Puškinschen Gedichtes "Prorok" berichtet, die postum erstmals in dem Sammelband "Moj Puškin " abgedruckt wurde.281 Die Arbeit dürfte nicht allzu lange vor Brjusovs Tod entstanden sein und gehört $z$ weifellos zur dritten Periode seiner kritischen Tätigkeit.

Die Untersuchung, die den Untertitel "Analiz stichotvorenija“ trägt, ist in sechs Abschnitte zerlegt, deren jeder sich mit einem bzw. $z$ wei Elementen befaßt. Brjusov setzt über diese Abschnitte folgende bezeichnende Uberschriften: 1. Vstuplenie; 2. Idejnaja kompozicija; 3. Vnešnjaja kompozicija; 4. Ritmika i strofika; 5. Evfonija. Zvukopis'; 6. Evfonija. Instrumentovka i rifmovka.

Wir finden in diesen Untertiteln fast alle die Bezeichnungen für Elemente wieder, die Brjusov seit Beginn der zweiten Periode immer wieder, wenn auch stets in anderer Anordnung, für theoretische Analysen gebraucht. Hier finden sie Anwendung auf ein einzelnes Gedicht, das Brjusov zu interpretieren sich vornahm.

Der erste Abschnitt, mit dem Titel "Vstuplenie", befaßt sich ausschließlich mit der Kritik des Textes und erarbeitet den Wortlaut des Gedichtes, welcher der weiteren Untersuchung zugrundeliegt.

Der zweite Abschnitt, "Idejnaja kompozicija“, versucht die vom

278 V. B r j u s o v: Zvukopis’ Puškina. „Peč. i rev." 1923, II. „Moj Puškin “ S. $229-245$.

270 ibid. S. 230.

280 Vgl. D. D. B la goj: Tvorčeskij put' Puškina. Moskau-Leningrad 1950, S. 189.

281 V. B r ju s ov: Prorok. „Moj Puškin ${ }^{\alpha}$ S. 279-297. 
Dichter in dem zu behandelnden Gedicht vorgenommene Synthese ${ }^{282}$ herauszuarbeiten. Die Interpretation, welche Brjusov in diesem Zusammenhang gibt, die Synthese der beiden einander widersprechenden Eigenschaften des Dichters, Sterblichkeit und Verkündung unsterblicher Offenbarungen, in der Person des Propheten, ist bereits im ersten Kapitel besprochen worden.

Den Weg, den Puškin in seinen Versen beschreitet, um eine solche Synthese zu erreichen, erklärt Brjusov damit, daß eine Reihe zweitrangiger Synthesen von einzelnen Bildern zur Gesamtsynthese führe.

Im dritten Abschnitt "Vnešnjaja kompozicija" gibt Brjusov eigentlich nur die schematische Disposition des Handlungsablaufes wieder. Die Aufteilung, die Brjusov hier gibt, sieht in gekürzter Form so aus: I. E in le it ung, 1. Ich, Wüste. 2 Verse. 2. Seraphim, Kreuzweg. 2 Verse. II. W a ndl ung. 1. Augenlicht. 4 Verse. 2. Gehör. 6 Verse. 3. Zunge. 6 Verse. 4. Herz. 4 Verse. III. $S \mathrm{chl}$ u B. 1. Ich, Leiche. 1 Vers. Stimme Gottes. 1 Vers. 2. Empfangen. 4 Verse. Dic Punkte $1-4$ von II. sind in sich nochmals jeweils zu zwei und zwei unterteilt.

Der vierte Abschnitt ist der "Rhythmik und Strophik" gewidmet. Bei der Untersuchung des Rhythmus geht Brjusov wieder davon aus, daß die Mannigfaltigkeit des Rhythmus bei Puškin durch die Kombination von Hypostasis (durch Pyrrhichius, seltener durch Spondeus) und Zäsur entsteht.

$\mathrm{Zu}$ diesem Zwedk ermittelt Brjusov zunächst rein statistisch das zahlenmäßige Verhältnis von Versen ohne Hypostasis, mit pyrrhichischer Hypostasis im ersten Versfuß, im zweiten, dritten, vierten, mit spondeischer Hypostasis im ersten, zweiten ... Versfuß usw. ${ }^{293}$

Danach wird Zeile für Zeile das Verhältnis von Hypostasis und Zäsur ermittelt. Brjusov gelangt dadurch zu dem Schluß, daß von den rhythmischen Variationen eine fünfmal, zwei Variationen dreimal, drei Variationen zweimal und zwölf Variationen nur einmal vorkommen. Auf diese Weise stellt Brjusov die Vielseitigkeit des Rhythmus im "Prorok" dar.

Der Strophik ist nur ein kurzer Absatz gewidmet, in dem festgestellt wird, daß diese der äußeren Komposition entspricht.

Der fünfte Abschnitt (Zvukopis') bietet eine bis ins letzte Detail gehende Untersuchung des Gedichtes vom Gesichtspunkt der konso-

282 Vgl. Sintetika poèzii.

$283 \mathrm{Vgl}$. B. O. U n beg a u n: Russian Versification S. $14 \mathrm{ff}$. 
nantischen Euphonie. Zeile für Zeile wird hier auf euphonische Figuren untersucht. Die verwendete Terminologie ist die in den "Opyty ${ }^{\alpha}$ von Brjusov eingeführte. Es gelingt Brjusov, seiner These in "Zvukopis' Puškina ${ }^{\alpha}$ entsprechend, in jeder Zeile des Gedichtes eine oder mehrere euphonische Figuren nachzuweisen.

Der letzte Abschnitt schließlich befaßt sich mit der vokalischen Euphonie des Gedichtes (Instrumentovka i rifmovka). Die Untersuchung über die "Instrumentovka ${ }^{\alpha}$ dieses Gedichtes ist die einzige von Brjusov konsequent durchgeführte dieser Art. Er geht zunächst wieder statistisch vor, indem er feststellt, daß von den 252 Silben, die das Gedicht enthält, 91, d. h. mehr als ein Drittel, die Laute i, ij, y, yj und unbetontes e ausmachen. Diese Laute werden dann je nach Häufigkeit ihres Vorkommens im Gedicht weiter aufgegliedert, auch nach betonten und unbetonten Silben. Anschließend nimmt Brjusov eine fortlaufende Analyse des Gedichtes hinsichtlich der Vokale vor. Dabei richtet er sein Hauptaugenmerk auf ein Schwinden oder Ansteigen der Häufigkeit von i-Lauten. Er gibt in diesem Zusammenhang einige Hinweise auf die Entsprechung des semantischen Gehalts der jeweils analysierten Verse. Brjusov gelangt zu dem Schluß, daß der Aufbau der Instrumentation in diesem Gedicht von dem Wort mit der „logischen Betonung ${ }^{\alpha}$ des letzten Verses ausgeht, das den betonten Vokal i enthält (žgi).

Am Schluß der Arbeit folgt noch eine kurze Besprechung des Reimschemas.

Trotz ihrer Ausführlichkeit hält Brjusov diese Untersuchung des Gedichtes "Prorok“ noch nicht für vollständig. Sie genügt auch nicht ganz seinen in früheren Aufsätzen geforderten methodischen Grundsätzen. Brjusov gibt diesem Gedanken am Schluß der Arbeit Ausdruck: „Zu dieser Analyse der gedanklichen und technischen Komposition, der Metrik und Rhythmik, der speziellen Euphonie (Zvukopis'), der Instrumentation und der Reime (der Euphonie) sollte eine gründliche Analyse der Melodik hinzugefügt werden (obwohl diese oben schon gestreift wurde), und ebenso eine Analyse der emotionalen Bedeutungen von Rhythmen und Lauten des Gedichtes (Fragen, die ebenfalls in diesem Aufsatz berührt wurden). Erst dann könnte die formale Untersuchung des Gedichtes als beendet angesehen werden. ${ }^{\alpha 284}$

284 Prorok. S. 297. 
Diese letzte Außerung gibt noch einmal eine Vorstellung von dem, was Brjusov von einer formalen Analyse eines literarischen Kunstwerkes erwartet. Wie vorher gezeigt wurde, begnügt er sich aber nicht nur mit einer Betrachtung der formalen Seite, sondern verlangt eine Beachtung aller Elemente, aus denen sich ein Kunstwerk zusammensetzt. 


\section{Zusammenfassung}

Betrachtet man rückschauend die Tätigkeit Brjusovs, dann treten bestimmte Schwerpunkte in seinen theoretischen und kritischen Arbeiten zutage. Es gilt nun zu unterscheiden, welche von ihnen von der nachfolgenden Entwicklung verdrängt, welche übernommen und weiterentwickelt wurden. Ebenso soll festgestellt werden, inwiefern das Gedankengut Brjusovs befruchtend oder anregend gewirkt hat.

Vor allem ist das Aufgreifen der Theorie Potebnjas zu nennen, das - sieht man von der ersten Periode ab - den Beginn der eigentlichen theoretischen und kritischen Tätigkeit Brjusovs darstellt.

Ferner gehören hierher auch die verschiedenen Ansätze, die Brjusov zu einer methodisch besser fundierten Forminterpretation literarischer Kunstwerke gemacht hat. Auf diesem Gebiet sind es im wesentlichen Belyj und Brjusov, denen die formalistische Schule zahlreiche Anregungen zu verdanken hat.

Ein unbestreitbares Verdienst Brjusovs ist es, als einer der ersten die Bedeutung der von ihm als "neuer Reim" bezeichneten Erscheinung erkannt und ihre wichtigsten Prinzipien zusammengefaßt und erklärt zu haben.

Die Arbeiten Brjusovs an einer russischen Verslehre führten, wie gezeigt wurde, zu keinem befriedigendem Ergebnis. Hier verlor er sich allzu sehr an die aus der antiken Verslehre übernommenen Kategorien, die ihm den Weg zum eigentlichen Wesen des russischen Verses verstellten und seine Arbeit dazu verurteilten, Fragment zu bleiben.

Die unmittelbaren Nachfolger der Symbolisten auf dem Gebiet der Literaturwissenschaft sind in Rußland die Formalisten. Mit diesen setzte eine starke Intensivierung der literaturwissenschaftlichen Tätigkeit ein. Der Weg dazu war u.a. dadurch geebnet worden, daß sich mit den Symbolisten die Literatur selbst der Theorie bemächtigte und auf diesem Gebiet Erhebliches leistete. Auf diese Weise 
fanden literaturtheoretische Probleme in bedeutend weiteren Kreisen als vorher Interesse.

Vor allem hat der Formalismus zahlreiche Anregungen den von den Symbolisten wieder aktivierten Ideen Potebnjas zu verdanken. Sklovskij möchte allerdings den Einfluß Potebnjas als unwesentlicher darstellen, als er in Wirklichkeit ist. Seinen Widerspruch begründet er hauptsächlich damit, daß Potebnja als das Wesen der Kunst das Denken in Bildern bezeichnet. "Bildhaftes Denken, schreibt Sklovskij dazu, ist in keinem Falle das, was alle Aspekte der Kunst vereinigt oder auch nur alle Aspekte der Wortkunst $\ldots{ }^{{ }^{2885}}$ Auch sei die Kunst nicht ein Mittel der "Erkenntnis" (poznanie), wie Potebnja lehrt, sondern sie soll uns das Empfinden für die Welt wiedergeben. Dies erreichte man dadurch, daß man das Erkennen verzögert, das Verstehen absichtlich erschwert. Das Merkmal des Künstlerischen besteht für Sklovskij darin, „daß es absichtlich zum Herausführen aus der Automatisation des Verstehens geschaffen wurde, daß darin das Sehen (videnie) das Ziel des Schaffenden bleibt ... ${ }^{4288}$

Dieses Erschweren des Verständnisses bezeichnet Sklovskij als den "Kunstgriff der erschwerten Form" (priem zatrudnennoj formy). Ebenfalls als Mittel zur Lösung aus der Automatisation bezeichnet er den "Kunstgriff der Verfremdung " (priem ostranenija). Die Dinge sollen dem Leser zunächst völlig fremd erscheinen, damit er mit dem Prozeß des Verstehens wieder von vorne beginne, so als habe er mit dem betreffenden Gegenstand noch nie etwas zu tun gehabt. Auf diese Weise wird der Augenblick des Erkennens hinausgeschoben, so daß bis dahin der Leser den Gegenstand wirklich "gesehen " hat, sich des Empfindens dafür bewußt geworden ist.

Die poetische Sprache ist für Šklovskij eine verfremdete Sprache. "Und eben um das Leben wieder zu empfinden, um die Dinge zu fühlen, um den Stein wieder steinern zu machen, dazu gibt es das, was wir Kunst nennen. Die ganze Kunst ist da, um uns das Empfinden für die Dinge zu geben, und zwar als Sehen und nicht als Erkennen. Als Kunstgriff der Kunst erweist sich der Kunstgriff der "Verfremdung " der Dinge und der Kunstgriff der erschwerten Form, der das Verstehen schwieriger macht und verzögert, da in der Kunst der Prozeß des Verstehens Selbstzweck wird und verlängert werden

295 Viktor $S k$ l $\circ$ v skij: O teorii prozy. Moskau-Leningrad 1925, S. 8. 288 ibid. S. 18. 
muß; Kunst ist das Mittel, das Werden der Dinge zu erleben, während das Fertige in der Kunst belanglos ist. ${ }^{\alpha 287}$

Das führr aber letzten Endes wieder zu dem Ergebnis, daß die Kunst dadurch, daß sie "sehen" lehrt, zu einem Vorgang der Erkenntnis wird. Dies ist von Potebnjas Idee nicht mehr sehr weit entfernt. 288

Einen treffenden Überblick über die geistigen Vorgänger der Formalisten gibt Viktor Žirmunskij, wenn er schreibt: „Die Suche nach einer historischen und theoretischen Poetik ist schon früher in der russischen Wissenschaft durch die Arbeiten A. N. Veselovskijs und A. A. Potebnjas betrieben worden. Doch haben wir lebendige Impulse zur methodologischen Untersuchung auf dem Gebiet der literarischen Form tatsächlich von den Theoretikern des Symbolismus empfangen ... ${ }^{\alpha 289}$

Das Bild der Formalisten vom Wesen der Literatur weicht insofern von dem Brjusovs und auch von dem Belyjs und Vjačeslav Ivanovs $a b$, als bei diesen für die Entstehung eines literarischen Werkes neben linguistischen Elementen auch emotionale Faktoren (Gefühle, Leidenschaften usw.) postuliert werden, während jene als einzige literarische Grundsubstanz das Wort anerkennen. „Das Material der Dichtung, sagt Ejchenbaum, sind weder Bilder noch Emotionen, sondern das Wort. Dichtung ist Wortkunst (slovesnoe iskusstvo) ..." ${ }^{290}$

Und Žirmunskij definiert: "Als das Material der Dichtung erscheint das Wort. Wir verstehen die Geschichte der Dichtung als Geschichte der Wortk u n s t". ${ }^{\prime 290 *}$ Ein Kunstwerk entsteht nach Ansicht der Formalisten dadurch, daß Worte durch die Anwendung von Kunstgriffen ("priem“, ein Ausdruck, den Brjusov im gleichen Zusammenhang, wenn auch nicht so ausschließlich, bereits in der zweiten Periode seiner Tätigkeit verwendete, wie in dieser Arbeit gezeigt wurde) zu einer Einheit zusammengefügt werden. Tomaševskij formuliert das wie folgt: „Bei der theoretischen Behandlung werden die literarischen Erscheinungen einer Ve r a ll g e m e inerung unterworfen und daher nicht in ihrer Individualität be-

287 ibid. S. 12.

$288 \mathrm{Vgl}$. V. E r l i ch: Russian Formalism. 's-Gravenhage 1955, S. 7 ff.

289 V. Zirmunskij: Voprosy teorii literatury. Leningrad 1928, S. 8.

200 B. E j c h e n b a u m: Literatura, teorija - kritika - polemika. Leningrad 1927, S. 28.

200a V. Zirmunskij: Valerij Brjusov i nasledie Puškina. Opyt sravnitel'no stilistið̌eskogo issledovanija. Peterburg 1922, S. 5. 
trachtet, sondern als die Ergebnisse der Anwendung allgemeiner Gesetze für den Aufbau literarischer Werke. Jedes Werk wird bewußt in seine Bestandteile zerlegt, im Aufbau eines Werkes unterscheidet man die Kunstgriffe eines analogen Aufbaues, d. h. Arten der Kombination von Wortmaterial zu einer künstlerischen Einheit. Diese Kunstgriffe erscheinen als das direkte Objekt der Poetik. " 201

Eine außerhalb des Formalen liegende Auffassung von der Seinsweise des literarischen Kunstwerkes finden wir erst wieder beim polnischen und čechischen Strukturalismus. Hier ist es vor allem Roman Ingarden, der, auf die Ideen Husserls zurüdkgehend, das literarische Kunstwerk als eine Struktur verschiedener Elementarschichten auffaßt.

Bei diesen Schichten handelt es sich um: „1. die Schicht der Wortlaute und der auf ihnen aufbauenden La utgebilde höherer Stufe; 2. die Schicht der Bedeutungseinheiten verschiedener Stufe; 3. die Schicht der mannigfaltigen schematisierten A n $\mathrm{s}$ ich $\mathrm{t}$ e $\mathrm{n}$ und Ansicht-Kontinuen und -Reihen und endlich 4. die Schicht der dargestellten Gegenständlichkeiten und ihrer Schicksale. “292 Das Wort selbst ist hier lediglich den beiden ersten Schichten zugeordnet.

Von einer ähnlichen Vorstellung geht auch Mukařovský aus.. ${ }^{293}$ Die Arbeit von Wellek und Warren gründet sich ebenfalls auf eine strukturelle Erklärung des literarischen Kunstwerkes, nur daß hier statt vier drei Schichten angenommen werden. Die vierte Schicht Ingardens, die Aspektschicht, wird hier in die "Welt"-Schicht, d.h. die Schicht der dargestellten Gegenständlichkeit, einbezogen. ${ }^{294}$

Von russischen Autoren der neuesten Zeit sei L. I. Timofeev erwähnt. Auch ihm genügt die rein formalistische Erklärung des literarischen Kunstwerkes nicht. In seinen 1958 erschienenen „Očerki teorii $\mathrm{i}$ istorii russkogo sticha" schreibt er: "Wir können nicht voraussetzen, wie es seinerzeit die Formalisten getan haben, daß der künstlerische Gedanke eines Verses in ihm selbst enthalten ist, das heißt, daß die Versform für sich allein uns bereits eine künstlerische

291 B. T O m a še v sk i j: Teorija literatury. Leningrad 1925, S. 6.

292 Roman I n g a r de n: Das literarische Kunstwerk. Tübingen 1960, S. 26.

$203 \mathrm{Vgl}$. Jan M uka ̌̀ ovský: Kapitoly z Ceské poetiky I. Prag 1946, S. $13 \mathrm{ff}$.

$294 \mathrm{Vgl}$. René W ellek, Austin Warren: Theorie der Literatur. Bad Homburg 1959, S. 169 f., S. 175. 
Befriedigung bereitet - durch ihre klangliche Organisiertheit, durch ihren Rhythmus (ritmičnost') usw. Außerhalb des ideellen Inhalts kann die Form, ihrer Verbindung mit der gedanklichen Seite des Wortes, beraubt, nicht funktionieren, und - allgemeiner - verliert das Kunstwerk im ganzen seine Bedeutung, es bleibt außerhalb unseres ästhetischen Gesichtsfeldes. “294" Timofeev sieht ein Kunstwerk als ein Ganzes, dessen Bestandteile und Faktoren, die es formen, zwar einzeln zu untersuchen sind, die aber für sich selbst keine Bedeutung haben. „Das historische Leben des Verses, schreibt er, zeigt seine Abhängigkeit von bestimmten, allgemein literarischen Gesetzmäßigkeiten, von einem bestimmten Genre und Stil, ebenso wie die Analyse eines konkreten poetischen Kunstwerkes uns zwingt, eine tiefe innere Verbindung $z$ wischen seinem Inhalt an Ideen und Bildern und dem eigentümlichen, individuellen Klang seiner Versform wahrzunehmen. ${ }^{\text {"299 }}{ }^{\mathrm{D}}$

An anderer Stelle erläutert Timofeev das Problem Inhalt-Form, wobei er beide Begriffe in enger Abhängigkeit voneinander sieht, aber sie als getrennte Faktoren beibehält: "Inhalt und Form - das sind vor allem korrelative Begriffe, d. h. einer kann nicht ohne den anderen existieren: die Form erscheint als Form von etwas, anders ist sie sinnlos; der Inhalt muß, um zu existieren, eine Form haben, die ihn nach außen hin bestimmt, anders kann er nicht in Erscheinung treten. Daher sind Inhalt und Form untrennbar miteinander verbunden. Ein Inhalt muß in einer Form Gestalt annehmen, außerhalb derer er nicht mit voller Bestimmtheit existieren kann; eine Form hat dann Sinn und Bedeutung, wenn sie der Außerung eines Inhalts dient. Und in der Abhängigkeit vom Inhalt erhält sie ihre Eigenart, die sie von anderen Formen unterscheidet, in denen andere Inhalte in Erscheinung treten, d. h. von anderen Erscheinungen. ${ }^{\text {2094c }}$

Das emotionale Moment eines Kunstwerkes liegt für Timofeev bereits in der verwendeten Sprache. Die Sprache, deren sich der Künstler in seinen Werken bedient, bezeichnet er als den ${ }_{n}$ emotionalen Typ der Sprache" im Gegensatz zur "logischen Sprache", deren sich z. B. die Wissenschaft bedient. Die diesbezügliche Definition Timofeevs lautet: "Wenn wir die logische Sprache, und zwar in erster Linie in

294a L. I. T i m of e e v: Ocerki teorii $\mathrm{i}$ istorii russkogo sticha. Moskau 1958, S. 4.

204b ibid.

204c L. I. T i m of e e v: Osnovy teorii literatury. Moskau 1959, S. 121. 
einer so ausgesprochenen Form wie der wissenschaftlichen Sprache, mit der emotionalen Sprache vergleichen, werden wir leicht bemerken, daß ihr grundlegender Unterschied in der Art und Weise liegt, in der sie ihren Inhalt zum Ausdrudk bringen. Im ersteren Falle fällt dieser Inhalt mit der Bedeutung der Wörter zusammen, besonders deutlich tritt dieser Zusammenfall beim terminus technicus zutage. Der Inhalt der Rede verlangt für seine Realisierung nicht die Einführung irgendwelcher subjektiv wertender Elemente, das Element des Affektiven wird auf ein Minimum reduziert, es ist untergeordnet. Die logische Sprache ist eine Sprache, die aus Wortbedeutung und ihren Kombinationen besteht.

Umgekehrt ist die emotionale Sprache, genauer die emotional gefärbte Sprache eine Sprache, in der die subjektiv wertenden Elemente die konstruktive Rolle spielen, indem sie die lexikalische Bedeutung des Wortes ergänzen und zuweilen verdrängen. Wenn sich für die logische Sprache als die ausgesprochenste und äußerste Form der terminus technicus erweist, dann spielt für die emotionale Sprache diese Rolle der äußersten Form die Interjektion, indem sie überhaupt keine ständige Bedeutung hat, sondern in jedem einzelnen Fall - ad hoc einen bestimmten Sinn annimmt. Dies ist die Sprache, die mit Wortbedeutungen operiert, in denen das, was man den in neren I $\mathrm{nhal}$ t nennen kann, vor ihrer unmittelbaren Bedeutung vorherrscht. ${ }^{\alpha 204 d}$

Bei einem Vergleich Brjusovscher Lehren über die formalen Elemente der Literatur mit denen seiner Nachfolger entsteht zunächst die Frage einer Aufteilung des gesamten Themenbereichs in einzelne Disziplinen. Diese Aufteilung ist bei den einzelnen Autoren verschieden. Auch Brjusov wechselt das Einteilungsschema im Laufe seiner Entwidklung immer wieder.

Ein Grundelement bei der formalen Betrachtung von Versdichtung ist das Metrum. Hierzu wird von den meisten Autoren auch die Strophenform gerechnet. Das andere Grundelement ist die Euphonie. Hierher wird von einigen Autoren auch der Reim gezählt, während andere ihn gemeinsam mit der Metrik abhandeln. Am verschwommensten und am meisten voneinander abweichend sind die Definitionen und Betrachtungsmethoden des Versrhythmus.

204d L. I. T im of e e v: Očerki teorii $\mathrm{i}$ istorii russkogo sticha. Moskau 1958, S. 20 . 
Sowohl Brjusov wie auch Belyj geben eine klare Definition dessen, was sie für den Rhythmus eines Verses halten und welche Faktoren sie für sein Entstehen verantwortlich machen. Eine bedeutende Erweiterung und Vertiefung erfährt das Problem des Rhythmus bei den Formalisten. Tomaševskij, der das Problem des Rhythmus in einem besonderen Aufsatz behandelt, gelangt zu dem Schluß, daß der Gesamtrhythmus eines Verses sich aus drei Teilrhythmen zusammensetzt, und zwar dem Rhythmus der Wortbetonung, dem Rhythmus der Satzintonation und dem "harmonischen Rhythmus", worunter Tomaševskij den Rhythmus versteht, der durch euphonische Effekte entsteht. Als übergeordneten Begriff führt Tomaševskij den "rhythmischen Impuls" ein. "Dieser Begriff des rhythmischen Impulses, d. h. des Grundprinzips, das in sich alle klanglichen Kunstgriffe vereinigt, erweist sich als außerordentlich wichtig bei der Analyse des Rhythmus der poetischen Sprache. ${ }^{\alpha 205}$ Im Gegensatz zu Belyj und Brjusov wird hier das Metrum eines Verses nicht als eigenes Element neben dem Rhythmus verstanden, sondern als eines der den Rhythmus formenden Elemente.

Ahnlich wie Tomaševskij faßt auch Jurij Tynjanov den Begriff des Rhythmus komplexer auf, als dies bei Belyj und Brjusov geschieht. Auch Tynjanov sieht den Rhythmus als einen den Faktoren Metrum, Wortinstrumentation (slovesnaja instrumentovka) und Reim übergeordneten Begriff. Die Definition wird hier durchgeführt, indem die Kennzeichen der verschiedenen Elemente einander gegenübergestellt werden. Dabei erweist es sich, daß Kennzeichen des Rhythmus ebenso gut auch als Kennzeichen z. B. des Metrums verstanden werden können. ${ }^{206}$

Auch Timofeev befaßt sich in seinem bereits zitierten Werk mit der Frage nach dem Rhythmus. Die rhythmische Einheit des Verses ist bei ihm eindeutig die Versz eil e. Er gibt dafür folgende Begründung an: "Was veranlaßt uns dazu, die Verszeile als rhythmische Einheit zu sehen? Vor allem doch dies, daß die Zeile eine intonationsmäßig in sich abgeschlossene Verbindung von Wörtern darstellt, eine vollständige sprachliche Einheit, ein verhältnismäßig selbständiges gedankliches und intonationsmäßiges Ganzes (manchmal

295 B. T o ma Ševskij: Problema stichotvornogo ritma. "Literaturnaja mysl ${ }^{\propto}$ II, 1923, S. 134.

$200 \mathrm{Vgl}$. Jurij T y n ja nov: Problem stichotvornogo jazyka. Leningrad 1924 , S. $28 \mathrm{ff}$. 
kann die Zeile auch aus einem Wort bestehen, was in diesem Falle, wie wir es verstehen, seine intonationsmäßige Selbständigkeit charakterisiert). Als ein Kennzeichen dieser Abgeschlossenheit zeigt sich die die Zeile abschließende Pause, deren Nichtbeachtung den Rhythmus des Verses zerstört, indem die Grenze zwischen seinen Einheiten verwischt wird und dadurch nicht mehr gestattet, das Rhythmische ihres Wechsels wahrzunehmen. "296"

Dies dürfte für die Untersuchung sehr vieler Kunstwerke in gebundener Sprache eine brauchbare Grundlage sein. In einigen Fällen jedoch (z. B. bei Autoren, die viel mit Binnenreimen arbeiten, oder anderen, die gerne einzelne Zeilen durch den Satzbau im Gedicht so ineinander übergehen lassen, daß mehrere Zeilen zusammen eine rhythmische Einheit bilden), müßte von diesem sich hier als zu starr erweisenden Prinzip abgegangen und der Rhythmus des betreffenden Gedichtes auf Grund der Annahme anderer, kleinerer oder größerer rhythmischer Einheiten untersucht werden.

Das von Brjusov in seiner Verslehre ("Kratkij kurs nauki o stiche“) ausgearbeitete System der russischen Metrik wird von den Formalisten, m. E. zu Recht, verworfen. In seiner Rezension von Brjusovs Verslehre begründet Roman Jakobson seine Ablehnung damit, daß das System Brjusovs an den Tatsachen der lebendigen russischen Sprache vorbeigehe. ${ }^{297}$ Die einfache Ubertragung der gesamten antiken Verslehre, die auf dem Wechsel von Längen und Kürzen beruht, auf die moderne russische Dichtung, bei der das tragende Element des Metrums der Wortakzent ist, wurde eigentlich von keinem späteren Gelehrten wieder aufgegriffen. So läßt z. B. Tomaševskij in seiner "Theorie der Literatur" zwar die zwei- und dreisilbigen Versfüße für die russische Dichtung gelten, löst jedoch Verse, die Brjusov in mehrsilbige Versfüße einteilt, in Gruppen von Jamben bzw. Trochäen auf. Den Begriff des Pyrrhichius verwendet Tomaševskij nicht, sondern er gründet seine metrischen Betrachtungen im wesentlichen auf Strophenformen (im Gegensatz zu Brjusov, der die Strophik als eigenes Gebiet behandelt wissen will). ${ }^{298}$

${ }^{290}$ a L. I. T i m of e e v: Očerki teorii $\mathrm{i}$ istorii russkogo sticha. Moskau 1958, S. $67 \mathrm{f}$.

$207 \mathrm{Vgl}$. R. O. Jak obs o n: Brjusovskaja stichologija i nauka o stiche S. $230 ;$ S. 240.

208 B. Tom a ševskij: Teorija literatury S. $111 \mathrm{ff}$. 
Hinsichtlich der Bewertung von Alliterationen und Assonanzen folgen die Formalisten weitgehend den Anregungen der Symbolisten. Ebenso wie bei den Symbolisten spielen auch bei den Formalisten Untersuchungen über die lautlichen Verhältnisse eines Kunstwerks eine wesentliche Rolle. Die Unterscheidung zwischen nzvukopis' und "instrumentovka ", die Brjusov macht, wird von den Formalisten, wie bereits erwähnt, nicht übernommen. Ihnen erscheint es zweckmäßiger, die Betrachtung von Konsonanten- und Vokalanordnung gleichzeitig durchzuführen. Dieses euphonische Kunstmittel wird von ihnen im allgemeinen als "slovesnaja instrumentovka " bezeichnet.

Interessant ist die Feststellung, wie weitgehend Symbolismus und Formalismus später verschiedentlich identifiziert wurden. So schreibt V. Asmus, ein Vertreter der "Parteilichkeit der Kunst", in "Literaturnoe nasledstvo" (1937): "Tatsächlich zieht sich von den theoretisch-literaturwissenschaftlichen Arbeiten der Symbolisten bis zu den Theorien des literarischen Formalismus, die in den ersten Jahren des imperialistischen Krieges hervorgetreten sind, ein direkter genetischer

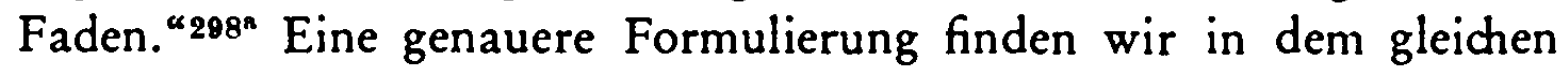
Aufsatz an anderer Stelle: „Der Formalismus, der Kampf gegen die Parteilichkeit der Kunst, ist keine zufällige und zweitrangige Tendenz des Symbolismus, sondern der innerste und wesentlichste Zug an ihm. Nicht eine Neugestaltung des Lebens mit Mitteln der Kunst, sondern ein sich vom Leben Abschließen mit Formen der Kunst $\mathrm{d}$ arin sieht der Symbolismus die wirkliche Bedeutung der Kunst. ${ }^{\text {(2988 }}$

L. I. Timofeev führt als wesentliches euphonisches Element der poetischen Sprache die "expressive Intonation " ein. Diese Intonation verleiht der Sprache den emotionalen Klang. „Eine Intonation ist naturgemäß mit jedem beliebigen Sprachtyp verbunden - sowohl mit der logischen als auch mit der affektiven Rede, aber in der emotional gefärbten Sprache hat sie die führende Bedeutung. Ein Wort besteht in der Rede nicht für sich selbst. Es lebt im Kontext, von dem es auch seinen realen Klang erhält. Diesen realen Klang, den lebendigen Sinn, gibt ihm auch die Intonation, welche es sozusagen an die anderen Wörter anpaßt, der Rede die organische Einheit ver-

\footnotetext{
298a V. A s m us: Filosofija i èstetika russkogo simvolizma. „Literaturnoe nasledstro“ Bd. 27-28, Moskau 1937, S. 2.

208 b ibid. S. 32.
} 
leiht. Die Intonation ist die Zeit und der Raum des lebendigen Wortes, nur in ihr existiert es und erhält seinen realen Sinn. ${ }^{\text {"208c }}$ Dabei ist der logischen Sprache und der emotionalen Sprache jeweils eine besondere Intonation zugeordnet: "Die logische Intonation hebt nur das hervor, was in der Lexik und im grammatischen Aufbau der Rede vorgegeben ist, sie fügt ihr nichts Neues oder Eigenständiges hinzu. Man kann sie die objektive oder grammatische Intonation nennen. Die emotionale Intonation aber hat eine selbständige sinngebende Funktion. Man kann sie die subjektiv-wertende, die expressive Intonation nennen. ${ }^{\alpha 298 d}$ Timofeev führt damit in die Versbetrachtung ein Element ein, das nicht an das Schriftbild gebunden und durch dieses nicht kontrollierbar ist. Der Autor eines Gedichtes will aber seinem Leser auch klangliche Werte vermitteln. Mit welchen Methoden er dabei vorgeht, das soll z. B. bei Brjusov oder den Formalisten eine Analyse der ninstrumentovka " ergeben. Diese aber hält sich an das geschriebene Wort. Das Verhältnis der Intonation zum schriftlichen Ausdruck beschreibt Timofeev wie folgt: „Diese zwei Typen der Intonation verleihen naturgemäß allen Mitteln der Intonation ihr Gepräge. Dies ist zum Teil daraus zu ersehen, daß die objektive grammatische Intonation sich vollständig mit der allgemein üblichen geschriebenen Interpunktion deckt, während sich die expressive Intonation nur bedingt mit dieser deckt, einer außerordentlich weit angelegten Interpretation Raum gibt und in bezug auf das Tempo, sowie bedingungslos in bezug auf die Klangfarbe, ausschließlich im Bereich der mündlichen Rede steht. ${ }^{\alpha 288 e}$

Die Analyse von Versen hinsichtlich euphonischer Figuren ist auch von den Strukturalisten übernommen worden. ${ }^{299}$ Desgleichen beruft sich auch Wellek in diesem Falle auf die Vorarbeiten der Formali. sten. ${ }^{300}$

Zusammenfassend kann gesagt werden, daß im wesentlichen die Bedeutung des literaturwissenschaftlichen und literaturkritischen Werkes Brjusovs darin liegt, neben anderen symbolistischen Autoren einerseits das Gedankengut Potebnjas wieder gegenwärtig gemacht,

${ }^{208 c}$ L. I. T i m of e e v: Očerki teorii $i$ istorii russkogo sticha. Moskau 1959, S. 22.

298d ibid. S. 27.

208e ibid. S. $27 \mathrm{f}$.

209 Vgl. Jan M uk a ł o v sk ý: Máchův „Máj“. Estetidká studie. Prag 1928.

$300 \mathrm{Vgl}$. René Welle k, Austin W a r r e n: Theorie der Literatur (S. $178 \mathrm{f}$., 179, 181, Anmerkung 9). 
andererseits belebendes, neues Gedankengut der russischen Literaturwissenschaft zugeführt zu haben.

Dadurch, daß sich hier Literaten selber neben ihrer dichterischen Tätigkeit mit rein theoretischen Problemen befaßten, wurde ein reges. weitverbreitetes Interesse an eben diesen theoretischen Problemen wachgerufen. Diese Tatsache dürfte zum nicht geringen Teil dafür verantwortlich sein, daß die Bewegung des Formalismus mit einer derartigen Intensität auftrat und sich eines so allgemeinen Interesses erfreute.

Wenn auch die Formalisten die Ideen und Methoden Brjusovs, Belyjs u. a. im einzelnen nicht in der gleichen Form übernommen haben, so sind sie doch, wie gezeigt wurde, durch sie angeregt worden. Ein großer Teil der Ideen ist weiterentwickelt, abgewandelt, in allgemeingültigere Formen gegossen worden.

Leider hat Brjusov keine ausführliche und zusammenfassende Erörterung seiner theoretischen Ideen niedergelegt. Seine Arbeiten sind stets kurz, oft fast aphorismenhaft, selten nur ist ein Gedanke in Einzelheiten ausgearbeitet. Diese nur mangelhafte Ausführung läßt ihn - wie zum Beispiel in seiner Verslehre - zuweilen bereits bei Fragen der Methodologie oder der Nomenklatur stehenbleiben. Fast in jeder Arbeit Brjusovs finden wir den Hinweis, daß man auf dem von ihm angedeuteten Weg fortfahren solle, ohne daß er das selber jemals durchgeführt hätte. Selbst in seiner verhältnismäßig sehr ausführlichen Analyse von Puškins Gedicht "Prorok" weist er, wie bereits gesagt, am Schluß darauf hin, daß die Analyse unvollständig sei und man es noch unter einer Reihe anderer Aspekte betrachten müsse.

Die Tatsache, daß Brjusov auf dem Weg über die Dichtung zur Kritik und Theorie gelangte, wirkte sich insofern negativ aus, als er allzu oft in seinen Analysen durch weltanschauliche Betrachtungen vom eigentlichen Stoff abschweift. Daher bemerken wir in einer Reihe seiner Abhandlungen auch ein der Sache nicht angemessenes Pathos im Stil. Dies trifft allerdings für die dritte Periode kaum mehr zu.

Jedoch überwog bei ihm das Streben nach Sachlichkeit, indem er stets für die Freiheit der Kunst von allen utilitaristischen Bindungen eintrat. Am wirksamsten gelangten Brjusovs theoretische Uberlegungen in seinen Ubersetzungen zur Anwendung. Viele dieser Arbeiten sind in der Qualität bis heute unerreicht geblieben. 
(t) 1)

and

117.15)

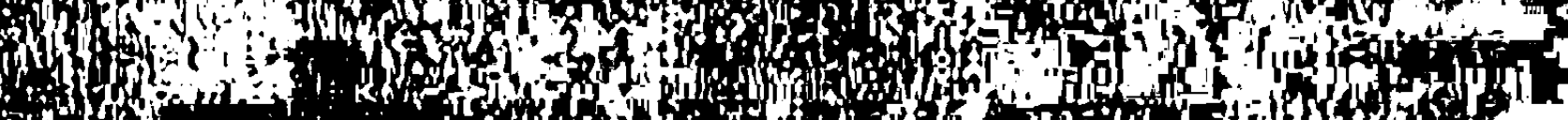
Fing

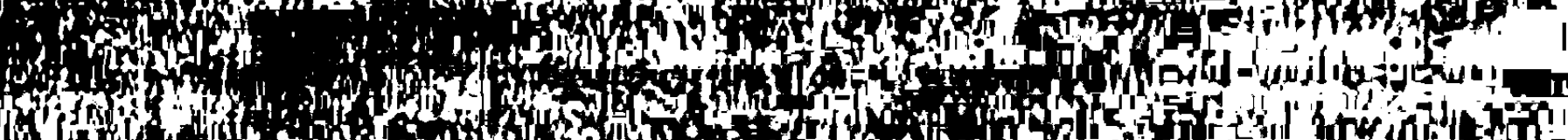

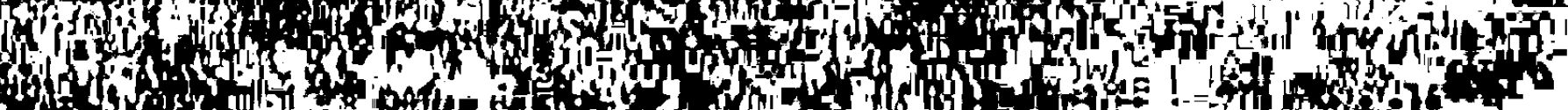
If Lef

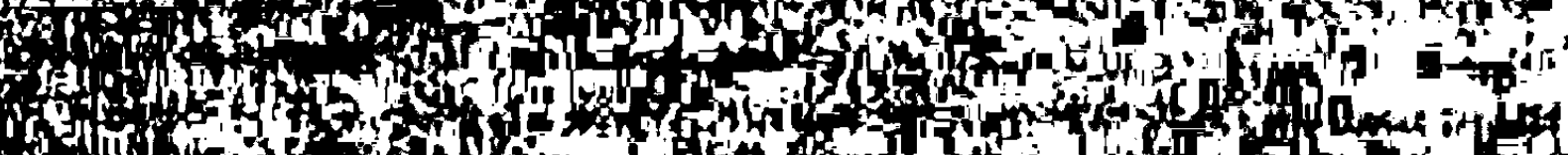
145 (4)

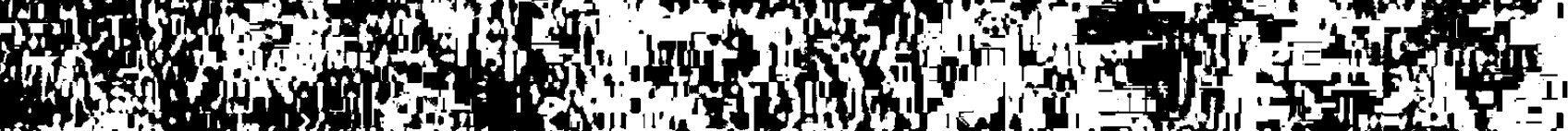

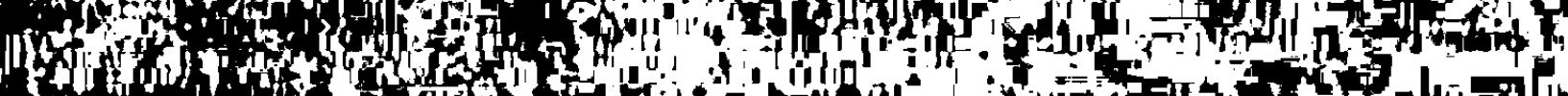
6. (1) and

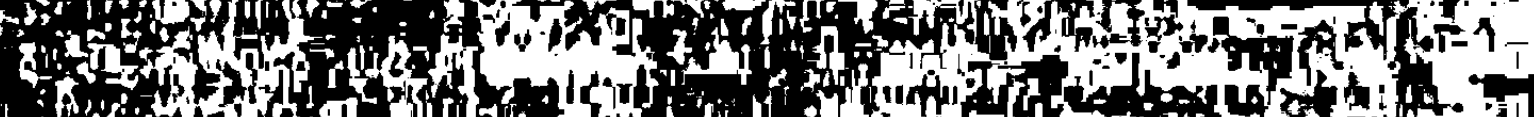
If

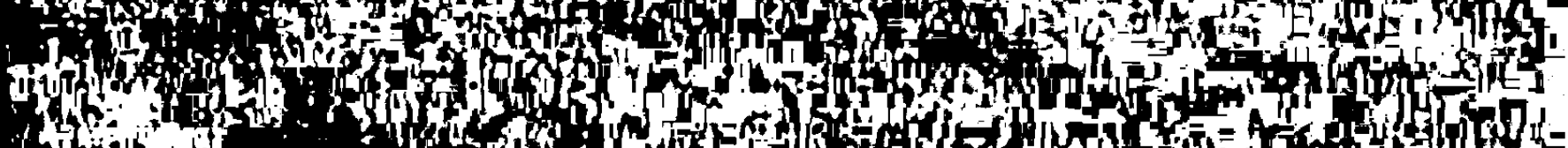

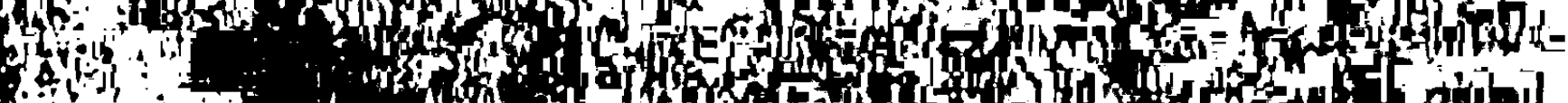

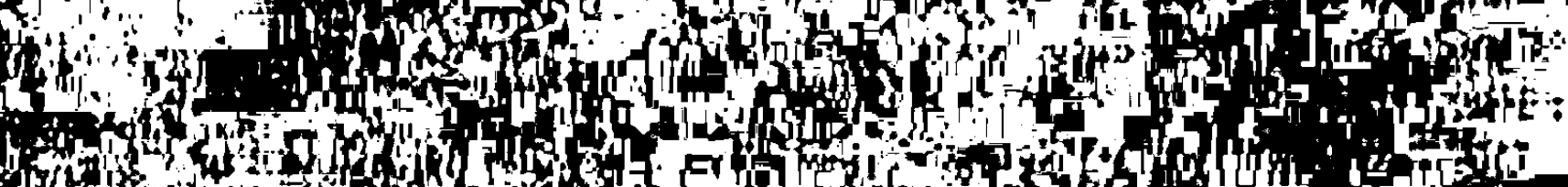

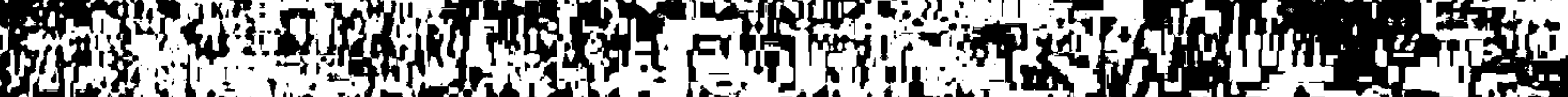

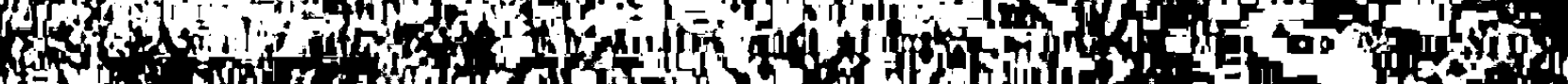

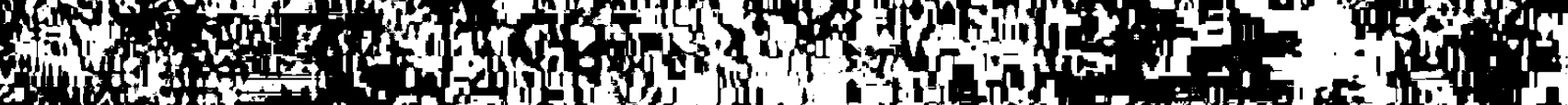
ant (t).

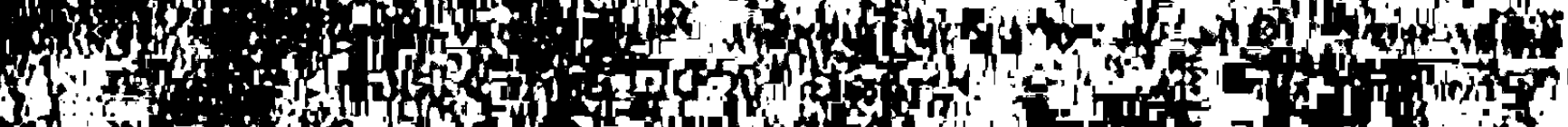
35 To if Aw

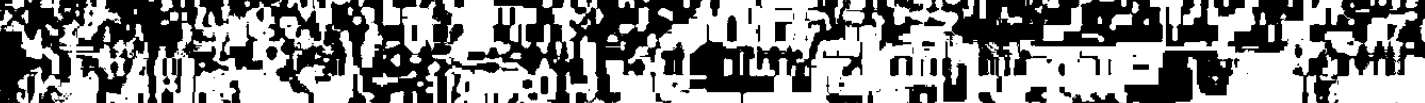

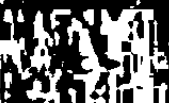

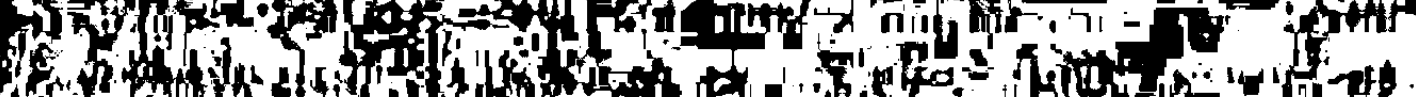

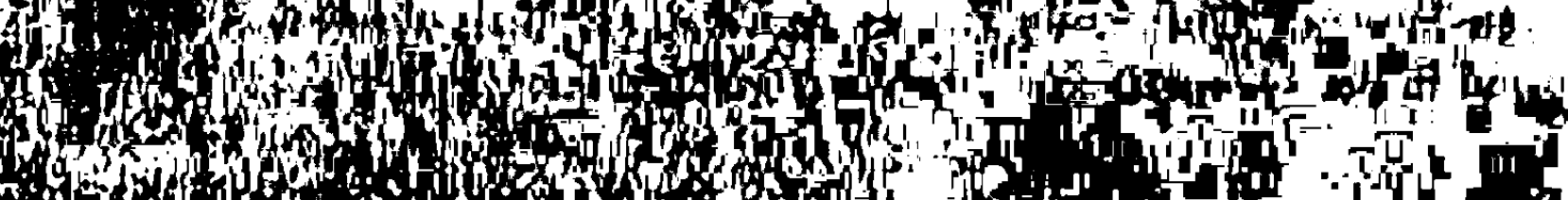

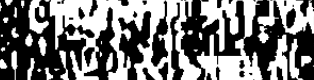
sing

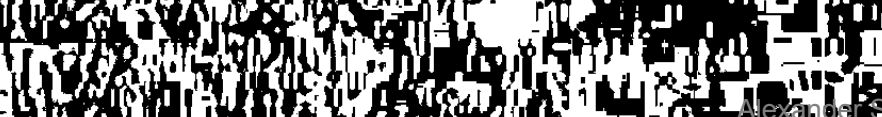

its 


\section{LITERATURVERZEICHNIS}

\section{A. Schriften Valerij Briusovs}

Polnoe sobranie sočinenij i perevodov. Bd. 1 2, 3, 4, 12, 13, 15, 21. St. Peterburg 1913-14.

Izbrannye sočinenija v dvuch tomach. Moskau 1955.

Dalekie i blizkie. Stat'i i zametki o russkich poètach ot Tjutčeva do našich dnej. Moskau 1912.

Moj Puškin. Moskau-Leningrad 1929.

Dnevniki 1891-1910. Moskau 1927.

Iz moej žizni. Moja junost'. Pamjati. Moskau 1927.

Pis'ma V. Ja. Brjusova k P. P. Percovu 1894-1896. Moskau 1927.

A ̌̌u $\mathrm{k}$ in N.: Valerij Brjusov $\mathbf{v}$ avtobiografičeskich zapisjach, pis'mach, vospominanijach sovremennikov i otzyvach kritiki. Moskau 1929.

O iskusstve. Moskau 1899.

Licejskie stichi Puškina. Moskau 1907.

Opyty po metrike i ritmike, po évfonii i sozvučijam, po strofike i formam. Moskau 1918.

Kratkij kurs nauki o stiche. Moskau 1919.

Osnovy stichovedenija. Moskau 1924.

Čto daet akademičeskoe izdanie sočinenij Puškina. "Russkij archiv" 1899, XII.

Istiny: načala i nameki. "Severnye cvety na 1901 g.

Mudroe ditja. "Mir iskusstva" 1901, VI.

Iskusstvo ili žizn'. ibid. 1903, IX.

K. D. Bal'mont. ibid. 1903, X.

Ključi tajn. "Vesy ${ }^{\alpha}$ 1904, I.

Vechi I: Strast'. ibid. 1904, VIII.

Poèt protivorečij. ibid. 1904, X.

René Ghil. ibid. 1904, XII.

Svjaščennaja žertva. ibid. 1905, I.

V zaščitu ot odnoj pochvaly. ibid. 1905, V.

Fialki v tigele. ibid. 1905, VII.

Odnomu razvjaznomu kritiku. ibid. 1905, IX-X.

Vechi: Svoboda slova. ibid. 1905, XI.

Vechi: Fakely. (Avrelij). ibid. 1906, V.

Novye perevody Vercharna. (Avrelij). ibid. 1906, IX.

Novye sborniki stichov. ibid. 1907, I.

Novye sborniki stichov. ibid. 1907, II.

Pisat' ili spisyvat'. ibid. 1907, III.

Novye sborniki stichov. ibid. 1907, V.

Tvorčestvo pobeditelej. (V. Bakulin). ibid. 1907, IX.

Novye sborniki stichov. ibid. 1907, X.

Zaščitniku avtoriteta. K kritike teksta Puškina. ibid. 1907, XI.

Debjutanty. ibid. 1908, III.

Dve knigi. ibid. 1908, VI.

Mednyj vsadnik. Biblioteka velikich pisatelej, pod. red. S. A. Vengerova.

Puškin t. III. St. Peterburg 1909. Izbr. soč. Bd. II, S. 421-452. 
Naučnaja poézija. "Russkaja mysl'“ 1909, VI.

O reči rabskoj, v zaščitu poèzii. "Apollon“ 1910, IX.

Ob odnom voprose ritma. ibid. 1910, XI.

Nekrasov kak poèt goroda. "Russkie vedomosti“ 25. XII. 1912. Izbr. soč. Bd. II, S. 231-236.

F. I. Tjutčev. Polnoe sobranie sơ̌inenija Tjuť̌eva (Vvedenie Valerija Brjusova). Moskau 1913.

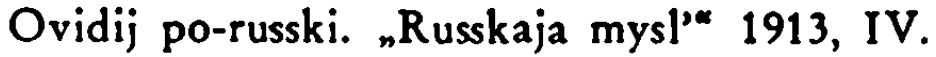

Dante sovremennosti. „Den’ж 25. XII. 1913. Izbr. sož. Bd. II, S. 237-245.

God russkoj poèzii. „Russkaja mysl’* 1914, V.

Stichotvornaja technika Pułkina. Biblioteka velikich pisatelej, pod. red.

S. A. Vengerova. Puškin t. VI. St. Peterburg 1915. Izbr. soč. Bd. II,

S. $371-408$.

Igor Severjanin. V sbornike "Kritika o tvorčestve Igorja Severjanina". Moskau 1916. Izbr. soč. Bd. II. S. 267-281.

Aleksandr Blok. " Russkaja literatura XX. veka" pod. red. S. A. Vengerova. T. II. kn. 2-ja. Moskau 1917. Izbr. soč. Bd. II, S. 282-294.

Gavriliada. Vstupitel'naja stat'ja i kritičeskie primečanija Valerija Brjusova. Moskau 1918.

Smysl sovremennoj poėzii. "Chudožestvennoe slovo* kn. 2-ja. Moskau 1920-1921.

Pox̌emu doly̌no izučat' Pư̌kina. "Moskovskij ponedel'nik" 1922, Nr. 6. Izbr. soč. Bd. II, S. 464-466.

Pogonja za obrazami. ibid. 1922, Nr. 12. Izbr. soč. Bd. II, S. 339-342.

Sredi stichov. "Pečat' i revoljucija" 1922, II.

Po povodu odnoi kritiki. ibid. 1922, II.

Pưkkin i krepostnoe pravo. ibid. 1922. II.

VČera, segodnja i zavtra russkoj poèzii. ibid. 1922, VII.

Raznostoronnost' Pư̌kina. "Izvestija VCIK ${ }^{\star}$ 1922, Nr. 34. Izbr. sox̌. Bd. II, S. 459-463.

Sredi stichov. „Pečat' i revoljucija * 1923, I.

Zvukopis' Puškina. ibid. 1923, II.

Sud akmeista. ibid. 1923, III.

Vercharn na Prokrustovom lože. ibid. 1923, III.

Sredi stichov. ibid. 1923, IV.

Otvet Georgiju Šengeli. ibid. 1923, VI.

O rifme. ibid. 1924, I.

Levizna Puškina v rifmach. ibid. 1924, II.

Sintetika poézii. "Problema poètiki" pod. red. V. Ja. Brjusova. MoskauLeningrad 1925. Izbr. soč. Bd. II, S. 356-370.

A n n u nz i o. Gabriele d'. Frančeska da Rimini. Tragedija v 5 dejstvijach. Perevod $z$ ital'janskogo razmerami podlinnika Valerija Brjusova i Vjač. Ivanova. St. Peterburg 1908.

Francuzkie liriki XIX. veka. Perevody v stichach i bio-bibliografičeskie primečanija Valerija Brjusova. St. Peterburg 1909.

G o e th e. Faust. Perevod Valerija Brjusova. Moskau-Leningrad 1928.

Ma eterlinck, Maurice. Peles i Melizanda. Stichi. Perevod Valerija Brjusova. Moskau 1907. 
- Izbienie mladencev. Rasskaz. S kritiko-biografičeskim očerkom o Meterlinke A. van Bevera. Perevod rasskaza prinadležit Brjusovu. Moskau 1904.

Po e, Edgar A. Polnoe sobranie poem i stichotvorenij. Perevod i predislovie Valerija Brjusova s kritiko-bibliografǐeskim kommentariem. MoskauLeningrad 1924.

Ve r h a e r e n, Emile. Stichi o sovremennosti, v perevode Valerija Brjusova. Moskau 1906.

- Elena Spartanskaja. Tragedija v 4 dejstvijach. Edinstvennyj, avtorizovannyj perevod s rukopisi (v stichach) Valerija Brjusova. Moskau 1909.

- Sobranie stichov. Perevody Valerija Brjusova. Moskau 1915.

Vergil. Eneida. Perevod Valerija Brjusova i Sergeja Solov'eva. MoskauLeningrad 1933.

Verla ine, Paul. Romansy bez slov. Perevod Valerija Brjusova. Moskau 1894.

- Sobranie stichov. V perevode Valerija Brjusova. Moskau 1911.

Wilde, Oscar. Gercoginja Paduanskaja. Drama v 5-ti dejstvijach, v stichach. Perevod Valerija Brjusova. Moskau 1911.

- Ballada Rèdingskoj tjur'my. Perevod s anglijskogo, razmerom podlinnika, Valerija Brjusova. Moskau 1915.

\section{B. Sonstige Literatur}

A d a m c z y k, Alexander: Russische Verskunst. "Münchener Beiträge zur Slavenkunde." Festgabe für Paul Diels, hsg. von Erwin Koschmieder und Alois Schmaus. München 1953, S. 179-201.

A nne nskij, I.: O sovremennom lirizme. "Apollon* 1909, I-II.

A sm us, V.: Filosofija i estetika russkogo simvolizma. "Literaturnoe nasledstvo Bd. 27-28. Moskau 1937.

B a l'm on t, K.: Poezija kak volłebstvo. Moskau 1915; Moskau 1922.

B el y j, Andrej: Apokalipsis v russkoj poezii. "Vesy" 1905, IV.

- V zaščitu od odnogo narekanija. Otkrytoe pis'mo Valeriju Brjusovu. ibid. 1905, VI.

- Simvolizm. Sbornik statej. Moskau 1910.

B e r gs o n, Henri: Denken und schöpferisches Werden. Obers. von L. Kottje. Meisenheim a. Glan 1948.

B la go j, D.: Brjusov. „Literaturnaja Enciklopedija“ Bd. I, Moskau 1929.

- Tvorčeskij put' Puškina. Moskau-Leningrad 1950.

B l ok, Aleksandr: O sovremennom sostojanii russkogo simvolizma. "Apollon ${ }^{*}$ 1910, VIII.

Carter, A. E.: The Idea of Decadence in French Literature 1830-1900. Toronto 1958.

Chodasevič, Vladislav: Literaturnye stat'i i vospominanija. New York 1954.

Croce, Benedetto: Grundriß der Asthetik. Ubers. von Th. Poppe. Leipzig 1913.

Cvet a ev a, Marina: Proza. New York 1953.

Donchin, Georgette: The Influence of French Symbolism on Russian Poetry. 's-Gravenhage 1958. 
E j ch en ba um, Boris: Melodika russkogo lirixeskogo sticha. Petrograd 1922.

- Literatura. Teorija - kritika - polemika. Leningrad 1927.

Erlich, Victor: Russian Formalism. History - Doctrine. 's-Gravenhage 1955.

Friedrich, Hugo: Die Struktur der modernen Lyrik. Hamburg 1956.

Ghil, René: Les dates et les oeuvres, Symbolisme et poésie scientifique. (5e édition). Paris 1926.

- Oeuvres complètes. T. I-III. Paris 1938.

Holthuse n, Johannes: Studien zur Asthetik und Poetik des russischen Symbolismus. Göttingen 1957.

$\mathrm{Humbold} t$, Wilhelm von: Öber die Verschiedenheit des menschlichen Sprachbaues. Hsg. Herbert Nette. Darmstadt 1949.

Ingarde n. Roman: Das literarische Kunstwerk. Halle a.d.S. 1931. 2. verbesserte und erweiterte Auflage, Tübingen 1960.

Istorija russkoj kritiki. T. I, II. Moskau-Leningrad 1958.

J a k obso n, Roman: Brjusovskaja stichologija i nauka o stiche. „Naučnye izvestija" 1922, II.

- and Morris $\mathrm{H}$ alle: Fundamentals of Language. 's-Gravenhage 1956.

I u revics. Pauls: Henri Bergson. Freiburg 1949.

Lednicki, Wacław: Pushkin's Bronze Horseman. Berkeley and Los Angeles 1955.

- Bits of Table Talk on Pushkin, Mickiewicz, Goethe. Turgenev and Sienkiewicz. Den Haag 1956.

Literaturnoe nasledstvo T. 27-28. Moskau 1937.

Masterstvo perevoda. Sbornik statej. Moskau 1959.

Muk a ̛̌ ov sk ý. Tan: Máchuv "Máj*. Estetidá studie. Prag 1928.

- Kapitoly z české poetiky. I, II. Prag 1946.

Gete, Faust. Perevod s nemedkogo B. P a ste r n a k a. Moskau 1957.

Potebnja, Aleksandr: Iz zapisok po teorii slovesnosti. Char'kov 1905.

- Jazyk i mysl'. 3. Aufl. Char'kov 1913.

Š e n g e li, G.: Brjusov meždu dvuch stul'ev. "Pečat' i revoljucija ${ }^{\alpha} 1923$, VI.

Sklovskij, Viktor: O teorii prozy. Moskau-Leningrad 1925; Moskau 1929.

Solov'e v, Vladimir: Smysl iskusstva. Berlin 1924.

- Deutsche Gesamtausgabe. Hrsg. Wladimir Szylkarski. Bd. II, VII. Freiburg 1953.

St e nder-P e ters e n, Adolf: Geschichte der russischen Literatur. Bd. II. München 1957.

S t okm a r, M. P.: Issledovanija $v$ oblasti russkogo narodnogo stichosloženija. Moskau 1952.

Struve, Gleb: Geschichte der Sowjetliteratur. Deutsche Ausgabe. Mündien 1957.

T a r a n ovski, Kiril: Ruski dvodelni ritmovi. Belgrad 1953.

T i m of cev, L.. N. V e nge rov: Kratkij slovar' literaturovedčeskich terminov. Moskau 1952.

T i m of e e v, L. I.: Oð̌erki teorii $\mathrm{i}$ istorii russkogo sticha. Moskau 1958.

- Osnovy teorii literatury. Moskau 1959. 
T om a ševskij, Boris: Problema stichotvornogo ritma. „Literaturnaja mysl'“ 1923, II.

- Teorija literatury (Poètika). Moskau-Leningrad 1925.

- Puškin. Moskau-Leningrad 1956.

- Stilistika i stichosloženie. Leningrad 1959.

T y n j a n o v, Jurij: Archaisty i novatory. Leningrad 1929.

- Problema stichotvornogo jazyka. Leningrad 1924.

Un be g a u n, B. O.: Russian Versification. Oxford 1956.

Vološi n, M.: Vercharn i Brjusov. „Vesy“ 1907, II.

We h rli, Max: Allgemeine Literaturwissenschaft. Bern 1951.

Wellek, René, Austin W a r r e n: Theory of Literature. New York 1949.

- Theorie der Literatur. Ubers. von E. und M. Lohner. Bad Homburg v. d. H. 1959.

Wil pert, Gero von: Sachwörterbuch der Literatur. Stuttgart 1955.

Z en'k ovskij, V.: Istorija russkoj filosofii. T. I-II. Paris 1948/50.

- Aus der Geschichte der ästhetischen Ideen in Rußland. Musagetes VII. 's-Gravenhage 1958.

Z i rmunskij, Viktor: Valerij Brjusov i nasledie Puškina. Petersburg 1922.

- Rifma, ee istorija i teorija. Petrograd 1923.

- Voprosy teorii literatury. Leningrad 1929.

- Valerij Brjusov i nasledie Puškina. Opyt sravnitel'no stilističeskogo issledovanija. Petersburg 1922. 


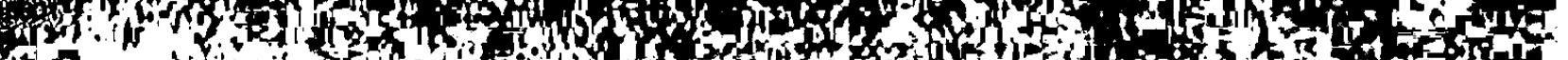

therd

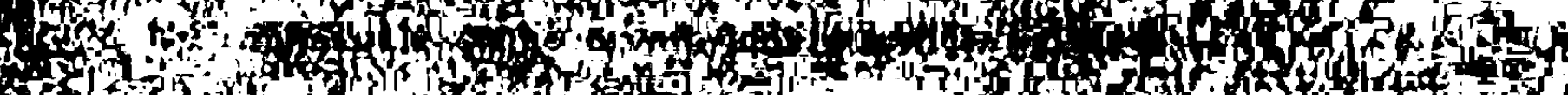

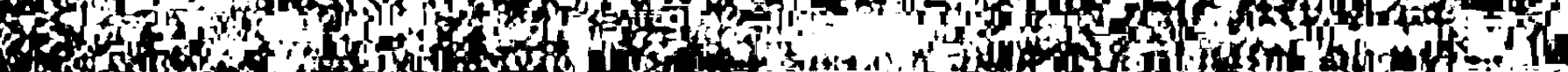

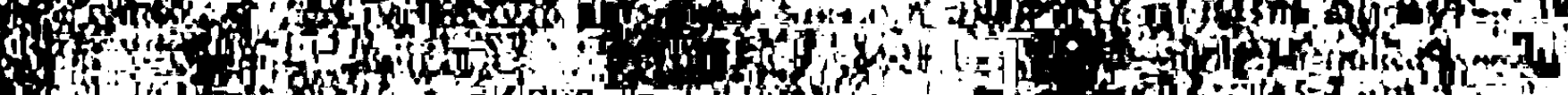

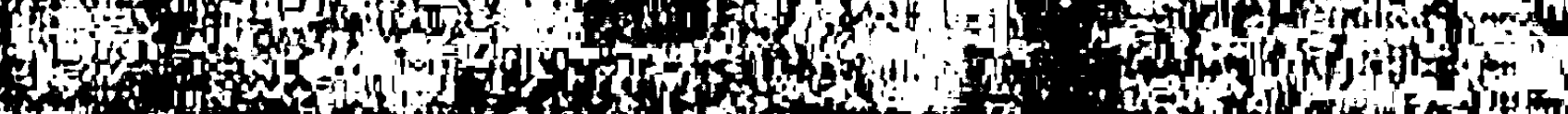

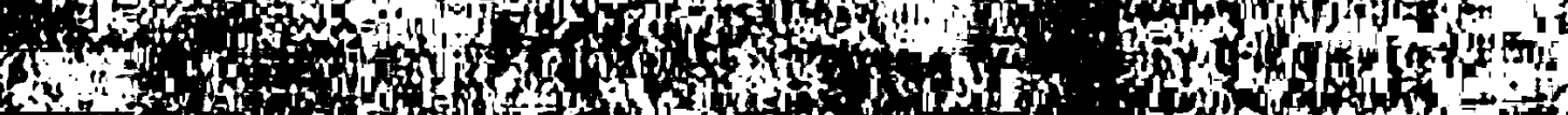

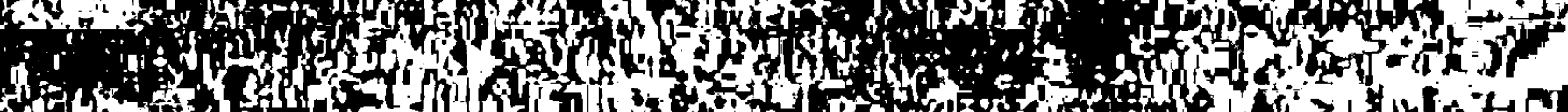
35 of

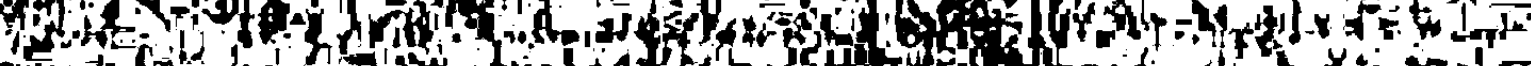
syla

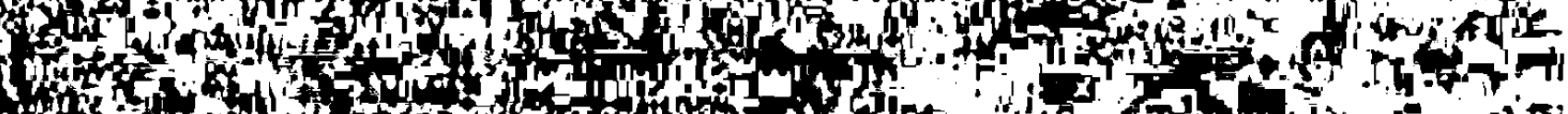

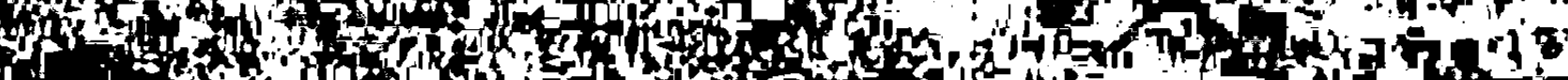
.

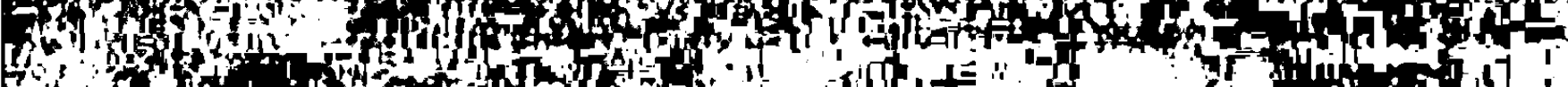
(3. ate

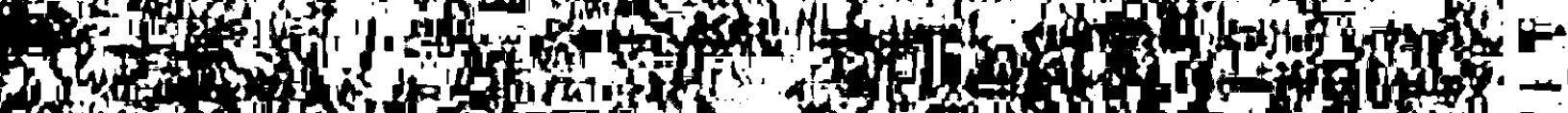

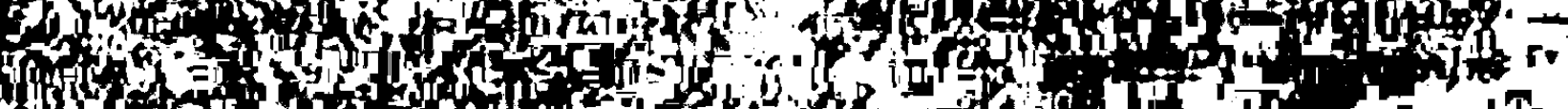
?h

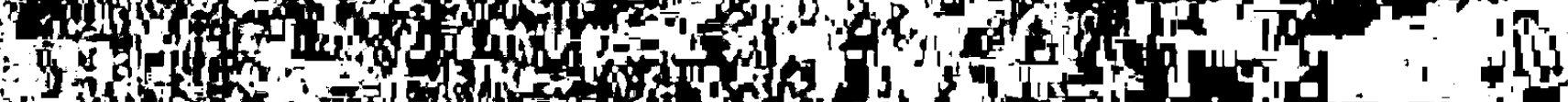
an

19.

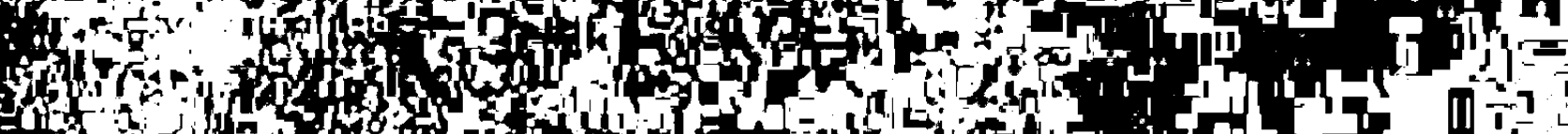
3 L if a

int $x$ intho for (1) 1

(1)

(1)

\section{t.

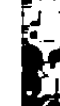

(2) ond

3 (n) Prof

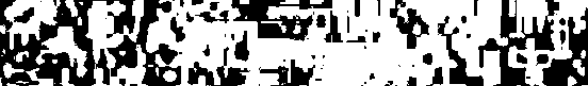

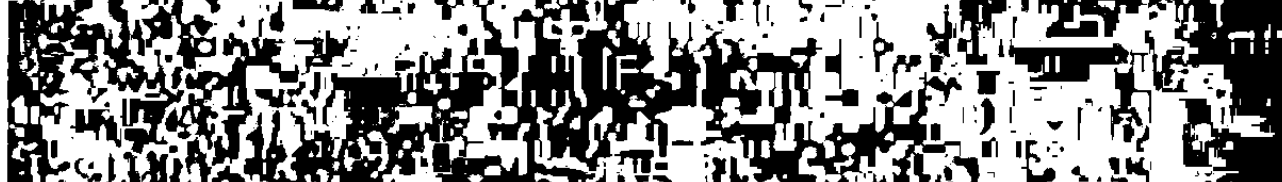

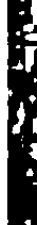

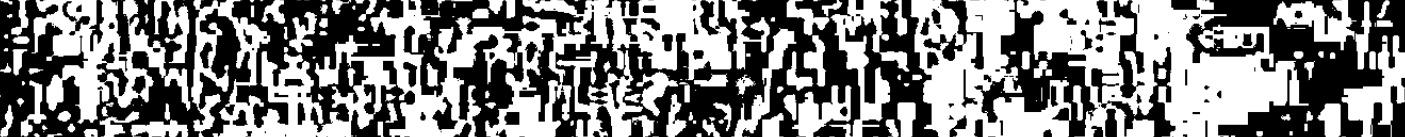
id.

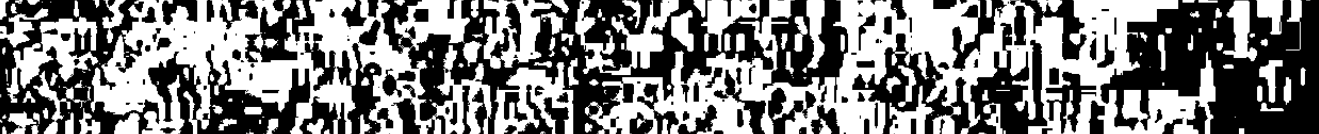

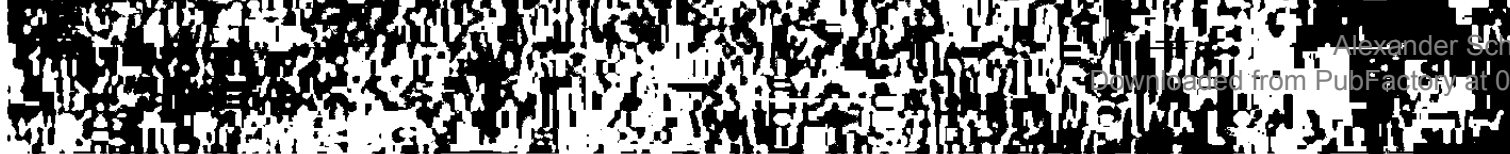

$\left.\right|_{0}$

(1) 


\section{Nachrort}

Als im Jabre 1916 die Formalisten mit ibren Theorien an die Offentlichkeit traten, geschah dies nicht zögernd, mit einigen Aufsätzen, sondern durch die Gründung einer Gesellschaft (OPOJAZ), in der sid) eine ganze Reibe von nambaften Theoretikern zusammengeschlossen hatte. Es entstand der Eindruck, als sei hier plötzlich etwas völlig Neues entstanden. Die Formalisten selber betonten oft, daß es ibre Absicht sei, die Theorien ibrer Vorläufer, vor allem Potebnjas, $z u$ widerlegen und durch eigene zu ersetzen. Aber es ist in der Zeit zwischen dem Wirken Potebnjas und dem Erscheinen der ersten maßgebenden Arbeit Viktor Šklovskijs viel auf diesem Gebiet gearbeitet worden. Besonders aktiv waren dabei die den Symbolisten zugebörenden Dichter Andrej Belyj und Valerij Brjusov. Ich habe die Arbeiten Brjusovs zum Gegenstand dieser Untersuchung gewäblt, denn er verfolgt - im Gegensatz zu Belyj - bis zuletzt rein literarische Ziele, obne Berüdssichtigung anderer, etwa religiöser Momente. Das aber ist einer der wesentlichen Grundsätze formalistischer Literaturtheorie. Somit war hier - wenn überbaupt - eine Verbindung zu suchen.

Bei der Beschaffung des Quellenmaterials und der Sekundärliteratur konnte ich mich zum großen Teil auf die umfangreichen Sammlungen der Münchener Staatsbibliothek und der Lenin-Bibliothek in Moskau stützen.

Diese Arbeit hat der Philosophischen Fakultät der Ludwig-Maximilians-Universität zu München im Wintersemester 1960 als Dissertation vorgelegen. 